\title{
The Geography of Racially Polarized Voting: Calibrating Surveys at the District Level*
}

\author{
Shiro Kuriwaki ${ }^{\dagger}$ Stephen Ansolabehere ${ }^{\ddagger}$ Angelo Dagonel $^{\S} \quad$ Soichiro Yamauchi $^{\mathbb{I}}$
}

January 2023

\begin{abstract}
Debates over racial voting, and over policies to combat vote dilution, turn on the extent to which groups' voting preferences differ and vary across geography. We present the first study of racial voting patterns in every congressional district in the US. Using large-sample surveys combined with aggregate demographic and election data, we find that national-level differences across racial groups explain 60 percent of the variation in district-level voting patterns, while geography explains 30 percent. Black voters consistently choose Democratic candidates across districts, while Hispanic and White voters' preferences vary considerably across geography. Districts with the highest racial polarization are concentrated in the parts of the South and Midwest. Importantly, multi-racial coalitions have become the norm: in most congressional districts, the winning majority requires support from minority voters. In arriving at these conclusions, we make methodological innovations that improve the precision and accuracy when modeling sparse survey data.
\end{abstract}

\footnotetext{
*We thank Matt Barreto, Andrew Gelman, Yair Ghitza, Rob Griffin, Andrew Hall, Kabir Khanna, Lauren Kennedy, Mayya Komisarchik, Jeff Lewis, Maxwell Palmer, Douglas Rivers, Jonathan Robinson, Jonathan Rodden, Yajuan Si, members of the Democracy and Polarization Lab at Stanford, and participants of Polmeth 2022 for their valuable suggestions.

Corresponding Author. Assistant Professor of Political Science, Department of Political Science, Yale University, United States. Website: www.shirokuriwaki.com. Email: shiro.kuriwaki@yale.edu. ORCID: 0000-0002-5687-2647.

Frank G. Thomson Professor of Government, Department of Government, Harvard University, United States. Website: scholar.harvard.edu/sansolabehere. Email: sda@gov.harvard.edu.

${ }^{\S} \mathrm{PhD}$ candidate, Department of Government, Harvard University, United States. Website: sites.google. $\mathrm{com} / \mathrm{g}$. harvard . edu/dagonel. Email: dagonel@g.harvard.edu.

IIIndependent scholar. Website: soichiroy.github.io. Email: soichiro@alumni.princeton.edu. ORCID: 0000-0003-0554-2717.
} 


\section{Table of Contents}

$\begin{array}{lr}\text { Introduction } & \mathbf{3}\end{array}$

Measuring Vote Choice By Race Using Surveys 6

Quantities of Interest . . . . . . . . . . . . . . . 7

Survey Data . . . . . . . . . . . . . . . 7

Challenges in Survey Inference . . . . . . . . . . . . . 9

$\begin{array}{ll}\text { Calibrating Surveys at the District Level } & 10\end{array}$

Hierarchical Regression . . . . . . . . . . . . . . . . . 11

Survey-assisted Synthetic Target Estimation . . . . . . . . . . . . . 13

Two-way Calibration to Election Results and External Surveys . . . 15

Evaluation and Validation . . . . . . . . . . . . . . 17

The Political Geography of Vote Choice by Race 21

The Racial Gap at the District Level . . . . . . . . . . . . . . . . 21

Group Cohesion . . . . . . . . . . . . . . . . . . . . . . . . . . . . . . . 24

Groups and Coalitions . . . . . . . . . . . . . 32

$\begin{array}{lr}\text { Conclusion } & 35\end{array}$

$\begin{array}{lr}\text { References } & \mathbf{4 0}\end{array}$

A Modeling Methodology $\quad$ A1

A.1 Notation . . . . . . . . . . . . . . . A A1

A.2 About the Cooperative Congressional Election Study . . . . . A2

A.3 Implementation of Hierarchical Regression . . . . . . . . . A3

A.4 Connections with Ecological Inference Estimators . . . . . . A5

A.5 Population Statistics for Target Estimation . . . . . . . . . A9

A.6 Survey-assisted Synthetic Target Estimation . . . . . . . . A9

A.7 Estimation of Joint Demographic Distributions . . . . . . . . A13

A.8 Estimation of a Calibrated Turnout Model . . . . . . . . . . A14

A.9 Grouping of States . . . . . . . . . . . . . . . A15

A.10 How Modeling Choices Affect Estimates . . . . . . . . . A15

B Additional Analyses $\quad \mathbf{A 1 7}$

B.1 Asian Americans . . . . . . . . . . . . . . . . A17

B.2 Comparison with Other Surveys . . . . . . . . . . . A18

B.3 Details on Florida Validation Analysis . . . . . . . . . . A19

B.4 Comparison with Ecological Inference in 50 States . . . . . A20

$\begin{array}{lll}\text { C Additional Estimates and Standard Errors } & \text { A24 }\end{array}$

C.1 Additional Estimates . . . . . . . . . . . . . . . . . A24

C.2 2020 Estimates . . . . . . . . . . . . . . A25

C.3 Racial Gap Estimates . . . . . . . . . . . . . . . A25

C.4 Standard Errors . . . . . . . . . . . . . . . . . . A29 


\section{INTRODUCTION}

The United States is a nation divided by color. Generations of social science have documented that the areas of the country with high Black and Hispanic populations, such as the Black Belt counties of the South or the Hispanic neighborhoods in southwestern cities, usually vote for candidates different than those who win in predominantly White areas (Key 1948; Kousser 1974; Davidson and Grofman 1994). Most scholarship attributes such differences to strong group identities and even animus between White and non-White groups (Grofman 1991; Dawson 1995; King 1996; Kinder and Sanders 1996). Yet other scholars identify instances where context and geography generate variation in group behavior (Gay 2001; Hopkins 2010; Enos 2017; Gimpel et al. 2020). It is difficult to gauge the relative importance of racial groups and of geography from aggregate data (Gelman 2009). The patterns that scholars think they see in aggregate election outcomes could, as Freedman et al. (1991) argued, be due to differences across neighborhoods instead of differences between groups.

This study uses survey data to offer the first nationwide assessment of racial voting patterns at the congressional district (CD) level. We find that racial groups on average vote differently from each other, but the differences across Black, Hispanic, White, and Other voters also vary across states and across CDs within states. Specifically, 60 percent of the variation in 2016 Presidential vote shares at the district-racial group level is explained by national differences across racial groups. Variation across regions, states, and CDs explains another 30 percent of the variation, with CDs explaining twice as much variation as states do. Nearly everywhere, Black voters vote at high rates for Democratic candidates. The voting behavior of Hispanic voters and of White voters is far more variable across geography. At least as far as racial group voting is concerned, then, our results reveal that national divisions (Hopkins 2018; Kinder and Sanders 1996) are more prominent than local divisions (Cramer 2016; Gimpel et al. 2020). 
One of the most striking features of contemporary politics that emerge is the degree to which both the Democratic and Republican parties rely on the support of White and minority voters. In most CDs the winning candidate relied on some support from at least one minority group in order to win a majority of votes. In two-thirds of Democratic-leaning districts, the Democratic majority consisted of combinations of Black, Hispanic, and White voters, with no single group determining the majority. In a quarter of Republican-leaning districts, the White vote alone was not sufficient to reach a majority. Republican majorities in those districts depended on the Republican votes of Hispanic or other racial minorities.

Our study makes contributions in three fields: race and voting behavior, survey methodology, and election law. First, we contribute to the study of racial voting in the United States by providing the first comprehensive picture of racial group voting patterns across all congressional districts. This allows us to test competing claims about whether national racial differences are due to groups themselves to or the local political culture where people live. Survey research has long documented national group differences: The 2016 Exit Polls estimates that about 60 percent of White voters nationwide voted for the Republican Presidential candidate, while 92 percent of Black voters, 70 percent of Hispanic voters, and 70 percent of Asian voters voted for the Democrat. A lengthy literature argues that people have clear, distinct vote preferences that are rooted in racial group identities (e.g., Kinder and Sanders 1996). Increasingly, though, scholarship on race and American elections has emphasized the importance of geographic variation in voting behavior of racial groups (Cho 1995; Gelman 2009; Erikson 2010; Enos 2017), especially differences between urban and rural areas (McKee 2008; Rodden 2019), differences across counties (Acharya, Blackwell, and Sen 2018), and variation across districts (Donovan 2010). We show that racial groups are not monolithic in their voting behaviors (Cho 1995; Erikson 2010). We find that Black voters vote overwhelmingly Democratic regardless of where they live, but the voting preferences of White and Hispanic voters vary across regions, states, and, even, districts within states. That said, 
we show that the variation in district-level Presidential voting behavior is explained primarily by differences across racial groups at the national-level. In short, who people are is more important than where they live.

Second, we improve upon existing survey modeling methods by developing two new calibration techniques. Even large surveys such as exit polls suffer from insufficient sample sizes to estimate group behavior in each congressional district with much precision. Political scientists have recently deployed Multilevel Regression and Poststratification (MRP) for small area estimation. MRP uses hierarchical modeling and calibration weights derived from population statistics to make subgroup estimates more precise (Gelman and Little 1997). However, the characteristics of the target population required for weighting are often not available (Leemann and Wasserfallen 2017). This is partly why MRP estimates for political polls can still be unrepresentative of small areas (Lauderdale et al. 2020). We create demographic weighting targets of the electorate at the district level using a technical innovation we call surveyassisted synthetic target estimation. This improves weighting estimates to the distribution of race, age, sex, and education within the actual electorate of each district. Furthermore, we develop a two-way survey calibration, which simultaneously calibrates estimates to both election results by geography and an external survey, instead of only to geography (e.g., Ghitza and Gelman 2013; Rosenman, McCartan, and Olivella 2023). This adjustment reduces bias in the estimates of group voting behavior at the CD-level due to unobservable selection bias in the survey.

Third, our analysis informs on-going debates over election laws and voting rights. Measuring the extent of racially polarized voting has been social science's key contribution to the development of election laws designed to protect minority voters (Pildes 2001). Significant questions remain as to where and how the law ought to apply. If voting patterns largely reflect national group differences, then a broad national policy is the best approach to fight vote dilution, as some have argued (Charles and Fuentes-Rohwer 2014; Cain and Zhang 2016). 
If a racial group's preferences vary substantially across geography, then a narrowly tailored approach to the law may be more effective and appropriate, as in the case of Alabama Legislative Black Caucus v. Alabama (2015). Almost all of the prior scholarship stops at statelevel estimates (Shaw 1997; Ansolabehere, Persily, and Stewart 2009, 2012; Stephanopoulos 2016; Smith, Kreitzer, and Suo 2020). Only Elmendorf and Spencer (2015) and Ghitza and Gelman (2020) provide estimates at the county-level, but those analyses do not apply to the most common application - redistricting. Our findings regarding the substantial national division in racial voting patterns and the variations across areas point to the need for both a broad national approach, as well as some degree of narrow tailoring to particular districts and areas.

\section{Measuring Vote Choice By Race Using Surveys}

Social scientists frequently seek to measure how individual behavior varies across geographic areas and demographic subgroups. Aggregate data alone cannot distinguish how much of the variation is attributable to differences across demographic groups or variation across levels of geography. Ecological inference techniques attempt to infer the characteristics of groups by studying how aggregate outcomes vary by the composition of the group in each aggregate unit. In doing so, standard ecological inference assumes that variations in the behavior of a racial group in different geographies are independent of the composition of the group (Freedman et al. 1991; Cho 1998; Ansolabehere and Rivers 1995, see also Online Appendix A.4 for a formal exposition). Moreover, ecological inference struggles to identify any estimate at all in districts where racial groups are highly integrated within all precincts. Our study estimates the contributions of racial groups and geography directly using individual-level survey data, rather than make assumptions about the structure of aggregate data. 


\section{Quantities of Interest}

Our central quantity of interest is the share of a candidate's support among a particular racial group in a particular district. Let $i \in\{1, \ldots, N\}$ index all individual voters who voted for a Republican or Democratic Presidential candidate. We index the voter's racial group as $g \in\{1, \ldots, G\}$, and congressional districts (CDs) as $j \in\{1, \ldots, J\}$ with $J=435$. We let $\mathcal{I}_{g j}$ denote the set of voters with race $g$ in district $j$, and $N_{g j}$ denote the total number of such voters. A voter has $Y_{i}=1$ if they voted for the Republican candidate, and $Y_{i}=0$ if they voted for the Democratic candidate. We are interested in the Republican voteshare in each racial group in each congressional district,

$$
\tau_{g j}=\frac{1}{N_{g j}} \sum_{i \in \mathcal{I}_{g j}} Y_{i},
$$

To report racial group differences, we then define the racial gap in district $j$ between Whites and a non-White racial group $g$ as

$$
\text { Racial Gap } \operatorname{gaj}_{j}=\tau_{\text {white, } j}-\tau_{g j}
$$

Voting is racially polarized if the vote shares of white and non-white groups are on the opposite sides of 50 percent.

\section{Survey Data}

We use the 2016 Cooperative Congressional Election Study and 2020 Cooperative Election Study. These surveys interview over 60,000 respondents nationwide, and validate records by matching them to vote histories available from voter registration data. It is one of the largest political surveys of American Politics and contains the information necessary for our model: vote choice, congressional district, turnout matched from the voter file, racial group 
identification, and other demographics.

Throughout this study, we group race into four categories: $g \in\{$ White, Black, Hispanic, All Others\}. Black is used interchangeably with African American, and Hispanic is used interchangeably with Latino in our analysis. As with the US Census, the CCES asks Hispanic ethnicity as a separate question from race. Respondents who are "any-part" Hispanic are coded as Hispanic (see Online Appendix A.2 for more detail of the survey and question wording). In the 2016 CCES, about 2 percent of White respondents and about 2 percent of Black respondents also identify as Hispanic. Coding these respondents as Hispanics rather than Whites or Blacks typically increases the estimated Republican vote among the Hispanic group by 2 percentage points and decreases the estimated Republican vote of Whites and Blacks by a few tenths of a percentage point. Separating voters in the "Other" categories into Asian, Native American, and multi-racial respondents requires even more data than is available with the CCES and Census surveys. We replicate our analysis for Asian American voters limited to four states where they comprise over 10 percent of the population (Online Appendix B).

Our outcome of interest is the respondent's self-reported vote in the election for President in each year. We focus on the office of President in this study because it is the only ticket elected nationwide, and our goal is a 50-state, 435-district comparison of voter preferences between the same set of contesting candidates. Party choice across votes for U.S. Senate, U.S. House, and Governor within a single respondent may differ, though less so in the modern era (Jacobson 2015; Kuriwaki 2021). We limit our anlaysis to validated voters, who are respondents whose personally identifiable information records have been matched to public voter rolls. We also limit our analysis to those who reported voting for a major party Presidential candidate. The choice to drop third-party voters is in part for the convenience of modeling the outcome as a binary variable, but also for comparability across states and districts. Working with voteshares as a proportion of the two-party vote is also desirable because the two-party 
Figure 1 - Sample sizes in each congressional district in the 2016 Cooperative Congressional Election Study. Samples are limited to validated voters who report voting for Donald Trump or Hillary Clinton, which we use in the survey model.

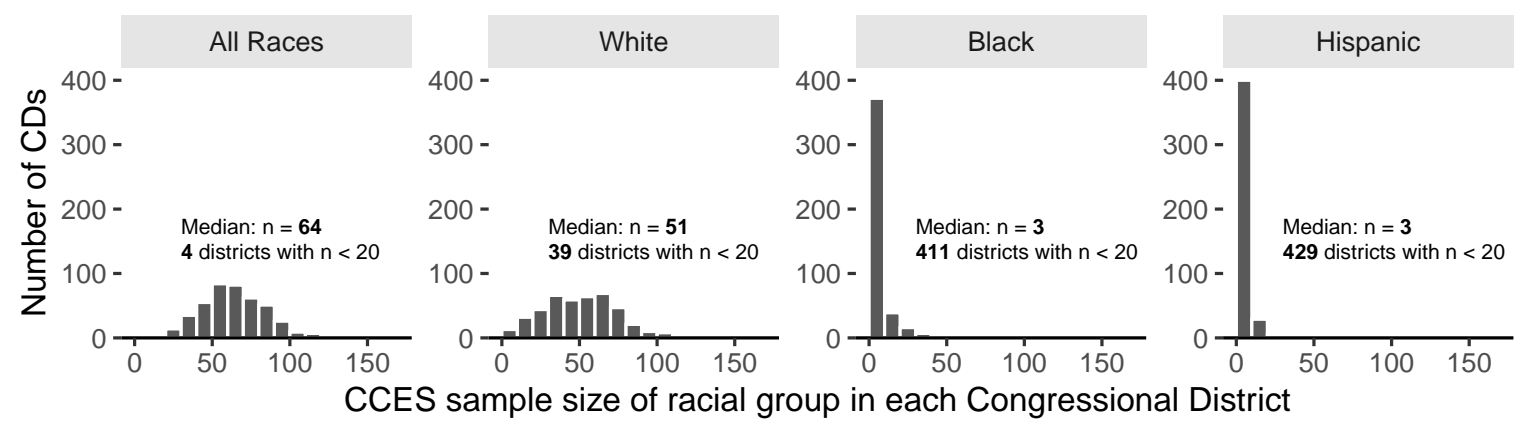

vote decides who wins the district or state. Thus, we focus on a subset of $n=28,462$ of the entire CCES in 2016 and $n=34,539$ for 2020.

\section{Challenges in Survey Inference}

Even with large surveys, including exit polls and the CCES, the number of observations for sub-state level geographies is still too small to estimate with precision individual-level variables within districts. In the subsample of the 2016 CCES studied here, the median sample size validated to be voters per congressional district is $n=64$, and the median district only includes $n=13$ voting respondents who are non-White (Figure 1). Recently, researchers have studied simlarly sized samples in counties to draw inferences about racial groups' preferences in these local geographies (Acharya, Blackwell, and Sen 2018; Kuziemko and Washington 2018). The samples in such small subgroups can be dangerously misleading (Ansolabehere, Luks, and Schaffner 2015). Even with a sample of $n=50$ in each group, the margin of error in the difference in proportions of those two groups is roughly 20 percentage points with a simple random sample, making any comparison uninformative. Hierarchical modeling proposed here offers a potential solution.

Another challenge for survey data is that the sample of each race and district subgroup 
may be unrepresentative of the population counterpart (Grimmer et al. 2018). The CCES release includes poststratitication weights that render its state subsamples representative of each state. However, these weights have no guarantees of making district subsamples representative of each district, and may only increase variance while failing to eliminate selection bias (Kuriwaki 2021, ch.4).

Some summary statistics of the population are known. A congressional district's composition of race and other demographics of adult citizens are reported by high-quality Census surveys. The total presidential vote in each district, across all races, is also known from election results. We model the noisy and potentially unrepresentative survey data to improve the estimate of the quantity of interest $\tau_{g j}$ by calibrating to Census statistics and electoral results.

\section{Calibrating Surveys at the District Level}

Estimation proceeds in three steps: (1) conduct a hierarchical regression to predict the probability of a Republican vote in each geographic and demographic subgroup, (2) weight these probabilities to the estimated population size of these subgroups, and (3) calibrate these estimates to external targets at higher levels of aggregation. Steps (1) and (2) together constitute MRP (Gelman and Little 1997). Dozens of studies, including many that use the CCES, have implemented MRP to estimate subgroup political behavior at the national or state levels (e.g., Lax and Phillips 2009; Warshaw and Rodden 2012; Broockman and Skovron 2018; Elmendorf and Spencer 2015; Hertel-Fernandez, Mildenberger, and Stokes 2019).

We make two innovations to existing MPR methods. First, we develop in step (2) a method of survey-assisted synthetic target estimation that combines partially available Census statistics into a single joint distribution. Post-stratification in prior MRP work has been limited by the lack of population variables jointly available in off-the-shelf datasets. Using our method, we can guarantee through weighting that the estimates are representative of the age group, 
sex, race, and education level of the population (according to the ACS) and the turnout rate in every congressional district. But this weighting may still be incomplete because of unmea-

sured selection bias. Second, we develop in step (3) a method of two-way calibration that matches targets both by geography and racial group, further reducing the potential bias in our estimates.

We generate estimates for both the 2016 CCES and the 2020 CES. Because there are no substantive differences in the methodology, we use the 2016 data as the running example and present 2020 results in Online Appendix C. In addition, we offer a validation analysis of voter registration by party and race in the state of Florida to show the accuracy and coverage of our approach compared to only using precinct-level aggregate data (ecological inference).

\section{Hierarchical Regression}

Traditional survey weights assign weights to each subgroup of respondents based on the demographic composition of the population within specific strata (such as states, regions, or districts). The estimated average vote $Y$ among subgroups of respondents may be highly imprecise because subgroup samples within strata become very small. MRP compensates for the sparsity of data within strata samples by borrowing information across strata about particular groups. We estimate a hierarchical regression that returns the probability that voters in district $j$ of race $g$ and of a certain age, sex, and education, votes for the Republican in a given year. The model applies a shrinkage estimator to impute these probabilities even for demographic combinations for which few respondents exist, respecting the geographic grouping of districts. This first step of our process is similar to the approach in Ghitza and Gelman (2013, 2020).

Our model takes the form

$$
\operatorname{Pr}\left(Y_{i}=1\right)=\operatorname{logit}^{-1}\left(\alpha_{j[i]}+\beta_{1 j[i]} \text { Black }_{i}+\beta_{2 j[i]} \text { Hispanic }_{i}+\beta_{3 j[i]} \text { Other }_{i}+\zeta_{j[i]}^{\top} \mathbf{W}_{i}\right)
$$


where the notation $j[i]$ denotes the district that respondent $i$ resides in; the indicator variables Black ${ }_{i}$ Hispanic $_{i}$, and Other ${ }_{i}$ equal 1 if respondent $i$ is of that race (with White as the omitted baseline); and $\mathbf{W}_{i}$ are individual-level predictors of education, age group, sex, and the interaction of education and race. The function $\operatorname{logit}^{-1}(\cdot)$ is the inverse logit function and transforms an unbounded value to a probability scale between 0 and 1 .

Importantly, this model specifies a hierarchical structure to the coefficients. We allow the coefficients to vary across congressional districts and as a function of the demographic composition of the districts. The intercept $\alpha$ is a batch of 435 coefficients with each value representing a district, rather than a single national intercept for all voters. We further encoded geographic hierarchy into these coefficients. Districts are nested within states, and states are nested within divisions, as follows:

$\alpha_{j} \sim \mathcal{N}\left(\alpha_{\text {state }[j]}+\boldsymbol{\rho}^{\top} \mathbf{V}_{j}, \sigma_{\text {cd }}^{2}\right), \quad \alpha_{\text {state }} \sim \mathcal{N}\left(\alpha_{\text {division[state }]}, \sigma_{\text {state }}^{2}\right), \quad \alpha_{\text {division }} \sim \mathcal{N}\left(\alpha, \sigma_{\text {division }}^{2}\right)$

where district-level variables $\mathbf{V}_{j}$ contains a spline expansion of the Republican Presidential voteshare in district $j$ (Daily Kos 2021) and the proportion of White voters in district $j$. The coefficients $\boldsymbol{\beta}_{1}, \boldsymbol{\beta}_{2}$, and $\boldsymbol{\beta}_{3}$ are each batches of coefficients that represent the difference in Republican vote among racial minorities relative to White voters. These also vary by congressional district. Here we specified the coefficient structure so that the values are centered to a national-level coefficient for each race shifted by the contextual effect of the group's population size in the district. ${ }^{1}$ Including the racial composition of the $\mathrm{CD}$ incorporates what the ecological inference literature calls linear contextual effects (Online Appendix A.4). The coefficients $\zeta$ on other covariates have a similar structure, but with the division-level parameter

1 For instance the batch of coefficient for Black voters are drawn from a similar geographic hierarchy as the $\boldsymbol{\alpha}$ terms: $\beta_{1 j} \sim \mathcal{N}\left(\beta_{1, \text { state }[j]}+\gamma \mathbf{X}_{j}, v_{\text {cd }}^{2}\right), \beta_{1, \text { state }} \sim \mathcal{N}\left(\beta_{1, \text { division[state }]}, v_{\text {state }}^{2}\right), \beta_{1 \text {, division }} \sim \mathcal{N}\left(\beta_{1}, v_{\text {division }}^{2}\right)$, such that the coefficients are ultimately centered on a value $\beta_{1}$, a national-level average difference between Black and White voters. Here $\mathbf{X}_{j}$ is the proportion of Black voters in district $j$. The coefficients $\boldsymbol{\beta}_{2}$ and $\boldsymbol{\beta}_{3}$ follow a similar structure. 
being centered at 0 .

We estimate the model with a Bayesian framework using the brms interface (Stan Development Team 2021; Bürkner 2017). We index posterior Monte Carlo samples from the model as $m=1, \ldots, M$ and we retained $M=2000$ thinned samples across 4 chains. The full specification of the implementation is described in Online Appendix A.

The modeling literature refers to this structure of modeling coefficients as random effects, with $\boldsymbol{\alpha}$ called random intercepts, and $\boldsymbol{\beta}$ and $\boldsymbol{\zeta}$ called random slopes (Gelman and Hill 2006). Random effects use sparse data effectively by shrinking estimates toward a state, regional, or national estimate. If there is no geographic variation, our model reduces to the standard logistic regression with district-level voteshare and national racial group differences (Ghitza and Gelman 2013, 765).

The specification of the model, obviously, can affect estimates. We examined a range of specifications through iterative model building (Gelman et al. 2020). We found that models with race coefficients varying by district lead to more variability in the final estimaets than models that let race coefficients vary by region. For example, the choice of specification affected the estimates for Hispanics by 6-10 percentage points.

\section{Survey-assisted Synthetic Target Estimation}

We develop a new algorithm for computing the target population. Standard MRP takes the weighted average of the predicted outcome from the hierarchical model, with weights designed to make the sample representative of demographics in the district. Doing so requires knowing the target distribution, or population size, of each [age $\times$ sex $\times$ education] group for each [race $\times \mathrm{CD}$ ] combination. Unfortunately, no such table of data is available from the United States Census. The Current Population Survey from the Census does not produce statistics at the CD level. The American Community Survey (ACS), the largest survey conducted by the Census, provides a table of the population for each [age $\times$ sex $\times$ education 
$\times \mathrm{CD}$ ] combination and a table of [race $\times \mathrm{CD}$ ], but not the joint table of the five variables (Online Appendix A.5). In fact, no such weighting target has been provided by public MRP studies.

We therefore develop an algorithm — survey-assisted synthetic target estimation — for fusing together two ACS tables and construct a table of [age $\times$ sex $\times$ education $\times$ race $\times$ CD]. The current recommendation in the MRP literature is either to avoid modeling by assuming independence between the covariates, or to take survey estimates of the joint distribution at face value (Leemann and Wasserfallen 2017; Kastellec et al. 2015). Both the survey data and known marginal constraints inform the joint distribution. Specifically, we estimate a multinomial regression predicting the four categories of education from race, age, and sex on survey data, with a constraint that the implied marginal distribution of education from that regression matches the education composition in each congressional district as reported in the ACS. ${ }^{2}$ The constraint is imposed simultaneously with estimation, instead of applied after fitting the regression (Ghitza and Steitz 2020). This algorithm is of general use to survey researchers and will improve future implementations of MRP and of survey weighting generally as it offers a solution to the limited release of Census tables.

The ACS statistics we use are for the general adult population (i.e., the voting age population), not voters. We therefore repeat the survey-assisted synthetic target estimation and model the turnout rate within each demographic cell. The turnout model involves predicting validated vote among CCES voters and non-voters with education, race, age, and sex, with a constraint that the implied turnout rate matches the actual turnout rate in each congressional district.

Our synthetic target estimation produces a turnout-adjusted [age $\times$ sex $\times$ education] table

2 Formally, let $Z$ be a categorical variable for education and $\mathbf{X}$ be the demographic predictors. The marginal distribution of $Z$ and the joint distribution of $\mathbf{X}$ is given by the ACS, but the joint distribution of $Z$ and $\mathbf{X}$ is unknown. A regression of $Z$ on $\mathbf{X}$ in the survey produces fitted probabilities $\widehat{\operatorname{Pr}}(Z \mid \mathbf{X})$ and allows us to compute the joint. We estimate this regression but with the constraint that $\sum_{\boldsymbol{x}} \widehat{\operatorname{Pr}}(Z \mid \mathbf{X}=\boldsymbol{x}) \operatorname{Pr}(\mathbf{X}=\boldsymbol{x})$ matches $\operatorname{Pr}(Z)$ for every district up to a small tolerance. Online Appendix A.6 - A.7 describes the estimation strategy and the specification in this example. 
of population sizes for each [race $\times \mathrm{CD}$ ]. Formally, we index a cell in the table for a given race $\times$ CD combination by $s \in \mathcal{S}_{g j}=$ [age $\times \operatorname{sex} \times$ education], so that $N_{g j s}$ denotes the population size of each cell $s$ for racial group $g$ at congressional district $j$. Each posterior sample $m$ of the estimated coefficients in the hierarchical model provides predicted probabilities of the Republican voteshare in each cell, denoted $\widehat{\pi}_{g j s}^{(m)}$. Then, we poststratify cell estimates by weighting them proportional to its associated size in the population:

$$
\widehat{\tau}_{g j}^{(m)}=\sum_{s \in \mathcal{S}_{g j}} \frac{N_{g j s}}{N_{g j}} \widehat{\pi}_{g j s}^{(m)} .
$$

This approach does not rely on acquiring a voter file or using estimates of race or education, such as Ghitza and Gelman (2020). Self-reported race is only available in the voterfiles of six states, all of them in the Deep South, and education is never available. Furthermore, the survey-assisted synthetic target algorithm is open-source; it does not rely on proprietary data or algorithms. ${ }^{3}$ Online Appendix A.3 describes the specifics of this modeling.

\section{Two-way Calibration to Election Results and External Surveys}

MRP also assumes ignorable selection into the survey conditional on available covariates ( $\mathrm{Si}$ 2021). Violation of those assumptions would yield biased estimates (Buttice and Highton 2013). Standard MRP does not adjust for possible selection bias and cannot control for a variable that is not measured in the weighting stage.

To adjust for selection bias that may remain even after poststratitfication, we calibrate the MRP estimates from Equation (3) so that the implied district vote matches the actual Republican Presidential voteshare in each congressional district, and the implied vote choice by race matches an external national estimate. For example, we can sum our estimates across racial groups as $\widehat{\tau}_{j}=\sum_{g=1}^{G}\left(N_{g j} / N_{j}\right) \widehat{\tau}_{g j}$, and denote the actual Republican voteshare in district

\footnotetext{
3 The full post-stratification table is available in the Harvard Dataverse (Kuriwaki et al. 2023).
} 
$j$ as $\tau_{j}$. Here $\tau_{j}$ is a target, and both $\widehat{\tau}_{j}$ and $\tau_{j}$ are observable. We do not observe a target for our main quantity of interest $\tau_{g j}$, but any observed difference between $\widehat{\tau}_{j}$ and $\tau_{j}$ can be due to bias in our estimates $\widehat{\tau}_{g j}$ that does not cancel out when aggregated.

Existing work proposes to shift each estimate by a constant so that the implied sum matches an election result (Ghitza and Gelman 2013; Rosenman, McCartan, and Olivella 2023). Unfortunately, such a one-way calibration may make the estimates of the racial gap $\tau_{\text {white, } j}-\tau_{\text {black }, j}$ even more biased if the estimates of each race-specific voteshare are biased in opposite directions. We find that this is precisely the case in the Florida subset of the CCES we use for validation in the subsequent section.

A two-way calibration adjusts the estimates to a racial group target at the national level (i.e., targets $\tau_{g}$ ), in addition to targeting the district level election results. It imposes two sets of additive corrections to the MRP estimates $\widehat{\tau}_{g j}$,

$$
\widetilde{\tau}_{g j}^{(m)}=\operatorname{logit}{ }^{-1}\left(\operatorname{logit}\left(\widehat{\tau}_{g j}^{(m)}\right)+\widehat{\delta}_{g}^{(m)}+\widehat{\delta}_{j}^{(m)}\right)
$$

where $\delta_{g}$ denotes the racial group correction, and $\delta_{j}$ denotes the geographic correction. The optimal value of the correction minimizes the sum of squared deviances at the national and district level:

$$
\begin{aligned}
\widehat{\boldsymbol{\delta}}^{(m)}=\underset{\delta}{\arg \min }\{\sum_{g=1}^{G} \frac{N_{g}}{N} \underbrace{\left(\tau_{g}-\sum_{j=1}^{J} \frac{N_{g j}}{N_{g}} \operatorname{logit}{ }^{-1}\left(\operatorname{logit}\left(\widehat{\tau}_{g j}^{(m)}\right)+\delta_{g}+\delta_{j}\right)\right)^{2}}_{\text {Deviation from racial group target for race } g} \\
+\sum_{j=1} \frac{N_{j}}{N} \underbrace{\left(\tau_{j}-\sum_{g=1}^{G} \frac{N_{g j}}{N_{j}} \operatorname{logit}{ }^{-1}\left(\operatorname{logit}\left(\widehat{\tau}_{g j}^{(m)}\right)+\delta_{g}+\delta_{j}\right)\right)^{2}}_{\text {Deviation from geographic target for district } j}\} .
\end{aligned}
$$

In other words, for each posterior sample $m$, we identify the correction factors that make all the weighted sums of adjusted quantities $\widetilde{\tau}_{g j}^{(m)}$ match the known election result $\tau_{j}$ and exter- 
nal estimate by racial group $\tau_{g}$ as close as possible. We estimate these corrections through numerical optimization.

We use the Presidential voteshare at the congressional district level as district-level targets $\tau_{j}$, and use the national estimates of vote choice reported by Catalist as the race-level national targets $\tau_{g}$. The Catalist targets are similar to the National Exit polls. Online Appendix B presents and compares these targets. The Catalist estimates of the Hispanic vote is about 2 to 3 percentage points more Democratic than the CCES before this calibration.

The mean of each posterior sample's calibrated estimate, $\widetilde{\tau}_{g j}=\sum_{m} \widetilde{\tau}_{g j}^{(m)} / M$, represents our best estimate of the vote choice for a specific racial group in a specific district. Our method guarantees that this estimate is (a) computed from a sample that is representative of each congressional district electorate's joint composition of sex, age, education, and race up to estimation error in the weighting target, and (b) further calibrated so that the estimates for each racial group approximately sum to known election results in the district or at higher levels of geography.

In the 2016 example, the one-way calibration to election results shifts the estimates of White voters' Trump vote up by 4 percentage points on average, and shifts the estimates among Hispanics up by 1 percentage point, although some districts are shifted in the opposite direction (Online Appendix A.10). The two-way calibration shifts the one-way calibrated White vote up even further towards Trump by 1 percentage points, and pulls the Hispanic vote down by 5 percentage points. These differences suggest that the underlying survey data under-represented Trump voters in most places even after weighting, but that pattern further varied across racial groups.

\section{Evaluation and Validation}

It is impossible to validate these methods for vote choice directly, because individual votes are not observed. Voter registration statistics in the state of Florida offer an excellent opportunity 
for evaluating the accuracy of our approach (de Benedictis Kessner 2015). Florida and North Carolina have voter registration by party and by race, and their data are publicly available. Party voter registration in Florida is highly correlated with Trump vote at the precinct level. In the CES, 83 percent of registered Republicans in Florida report voting for the Republican President, while only 50 percent of registered voters with no party affiliation voted for Trump. We choose to study Florida as the state has substantial Black, Hispanic, and White populations and a large number of districts.

We follow the same methods and post-stratification target as our main analysis and refer to our estimates as the MRP estimates. Instead of modeling the Trump vote in the hierarchical regression stage, we model whether or not the respondent's validated voter registration records them as a Republican registrant. We use the subset of our survey respondents who are in Florida, because unlike the Trump vote, only some states record party registration on their voter files. This means that we partially pool across districts within Florida, which vary in their racial and partisan characteristics.

We also perform a validation with Ecological Inference (EI) using precinct aggregate data, which is the dominant method used to study vote choice by race. We acquired an aggregate dataset recording the racial composition and the party registration composition in each Florida precinct. The average congressional district in this data is represented by 200 precincts, and the median precinct includes 1,300 voters (Details of the dataset are in Online Appendix B.3). We ran a standard multinomial ecological inference model (Collingwood et al. 2016) with the same 4 racial categories as MRP and 3 party categories (Republican, Democrat, Non-Party Affiliated and all other parties). We run a separate model from each district, using that district's precincts only.

We find that our method produces reasonably accurate estimates and reasonable measures of uncertainty. Moreover, these estimates have better coverage properties than a standard ecological inference method (EI) that has access to data on the entire population aggregated into 
Figure 2 - Validation of MRP and Ecological Inference Models in Florida. Each model predicts the proportion of each racial group electorate in each congressional district that are registered Republicans. Statistics in each facet show Root Mean Square Error across districts and the Mean Error (estimate minus truth) across 27 districts. Uncertainty intervals are 80 percent credible intervals. See Online Appendix B.3 for detailed methodology.
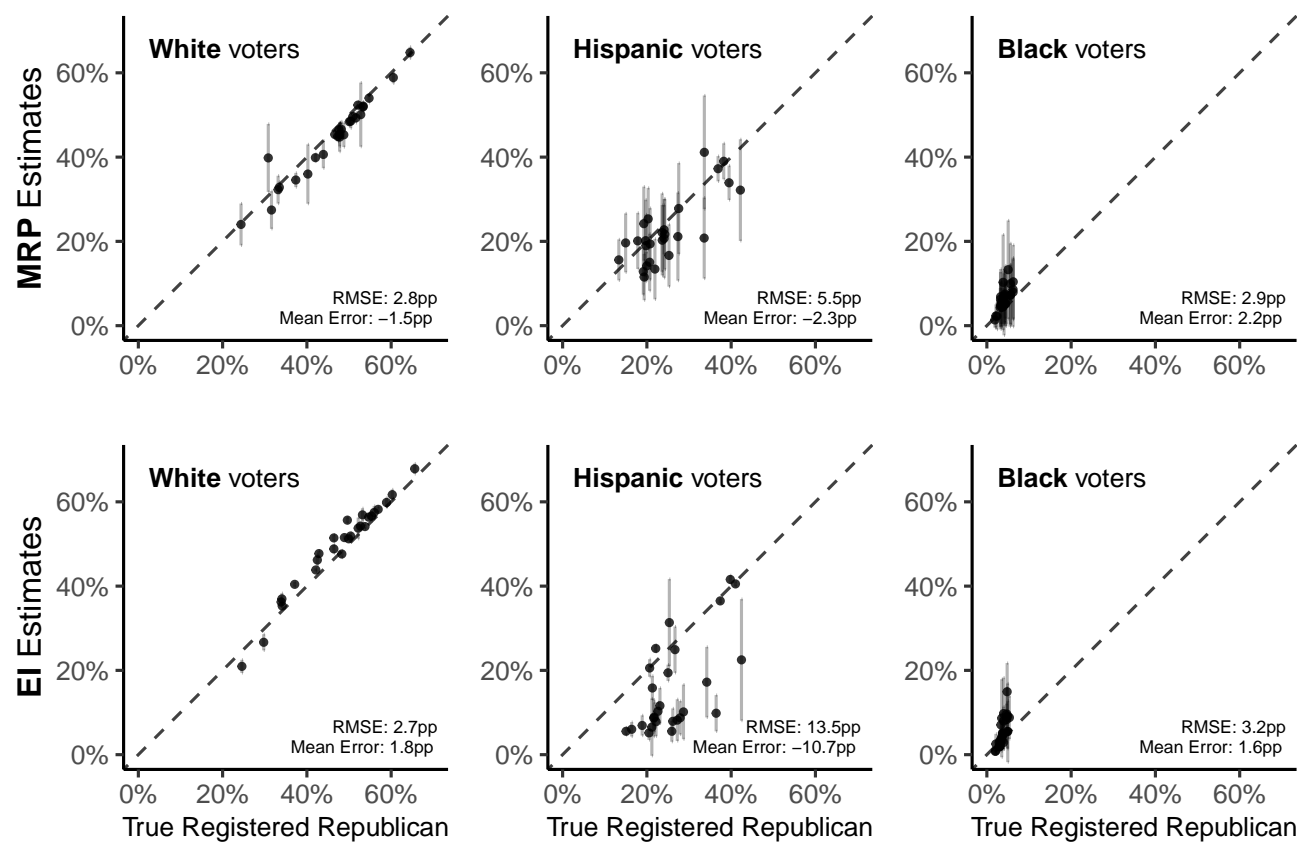

precincts. Figure 2 compares Republican registration share for a racial group in a congressional district on the $\mathrm{x}$-axis with the corresponding estimates from our MRP method and traditional EI in the y-axis. Each graph shows the Root Mean Square Error (RMSE), which captures the total error across all districts, and the Mean Error which distinguishes whether these errors systematically tend to overestimate or underestimate.

Our survey-based estimates and EI have comparably-sized error in estimating the Republican registration of White voters, with a RMSE around 3 percentage points. However, the errors go in opposite directions: our survey-based approach tends to underestimate the Republican-ness, while EI tends to overeestimate. For Hispanic voters, our estimates outperform EI estimates more than two-fold (an RMSE of 5.5 percentage points vs. 13.5 for EI estimates). Using the survey methods developed here, thus, indicates promise in estimating 
more accurately the voting preferences for groups. Using ecological inference can lead to substantively different conclusions about racial cohesion and polarization, and tends to show higher levels of polarization than does the survey data.

Survey estimates using hierarchical regression quantify uncertainty reasonably well, while the confidence intervals for EI are too tight. For all four racial groups, the 80 percent confidence intervals of each of our survey-based estimates cover the true value in 78.7 percent of 108 district $\times$ race combinations. The 80 percent confidence intervals of the EI estimates cover the true value in only 38 percent of the 108 estimates. The lack of coverage for EI owes partly to the inaccuracy of EI for Hispanic registrants and partly to the fact that the standard errors are overly tight for Black and White registrants. Appropriately calibrating survey data using our three-step approach, then, can lead to more accurate estimates and inferences than traditional survey data with weights or aggregate data methods such as EI. We leave to further research the questions of diagnosing issues with EI and how applications of that method might be improved. Although our method and MRP in general does have its own errors, our method relies on individual-level data and can provide accurate estimates of the relationship between race and vote choice.

Our validation using data from Florida is the best setting for a comparison of the accuracy of EI and our survey-based approach. Most other states lack voter file data on race and party. However, in Online Appendix B.4 we generate ecological inference estimates with 2020 Presidential election data and voting age population Census statistics for all 435 districts, and show where our estimates differ. In the average district, EI differs from our survey estimates by over 10 percentage points for White voters and Black voters, and over 20 percentage points for Hispanic voters. 


\section{The Political Geography of Vote Choice by Race}

The estimates offer a nuanced picture of the geography of racial voting preferences. Consistent with the group voting literature, Black voters overwhelmingly prefer Democrats and that preference does not appear to vary by geography. Consistent with the perspective that geography and context matter, the preferences of White and Hispanic voters vary considerably with place.

\section{The Racial Gap at the District Level}

The gap between White and non-White voting preferences varies considerably across the United States. Figure 3 maps the racial gap between White and all non-White voters (defined in Equation (1)) from our final estimates. Because congressional districts are roughly equal in population but vary in land area, we use the cartogram by Daily Kos that sizes districts equally while approximating each district's location within a state. ${ }^{4}$

The dark red area of the map, centered in Louisiana, Mississippi, Alabama, are the CDs that exhibit the highest racial gaps, in excess of 60 percentage points. The seven highest racial gap estimates all appear in Mississippi and Alabama. In these districts, the gap between White and non-White voters is close to 70 percentage points.

The districts with the lowest racial gap tend to be urban areas. In 2016, the five least polarized districts include NY-12 (East side of Manhattan and parts of Queens ${ }^{5}$ ), CA-12 (San Francisco, represented by Speaker Pelosi), CA-13 (Oakland, Rep. Barbara Lee (D)), and WA07 (city of Seattle, Rep. Pramila Jayapal). In these districts, the racial gap ranges from 6 to

\footnotetext{
4 As a result, locations are not exact. For example, districts in New York City are placed closer to upstate New York because there are too many NYC districts to fit in the southeast corner. The correspondence between polygons in this map and each district is given in Online Appendix C. Substantively interpretable names of those districts (e.g. East Bronx) are given in the estimates in Dataverse, https://doi .org/10.7910/DVN/ MAZNJ6.

5 Throughout the paper, we refer to the geographies and representatives as of 2021.
} 
Figure 3 - Racial Gap between White and Non-White Voters. Colors in each congressional district show the point estimate of the estimated racial gap in the 2016 Republican vote between Whites and Non-Whites in that district (Equation (1)). The map is displayed in the Daily Kos cartogram (http://dkel.ec/map): Districts are placed in their approximate place within the state, and states are sized by their population. In the bottom panel, each district point estimate is represented by a point on the vertical axis. Districts are sorted first by Division in facets (from West to East), then by state (alphabetical within Division), then by district number. States are annotated and alternatively colored black and gray for visual clarity.
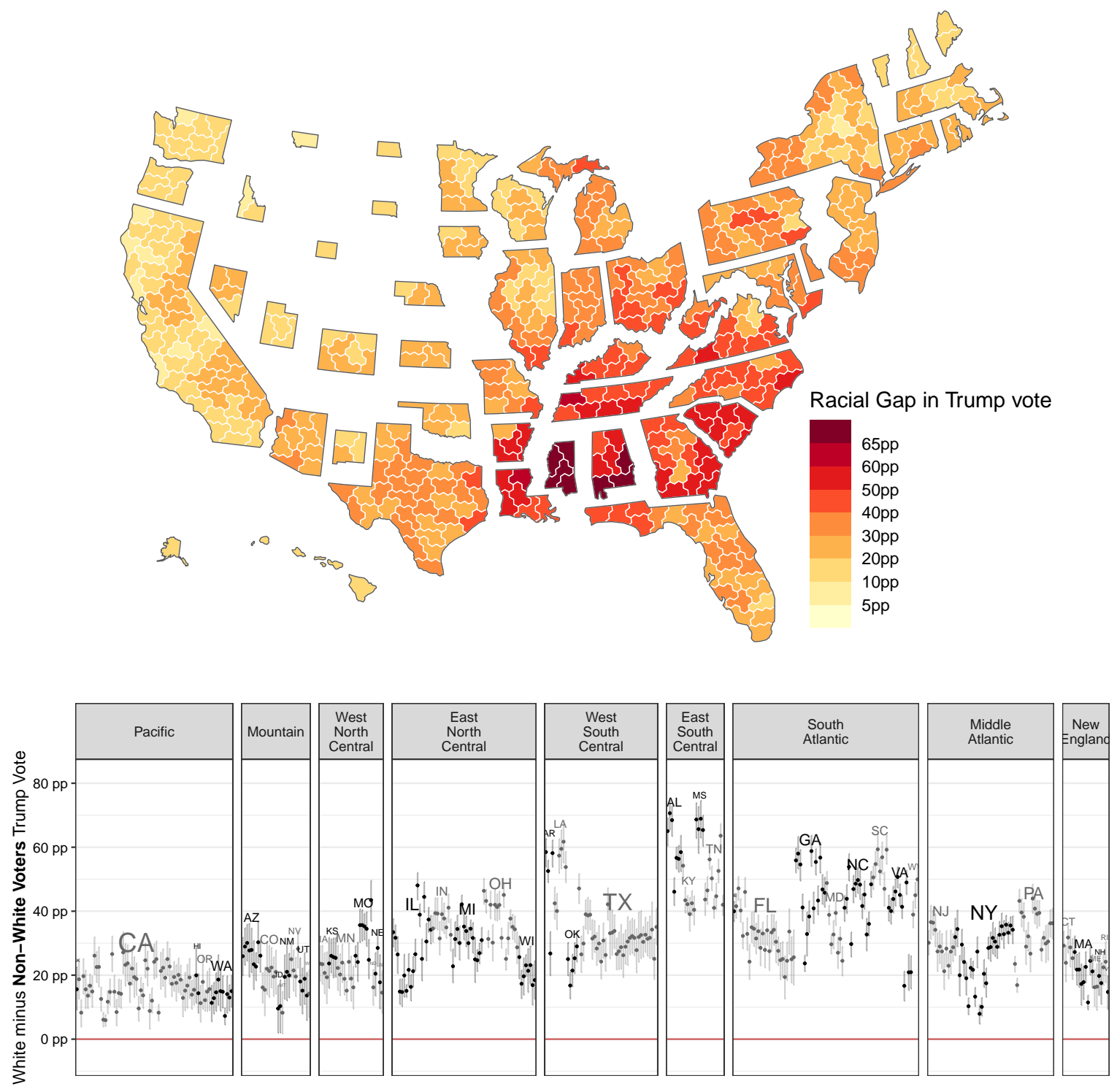
8 percentage points. The distribution of the racial gap is skewed, with high estimates in the Deep South districts pulling the average district's racial gap to be about 2 percentage points higher than the median district (Online Appendix C).

Although the deep red parts of the map are visually striking, the interpretation of the gap and its magnitude depends on the context. A racial gap of 35 percentage points would arise from an electorate in which 70 percent of White voters vote for the Republican and 35 percent of non-White voters vote for the Republican candidate. Such a situation exhibits racially polarized voting and may require creation of a majority minority district under Section 2 the VRA. However, a CD in which 95 percent of non-Whites vote Democratic and 60 percent of Whites vote Democratic has a similarly large racial gap (35 points) but is not racially polarized, because a majority of both groups prefer the same candidate.

Disaggregation by district highlights the variation within a state. For example, Chicago and the northern parts of Illinois have the lowest racial gap estimates in the Midwest but districts in Southern Illinois adjacent to St. Louis have racial gaps as high as those in Tennessee and TX-01 (northeastern Texas, represented by Rep. Louie Gohmert). A similar pattern occurs in Virginia, where the DC suburbs of VA-08, VA-10, and VA-11 have low racial gap values similar to the Boston suburbs, but other Virginia districts have racial gap values that are in the top quarter of all districts.

From coast to coast, the measures of racial gap heightens in the Midwest and the South, and falls again in New England. The bottom panel in Figure 3 shows the same estimates of differences on a common vertical axis, and shows the 80 percent credible interval for the uncertainty in the estimates. Almost all districts have intervals that do not include zero. ${ }^{6}$

6 We compute the 80 percent credible interval of the difference in $\widetilde{\tau}_{\text {white, } j}$ and non-White vote $\widetilde{\tau}_{g, j}$ by taking the 10th and 90th quantiles of the 2000 posterior sample estimates of differences. The posterior distribution also allows us to account for the dependency between the White vote and the minority vote conditional on a district, which could be positively or negatively correlated and violate the standard assumption in two-sample t-tests. 
Figure 4 - 2016 Republican Vote by Racial Group in Congressional Districts. Each district is colored by the estimated two-party voteshare for the Republican Presidential candidate.

White Voters

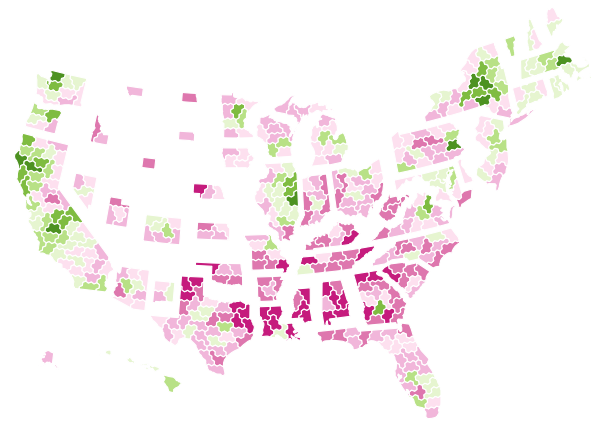

Trump's Two-Party Vote
Hispanic Voters

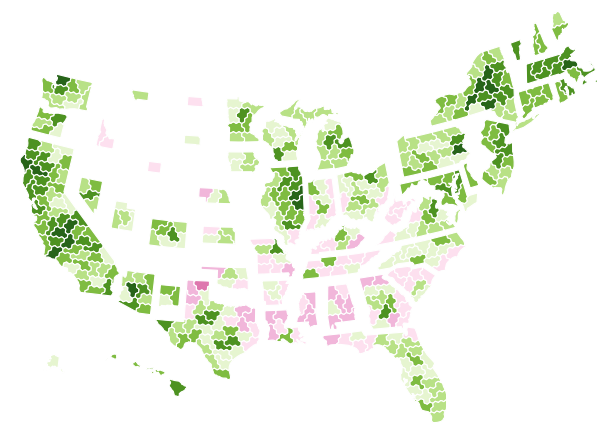

$10 \% \quad 20 \% \quad 30 \% \quad 40 \% \quad 50 \% \quad 60 \% \quad 70 \% \quad 80 \% 90 \%$
Black Voters

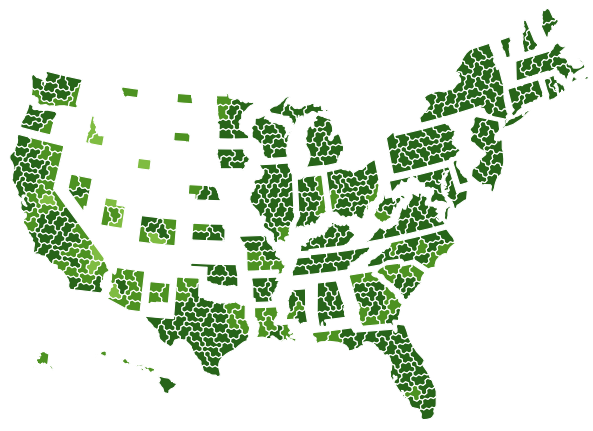

\section{Group Cohesion}

The variation in the racial gap between White and non-White voters is largely driven by White voters and Hispanic voters. Black voters cohesively vote for the Democratic party in all congressional districts. Here we examine the cohesiveness of each group nationally and across districts, states, and regions. Figure 4 decomposes the cohesion estimates of vote choice into the two-party voteshare by the three major racial groups.

The voting tendencies of White voters in the urban areas of California, New York, and Illinois are a stark contrast to White voters in the Deep South, where over 90 percent of White voters voted for Trump. Hispanic voters also exhibit high levels of variation. Hispanic voters in Southern Florida are more Republican than the Hispanics in San Francisco or Chicago. Among districts where over 40 percent of the electorate is Hispanic, the district in which the Hispanic voters are the most Republican is FL-25, which has the largest Cuban American population in the US and is represented by Rep. Díaz-Balart (R).

We use the term cohesion to refer to the voting behavior of a group (Pildes 2001; Atsusaka 
Figure 5 - District Level Cohesion. The range of district-level cohesion of each of the three racial groups, quantified as the absolute distance from 50 percent of the point estimate of the group's two-party support in the district. States where the Black or Hispanic population is less than 2 percent of the electorate are not analyzed.

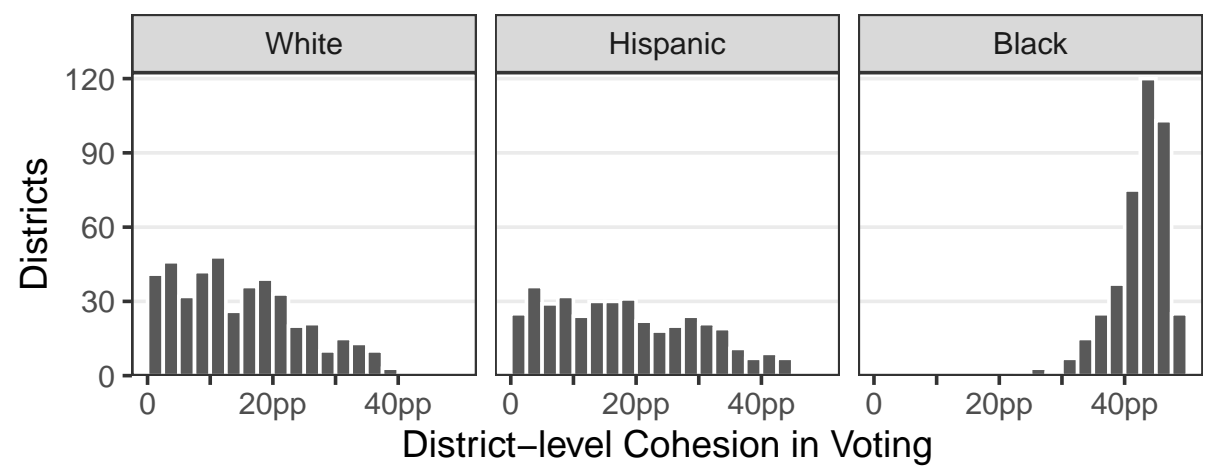

2021). Cohesion equals the absolute deviation of the point estimate of the percent of a group that votes for the Republican from 50 percent. For example, White voters voting 85 percent for Donald Trump will have the same cohesion value as Hispanic voters voting 15 percent for Trump: 35 percentage points. Figure 5 shows the range of these district cohesion scores for White, Hispanic, and Black voters. Black voters are highly cohesive in their preferred candidate, while Hispanic and White voters show considerable variation in the degree of cohesion across CDs. In 385 districts, Black voters' cohesion is over 0.35 (i.e., 85 percent vote for one party); White voters have the same level of cohesion in only 13 districts and Hispanic voters in only 35 . Using ecological inference on precinct-level election data produced higher cohesion estimates for White voters (by 6 percentage points on average) and Hispanic voters (12 percentage points), with lower cross-district variance.

Our goal is to measure the magnitude and patterns of racial group preferences, not to explain their source. ${ }^{7}$ Nonetheless, it is worth noting that there is a clear urban-rural gradient evident in Figure 4. Our estimates reveal a substantial difference between the most urban and most rural CDs among White voters and among Hispanic voters. White voters in urban

\footnotetext{
7 Work that seeks to explain geographic or racial variations in preferences highlight place-based identities (Cramer 2016; Munis 2020), racialized social constraint (White and Laird 2020), and political incorporation (Masuoka et al. 2018; Alvarez and Bedolla 2003)
} 
districts are more Democratic than White voters in suburban districts, and even more so than White voters in rural districts. That pattern is consistent with research on group preferences as a function of ZIP code density and distance to large cities (Gimpel et al. 2020), and it is consistent with the notion that voting rights law needs to be narrowly tailored to the voting patterns in particular areas. Even still, within urban, suburban and rural CDs, a 20-percentage point difference between White and Hispanic voters remain. Substantial racial group differences, then, are not just a matter of where people live.

Districts are, in turn, nested within states and regions. Table 1 shows our point estimates of vote by race at the national level, then separates this estimate to the four U.S. Census regions, then by the nine Census divisions, and then by each of the 50 states. Our statewide and national estimates differ from other surveys such as the National Exit Polls by only a few percentage points (Online Appendix B). ${ }^{8}$ Our procedure increases the precision, i.e. decreases the standard error, in subgroup estimates, relative to the raw or post-stratification weighted survey data at the CD or state level. The standard error of our state-level estimates ranges from about 0.005 to 0.10 , inversely proportional to the size of the group (Online Appendix C.4). For example, there are roughly $n=300$ Alabama voters in our survey data, a quarter of whom are Black. That implies a standard error of about 0.035 for White voters in Alabama and 0.06 for Black voters when the sample is taken as-is with no modeling. The comparable standard error of our modeled estimates is about 0.01 for White voters and 0.025 for Black voters.

In 2016, the White - Non-White gap was 37 percentage points: 59 percent of White voters voted Trump, whereas only 29 percent of Hispanic voters and 7 percent of Black voters voted for Trump. But Whites in the Northeast were 8 points less likely to support Trump than Whites in the Midwest, and 18 points less likely than Whites in the South (Table 1(a)). Within the Northeast, moreover, voting among Whites differed by 10 points between New

8 An exception is a 10-15 point difference with Latino Decisions and CMPS on the Republican vote of Hispanics, which we discuss in Appendix B. 
England (45 percent) and the Middle Atlantic states (54 percent) of New York, New Jersey, and Pennsylvania (Table 1(b)). At the state level we see further variation. The Republican voting patterns among White voters in the Deep South states are different from those the peripheral South states (McKee and Springer 2015), as well as different within other regions.

Overall, Table 1 shows how measuring the racial gap only at the state or national level mask important variation in large states. With state-level estimates, White voters appear solidly Republican: In all states but five in New England and four in the Pacific West, the majority of White voters vote for Donald Trump in 2016. But state groupings mask other differences in congressional district constituencies like the urban-rural divide.

An analysis of variance (ANOVA) is an ideal framework for summarizing the relative importance of racial group differences and nested geographic group differences (Gelman and Hill 2006, ch.22). An ANOVA can partition the overall variation in our estimates by the variation explained by a race-level average, a geography-level average, or the interaction of race and geography. Recall that we have $G \times J \times M$ estimates of vote choice $\widetilde{\tau}_{g j}$ for each racial group $g$ and congressional district $j$. We first consider the following three-part decomposition,

$$
\widetilde{\tau}_{g j}=\mu+\phi_{g}+\eta_{j}+\gamma_{g j}+\varepsilon_{g j}
$$

where we partition the estimates of vote choice into the racial group component $(\phi)$, the geography component $(\eta)$, and their interaction $(\gamma)$. The error term $\varepsilon$ represents sampling variation. By decomposing district-race vote shares in this way, we are defining the geography component as a single Republican voteshare for a given district $j$ that does not vary by racial group. It can be thought of as the normal partisan lean of the entire district. The definition is agnostic as to whether this partisan lean is due to factors such as rurality, or place-based identities.

We are interested in how much variation in the patterns we found is explained by each 
Table 1 - 2016 Republican Vote by Racial Group in Regions, Divisions, and States

(a) By Region

\begin{tabular}{rccccc}
\hline & & \multicolumn{3}{c}{ Non-Whites } & \\
\cline { 3 - 5 } & White & All & Black & Hisp. & All \\
\hline Northeast & 51 & 17 & 4 & 20 & 43 \\
South & 69 & 23 & 8 & 37 & 55 \\
North Central & 59 & 19 & 5 & 29 & 53 \\
West & 50 & 26 & 9 & 25 & 42 \\
\hline National & 59 & 22 & 7 & 29 & 49 \\
\hline
\end{tabular}

(b) By Division, nested within Region

\begin{tabular}{|c|c|c|c|c|c|}
\hline & \multirow[b]{2}{*}{ White } & \multicolumn{3}{|c|}{ Non-Whites } & \multirow[b]{2}{*}{ All } \\
\hline & & All & Black & Hisp. & \\
\hline \multicolumn{6}{|l|}{ Northeast } \\
\hline New England & 45 & 19 & 3 & 19 & 41 \\
\hline Middle Atlantic & 54 & 16 & 4 & 21 & 44 \\
\hline \multicolumn{6}{|l|}{ South } \\
\hline South Atlantic & 64 & 21 & 7 & 37 & 51 \\
\hline East South Central & 77 & 16 & 7 & 50 & 64 \\
\hline West South Central & 72 & 30 & 9 & 37 & 58 \\
\hline \multicolumn{6}{|l|}{ North Central } \\
\hline East North Central & 57 & 17 & 5 & 25 & 51 \\
\hline West North Central & 61 & 28 & 6 & 39 & 57 \\
\hline \multicolumn{6}{|l|}{ West } \\
\hline Mountain & 59 & 33 & 13 & 29 & 53 \\
\hline Pacific & 44 & 24 & 9 & 23 & 36 \\
\hline National & 59 & 22 & 7 & 29 & 49 \\
\hline
\end{tabular}

Note: Numbers show two-party voteshare for the Republican Presidential candidate for each geography and racial group rounded to the nearest full percentage point. Columns represent, from left to right, the Republican vote among White voters, all non-White voters, Black voters, (any-part) Hispanic voters, and all racial groups in the geography. Numbers in parentheses are those where we estimate the racial group comprises only 2 percent or less of the geography's electorate. See Online Appendix C.4 for standard errors of the state-level point estimates. (c) By State, nested within Division

\begin{tabular}{|c|c|c|c|c|c|}
\hline & \multirow[b]{2}{*}{ White } & \multicolumn{3}{|c|}{ Non-Whites } & \multirow[b]{2}{*}{ All } \\
\hline & & All & Black & Hisp. & \\
\hline \multicolumn{6}{|l|}{ New England } \\
\hline Connecticut & 50 & 20 & 4 & 24 & 43 \\
\hline Maine & 49 & 33 & (4) & (26) & 49 \\
\hline Massachusetts & 40 & 16 & 2 & 15 & 36 \\
\hline New Hampshire & 51 & 32 & (4) & $(25)$ & 50 \\
\hline Rhode Island & 45 & 21 & 3 & 21 & 42 \\
\hline Vermont & 36 & 21 & (2) & (15) & 35 \\
\hline \multicolumn{6}{|l|}{ Middle Atlantic } \\
\hline New Jersey & 55 & 20 & 4 & 22 & 43 \\
\hline New York & 50 & 15 & 4 & 18 & 39 \\
\hline Pennsylvania & 58 & 15 & 3 & 28 & 51 \\
\hline \multicolumn{6}{|l|}{ South Atlantic } \\
\hline Delaware & 54 & 14 & 5 & 26 & 44 \\
\hline Florida & 63 & 27 & 6 & 37 & 51 \\
\hline Georgia & 73 & 19 & 8 & 44 & 53 \\
\hline Maryland & 51 & 13 & 6 & 25 & 36 \\
\hline North Carolina & 66 & 19 & 8 & 39 & 52 \\
\hline South Carolina & 73 & 17 & 10 & 50 & 58 \\
\hline Virginia & 60 & 19 & 7 & 32 & 47 \\
\hline West Virginia & 74 & 29 & 9 & $(54)$ & 72 \\
\hline \multicolumn{6}{|l|}{ East South Central } \\
\hline Alabama & 83 & 17 & 7 & 60 & 65 \\
\hline Kent & 71 & 21 & 3 & 40 & 66 \\
\hline Mississippi & 84 & 15 & 10 & $(60)$ & 60 \\
\hline Tennessee & 74 & 15 & 3 & 44 & 64 \\
\hline \multicolumn{6}{|c|}{ West South Central } \\
\hline Arkansas & 74 & 23 & 8 & 45 & 65 \\
\hline Louisi & 81 & 22 & 13 & 54 & 61 \\
\hline Oklahoma & 73 & 48 & 6 & 48 & 70 \\
\hline Texas & 70 & 31 & 6 & 36 & 55 \\
\hline \multicolumn{6}{|l|}{ East North Central } \\
\hline Illinois & 51 & 15 & 5 & 19 & 41 \\
\hline Indiana & 65 & 23 & 7 & 38 & 60 \\
\hline Michig & 57 & 17 & 5 & 31 & 51 \\
\hline Ohio & 61 & 16 & 6 & (34) & 55 \\
\hline Wisconsin & 54 & 23 & 3 & 31 & 51 \\
\hline \multicolumn{6}{|l|}{ West North Central } \\
\hline Jиче & 57 & 35 & 7 & 43 & 55 \\
\hline Kansas & 65 & 37 & 8 & 43 & 61 \\
\hline Minnesota & 53 & 24 & 4 & 27 & 50 \\
\hline Mioro & 66 & 20 & 6 & (43) & 60 \\
\hline Nebraska & 66 & 39 & 8 & 46 & 64 \\
\hline th Dakota & 71 & 55 & (12) & $(52)$ & 70 \\
\hline South Dakota & 67 & 53 & (10) & $(47)$ & 66 \\
\hline \multicolumn{6}{|l|}{ Mountain } \\
\hline Arizo & 60 & 28 & 13 & 23 & 52 \\
\hline Colorado & 52 & 31 & 12 & 30 & 48 \\
\hline & 69 & 59 & (24) & 53 & 69 \\
\hline Montana & 62 & 54 & (16) & (38) & 62 \\
\hline Nevada & 57 & 32 & 12 & 28 & 49 \\
\hline New Mexico & 55 & 34 & (14) & 32 & 46 \\
\hline Utah & 65 & 48 & (18) & 39 & 63 \\
\hline Wyoming & 77 & 63 & $(27)$ & 59 & 76 \\
\hline \multicolumn{6}{|l|}{ Pacific } \\
\hline A & 62 & 47 & 16 & 45 & 59 \\
\hline California & 43 & 23 & 9 & 22 & 34 \\
\hline Hawaii & 42 & 26 & 9 & 23 & 33 \\
\hline Oreg & 46 & 29 & (6) & 27 & 44 \\
\hline Washington & 45 & 28 & 7 & 30 & 42 \\
\hline National & 59 & 22 & 7 & 29 & 49 \\
\hline
\end{tabular}


component. In ANOVA these relative importance measures are given by

$$
\widehat{\kappa}_{\text {race }}=\frac{J \sum_{g=1}^{G} \widehat{\phi}_{g}^{2}}{\operatorname{TSS}(\widetilde{\tau})}, \quad \text { and } \quad \widehat{\kappa}_{\mathrm{cd}}=\frac{G \sum_{j=1}^{J} \widehat{\eta}_{j}^{2}}{\operatorname{TSS}(\widetilde{\tau})}
$$

where TSS is the total sums of squares $\operatorname{TSS}(\widetilde{\tau})=\sum_{g} \sum_{j}\left(\widetilde{\tau}_{g j}-\widehat{\mu}\right)^{2}$. The components are estimated via OLS with the sum-to-zero constraint on each group of coefficients, $\sum_{g} \phi_{g}=$ $\sum_{j} \eta_{j}=\sum_{j} \sum_{g} \gamma_{g j}=0 .{ }^{9}$ We interpret the $\kappa$ term for each component as a proportion because they sum to $1 .{ }^{10}$ A large value of $\widehat{\kappa}_{\text {race }}$ would indicate that the variation in the final estimate is largely explained by a single national racial group difference in Republican voteshare that does not vary with geography, while a large value of $\widehat{\kappa}_{\text {region }}+\widehat{\kappa}_{\text {state }}+\widehat{\kappa}_{\text {cd }}$ would imply that a region, state, or district-level voteshare explains more of the total variation in the estimates. A large value of $\widehat{\kappa}_{\text {residual }}$ would imply that much of variability is posterior estimation uncertainty rather than anything systematic.

The simple model in Equation (4) can be made more elaborate to partition the geographic component $\eta$ to states and regions, in addition to districts. This amounts to estimating separate terms for state and region components, e.g. $\eta_{\operatorname{state}[j]}$ and $\eta_{\text {region }[j]}$. If a single value for an entire state or entire region is sufficient to entirely explain district-level geographic variation, all of the variation previously attributed to $\eta_{\mathrm{cd}}$ will shift to the variation explained by $\eta_{\text {state }}$.

The ANOVA results are summarized in Table 2. Model (1), corresponding to Equation (4), shows that about 60 percent of the total variation in the district- and race-level vote is explained by a national race pattern, 29 percent is explained by geography, and the interaction of the two (i.e., differences between races that vary depending on the geography) explains the

9 For computational tractability we use every tenth sample from $M$ total.

10 We define the quantity for the interaction term $\widehat{\kappa}_{\text {racexcd }}$ and for the residual similarly,

$$
\widehat{\kappa}_{\text {race } \times \mathrm{cd}}=\frac{\sum_{j=1}^{G} \sum_{j=1}^{J} \widehat{\gamma}_{g j}^{2}}{\operatorname{TSS}(\widetilde{\tau})}, \quad \text { and } \quad \widehat{\kappa}_{\text {residual }}=\frac{\sum_{j=1}^{G} \sum_{j=1}^{J} \widehat{\varepsilon}_{g j}^{2}}{\operatorname{TSS}(\widetilde{\tau})}
$$

where $\widehat{\varepsilon}_{g j}=\widetilde{\tau}_{g j}-\widehat{\mu}-\widehat{\phi}_{g}-\widehat{\eta}_{j}-\widehat{\gamma}_{g j}$. Then the four quantities sum to one, $\widehat{\kappa}_{\text {race }}+\widehat{\kappa}_{\mathrm{cd}}+\widehat{\kappa}_{\mathrm{race} \times \mathrm{cd}}+\widehat{\kappa}_{\text {residual }}=1$. 
Table 2 - Proportion of Variance Explained by Race and Geography. Each column represents an ANOVA model estimated from a tenth of the posterior sample estimates of the district- and race-level vote. Proportions show the fraction of variance in the outcome explained by each type of variable $(\widehat{\kappa})$, and sum to 1 . The last two rows presents the variance across samples (or the total sums of squares divided by the sample size) and the number of posterior samples used.

\begin{tabular}{|c|c|c|c|c|c|}
\hline & \multicolumn{5}{|c|}{ Fraction of Variation Explained } \\
\hline & \multicolumn{2}{|c|}{ Across Races } & \multicolumn{3}{|c|}{ Within Race } \\
\hline & (1) & (2) & $\begin{array}{c}\text { White } \\
\text { (3) }\end{array}$ & $\begin{array}{l}\text { Black } \\
(4)\end{array}$ & $\begin{array}{c}\text { Hispanic } \\
\text { (5) }\end{array}$ \\
\hline \multicolumn{6}{|l|}{ Race / Ethnicity } \\
\hline Racial Group & .60 & .60 & & & \\
\hline \multicolumn{6}{|l|}{ Geography } \\
\hline Congressional District & .28 & .15 & .54 & .30 & .39 \\
\hline State & & .06 & .19 & .14 & .16 \\
\hline Region & & .07 & .26 & .18 & .23 \\
\hline \multicolumn{6}{|l|}{ Race $\times$ Geography } \\
\hline Race $\times$ Congressional District & .07 & .03 & & & \\
\hline Race $\times$ State & & .02 & & & \\
\hline Race $\times$ Region & & .03 & & & \\
\hline \multicolumn{6}{|l|}{ Sampling Variation } \\
\hline Residuals & .05 & .05 & .01 & .38 & .22 \\
\hline Total Variance & 0.056 & 0.056 & 0.027 & 0.0034 & 0.029 \\
\hline Samples & 348,000 & 348,000 & 87,000 & 87,000 & 87,000 \\
\hline
\end{tabular}

remaining 7 percent. Model (2) decomposes the geographic component into districts (nested within states), states (nested within regions), and regions. Congressional districts explain 16 percent of the variation above and beyond larger geographies, whereas states explain only 6 percent and regions explain 7 percent. Estimation uncertainty accounts for about 5 percent of the variation in our data.

The weight of geography (i.e., CD, state, and region) also varies within each racial group. Models (3) - (5) use the estimates of one racial group at a time so that there is no race-level variation. The last row shows that the total variation in the Trump vote among White and Hispanic voters is more than five times larger than the total variation observed for Black 
voters. In all racial groups, the district level accounts for more than twice as much variability in the total estimates than state or region-level averages. White and Hispanic voters vary more than Black voters, and the bulk of the variation occurs at the district level.

At a high-level, then, differences in the average vote choice of racial groups nationwide explains twice as much of the systematic variation in voting as does the $\mathrm{CD}$, state, or region. Sixty percent of the variation in the vote of racial groups within a particular congressional district can be accounted for by the average national vote of the groups. The normal vote of a $\mathrm{CD}$, state, or region explains 30 percent of the remaining variation. A final 10 percent of the variation is due to the fact that voting patterns of a given racial group change by geography. In other words, while we do find substantial sub-state variation, geography (i.e., CD, state, and region) explains at most a third of the total variation across all district-race combinations.

Ecological inference estimates yield different conclusions on the explanatory power of geography. We applied the same ANOVA modeling to the posterior sample of ecological inference estimates, which were generated from applying EI one district at a time, described in Online Appendix B. The national race component explains roughly the same amount of variation across both methods (both .52 in 2020). However, state, region, and district explain twice as much of the variation using MRP than using EI (.34 versus .15). Because MRP models district level variation as a random effect, it allows for more efficient estimation of the district component $\kappa_{\mathrm{cd}}$. EI implemented at the district level forces that variation onto the interaction component $\kappa_{\text {racexcd }}$. One may improve EI by allowing partial pooling across districts, but that is not conventionally done.

Our analysis examines a group's voting behaviors, rather than beliefs, ideologies or issue preferences. Our findings reaffirm the lack of variation in party vote among Black voters, but there are certainly diverse dynamics within that group beyond party choice (White and Laird 2020; Jefferson 2021). Even still, we examine measures of ideology or belief, and the methods developed here open up opportunities to model any survey item to explore how 
ideology or public opinion may vary within groups.

\section{Groups and Coalitions}

Finally, we turn to the potential of groups to form coalitions. The emerging voting power of Black and Hispanic groups over the past three decades and the cohesiveness of these groups raises the possibility that the two groups may vote sufficiently strongly together in general elections to be able jointly to elect their preferred candidates (Axelrod 1972; Grofman, Handley, and Lublin 2000; Barreto, Collingwood, and Manzano 2010; Atsusaka 2021). The demographic realities of contemporary America are putting pressure on voting rights law to accommodate the possibility of multi-racial coalitions (Pildes 2001).

Coalition voting can be operationalized two ways. First, how often do the majority of each group of minority voters prefer the same candidates? The point estimates underlying Figure 4 indicate that in 356 out of 435 CDs ( 82 percent), a majority of Black voters and a majority of Hispanic voters voted for the same candidate. Majorities of White and Hispanic voters voted for the same candidate in 216 CDs (49 percent), and majorities of White and Black voters voted for the same candidate in 136 (31 percent).

Second, which group or groups are pivotal (Ingham 2019; Snyder 1989)? We identify the pivotal racial group or groups in each CD using the 2016 Presidential vote. We divide each congressional district into whether it reports more votes won by the Republican, Donald Trump, or the Democrat, Hilary Clinton. We then use the point estimates of the vote shares of the Democratic and Republican candidates for each racial group in each $\mathrm{CD}$, and then calculate the total vote for each group that went to the Democrat and to the Republican. ${ }^{11}$ Using those totals we determine which groups were pivotal in giving the winning candidate her or his majority. We distinguish these districts in Figure 6 and tabulate the frequency of

11 Our hierarchical regression model estimates a voteshare. We multiply this with the total number of voters for the race-district combination, estimated in our target distribution. 
Table 3 - Typology of Racial Coalitions. Ability of party supporters in each racial group to win a majority of votes either on its own or as a coalition. The party of the district refers to the party that won the two-party Presidential election vote in each congressional district.

\begin{tabular}{rcc}
\hline Racial Group Composition for Sufficient for a Majority & Democratic CDs & Republican CDs \\
\hline White voters alone & 20 & 179 \\
Black voters alone & 10 & 0 \\
Hispanic voters alone & 2 & 0 \\
Black and Hispanic voters & 18 & 0 \\
Black, Hispanic, and Other non-White voters & 15 & 0 \\
White and non-White & 140 & 51 \\
\hline Total & 205 & 230 \\
\hline
\end{tabular}

each type in Table 3.

The striking finding in Table 3 is that minority voters are pivotal in more than half of the districts. In 236 of the $435 \mathrm{CDs}$, minority voters, either one group singly or together with White voters, were pivotal in determining which candidate won the majority of the vote. For example, in UT-04 which includes Salt Lake County, White voters comprise close to 80 percent of the electorate but voted sufficiently for Clinton that White Trump voters alone fall short of a majority. Given their large population, White voters are often part of a pivotal set of racial groups as well: their vote is needed in 390 districts for the winning candidate.

Among the 236 districts where minority voters are part of a pivotal coalition, 45 are those in which minority voters are pivotal without White voters. Black voters are large and cohesive enough to deliver a majority of the district vote "alone" (i.e., without relying on other racial groups) in 10 districts, and Hispanics voters are pivotal alone in 2 (Table 3). In a separate 33 districts, minority groups (including Asian Americans, Native Americans, and multi-racial voters), voted with sufficient cohesion to account for a majority of the votes. The center-left panel of Figure 6 identifies these districts. All 45 of districts were won by Hillary Clinton, the Democrat. In no district did Trump's majority rest solely on non-White voters.

In 199 of the 435 districts, White voters alone are large enough to deliver the majority of the votes cast for the winning candidate. The overwhelming majority (179 out of 199) of 
Figure 6 - Coalitional and Crossover Districts. 435 congressional districts in the 2016 Presidential election are classified into one of 6 types listed in Table 3. Maps on the left show districts won by the Democrat, and maps on the right show districts won by the Republican. Districts are placed in the same map as Figure 3.
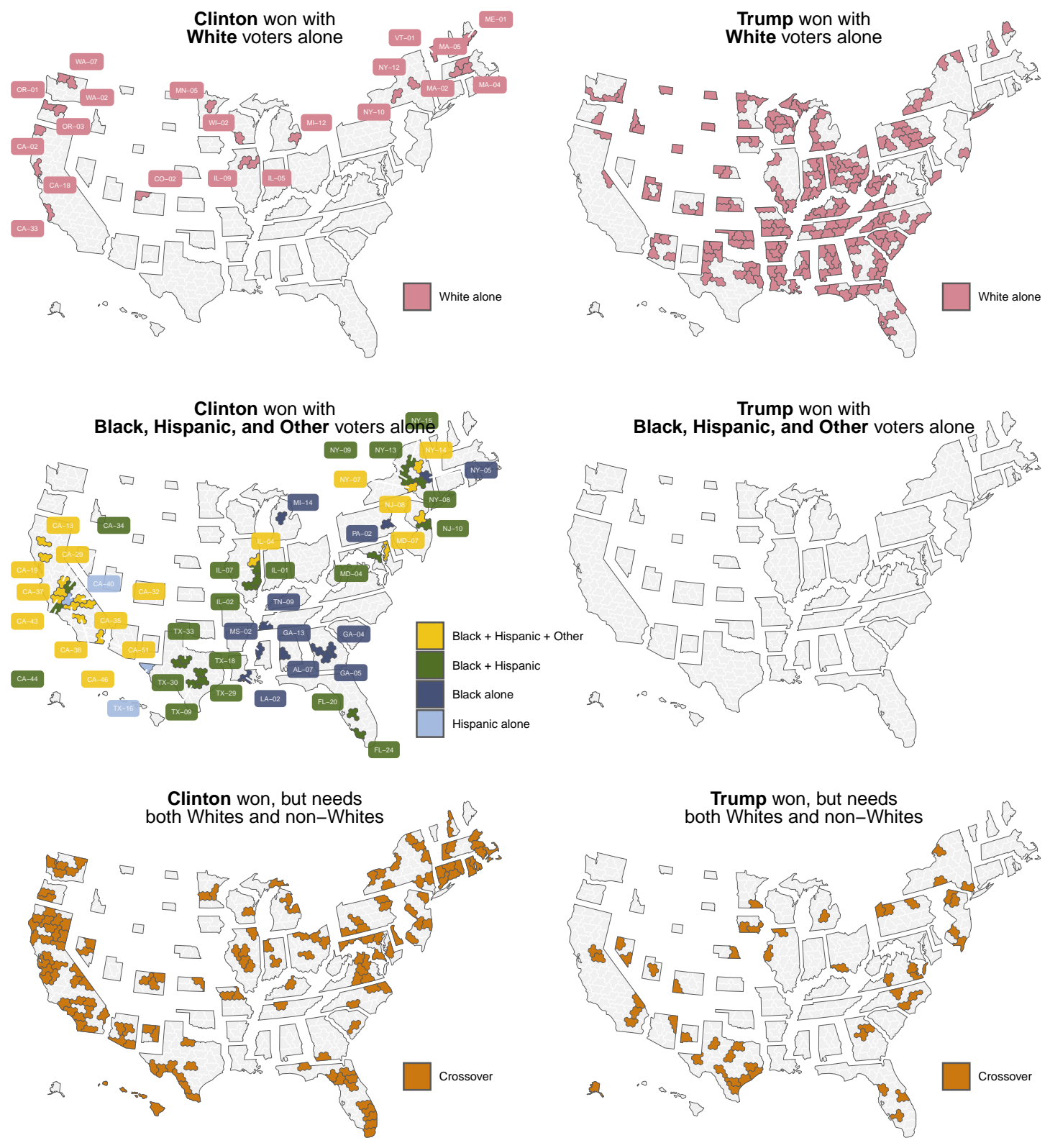
these heavily White districts voted for Trump.

These statistics suggest that both parties rely on coalitions of White and minority voters. In a fifth of districts Trump won in 2016, Trump needed support of both White and non-White voters to win (Table 3). The Democratic party relies much more on the votes from multiple racial groups. Among the 205 districts won by Clinton in 2016, her majorities relied on a coalition of White and minority voters in 140 districts. Clinton won only 20 districts in which the White vote alone was sufficient to win a majority. This is the multi-racial electoral context that Pildes (2001) foresaw, and it presents new complexities for the crafting and application of voting rights laws. However, the degree of reliance is asymmetric. White voters alone were sufficient to win a majority of votes in districts Trump won, while in the majority of districts Clinton won, Democrats needed votes from both White voters and minority voters (Table 3).

\section{Conclusion}

This study offers the first set of estimates of racially polarized voting at the congressional district level for all 435 congressional districts and 50 states. Our findings immediately inform debates over persistence of importance of race and regionalism in US elections, specifically the extent to which the racial divide in the US is a national phenomenon or is regionally concentrated. We find national division in the average vote across racial groups that explains 60 percent of the variation in our estimates. Nationally, 24 percent of non-White voters voted Republican while 59 percent of Whites voted for the Republican in 2016 - a 35 point difference. There are, however, significant cross-state and within-state variations in group voting behavior as well. Black voting behavior is far more consistent across districts and states than Hispanics or Whites. Hispanic and White voting behavior varies considerably. For instance, only 40 percent of Whites voters voted for the Republican in Massachusetts, compared to 86 
percent in Mississippi. The structure of the variation we find within groups across the CD, state, and regional levels is analogous to that of Erikson, Wright, and McIver (1989), which finds ideological variation within the Republican and Democratic party across states.

Our findings show the complex dynamics of racial group politics in the United States. Differences in election outcomes are explained by both differences across groups and the aggregate differences by geography. And through analyzing patterns of vote share, withindistrict polarization, and group size, we find that most congressional districts were won either with a multi-racial coalition or a significant cross-over vote of either whites of minorities in 2016. These group dynamics are present even though White and non-White voters are polarized nationally. This fact points to an increasingly important reality for both major political parties in the United States: support from minority voters is a necessity for both parties to win a congressional majority. Demographic trends will only increase the importance of Asian, Black, and Hispanic votes within both parties.

As the voting behavior of the United States electorate shifts, so too must the laws and policies that prevent racial vote dilution. Our analysis supports both the need for federal voting rights law and the need for the narrow tailoring federal and state rules to specific areas in line with the principles of federalism. Many of the divisions across racial groups that existed in the past remain. Those divisions do, however, vary across regions and states and, even, within states. Majority minority districts may be required, then, in some areas within a state but not others. Our study offers a new assessment, informed by individual-level data, of where such districts may be required to protect minority voters.

Our article also offers innovations in the analysis of survey data that open the possibility of using individual data where only aggregates were available before. The modifications to the existing MRP procedure in our framework can integrate more survey data and aggregate statistics together, generating more reliable survey-based estimates of group voting behavior at different levels of geographic aggregation. Use cases for these methods abound in the 
social sciences. We have focused on racial voting patterns at the level of districts and states, but this approach could easily be applied to other geographies, such as metropolitan areas, counties, and cities, or to other demographic groups. For example, the tools developed here allow researchers to distinguish specific cultures or nations of origin of more broadly defined groups, such as Mexican Americans, Puerto Ricans, and Cuban Americans, who are generally combined under the label Hispanic or Latinx.

There is immense potential to extend these methods to more difficult settings with even sparser data, but we also think that such applications must be developed with care, must be attuned to the particular problem at hand, and must be validated whenever possible. Important extensions to the method include accounting for geographic adjacency of districts (Morris et al. 2019), and the integration of multiple surveys to increase the sample sizes of particular groups (Frasure-Yokley et al. 2020; Barreto et al. 2018). Integrating other surveys will require extending the methods presented here to reflect the surveys' timing, mode, question-wording, and sampling that could confound the interpretations of differences. There is also a practical implication for ecological inference methods. Pooling across all districts as in a nationwide EI may violate constancy assumptions, but running separate EI methods by district can underestimate the shared explanatory power of cross-district geography. Implementing partial pooling in EI methods may improve estimation.

Finally, our analysis speaks to one of the most important emerging problems in voting rights law. The Voting Rights Act of 1965 was developed in an era when politics was often Black versus White. Today, Hispanics are the second largest racial group and Asians are growing quickly. Should the Voting Rights Act require minority coalition districts, and if so, where (Pildes 2001)? Our results show that in most districts the majorities of Black and Hispanic voters both support the same party. That does not mean that minority coalition districts can always be drawn, but there is considerable potential for such districts throughout the United States. This approach to representation would more accurately reflect the realities 
of racial voting patterns in American politics today. 


\section{Data Availability Statement}

Research documentation and data that support the findings of this study are openly available in the American Political Science Review Dataverse at https://doi.org/10.7910/DvN/Vx5N1V, and updated estimates are available via Dataverse https://doi .org/10.7910/DVN/MAZnJ6. Software to implement our methods are publicly available through the R packages ccesMRPprep, ccesMRPprep, and synthjoint. The packages are also archived in the Dataverse replication repository.

\section{Funding Statement}

This research was supported by NSF grant 1926424 .

\section{CONFLiCt OF INTEREST}

The authors declare no ethical issues or conflicts of interest in this research.

\section{Human Subjects}

The authors affirm this research did not involve human subjects. 


\section{REFERENCES}

Acharya, Avidit, Matthew Blackwell, and Maya Sen. 2018. Deep Roots: How Slavery Still Shapes Southern Politics. Princeton, NJ: Princeton University Press.

Alvarez, R. Michael, and Lisa Garcia Bedolla. 2003. "The foundations of Latino voter partisanship: Evidence from the 2000 election." The Journal of Politics 65 (1): 31-49.

Ansolabehere, Stephen, Samantha Luks, and Brian F. Schaffner. 2015. "The perils of cherry picking low frequency events in large sample surveys." Electoral Studies 40:409-410.

Ansolabehere, Stephen, Nathaniel Persily, and Charles Stewart. 2009. "Race, region, and vote choice in the 2008 Election: Implications for the future of the Voting Rights Act." Harvard Law Review 123:1385.

- 2012. "Regional differences in racial polarization in the 2012 Presidential Election: Implications for the constitutionality of Section 5 of the Voting Rights Act." Harvard Law Review 126:205.

Ansolabehere, Stephen, and Douglas Rivers. 1995. "Bias in Ecological Regression.” MIT Department of Political Science Manuscript.

Atsusaka, Yuki. 2021. "A Logical Model for Predicting Minority Representation: Application to Redistricting and Voting Rights Cases." American Political Science Review 115 (4): $1210-1225$.

Axelrod, Robert. 1972. "Where the votes come from: An analysis of electoral coalitions, 1952-1968." American Political Science Review 66 (1): 11-20.

Barreto, Matt A., Loren Collingwood, and Sylvia Manzano. 2010. "A new measure of group influence in presidential elections: Assessing Latino influence in 2008." Political Research Quarterly 63 (4): 908-921.

Barreto, Matt A., Lorrie Frasure-Yokley, Edward D. Vargas, and Janelle Wong. 2018. "Best practices in collecting online data with Asian, Black, Latino, and White respondents: evidence from the 2016 Collaborative Multiracial Post-election Survey." Politics, Groups, and Identities 6 (1): 171-180.

de Benedictis Kessner, Justin. 2015. "Evidence in Voting Rights Act Litigation: Producing Accurate Estimates of Racial Voting Patterns.” Election Law Journal 14 (4): 361-381. 
Broockman, David E., and Christopher Skovron. 2018. "Bias in perceptions of public opinion among American political elites.” American Political Science Review 112 (3): 542-563.

Bürkner, Paul-Christian. 2017. "brms: An R Package for Bayesian Multilevel Models Using Stan.” Journal of Statistical Software 80 (1): 1-28.

Buttice, Matthew K., and Benjamin Highton. 2013. "How does multilevel regression and poststratification perform with conventional national surveys?" Political Analysis 21 (4): 449-467.

Cain, Bruce E., and Emily R. Zhang. 2016. "Blurred Lines: Conjoined Polarization and Voting Rights." Ohio State Law Journal 77:867-904.

Charles, Guy-Uriel E., and Luis Fuentes-Rohwer. 2014. “The Voting Rights Act in Winter: The Death of a Superstatue.” Iowa Law Review 100:1389-1439.

Cho, Wendy K. Tam. 1995. “Asians — A monolithic voting bloc?” Political Behavior 17 (2): 223-249.

- 1998. "Iff the assumption fits: A comment on the King ecological inference solution." Political Analysis 7:143-163.

Collingwood, Loren, Kassra Oskooii, Sergio Garcia-Rios, and Matt Barreto. 2016. “eiCompare: Comparing Ecological Inference Estimates across EI and EI: R x C." The R Journal 8 (2): 92.

Cramer, Katherine J. 2016. The Politics of Resentment: Rural consciousness in Wisconsin and the rise of Scott Walker. Chicago, IL: University of Chicago Press.

Daily Kos. 2021. "Calculating Statewide Election Results by Congressional and Legislative District: Statement of Methodology."

Davidson, Chandler, and Bernard Grofman. 1994. Quiet Revolution in the South: The Impact of the Voting Rights Act, 1965-1990. Princeton, NJ: Princeton University Press.

Dawson, Michael C. 1995. Behind the Mule: Race and Class in African-American Politics. Princeton, NJ: Princeton University Press.

Donovan, Todd. 2010. “Obama and the White Vote.” Political Research Quarterly 63 (4): 863-874. 
Elmendorf, Christopher S., and Douglas M. Spencer. 2015. "Administering Section 2 of the Voting Rights Act After Shelby County.” Columbia Law Review 115:2143-2218.

Enos, Ryan D. 2017. The Space Between Us: Social Geography and Politics. Cambridge, UK: Cambridge University Press.

Erikson, Robert S. 2010. "Hispanic Voting in the American States: The Case of 2004," edited by Rodolfo O. de La Garza, Louis DeSipio, and David L. Leal. Notre Dame, IN: University of Notre Dame Press.

Erikson, Robert S., Gerald C. Wright, and John P. McIver. 1989. "Political parties, public opinion, and state policy in the United States." American Political Science Review 83 (3): 729-750.

Frasure-Yokley, Lorrie, Janelle Wong, Edward Vargas, and Matt Barreto. 2020. "The Collaborative Multiracial Post-Election Survey (CMPS): Building the academic pipeline through data access, publication, and networking opportunities." PS: Political Science \& Politics 53 (1): 150-151.

Freedman, David A., Stephen P. Klein, Jerome Sacks, Charles A. Smyth, and Charles G. Everett. 1991. "Ecological regression and voting rights.” Evaluation Review 15 (6): 673711.

Gay, Claudine. 2001. "The Effect of Black Congressional Representation on Political Participation.” American Political Science Review 95 (3): 589-602.

Gelman, Andrew. 2009. Red State, Blue State, Rich State, Poor State: Why Americans Vote the Way They Do. Princeton, NJ: Princeton University Press.

Gelman, Andrew, and Jennifer Hill. 2006. Data analysis using regression and multilevel / hierarchical models. Cambridge, UK: Cambridge University Press.

Gelman, Andrew, and Thomas C. Little. 1997. "Poststratification into many categories using hierarchical logistic regression." Survey Methodology 23 (2): 127-135.

Gelman, Andrew, et al. 2020. "Bayesian Workflow." arXiv preprint arXiv:2011.01808.

Ghitza, Yair, and Andrew Gelman. 2013. "Deep interactions with MRP: Election turnout and voting patterns among small electoral subgroups." American Journal of Political Science 57 (3): 762-776. 
Ghitza, Yair, and Andrew Gelman. 2020. "Voter Registration Databases and MRP: Toward the Use of Large-Scale Databases in Public Opinion Research." Political Analysis 28 (4): 507-531.

Ghitza, Yair, and Mark Steitz. 2020. "DEEP-MAPS Model of the Labor Force.” Working Paper.

Gimpel, James G., Nathan Lovin, Bryant Moy, and Andrew Reeves. 2020. "The Urban-Rural Gulf in American Political Behavior.” Political Behavior 42 (4): 1343-1368.

Grimmer, Justin, Eitan Hersh, Marc Meredith, Jonathan Mummolo, and Clayton Nall. 2018. "Obstacles to estimating voter ID laws' effect on turnout." The Journal of Politics 80 (3): 1045-1051.

Grofman, Bernard. 1991. "Statistics without Substance: A Critique of Freedman et al. and Clark and Morrison.” Evaluation Review 15 (6): 746-769.

Grofman, Bernard, Lisa Handley, and David Lublin. 2000. "Drawing effective minority districts: A conceptual framework and some empirical evidence." North Carolina Law Review 79:1383-1430.

Hertel-Fernandez, Alexander, Matto Mildenberger, and Leah C. Stokes. 2019. "Legislative staff and representation in Congress." American Political Science Review 113 (1): 1-18.

Hopkins, Daniel J. 2010. "Politicized Places: Explaining Where and When Immigrants Provoke Local Opposition.” American Political Science Review 104 (1): 40-60.

- 2018. The Increasingly United States: How and why American Political Behavior Nationalized. Chicago, IL: University of Chicago Press.

Ingham, Sean. 2019. Rule by Multiple Majorities: A New Theory of Popular Control. Cambridge, UK: Cambridge University Press.

Jacobson, Gary C. 2015. "It's Nothing Personal: The Decline of the Incumbency Advantage in US House Elections." The Journal of Politics 77 (3): 861-873.

Jefferson, Hakeem. 2021. "The Curious Case of Black Conservatives: Construct Validity and the 7-point Liberal- Conservative Scale.” Working Paper.

Kastellec, Jonathan P., Jeffrey R. Lax, Michael Malecki, and Justin H. Phillips. 2015. "Polarizing the electoral connection: Partisan representation in Supreme Court confirmation politics." The Journal of Politics 77 (3): 787-804. 
Key, V. O. 1948. Southern Politics in State and Nation. Knoxville, TN: University of Tennessee Press.

Kinder, Donald R., and Lynn M. Sanders. 1996. Divided by Color: Racial Politics and Democratic Ideals. Chicago, IL: University of Chicago Press.

King, Gary. 1996. “Why Context Should Not Count.” Political Geography 15 (2): 159-164.

Kousser, J. Morgan. 1974. The Shaping of Southern Politics: Suffrage Restriction and the Establishment of the One-Party South, 1880-1910. New Haven, CT: Yale University Press.

Kuriwaki, Shiro. 2021. "The Swing Voter Paradox: Electoral Politics in a Nationalized Era." PhD diss., Harvard University.

Kuriwaki, Shiro, Stephen Ansolabehere, Angelo Dagonel, and Soichiro Yamauchi. 2023. "Modeled vote share for geographic and racial subgroups with survey and ecological data." Harvard Dataverse.

Kuziemko, Ilyana, and Ebonya Washington. 2018. "Why did the Democrats lose the South? Bringing new data to an old debate." American Economic Review 108 (10): 2830-2867.

Lauderdale, Benjamin E., Delia Bailey, Jack Blumenau, and Douglas Rivers. 2020. "Modelbased pre-election polling for national and sub-national outcomes in the US and UK." International Journal of Forecasting 36 (2): 399-413.

Lax, Jeffrey R., and Justin H. Phillips. 2009. "How Should We Estimate Public Opinion in The States?” American Journal of Political Science 53 (1): 107-121.

Leemann, Lucas, and Fabio Wasserfallen. 2017. "Extending the Use and Prediction Precision of Subnational Public Opinion Estimation.” American Journal of Political Science 61 (4): 1003-1022.

Masuoka, Natalie, Hahrie Han, Vivien Leung, and Bang Quan Zheng. 2018. "Understanding the Asian American vote in the 2016 election." Journal of Race, Ethnicity, and Politics 3 (1): 189-215.

McKee, Seth C. 2008. "Rural voters and the polarization of American presidential elections." PS: Political Science \& Politics 41 (1): 101-108.

McKee, Seth C., and Melanie J. Springer. 2015. "A tale of "Two Souths": White voting behavior in contemporary Southern elections.” Social Science Quarterly 96 (2): 588-607. 
Morris, Mitzi, et al. 2019. "Bayesian hierarchical spatial models: Implementing the Besag York Mollié model in Stan.” Spatial and Spatio-temporal Epidemiology 31:100301.

Munis, B. Kal. 2020. "Divided by place: The enduring geographical fault lines of American politics." PhD diss., University of Virginia.

Pildes, Richard H. 2001. "Is Voting-Rights Law Now at War with Itself? Social Science and Voting Rights in the 2000s." North Carolina Law Review 80:1517-1574.

Rodden, Jonathan A. 2019. Why Cities Lose: The Deep Roots of the Urban-Rural Political Divide. New York, NY: Basic Books.

Rosenman, Evan T.R., Cory McCartan, and Santiago Olivella. 2023. "Recalibration of Predicted Probabilities Using the 'Logit Shift': Why does it work, and when can it be expected to work well?" Political Analysis.

Shaw, Daron R. 1997. “Estimating racially polarized voting: A view from the states.” Political Research Quarterly 50 (1): 49-74.

Si, Yajuan. 2021. "On the Use of Auxiliary Variables in Multilevel Regression and Poststratification." arXiv preprint arXiv:2011.00360.

Smith, Candis Watts, Rebecca J. Kreitzer, and Feiya Suo. 2020. "The dynamics of racial resentment across the 50 US states." Perspectives on Politics 18 (2): 527-538.

Snyder, James M. 1989. "Political geography and interest-group power." Social Choice and Welfare 6 (2): 103-125.

Stan Development Team. 2021. "Stan Modeling Language Users Guide and Reference Manual 2.28."

Stephanopoulos, Nicholas O. 2016. "Race, Place, and Power.” Stanford Law Review 68:13231408.

Warshaw, Christopher, and Jonathan A. Rodden. 2012. "How should we measure district-level public opinion on individual issues?” The Journal of Politics 74 (1): 203-219.

White, Ismail K., and Chryl N. Laird. 2020. Steadfast Democrats: How Social Forces Shape Black Political Behavior. Princeton, NJ: Princeton University Press. 


\section{Online Appendix for Kuriwaki et al., The Geography of Racially Polarized Voting: Calibrating Surveys at the District Level}

\section{A Modeling Methodology}

\section{A.1 Notation}

Throughout the paper and suppplemental material, we use the following notation.

Indices:

\begin{tabular}{cl}
\hline$i$ & Individuals (up to $N$, in set $\mathcal{I}$ ) \\
$g$ & Racial Group (up to $G$, in set $\mathcal{G}$ ) \\
$j$ & Congressional Districts (up to $J$, in set $\mathcal{J}$ ) \\
$s$ & Cells for demographic variables $\times$ geography (in set $\mathcal{S}$ ) \\
$m$ & MCMC posterior samples (up to $M$ ) \\
\hline
\end{tabular}

Variables and Constants:

\begin{tabular}{cl}
\hline$N$ & Population size \\
$n$ & Sample size of respondents \\
$Y$ & Vote for Republican Presidential candidate (binary) \\
$X, Z$ & Covariates \\
\hline
\end{tabular}

Quantities of Interest:

$\tau$ The Republican voteshare in a given geography or race

$\pi$ Estimated probability at the cell-level, from a logit regression of $Y$

$\delta$ A correction factor on the logit scale to better estimate $\tau$

$\kappa \quad$ Fraction of the variation in $\tau$ explained by components

Parameters:

\begin{tabular}{cl}
\hline$\alpha$ & Random effect intercepts \\
$\beta$ & Coefficients on demographic variables, random slopes \\
$\sigma^{2}, v^{2}$ & Variance governing random effects \\
\hline
\end{tabular}




\section{A.2 About the Cooperative Congressional Election Study}

We use the CCES because it is the only survey dataset whose microdata is publicly available, has sufficient coverage of all 435 congressional districts, measures validated vote, and includes geographic indicators for those districts in its public use file. The CMPS, a multilingual survey, imposes a three-year lag on the public release of the data. The face-to-face sample of the American National Election Study (ANES) cannot sample all districts. In its worst year, only one percent of the ANES sample came from a competitive open-seat congressional district (Stoker and Bowers 2002). Exit polls have selection issues in the opposite direction: they oversample battleground districts with more media interest. That explains why earlier survey studies of vote choice by race have only produced state-level estimates.

Like most modern internet surveys, the CCES is partly on an opt-in sample, so it provides reliable inferences only with appropriate adjustments after data collection, such as calibration and post-stratification (Rivers 2007). The CCES takes a larger pool of respondents from an online panel, and then prunes the respondents so that it matches the demographics of the adult population at the state level. Its poststratification weights correct for any remaining imbalances at the state level. The estimated vote for statewide elections is about 2-3 percentage points in root mean square error (Ansolabehere and Rivers 2013).

The Presidential vote question is worded:

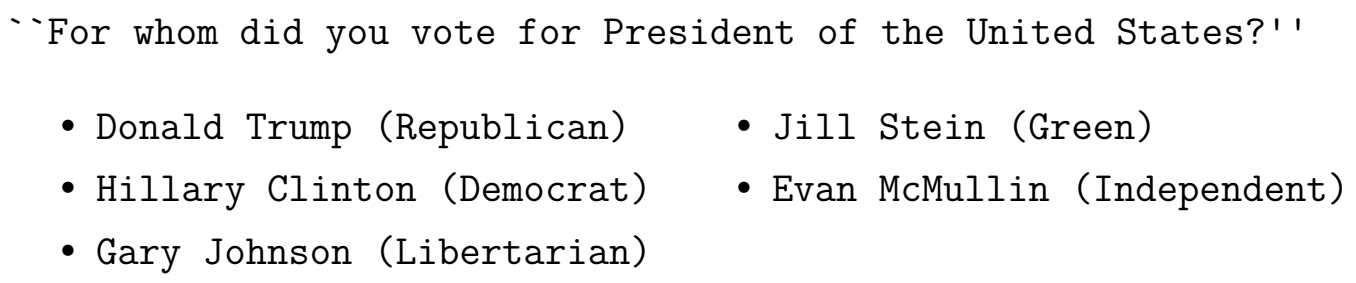

Table A.1 specifies how we bin and categorize the demographic variables in the CCES. The race and ethnicity question, in particular, is worded in the following way:

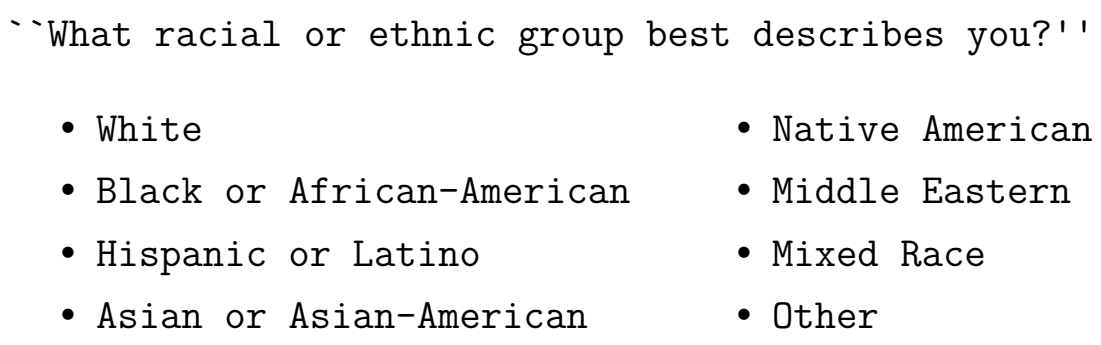

- White

- Black or African-American

- Hispanic or Latino

- Asian or Asian-American

- Native American

- Middle Eastern

- Mixed Race

- Other

And for those who do not respond "Hispanic or Latino", the CCES asks a follow-up question, 

'Are you of Spanish, Latino, or Hispanic origin or descent?' '
- Yes
- No

As explained in the main text, if a respondent answers Hispanic on either of the two questions, we label that respondent as Hispanic. Non-Hispanics are then coded as Whites, Blacks, or Others according to their responses in the first question. The "Other" category encompasses all categories other than White, Black, and Hispanic.

Table A.1 - Demographic covariates for vote-choice model. We use race, education, age group, and sex as well as Trump's voteshare to predict the vote choice.

\begin{tabular}{cccc}
\hline Race & Education & Age & Sex \\
\hline White & High School or Less & $18-24$ & Female \\
Black & Some College & $25-34$ & Male \\
Hispanic & 4-Year College & $35-44$ & \\
Other & Post-graduate & $45-64$ & \\
& & $65+$ & \\
\hline
\end{tabular}

\section{A.3 Implementation of Hierarchical Regression}

Functional form The model specification we described in Section translates to, in R notation,

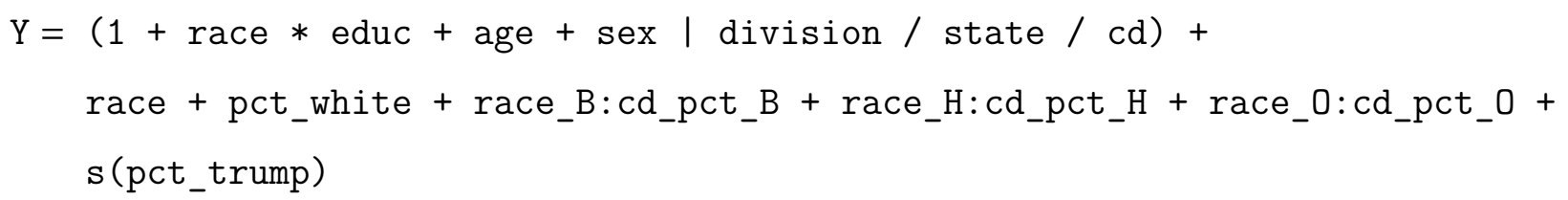

as a logit regression, where

- $\mathrm{Y}$ is a binary variable indicating 1 if the respondent voted for Donald Trump and 0 if they voted for Clinton,

- (... I division / state / cd) indicates there are random effects by every CD, which are nested within states, which are in turn nested within Divisions, with the notation $\mathrm{A} / \mathrm{B}$ being shorthand for $\mathrm{A}+\mathrm{A} * \mathrm{~B}$,

- $(1+$ race $+\ldots \mid \ldots)$ indicates there are varying coefficients on race for each of the random effect intercepts on the right hand side of the bar, 
- race indicates a fixed effect for a national difference between racial groups (as opposed to those that varying coefficients by geography), and is an individual level categorical variable (taking on four levels, with White being the baseline),

- race_B:cd_pct_B indicates that an indicator variable for whether the respondent is Black (race_B) is interacted with the estimated percent of that individual's district that is Black (cd_pct_B), with $\mathrm{H}$ indicating Hispanics and $\mathrm{O}$ indicating the Other racial group, and

- s(pct_trump, ...) indicates a flexible spline of Trump's voteshare in each congressional district. Daily Kos estimates this information from precinct results assigning them to their congressional district, and thus this quantity is known almost exactly (Daily Kos 2021).

Prior Specification Counter to the intuition that less informative priors imply more flexible values, Figure A.1 shows that less informative priors actually imply more opinionated predicted outcomes (Gelman et al. 2020). To obtain a prior predictive distribution, we sampled only from the prior with the data matrix structure following the terms in the model. A $\operatorname{Normal}\left(0,5^{2}\right)$ prior for all random effects and intercepts, typically considered an uninformative prior, has enough of a heavy tail that compounds into the large absolute values on the logit scale when combined in dozens of linear combinations. That implies a separation into 0 and 1 on the probability scale shown in the figure, which we believe is too extreme a prior.

In our specifications, we choose a $\operatorname{Normal}\left(0,1^{2}\right)$ prior. This prior creates enough mass at all values of the support of the outcome (Figure A.1). It has two modes at 0 and 1, but we are willing to accept this as saying that some demographic cells may have a high probability of voting Republican or Democrat.

For the correlation matrix between the geographic random effects, we used an LKJ correlation matrix with a parameter of 1 (default in the package), similar to a flat prior in other classes of priors.

Sampling We estimate samples with 4 chains, using the Hamilton Monte Carlo in Stan. Each chain contains 1000 burn-in samples which are discarded followed by 1000 samples that are used. These 1000 samples are then thinned by 2 to result in 500 samples. Across 4 chains, we are left with 2000 retained samples. 
Figure A.1 - Implication of Different Prior Specifications on Prior Predictive Outcome. A fraction of the predictive distribution sampled only from the input prior distribution. Input priors vary in the standard deviation of the Normal and facets are arranged from a tight prior of $\operatorname{Normal}(0,0.01)$ to a less informative prior of $\operatorname{Normal}(0,5)$.
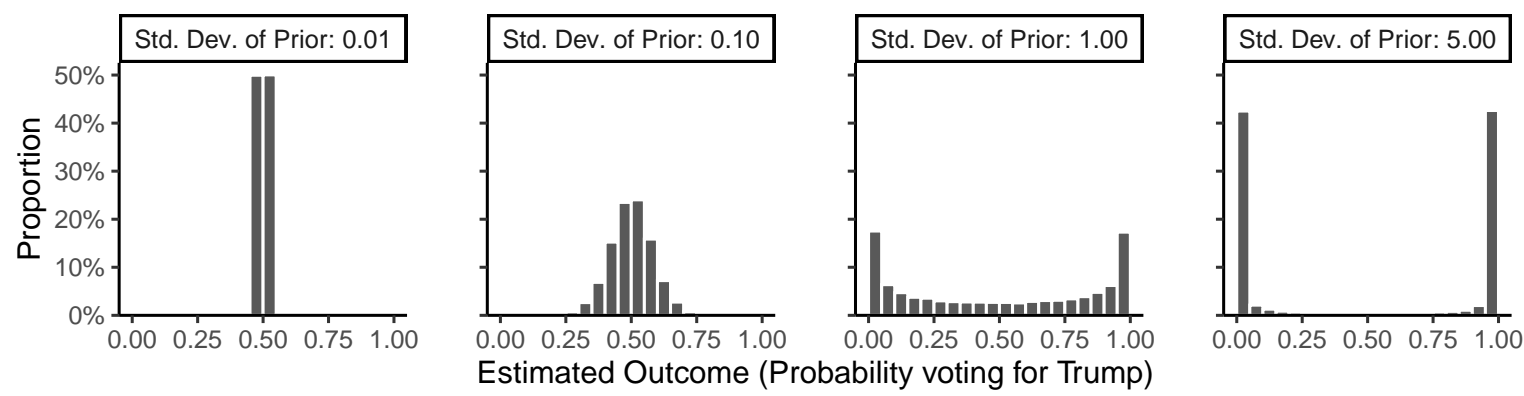

\section{A.4 Connections with Ecological Inference Estimators}

Here we show that our survey-based approach can reduce to the same estimator as a ecological inference (EI) estimator with linear contextual effects. Linear contextual effects are difficult to model in EI, but easier in individual-level data in surveys. This section also serves as a more careful explanation of how partial pooling works in our main model.

In the following, let $j$ index districts. For simplicity, we assume that each district has two groups, $g \in\{B, W\}$ (Black voters and White voters). The discussion below applies to the case of multiple groups with additional notation.

Survey Estimator Small area estimation (SAE) uses the survey data and constructs estimators by partially pooling information across areas to reduce variance. We first define the direct estimator for the Black in district $j$ as

$$
\widehat{\tau}_{B j}^{\mathrm{dir}}=\frac{1}{n_{B j}} \sum_{i \in S_{B j}} Y_{i}
$$

where $Y_{i}$ is the survey outcome for unit $i, S_{B j}$ denotes the set of sampled respondents in district $j$ who belong to group $B$, and $n_{B j}$ is the sample size of this group. We define the direct estimator for the White $\widehat{\tau}_{W j}$ similarly. Under the standard assumptions, the direct estimator is unbiased and approximately normal $\widehat{\tau}_{g j} \dot{\sim} \mathcal{N}\left(0, v_{g}^{2} / n_{g j}\right)$. This estimator is prohibitively high-variance because typically $n_{g j}$ is small.

The regression-based SAE estimator in its simplest form can be characterized as coming 
from the following random effects equation

$$
\tau_{g j}=\gamma_{g}+\delta_{g} X_{j}+\epsilon_{g j}, \quad \epsilon_{g j} \sim \mathcal{N}\left(0, \sigma_{g}^{2}\right)
$$

where $\epsilon$ is a error term, $\gamma_{g}$ is a fixed effect for race and $X_{j}$ is the proportion Black. The variable $X$ can include other district level variables, but we focus on the proportion Black for a simpler comparison with EI. Note that the main model we estimate in our article is more complex than this, by using varying slopes to effectively estimate demographic subgroups (e.g. individual education and gender) that comprise the population subgroup $\mathcal{S}_{B j}$.

The pooling model in Equation (5) models the heterogeneity of the voting behavior of each group as a function of the proportion Black. If the voting behavior of the black voters is uncorrelated with the racial composition, we would have $\delta_{B}=0$. As we discuss below, the ecological inference model does require that the proportion Black and the voting behavior be uncorrelated at the precinct level, and it must hold for the both racial groups simultaneously $\delta_{B}=\delta_{W}=0$. In contrast, the modeling approach for SAE in Equation (5) allows for $\delta_{B} \neq 0$. This implies that if the White voters in a majority-White district and the White voters in a minority-White district have different voting behavior, the model is able to capture the heterogeneity as long as it is a function of $X_{j}$ included in the model.

Furthermore, the formula in (5) clarifies that two groups $B$ and $W$ have different sets of coefficients $\left\{\gamma_{B}, \delta_{B}\right\}$ and $\left\{\gamma_{W}, \delta_{W}\right\}$. This implies that heterogeneity of the Black voters and that of the White voters are allowed to be different. For example, Black voters in a majority-White district might behave differently from Black voters in a minority-majority district, while White voters might be more homogeneous across districts. In such a case, we would have a large value of $\delta_{B}$ so that $\tau_{B j}$ varies across districts, while a slope for the White voters might be small $\delta_{W}$ to reflect their homogeneous behaviors.

The estimator of $\widehat{\tau}_{g j}^{\mathrm{SA}}$ is a partial pooling estimator, which takes the form

$$
\begin{aligned}
\widehat{\tau}_{g j}^{\mathrm{SA}} & =\left(1-w_{g j}\right) \widehat{\tau}_{g j}^{\mathrm{dir}}+w_{g j}\left(\widehat{\gamma}_{g}+\widehat{\delta}_{g} X_{j}\right) \\
& =\widehat{\tau}_{g j}^{\mathrm{dir}}+w_{g j}\left[\left(\widehat{\gamma}_{g}+\widehat{\delta}_{g} X_{j}\right)-\widehat{\tau}_{g j}^{\mathrm{dir}}\right]
\end{aligned}
$$

where $w_{g j}=\sigma_{g}^{-2} /\left(\sigma_{g}^{-2}+v_{g j}^{-2} n_{g j}\right)$ is the relative weight placed on the indirect estimator (i.e., away from the direct estimator). We therefore see that the partial pooling places more weight on the direct estimator as its sample size $n_{g j}$ increases, and places less weight as the variance of the random effect $\sigma_{g}^{2}$ increases. 
The coefficients $\gamma_{g}$ and $\delta_{g}$ are estimated by regressing $\widetilde{\tau}_{g j}^{\text {dir }}$ on $X_{j}$,

$$
\min _{\gamma_{g}, \delta_{g}} \sum_{j=1}^{J}\left[\widehat{\tau}_{g j}^{\mathrm{dir}}-\left(\gamma_{g}+\delta_{g} X_{j}\right)\right]^{2}
$$

The formula in Equation (6) shows that the bias of $\widehat{\tau}_{g j}^{\mathrm{SA}}$ is a function of how far the truth $\tau_{g j}$ is from the predicted value based on the pooling model,

$$
\operatorname{Bias}\left(\widehat{\tau}_{g j}^{\mathrm{SA}}\right)=w_{g j} \mathbb{E}\left[\left(\widehat{\gamma}_{g}+\widehat{\delta}_{g} X_{j}\right)-\tau_{g j}\right] \stackrel{n_{g j} \rightarrow \infty}{\longrightarrow} 0
$$

This shows that the bias of the SAE estimate for Black voters in district $j$ tends to be large when the predicted value $\widehat{\gamma}_{B}+\widehat{\delta}_{B} X_{j}$ is far from the truth. For example, the prediction might be inaccurate when the proportion Black $X_{j}$ explains only a fraction variation of $\tau_{g j}$ across districts. This is because with large unexplained variance, two districts with similar characteristics $X_{j} \approx X_{j^{\prime}}$ tend to have different voting preferences $\tau_{g j} \neq \tau_{g j^{\prime}}$. We can reduce the magnitude of the bias by including additional variables at the district level, in addition to the proportion Black. In our main specification of this article we include the Trump vote share at the district level as another covariate in the pooling model, and further include varying slopes for education, sex, and age group for each district random effect. We also note that the specification of the pooling can be flexible and need not be linear. In fact, our main specification includes the Trump vote share via a cubic spline.

In another extreme when $n_{g j} \rightarrow 0$, the SAE approach allows the estimate to reduce to

$$
\begin{aligned}
& \hat{\tau}_{W j}^{\mathrm{SA}} \rightarrow \hat{\gamma}_{W}+\hat{\delta}_{W} X_{j} \\
& \hat{\tau}_{B j}^{\mathrm{SA}} \rightarrow \hat{\gamma}_{B}+\hat{\delta}_{B} X_{j}
\end{aligned}
$$

In other words, our model estimates group behaviors such that estimates vary with the contextual variable of racial composition, even with very small samples. As $n_{g j}$ becomes smaller, the small area estimator is pulled towards the national race coefficient $\gamma_{g}$, representing other people of the same race in different areas. But it is also pulled towards $\delta X_{j}$, the group-specific estimate for people who live in areas with a similar racial composition $X_{j}$.

EI Estimator On the other hand, consider an ecological inference (EI) for the same quantity of interest, $\tau_{g j}$ with $g \in\{B, W\}$. The EI uses data at the level of precincts, which we denote 
$h \in\{1, \ldots, H\}$. We start from the accounting identity:

$$
\tau_{j h}=\tau_{B j h} X_{j h}+\tau_{W j h}\left(1-X_{j h}\right)
$$

where $\tau_{j h}$ is the aggregate vote share at precinct $h$ in district $j, X_{j h}$ is the proportion Black of the precinct, and $\tau_{B j h}$ is the unobserved race-specific vote share at the precinct level for Black voters.

The simple form of ecological regression relies on what is known as the constancy equation. Goodman showed that for the EI estimators $\widehat{\tau}_{W j}^{\mathrm{EI}}$ and $\widehat{\tau}_{B j}^{\mathrm{EI}}$ to be unbiased, the precinct level race-specific vote share and the proportion Black need to be uncorrelated, $\operatorname{Cov}\left(\tau_{B j h}, X_{j h}\right)=$ $\operatorname{Cov}\left(\tau_{W j h}, X_{j h}\right)=0$ which assumes that $\operatorname{Cov}\left(\tau_{B j h}, X_{j h}\right)=\operatorname{Cov}\left(\tau_{W j h}, X_{j h}\right)=0$.

This constancy assumption implies that

$$
\begin{aligned}
\mathbb{E}\left(\tau_{j h} \mid X_{j h}\right) & =\tau_{B j} X_{j h}+\tau_{W j}\left(1-X_{j h}\right) \\
& =\tau_{W j}+\left(\tau_{B j}-\tau_{W j}\right) X_{j h}
\end{aligned}
$$

where $\tau_{B j}=\mathbb{E}\left(\tau_{B j h}\right)$ and $\tau_{W j}=\mathbb{E}\left(\tau_{W j h}\right)$.

Under these conditions, we can derive the EI estimator $\widehat{\tau}_{g j}^{\mathrm{EI}}$ with a least squares regression:

$$
\min _{\alpha, \beta} \sum_{h=1}^{H}\left[\tau_{j h}-\left(\alpha+\beta X_{j h}\right)\right]^{2},
$$

and we obtain

$$
\widehat{\tau}_{W j}^{\mathrm{EI}}=\widehat{\alpha}, \quad \text { and } \quad \widehat{\tau}_{B j}^{\mathrm{EI}}=\widehat{\alpha}+\widehat{\beta} .
$$

The constancy assumption made in the above clearly satisfies this condition.

Put another way, estimates will be biased if either of the racial groups' heterogeneity is explained by the racial composition. The survey-based small area estimates can account for heterogeneities across racial groups and districts by adjusting district-level covariates and allowing for race-specific coefficients, whereas the traditional EI in its simplest form cannot run with contextual effects and assumes away heterogeneities. Although linear contextual models have been proposed in ecological inference (Przeworski 1974), estimation of these models remain largely intractable because of under-identification (Ansolabehere and Rivers 1995). This problem arises because EI uses only the aggregate (i.e., not race specific) outcome. The SAE approach avoids the problem by utilizing the race specific direct estimators which are only available in the survey. 


\section{A.5 Population Statistics for Target Estimation}

First, the population demographics come from the American Community Survey. We obtain the estimated adult population for each of the 160 cells implied by the crossed-combination of the demographics in the CCES, for each of the 435 congressional districts. For 2016, the [age $\times$ sex $\times$ education $\times$ CD] distribution uses 20161 -year ACS estimates. The [race $\times$ CD] distribution uses the 2015-2018 5-year ACS estimates. We used the 5-year ACS only for race because the 2016 1-year ACS estimates estimated 0 people of racial minorities in some congressional districts such as the at-large district of Wyoming.

Second, we separate these counts into voters and non-voters, by estimating the probability of turnout for each cell. Therefore, we further partition our 70,000-cell $([160 \times 435])$ table into a $[160 \times 435 \times 2]$ table and then take only the half that represents the voting population. Our synthetic target updates the distribution of voters so that the turnout rate matches the turnout as a proportion of the voting age population at each congressional district.

\section{A.6 Survey-assisted Synthetic Target Estimation}

Here we formalize our procedure for estimating a high dimensional target distribution for poststratification. The methods discussed are implemented in the synthjoint package.

Motivation In this subsection, we describe our method for quickly integrating marginal and partial joint distributions with the assistance of an individual-level survey dataset. The general idea is to estimate the conditional distribution in the survey data via regression, while constraining the parameters so that a predicted marginal distribution matches the population marginal distribution. We work with multinomial logit regressions because most survey outcomes such are categorical instead of continuous.

Let $\mathbf{X}$ denote a set of variables that we have access to the joint distribution in the population, and let $Z$ denote a variable that we only get to know the marginal distribution in the population. The goal is to estimate the joint distribution $p(\mathbf{X}, Z)$.

Suppose that we have survey sample where we observe the joint distribution $p(\mathbf{X}, Z \mid S=$ 1 ) where $S=1$ indicates that the distribution is conditional on the survey sample. Unless the survey data is constructed via random sampling from the population, the joint distribution conditional on $S=1$ does not match the joint distribution of interest, $p(\mathbf{X}, Z \mid S=1) \neq$ $p(\mathbf{X}, Z)$.

The idea behind our approach is to estimate the conditional distribution of $Z$ given $\mathbf{X}$ 
from the survey and estimate $p(Z \mid \mathbf{X})$. Because $p(\mathbf{X}, Z)=p(Z \mid \mathbf{X}) p(\mathbf{X})$, we can obtain the target joint distribution by estimating the conditional distribution of $Z$ given $\mathbf{X}$. In our setting, $p(\mathbf{X})$ is already observed in the population.

If we could assume that $Z \Perp S \mid \mathbf{X}$, we would have that

$$
p(Z \mid \mathbf{X})=p(Z \mid \mathbf{X}, S=1) .
$$

Thus, estimating the relationship between $Z$ and $\mathbf{X}$ in the survey data will provide an unbiased estimate of the joint distribution $\widehat{p}(Z, \mathbf{X})=\widehat{p}(Z \mid \mathbf{X}, S=1) p(\mathbf{X})$. However, the conditional independence assumption is not appropriate when we want to weight on $Z$. Conditional independence would imply that accounting for $Z$ in the weighting is unnecessary.

Proposed approach Instead of imposing the conditional independence assumption to obtain the conditional distribution $p(Z \mid \mathbf{X})$, we propose to find a probability distribution that satisfies the following equality constraint:

$$
\int p(Z, \mathbf{X}) d \mathbf{X}=\int p_{\beta}(Z \mid \mathbf{X}, S=1) p(\mathbf{X}) d \mathbf{X},
$$

which implies that marginally the predicted distribution $p_{\beta}(Z \mid \mathbf{X}, S=1)$ matches the marginal population target $p(Z)$. This differs from the approach in Kastellec et al. (2015) and the second proposal in Leemann and Wasserfallen (2017), which both estimate the first term on the right hand side but do not enforce a constraint.

Note that the above constraint does not immediately imply that $p(Z \mid \mathbf{X})=p(Z \mid \mathbf{X}, S=$ 1). However, even when the conditional independence assumption does not hold, the above constraint incorporates the population information.

Finally, we estimate $p(Z \mid \mathbf{X}, S=1)$ from the survey data such that the above constraint is satisfied.

Data generating process We consider a case where $Z$ is categorical, so that $p(Z \mid \mathbf{X}, S=$ 1) can be modeled by the multinomial logit. Let $Z_{i} \in\{1, \ldots, K\}$ denote the "marginal" variable for unit $i$ in the survey sample. Then, the multinomial regression is specified as

$$
\operatorname{Pr}\left(Z_{i}=k \mid \mathbf{X}_{i}, S_{i}=1\right)=\frac{\exp \left(\boldsymbol{\beta}_{k}^{\top} \widetilde{\mathbf{X}}_{i}\right)}{\sum_{k^{\prime}=1}^{K} \exp \left(\boldsymbol{\beta}_{k^{\prime}}^{\top} \widetilde{\mathbf{X}}_{i}\right)}
$$


where we set $\boldsymbol{\beta}_{1}=\mathbf{0}$ for identification. Here, $\widetilde{\mathbf{X}}_{i}$ includes the intercept as well as interaction terms between variables.

Estimation with exact constraints Now, we could estimate $\boldsymbol{\beta}$ by maximum likelihood, but we wish to impose the constraint from the observed marginal distribution as discussed above. Specifically, we impose the following

$$
\underbrace{\operatorname{Pr}(Z=k)}_{\text {population dist. }}=\mathbb{E}_{\mathbf{X} \sim p(\mathbf{X})}\left\{\frac{\exp \left(\boldsymbol{\beta}_{k}^{\top} \widetilde{\mathbf{X}}_{i}\right)}{\sum_{k^{\prime}=1}^{K} \exp \left(\boldsymbol{\beta}_{k^{\prime}}^{\top} \widetilde{\mathbf{X}}_{i}\right)}\right\}
$$

where the expectation on the right hand side is over the population distribution of $\mathbf{X}$.

Therefore, we can estimate $\boldsymbol{\beta}$ by incorporating the additional moment condition. In practice, we can estimate the parameter by constrained optimization. Let $\mathcal{L}_{n}(\boldsymbol{\beta})$ denote the loglikelihood function of the multinomial logit, such that

$$
\mathcal{L}_{n}(\boldsymbol{\beta}) \equiv \log \ell_{n}(\boldsymbol{\beta}), \quad \ell_{n}(\boldsymbol{\beta})=\prod_{i=1}^{n} \prod_{k=1}^{K}\left\{\frac{\exp \left(\boldsymbol{\beta}_{k}^{\top} \widetilde{\mathbf{X}}_{i}\right)}{\sum_{k^{\prime}=1}^{K} \exp \left(\boldsymbol{\beta}_{k^{\prime}}^{\top} \widetilde{\mathbf{X}}_{i}\right)}\right\}^{\mathbf{1}\left\{Z_{i}=k\right\}}
$$

where the product is over respondents in the survey data.

We then obtain the estimate by solving the following constrained optimization:

$$
\begin{array}{ll}
\text { maximize } & \mathcal{L}_{n}(\boldsymbol{\beta}) \\
\text { subject to } & \boldsymbol{g}(\boldsymbol{\beta})=\mathbf{0}
\end{array}
$$

where

$$
g_{k}(\boldsymbol{\beta})=\operatorname{Pr}(Z=k)=\mathbb{E}_{\mathbf{X} \sim p(\mathbf{X})}\left\{\frac{\exp \left(\boldsymbol{\beta}_{k}^{\top} \widetilde{\mathbf{X}}_{i}\right)}{\sum_{k^{\prime}=1}^{K} \exp \left(\boldsymbol{\beta}_{k^{\prime}}^{\top} \widetilde{\mathbf{X}}_{i}\right)}\right\}
$$

Estimation for exact constraints with Polya Gamma augmentation We first show that we can find a solution to the above problem by the EM algorithm. In this paper we will not use this exact algorithm and instead approximate it with an additional layer of optimization, but the general form of the procedure is still useful to outline and will be used in the initialization step of our actual algorithm.

Suppose that we fix parameters $\boldsymbol{\beta}_{-k}$, and try to estimate $\boldsymbol{\beta}_{k}$ (coefficients for the $k$ th cate- 
gory). By the EM algorithm derived in Yamauchi (2021), we have the following M-step,

$$
\begin{array}{ll}
\operatorname{maximize} & Q_{k}\left(\boldsymbol{\beta}_{k}\right) \\
\text { subject to } & g_{k}\left(\boldsymbol{\beta}_{k}\right)=0
\end{array}
$$

where the objective function is quadratic in $\boldsymbol{\beta}_{k}$ after conditioning on the augmented PolyaGamma random variable $\omega$.

$$
Q_{k}\left(\boldsymbol{\beta}_{k}\right)=-\frac{1}{2} \boldsymbol{\beta}_{k}^{\top}\left(\mathbf{S}+\boldsymbol{\Sigma}_{0}^{-1}\right) \boldsymbol{\beta}_{k}+\boldsymbol{\beta}_{k}^{\top}\left(\widetilde{\mathbf{X}}^{\top} \boldsymbol{d}+\boldsymbol{\Sigma}_{0}^{-1} \boldsymbol{\mu}_{0}\right)
$$

where $\mathbf{S}=\widetilde{\mathbf{X}}^{\top} \operatorname{diag}\left(\left\{\omega_{i k}\right\}_{i=1}^{n}\right) \mathbf{X}$ and $d_{i}=\mathbb{E}\left[\omega_{i k}\right] \log \left(\sum_{k^{\prime}=k} \beta_{k^{\prime}}^{\top} \widetilde{\mathbf{X}}_{i}\right)+\left(Z_{i k}-1 / 2\right)$.

We can obtain the update by considering the Lagrangian

$$
L\left(\boldsymbol{\beta}_{k}, \lambda\right)=Q_{k}\left(\boldsymbol{\beta}_{k}\right)+\lambda g_{k}\left(\boldsymbol{\beta}_{k}\right) .
$$

The optimality conditions requires we solve for

$$
\left[\begin{array}{c}
\frac{\partial}{\partial \boldsymbol{\beta}_{k}} L\left(\boldsymbol{\beta}_{k}, \lambda\right) \\
\frac{\partial}{\partial \lambda} L\left(\boldsymbol{\beta}_{k}, \lambda\right)
\end{array}\right]=\nabla L\left(\boldsymbol{\beta}_{k}, \lambda\right)=\mathbf{0}
$$

where each component of the gradient is

$$
\begin{aligned}
\frac{\partial}{\partial \boldsymbol{\beta}_{k}} L\left(\boldsymbol{\beta}_{k}, \lambda\right) & =-\left(\mathbf{S}+\boldsymbol{\Sigma}_{0}^{-1}\right) \boldsymbol{\beta}_{k}+\left(\widetilde{\mathbf{X}}^{\top} \boldsymbol{d}+\boldsymbol{\Sigma}_{0}^{-1} \boldsymbol{\mu}_{0}\right)+\lambda \frac{\partial}{\partial \boldsymbol{\beta}_{k}} g_{k}\left(\boldsymbol{\beta}_{k}\right), \\
\frac{\partial}{\partial \lambda} L\left(\boldsymbol{\beta}_{k}, \lambda\right) & =Q_{k}\left(\boldsymbol{\beta}_{k}\right)+g_{k}\left(\boldsymbol{\beta}_{k}\right) .
\end{aligned}
$$

With these gradient functions, we update the estimate of $\widetilde{\boldsymbol{\beta}}_{k}=\left(\boldsymbol{\beta}_{k}, \lambda\right)$ with the Newtonmethod, so that at iteration $(t+1)$,

$$
\widetilde{\boldsymbol{\beta}}_{k}^{(t+1)}=\widetilde{\boldsymbol{\beta}}_{k}^{(t)}+\left(\nabla^{2} L\left(\boldsymbol{\beta}_{k}^{(t)}, \lambda^{(t)}\right)\right)^{-1} \nabla L\left(\boldsymbol{\beta}_{k}^{(t)}, \lambda^{(t)}\right)
$$

We then implement the E-step by evaluating $\mathbb{E}\left[\omega_{i k}\right]$, which follows directly from the mean of a Polya-Gamma random variable,

$$
\mathbb{E}\left[\omega_{i k}\right]=\frac{1}{2 \widehat{\psi}_{i k}} \tanh \left(\widehat{\psi}_{i k} / 2\right)
$$


where $\widehat{\psi}_{i k}=\boldsymbol{\beta}_{k}^{\top} \widetilde{\mathbf{X}}_{i}-\log \sum_{k^{\prime} \neq k} \exp \left(\boldsymbol{\beta}_{k^{\prime}}^{\top} \widetilde{\mathbf{X}}_{i}\right)$

Relaxing the exact constraint The exact constraint $g(\boldsymbol{\beta})=\mathbf{0}$ can lead to unstable estimates when the population distribution and survey data are quite different. In practice, therefore, we do not use the full EM algorithm described above. We instead run a version relaxing the constraint with a slack parameter $\epsilon$. Instead of setting the constraint function $g$ to 0 , we reformulate the question as

$$
\begin{array}{ll}
\text { maximize } & \mathcal{L}_{n}(\boldsymbol{\beta}) \\
\text { subject to } & \|\boldsymbol{g}(\boldsymbol{\beta})\|_{1} \leq \epsilon
\end{array}
$$

where the constraint bounds the total variation distance between the predicted marginal distribution of $Z$ and the population distribution. $\epsilon$ is therefore the sum of absolute deviations on the probability scale. Because the fraction of categories must sum to 1 , this deviation is bounded between 0 and 2 .

We solve this optimization problem by entering its Lagrangian in R's coordinate-wise optimization routine which is common, but with a novel initialization step: As initial values of $\boldsymbol{\beta}$, we estimate the multinomial with no constraints, using the Polya-Gamma augmentation described in the previous section. The fast estimation of the multinomial model at this stage substantially reduces the time required for convergence in the coordinate-wise optimization.

Estimating the joint probability After estimating the model parameters $\widehat{\boldsymbol{\beta}}$ for the conditional distribution, we obtain the population joint probability as

$$
\widehat{\operatorname{Pr}}(Z=k, \mathbf{X}=\boldsymbol{x})=\frac{\exp \left(\widehat{\boldsymbol{\beta}}_{k}^{\top} \widetilde{\boldsymbol{x}}\right)}{\sum_{k^{\prime}=1}^{K} \exp \left(\widehat{\boldsymbol{\beta}}_{k^{\prime}}^{\top} \widetilde{\boldsymbol{x}}\right)} \times \operatorname{Pr}(\mathbf{X}=\boldsymbol{x}) .
$$

\section{A.7 Estimation of Joint Demographic Distributions}

In the next two subsections, we document how we implement the synthetic target estimation algorithm described above. For a poststratification target of the voting age population by each congressional district, we start with the CCES survey data and ACS summary statistics. Although the ACS reports summary statistics at the congressional district level of U.S. adults, it does not report the joint four-way distribution of age, sex, race, and education for each district. We use the following two partitions of the US adult population in each geographic 
unit:

- Age group by sex by race: Census table B01001, for subtables B, C, D, F, G, H, I, using variable codes $7-16,22-31$ in each subtable.

- Age group by sex by education: Census table B15001, for variable codes 4-83, excluding variables $11,19,27,35,43,44,52,60,68,76$.

These variable codes are also listed in the ccesMRPprep package, under acscodes_sex_age_educ and acscodes_sex_age_race.

Calibration occurs at the CD-level. We estimate a outcome-balanced multinomial logit predicting 4-way categorization of education, such that the weighted proportion of education in each district matches that of the provided ACS table. The predictive slack in equation (12) was set to $\epsilon=0.01$.

The predictors of the education were racial group interacted with age group, and an intercept for sex. Levels of the variable are recoded to be consistent with the CCES survey data and the ACS, which is described in the main text. In R notation, this amounts to educ $\sim$ race $*$ age + female.

Because not all states and certainly not all districts have enough data points to estimate this model, we use a grouping of states defined in Figure A.2. For each district $j$, we fit the multinomial logit model using all survey responses from the set of states that includes district $j$.

\section{A.8 Estimation of a Calibrated Turnout Model}

We start with the 4-way demographic table from above and wish to estimate the turnout rate in each covariate set $s$. We again use the CCES, where turnout is 1 if the voter matches to the Catalist voter file in the state and 0 otherwise. This validated vote variable is a standard variable in the public release of the CCES. We use the outcome-balancing multinomial logit predicting a binary variable for turnout, such that the weighted turnout rate in the CD is equal to the observed turnout as a population of the Voting Age Population in the CD. We use the highest office turnout and VAP statistics reported by Daily Kos (2021). We set the predictive slack in equation (12) to $\epsilon=0.001$.

The turnout model takes the form turnout $\sim$ race $*$ age + female + educ. Because the contribution of these variables may differ by area, we estimate these models state by state. Because some states' samples have insufficient observations to fit this model, we 
again fit the multinomial logit model using all survey responses from the set of states in Figure A. 2 that includes the state in question.

\section{A.9 Grouping of States}

In survey-assisted synthetic target estimation, it becomes necessary to group small states together or group a small state into a large state to so there is sufficient data. We therefore use survey data from the groupings shown in Figure A.2 to estimate district-specific or statespecific targets.

Figure A.2 - Groupings of states for estimates of sufficient sample size.
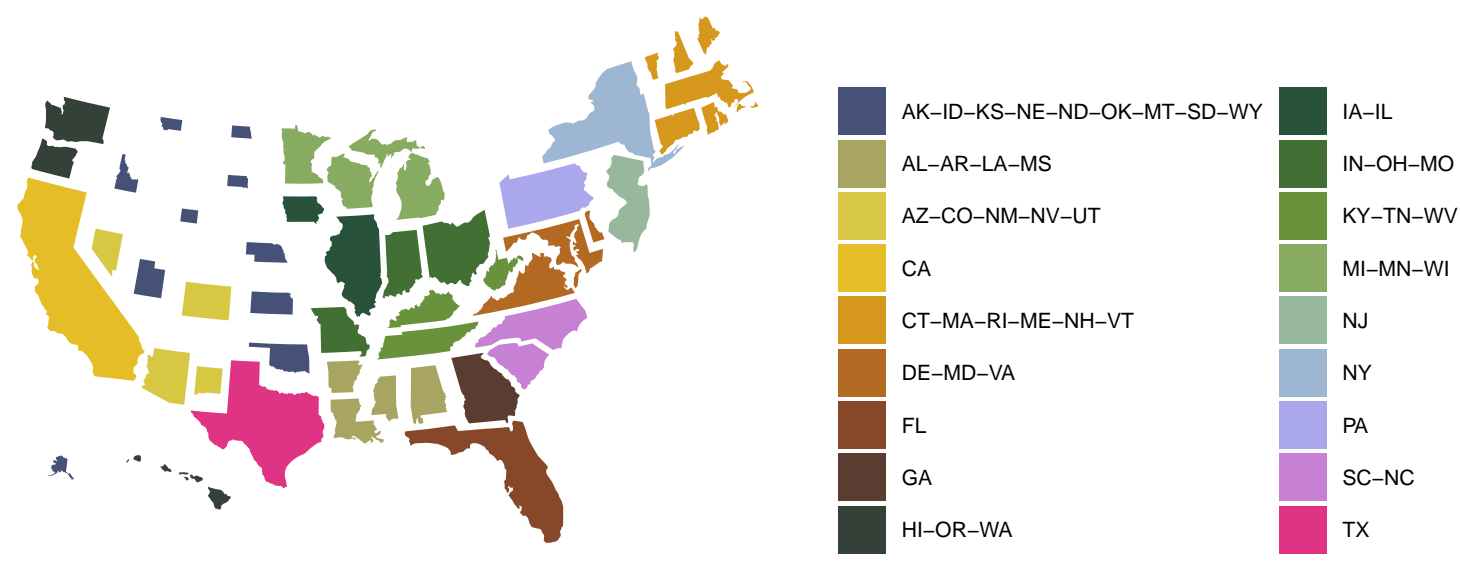

We grouped states based on geographic proximity and political patterns to group states. Changing the groupings to smaller geographies and simpler regression models changed final estimates by 1-2 percentage points in the average district, for each race.

The hierarchical modeling that is used in the main CCES specification can in theory be used to overcome such small sample problems. The reason why we group states in this preparation stage only is because the outcome balancing multinomial model does not partially pool, and limited by the interactions that exist in the data.

\section{A.10 How Modeling Choices Affect Estimates}

Figure A.3 shows how our estimates change by the degree of calibration. Here the hierarchical model and the post-stratification are held fixed, but the post-MRP calibration changes. 
The graph shows that calibration changes point estimates by around 5-7 percentage points for White and Hispanic voters. Two-way calibration changes the one-way calibration by almost linearly shifting White voters to be more Republican and Hispanic voters to be less Republican in this case. In practice, we implement the two calibrations in the calibration step simultaneously, instead of one calibration after another.

Figure A.3 - Consequences of Calibration. Each row of three scatter plots show the differences in final point estimates depending on the level of calibration discussed in the paper. (1) MRP estimates without any calibration, (2) MRP estimates with a one-way calibration to district-level voteshare, and (3) MRP estimates with a two-way calibration developed in this paper to district-level voteshare and a national vote by race constraint. Statistics show the root mean square difference (RMSD) and mean difference.
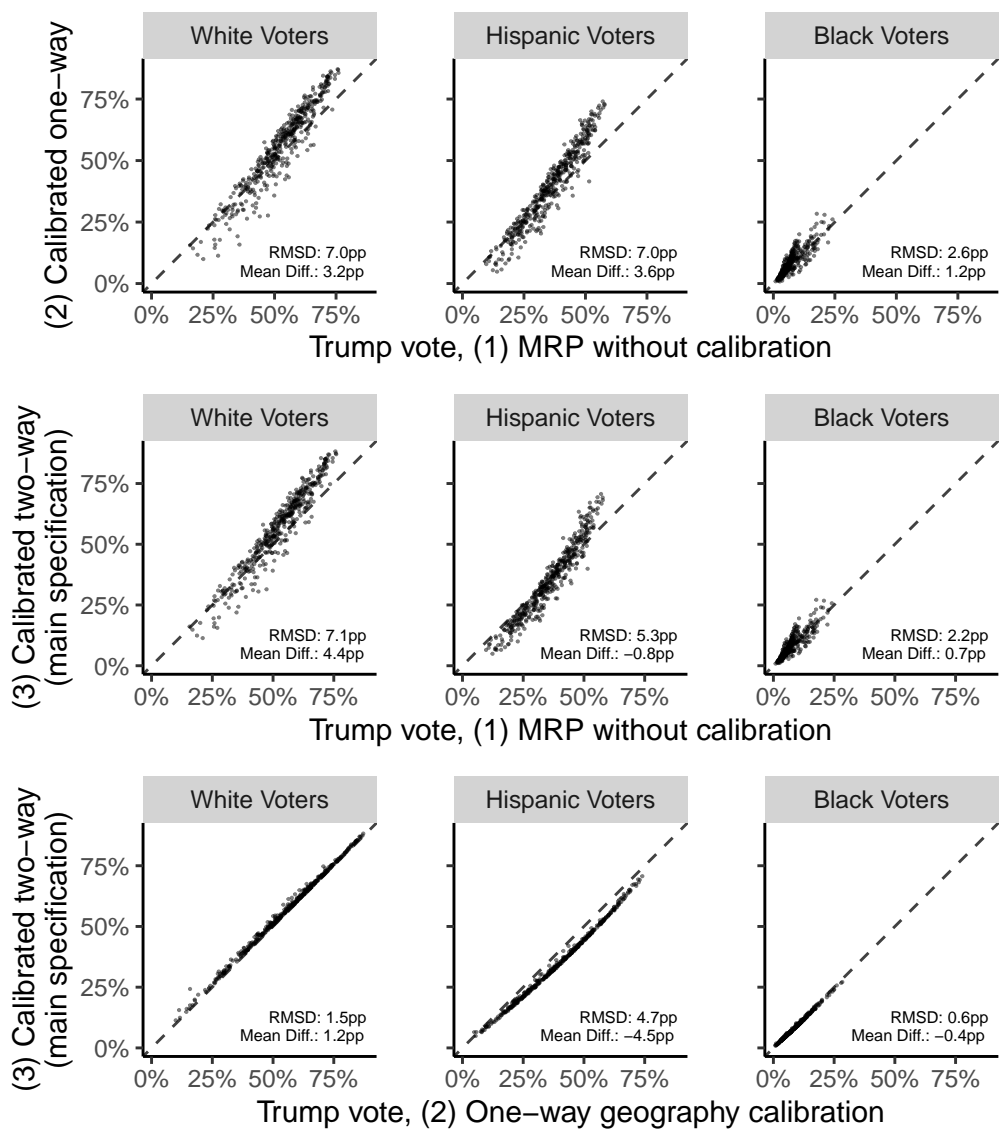


\section{B Additional Analyses}

\section{B.1 Asian Americans}

In our main analysis, we focus on Black and Hispanic voters and do not separate out Asian American voters from remaining Other racial minorities. The CCES and ACS does record Asian American as a response option in their data and it is possible to construct a hierarchical model that makes this distinction. However, the synthetic joint population estimation currently cannot model separate population counts for Asian Americans because its population is heavily concentrated in a handful of states.

In this section, we analyze the Asian American vote separately but only for the states in which a sufficiently large fraction of the population are Asian Americans. Figure B.1 shows point estimates and compares them with the other three racial groups.

Figure B.1 - Comparison of Asian American voting estimates in select states. We estimated joint poststratification tables separating out Asian Americans from the other races, in states with at least 10 percent of Asian American adults. Those states are California, Washington, Hawaii, and New Jersey. Only CDs with an estimated 10 percent of more of the electorate being Asian American are shown.

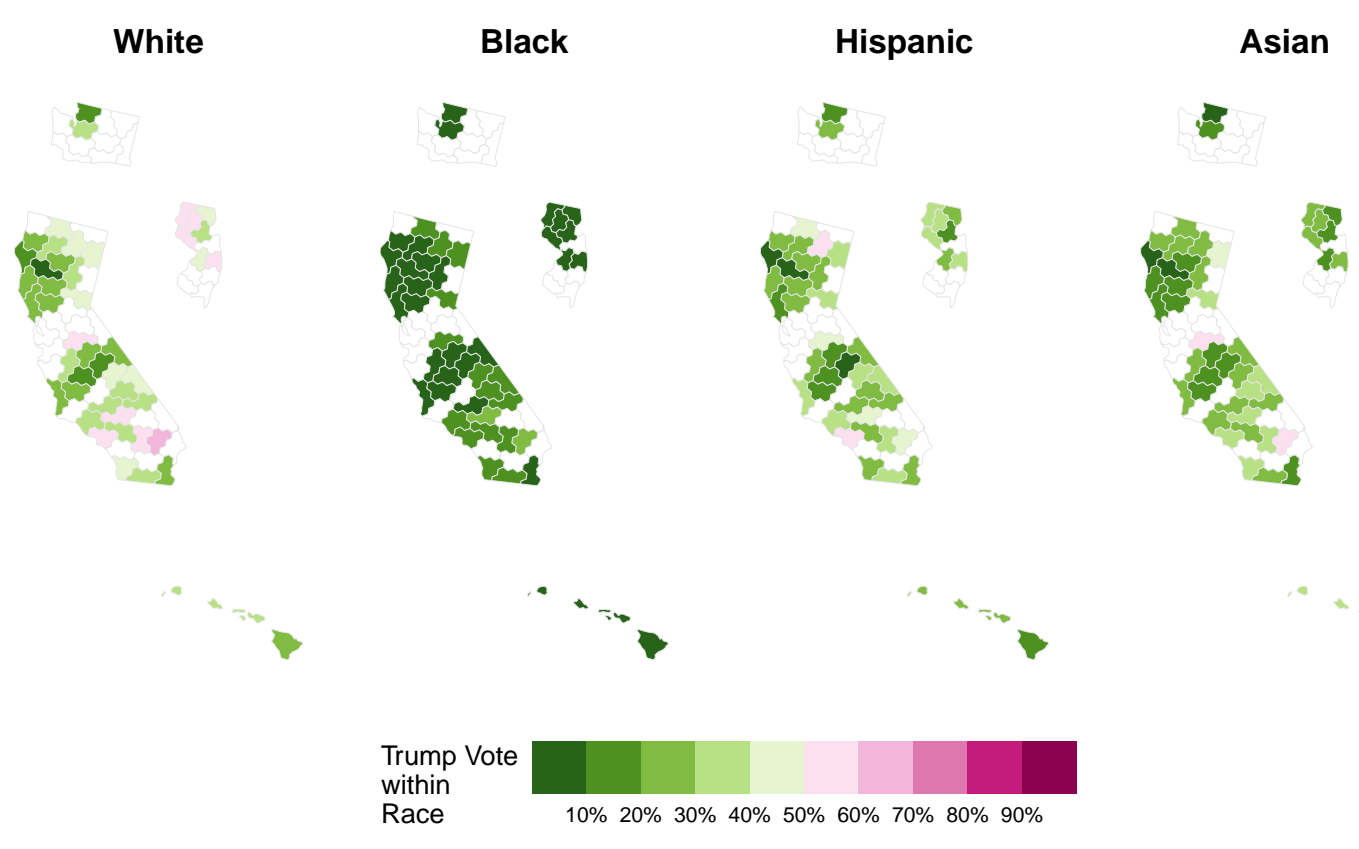


Table B.1 - Comparison of Survey Estimates. All estimates show two party Republican vote in the Presidential election. Exit Polls use the National Election Poll (as published in CNN). Catalist refers to Catalist's MRP estimates. LD refers to Latino Decisions and the American Election Eve Poll. CMPS refers to the Collaborative MultiRacial Post-Election Survey. See Appendix C.4 for standard errors for estimates in this paper.

\begin{tabular}{|c|c|c|c|c|c|c|c|c|c|c|}
\hline \multirow{2}{*}{$\begin{array}{l}\text { Republican } \\
\text { vote } \\
\text { among }\end{array}$} & \multicolumn{5}{|c|}{2016} & \multicolumn{5}{|c|}{2020} \\
\hline & This Paper & Exits & Catalist & LD & CMPS & This Paper & Exits & Catalist & $\mathrm{LD}$ & CMPS \\
\hline \multicolumn{11}{|l|}{ National } \\
\hline White & 59 & 61 & 59 & & 57 & 57 & 59 & 56 & 58 & 52 \\
\hline Black & 7 & 8 & 7 & & 5 & 10 & 12 & 10 & 9 & 10 \\
\hline Hispanic & 30 & 30 & 29 & 19 & 19 & 38 & 33 & 36 & 28 & 23 \\
\hline \multicolumn{11}{|l|}{ Wisconsin } \\
\hline White & 54 & 56 & 54 & & & 53 & 53 & 53 & 57 & \\
\hline Black & 4 & 6 & 8 & & & 8 & 8 & 10 & 5 & \\
\hline Hispanic & 30 & 35 & 34 & 10 & & 33 & 38 & 44 & 22 & \\
\hline \multicolumn{11}{|l|}{ Florida } \\
\hline White & 63 & 67 & & & & 62 & 63 & & 57 & \\
\hline Black & 7 & 9 & & & & 10 & 10 & & 9 & \\
\hline Hispanic & 39 & 36 & & 32 & & 47 & 46 & & 39 & \\
\hline \multicolumn{11}{|l|}{ Texas } \\
\hline White & 71 & 73 & & & & 66 & 67 & & 66 & \\
\hline Black & 7 & 12 & & & & 9 & 9 & & 10 & \\
\hline Hispanic & 38 & 36 & & 17 & & 43 & 41 & & 30 & \\
\hline
\end{tabular}

Note: Numbers are taken from the National Exit Polls listed by CNN (2016, 2020), Catalist website, Latino Decisions website (2016, 2020), Collaborative Multiracial Post-election Survey $(2016,2020)$. Blank cells indicate the survey has not publicly released an estimate.

\section{B.2 Comparison with Other Surveys}

Table B.1 compares the estimates from other sources of data. These differences could be due to simple random sampling error, differences in turnout estimation, timing of the survey, differences in how racial groups are defined, and survey coverage. We do not have access to the raw data or methodology of all other surveys to conduct a full-fledged comparison.

One discrepancy that stands out is that the estimates by Latino Decisions (LD) and CMPS of the Hispanic vote are more Democratic than the other surveys by double digits. Barreto, Reny, and Wilcox-Archuleta (2017) discussed some reasons for why this might be the case. Discussing the Exit Poll, they point out that a bad selection of precincts to poll might have biased the estimates, and they also question whether the Exit Poll's composition of the His- 
panic respondents is consistent with the Census. These two critiques would apply less to an online survey like the CCES that is then weighted to Census composition figures. A third potential reason is the lack of the Spanish language option in the CCES. A fourth potential reason is that LD and CMPS could be using a different definition of Latinos and recruitment method than the CCES or Exit Polls.

Barreto, Reny, and Wilcox-Archuleta (2017) use precinct-level data as suggestive evidence that the Hispanic Republican vote is much lower than what the Exit Poll has reported. The thrust of such evidence is a homogeneous precinct analysis. Focusing on New York state, for example, Barreto (2016) shows that precincts in which over 80 percent of the electorate are estimated to be Hispanic often reported a Clinton vote of over 90 percent. The implication is that the Exit Poll's estimates of a 23 percent Trump vote among New York Hispanics is unreasonable. However, our validation analysis in Florida suggests that ecological inference may be underestimating the true Republican vote among Hispanic voters. Because our study provides district level estimates below the state-level, we can provide a suggestive test of this independence assumption.

\section{B.3 Details on Florida Validation Analysis}

Data We use Catalist's cleaned voterfile query tool to extract precinct-level aggregates and joint counts of race and party registration. In September 2021, we queried the number of voters (registered in Florida) who voted in the 2016 Presidential Election (wherever they were in 2016). Catalist assigns these voters to the precinct that they are registered in at the time of the query. The race and party registration data are information as of the time of the query as well (not the time of the 2016 election).

After assigning congressional districts to split precincts, we are left with precincts comprising 8.3 million voters. There were 9.4 million votes in the 2016 election. Some of the drop in population is due to the snapshot of the voterfile being pulled not being accurate. We sample 10,000 posterior iterations for each congressional district.

To evaluate the validity of the EI method, we take the actual share of each racial group in each district that are Republican from the same precinct-level dataset. Separately, we purchased a CD-level dataset from Catalist that records the counts of each race and party registration of 2016 voters by their 2016 districts. Because we do not want to attribute errors in EI to discrepancies between our precinct data query and the ground truth, we evaluate the EI estimates based on the ground truth calculated from the same precinct dataset and evaluate the MRP estimates based on the ground truth based on the more accurate counts purchased from 
Catalist. The two CD-level ground truth measures are correlated at 0.97 for White voters, 0.98 for Hispanic voters, and 0.89 for Black voters.

Setting Florida and North Carolina are the only two states that ask voter registrants to identify with both a party and a racial group, and makes this information, along with precinct and turnout information, public in their voterfile. Therefore, the proportion of voters in a specific district and of a specific race who register with the Republican party is known precisely through an administrative dataset. We therefore conduct a validation of our MRP method and ecological inference (EI) where the quantity of interest is

$$
\operatorname{Pr}(\text { Registration }=\text { Republican } \mid \text { Race } g \text {, District } j, \text { Turnout }),
$$

that is, the proportion of the electorate in district $j$ with racial identification $g$ that is registered for the Republican party.

MRP methodology The CCES includes a variable for party registration that comes directly from the Catalist voter file match. In other words, in the CCES party registration is observed without error. We estimate a MRP model predicting party registration in Florida with the same methods described in this paper with a few differences. First, we estimate the model only on Florida data, since not all states have party registration on the voter file. We also evaluated an MRP estimate with only one-way calibration to district geography rather than a two-way calibration. The error rate increases for White voters, but the MRP error rate for Hispanic and Black voters are still lower than that for EI.

Ecological Inference in Practice This setting is a favorable data setting for ecological inference of racial polarized voting than the modal case. The registered race and the party registered race is exactly known in this voter file data. In 48 other states, this data is unobserved. In all but six southern states, analysts use Census estimates the composition of each race in the (citizen) voting age population as their measure of race at the precinct level, or they use a race classification estimator such as Bayesian-Improves Surname Geocoding to predict race within the voter file. Party registration is only available in 31 states as well.

\section{B.4 Comparison with Ecological Inference in 50 States}

We next extend our comparison between our survey-based method and EI to other states, beyond where validation data is available. We use Census and election results data at the 
Figure B.2 - Comparison of MRP and Ecological Inference Estimates. Both model predicts the proportion of each racial group electorate in each congressional district that voted for the Republican Presidential candidate in 2020. Statistics in each facet show root mean square difference (RMSD) and mean difference between EI and MRP estimates.
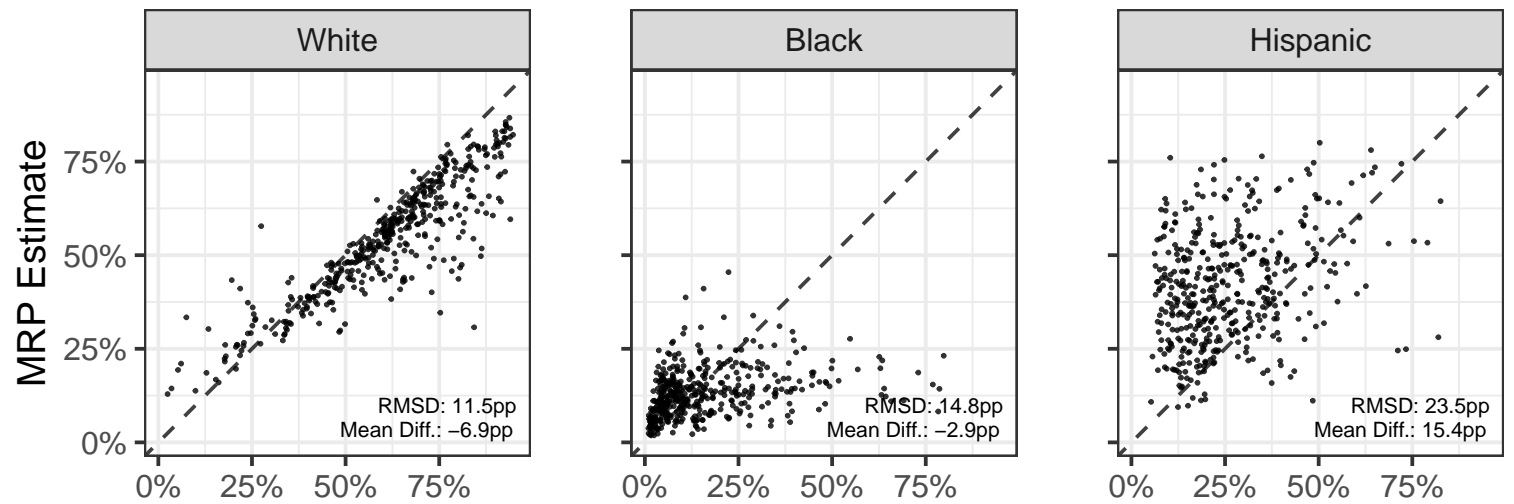

El Estimate of Trump Vote

precinct-level which are then assigned to districts as of 2020, estimated by McCartan et al. (2022). We compare our method's and EI's estimate for the 2020 election instead of the 2016 election, because the 2020 election is done closer to the 2020 decennial Census that provided the racial composition information used for EI. Our comparison covers 435 districts in all 50 states.

We take racial compositions within the Voting Age Population (VAP). This is different from the Citizen Voting Age Population or the turnout population, but the decennial Census does not ask citizenship and standard ecological inference must rely on such incomplete data. Within each congressional district, we sample 5000 thinned draws from the 4 by 2 ecological inference model as in Appendix B.3, with the these data.

Figure B. 2 compares estimates of Trump vote share for White, Black and Hispanic voters in a congressional district, with EI estimates on the X-axis and our $2020 \mathrm{MRP}$ estimates on the y-axis. Among White voters, MRP often produces lower estimates of Republican voteshare than EI with an average discrepancy of 12 percentage points in root mean square difference. Among Hispanic voters, we find the opposite, where MRP often produces higher estimates of Republican voteshare than EI. The discrepancy here is even larger, about 23 percentage points. Hispanic estimates have more uncertainty in them due to small subgroup samples, but even accounting for the standard errors of both the MRP and EI estimates, the difference is statistically significant at a 0.01 level in 52 percent of the districts under consideration. 
Figure B.3 - MRP and EI Differences by Group Size and Homogeneity. The top graph plots the raw difference between district-group level MRP and EI estimates on the $\mathrm{y}$-axis, and the district level group size on the x-axis, for White, Black, and Hispanic voting populations. The bottom graph plots the t-statistic for district-group's MRP and EI estimates on the y-axis, against the percent of homogeneous precincts (precincts with or greater than 90 percent of a group voting population) in that district on the $\mathrm{x}$-axis.
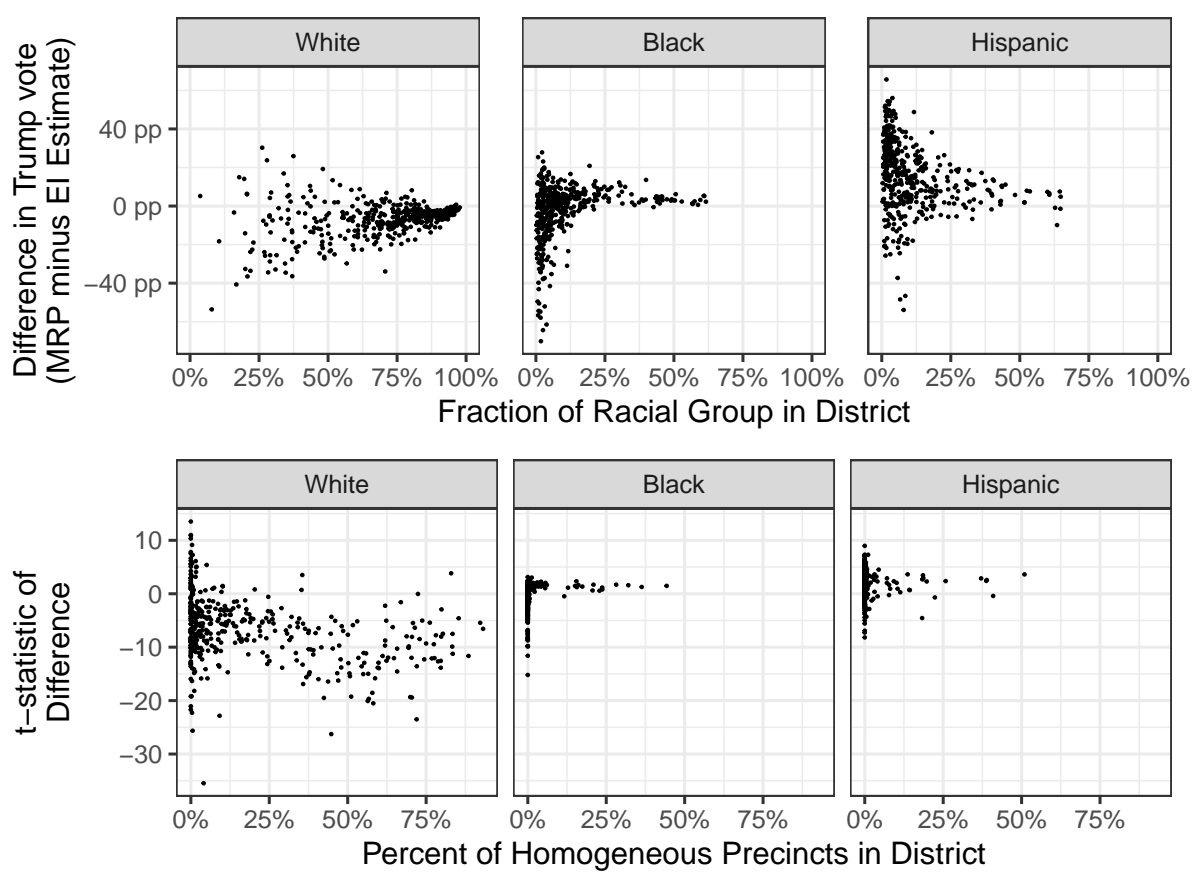

States with large Hispanic voting populations have much smaller differences between MRP and EI estimates of Republican voteshare. The RMSD for Hispanic MRP and EI estimates is between 11 and 16 percentage points in Southwestern states like Arizona, California, and Texas. In states with small Hispanic voting populations like Alabama and Mississippi, the discrepancy is above 40 percentage points.

Similarly, states with larger Black voting populations demonstrate smaller differences between MRP and EI estimates of Republican voteshare. In Southern states like Alabama, Florida, and Georgia, the RMSD for Black MRP and EI estimates is between 6 and 10 percentage points. However in Southerwestern states like Arizona, California and Colorado, the RMSD is between 20 and 24 percentage points. Overall, EI estimates Black voters to be 14 percentage points more Republican than MRP estimates.

Figure B.3 plots the differences between MRP and EI estimates against district-group level demographics. The top graph demonstrates that differences between MRP and EI esti- 
Table B.2 - MRP and EI White - Non-White Racial Gap. Each column represents summary statistics of MRP and EI reliant estimates of the White - non-White racial gap (Equation (1)) using the point estimates from Figure B.2.

\begin{tabular}{lcc}
\hline Statistic & MRP & EI \\
\hline Minimum & 0.04 & -0.28 \\
District in 25th Percentile & 0.14 & 0.28 \\
Median District & 0.22 & 0.43 \\
Mean district & 0.24 & 0.41 \\
National Gap & 0.29 & 0.42 \\
District in 75th Percentile & 0.30 & 0.57 \\
Maximum & 0.65 & 0.86 \\
Standard deviation & 0.12 & 0.23 \\
\hline
\end{tabular}

mates decreases towards zero as the size of a group voting population increases. The bottom graph plots the relationship between the t-statistic of the difference measuring the difference between MRP and EI estimates for a district, against a district's percent of homogeneous precincts. Estimates for a group differ most when that group has little to no homogeneous precincts. For Black and Hispanic populations, the difference between MRP and EI estimates decreases as their percentage of homogeneous precincts increases.

In contrast, MRP and EI differences grow larger as the percentage of homogeneously White precincts increases. In these districts with large White populations, an increasing percentage of homogeneously White precinct amounts to an increasingly large number of White voters, which may introduce greater variance in preferences.

The differences between MRP and EI estimates shown in Figure B.2 lead to different estimates of the racial gap. EI estimates White voters to be more cohesively Republican and Hispanic voters to be more cohesively Democratic, leading to larger estimates of the White - non-White racial gap. Table B.2 compares summary statistics on the absolute difference between White and non-White estimates of Trump voteshare. EI produces larger racial gap estimates than MRP across nearly all summary statistics. The median White - non-White racial gap is 22 percentage points under MRP, but 43 percentage points under EI. 


\section{Additional Estimates and Standard Errors}

\section{C.1 Additional Estimates}

A table of estimates for each district and race in 2016 and 2020 are provided in a separate Dataverse repository, https://doi.org/10.7910/DVN/MAZNJ6 (Kuriwaki et al. 2023).

The district's names and descriptions are all as of 2021. The names of the CD come from the Daily Kos name in August 2019 (Daily Kos 2019). When there was significant redistricting between the 2016 and 2020 elections, we model the contemporaneous districts and name them separately. Pennsylvania redrew its Congressional districts in 2018, so we designated districts with the help of Daily Kos and Lara Putnam. The geographic associaton is shown in Figure C.1 and the names of each district.

Figure C.1 - Location of specific Congressional Districts. The Daily Kos district map used throughout this paper places congressional districts roughly according to their relative place in the state. The following figure indicates which districts are placed where.

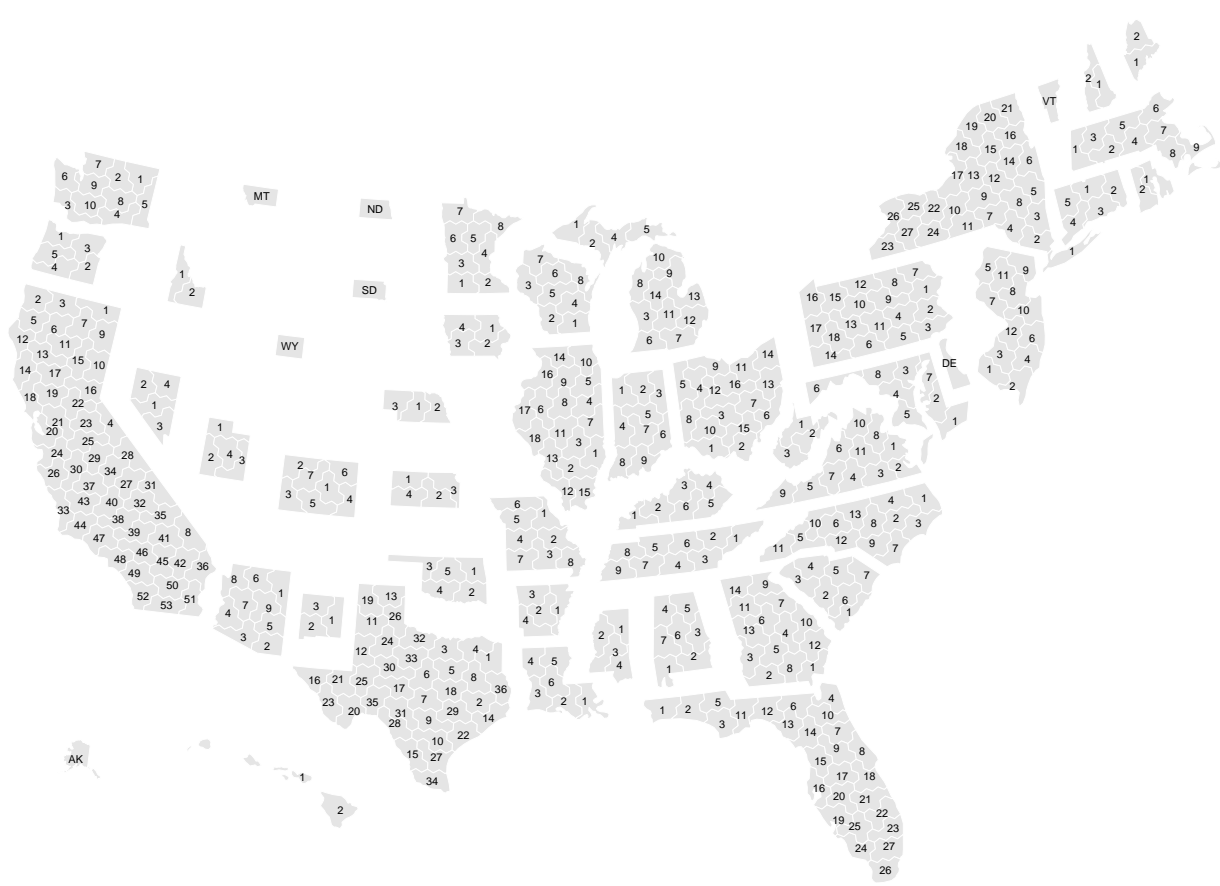




\section{C.2 2020 Estimates}

While this paper focused on 2016 in the main text, we estimated the same quantities using the 2020 Presidential election between Donald Trump and Joe Biden. Weighting and calibration targets were updated to use 2020 statistics. One exception is the voting age population statistics of the ACS. The ACS has only released experimental data for 2020 because of low response rates during COVID-19. We instead take the average of 2019 and 2021.

We took the 2016 and 2020 estimates and compared the estimates of each CD-race combination. That said, these comparisons cannot fully represent the underlying change in a racial group's overall voting preferences because of differential turnout.

Table C. 1 shows the results of these estimates at the state-level and up. The format mirrors Table 1 in 2016.

Figure C. 2 shows that Whites and Non-Whites moved in opposite directions, in a direction that reduced racial polarization. Whites became less supportive of the Republican Presidential candidate by about 2.5 percentage points and Non-Whites became more supportive by about 3.5 points. Hispanics moved more than Blacks but both moved in the same direction. In other words, the difference in Republican vote between White voters and non-White voters decreased by over 6 percentage points.

\section{C.3 Racial Gap Estimates}

Figure C. 3 and Table C.2 show the full distribution and summary statistics of the racial gap measure discussed inthe main text.

Figure C.4 separates the White - non-White racial gap into the White - Black racial gap and the White - Hispanic racial gap. 
Table C.1 - 2020 Republican Vote by Race and Geography

(a) Region Level

\begin{tabular}{rccccc}
\hline & & \multicolumn{3}{c}{ Non-Whites } & \\
\cline { 3 - 5 } & White & All & Black & Hisp. & All \\
\hline Northeast & 48 & 22 & 10 & 29 & 42 \\
South & 66 & 27 & 10 & 44 & 53 \\
North Central & 56 & 24 & 9 & 37 & 51 \\
West & 48 & 31 & 12 & 34 & 42 \\
\hline National & 56 & 28 & 10 & 38 & 48 \\
\hline
\end{tabular}

(b) Division Level

\begin{tabular}{rrrrrr}
\hline & & \multicolumn{3}{c}{ Non-Whites } & \\
\cline { 3 - 4 } & White & All & Black & Hisp. & All \\
\hline Northeast & & & & & \\
New England & 40 & 25 & 12 & 28 & 38 \\
Middle Atlantic & 52 & 22 & 9 & 29 & 44 \\
South & & & & & \\
South Atlantic & 62 & 25 & 10 & 43 & 49 \\
East South Central & 73 & 22 & 11 & 60 & 62 \\
West South Central & 69 & 34 & 11 & 44 & 56 \\
North Central & & & & & \\
East North Central & 56 & 21 & 8 & 35 & 50 \\
West North Central & 58 & 32 & 14 & 42 & 55 \\
West & & & & & \\
Mountain & 56 & 39 & 16 & 40 & 51 \\
Pacific & 43 & 29 & 10 & 32 & 37 \\
\hline National & 56 & 28 & 10 & 38 & 48 \\
\hline
\end{tabular}

(c) State Level

\begin{tabular}{|c|c|c|c|c|c|}
\hline & \multirow[b]{2}{*}{ White } & \multicolumn{3}{|c|}{ Non-Whites } & \multirow[b]{2}{*}{ All } \\
\hline & & All & Black & Hisp. & \\
\hline \multicolumn{6}{|l|}{ New England } \\
\hline Connecticut & 44 & 28 & 15 & 34 & 40 \\
\hline Maine & 46 & 33 & (12) & $(38)$ & 46 \\
\hline Massachusetts & 36 & 22 & 10 & 22 & 33 \\
\hline New Hampshire & 47 & 36 & $(16)$ & (33) & 46 \\
\hline Rhode Island & 42 & 28 & 11 & 33 & 40 \\
\hline Vermont & 32 & 22 & (8) & (24) & 32 \\
\hline \multicolumn{6}{|l|}{ Middle Atlantic } \\
\hline New Jersey & 50 & 27 & 11 & 34 & 42 \\
\hline New York & 49 & 20 & 9 & 26 & 40 \\
\hline Pennsylvania & 56 & 19 & 8 & 32 & 50 \\
\hline \multicolumn{6}{|l|}{ South Atlantic } \\
\hline Delaware & 48 & 22 & 12 & 33 & 41 \\
\hline Florida & 62 & 34 & 10 & 46 & 52 \\
\hline Georgia & 70 & 20 & 9 & 45 & 50 \\
\hline Maryland & 46 & 15 & 6 & 25 & 33 \\
\hline North Carolina & 62 & 24 & 13 & 40 & 51 \\
\hline South Carolina & 70 & 20 & 10 & 59 & 56 \\
\hline Virginia & 56 & 22 & 9 & 33 & 45 \\
\hline West Virginia & 72 & 38 & 16 & $(51)$ & 70 \\
\hline \multicolumn{6}{|l|}{ East South Central } \\
\hline Alabama & 79 & 22 & 12 & 71 & 63 \\
\hline Kentucky & 68 & 26 & 11 & $(48)$ & 63 \\
\hline Mississippi & 82 & 19 & 13 & (73) & 59 \\
\hline Tennessee & 70 & 22 & 7 & 54 & 62 \\
\hline \multicolumn{6}{|l|}{ West South Central } \\
\hline Arkansas & 72 & 30 & 12 & 55 & 64 \\
\hline Louisiana & 79 & 23 & 13 & 61 & 60 \\
\hline Oklahoma & 71 & 47 & 14 & 62 & 67 \\
\hline Texas & 65 & 35 & 9 & 42 & 53 \\
\hline \multicolumn{6}{|l|}{ East North Central } \\
\hline Illinois & 50 & 19 & 6 & 32 & 42 \\
\hline Indiana & 62 & 28 & 14 & 42 & 58 \\
\hline Michigan & 55 & 21 & 7 & 40 & 49 \\
\hline Ohio & 59 & 19 & 9 & $(38)$ & 54 \\
\hline Wisconsin & 53 & 27 & 8 & 35 & 50 \\
\hline \multicolumn{6}{|l|}{ West North Central } \\
\hline Iowa & 56 & 37 & 16 & 46 & 54 \\
\hline Kansas & 61 & 41 & 20 & 51 & 58 \\
\hline Minnesota & 50 & 25 & 11 & 30 & 46 \\
\hline Missouri & 63 & 26 & 12 & (44) & 58 \\
\hline Nebraska & 63 & 41 & 20 & 49 & 60 \\
\hline North Dakota & 69 & 51 & $(27)$ & (53) & 67 \\
\hline South Dakota & 64 & 55 & (22) & $(57)$ & 64 \\
\hline \multicolumn{6}{|l|}{ Mountain } \\
\hline Arizona & 57 & 36 & 15 & 35 & 50 \\
\hline Colorado & 47 & 33 & 15 & 35 & 43 \\
\hline Idaho & 67 & 62 & (29) & 59 & 66 \\
\hline Montana & 59 & 54 & (30) & $(53)$ & 59 \\
\hline Nevada & 55 & 41 & 16 & 50 & 49 \\
\hline New Mexico & 51 & 39 & (19) & 40 & 45 \\
\hline Utah & 63 & 51 & (27) & 48 & 61 \\
\hline Wyoming & 73 & 66 & (34) & 67 & 73 \\
\hline \multicolumn{6}{|l|}{ Pacific } \\
\hline Alaska & 58 & 48 & 17 & 46 & 55 \\
\hline California & 42 & 28 & 10 & 31 & 35 \\
\hline Hawaii & 42 & 31 & 14 & 26 & 35 \\
\hline Oregon & 44 & 32 & (9) & 33 & 42 \\
\hline Washington & 43 & 31 & 10 & 34 & 40 \\
\hline National & 56 & 28 & 10 & 38 & 48 \\
\hline
\end{tabular}


Figure C.2 - Changes in Republican vote by racial group, 2016 to 2020. Each point is our CD-level estimate for a racial group. We exclude CDs in Pennsylvania and North Carolina because district lines changed between 2016 and 2020 in those states. Summary statistics show mean change in a pair of CDs without taking the absolute value.

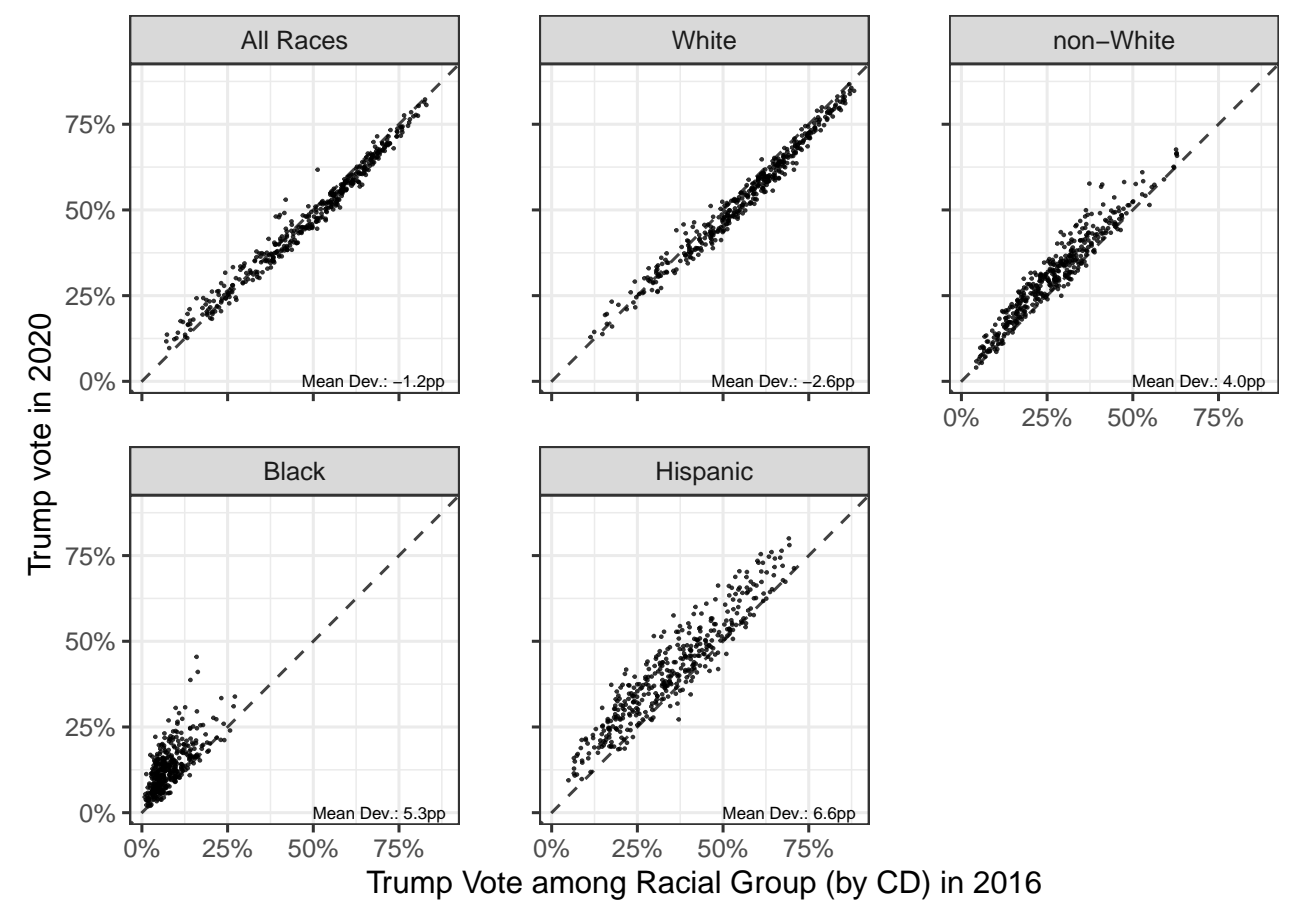

Figure C.3 - Distribution of CD-level Racial Gap Estimates. A histogram of the distribution shown in Figure 3.

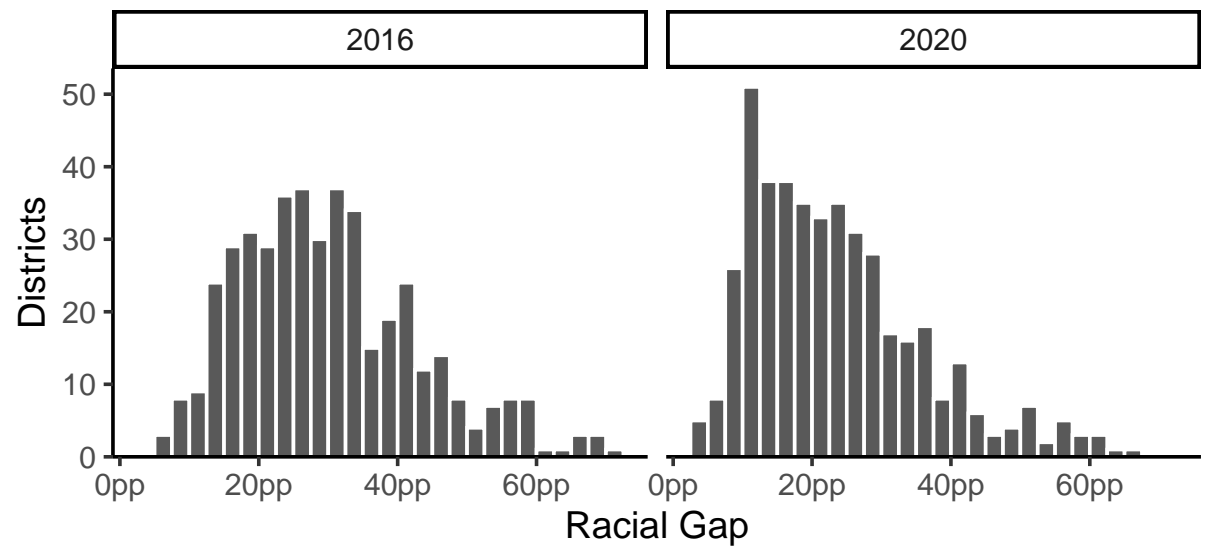


Table C.2 - Summary Statistics of CD-level Racial Gap

\begin{tabular}{lcc}
\hline Statistic & 2016 & 2020 \\
\hline Minimum & 0.06 & 0.04 \\
District in 25th Percentile & 0.21 & 0.14 \\
Median District & 0.29 & 0.22 \\
Mean District & 0.30 & 0.24 \\
National Gap & 0.36 & 0.29 \\
District in 75th Percentile & 0.39 & 0.30 \\
Maximum & 0.71 & 0.65 \\
Standard Deviation & 0.13 & 0.12 \\
\hline
\end{tabular}

Figure C.4 - The White-Black and White-Hispanic Racial Gap. Bars show 80 percent credible intervals. The arrangement of districts follows Figure 3.

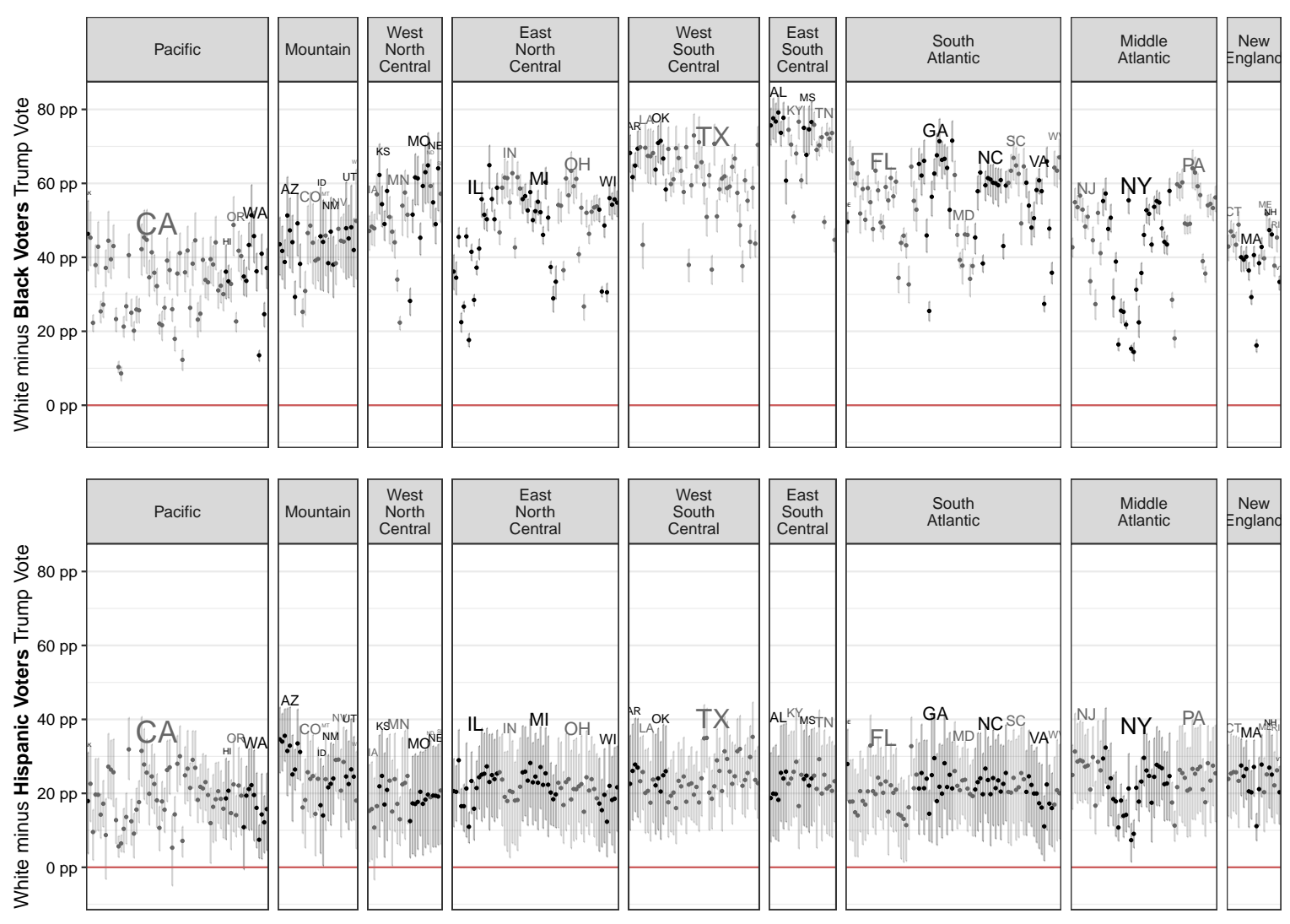




\section{C.4 Standard Errors}

Table 1 compares point estimates, but some of the differences between state-level point estimates are statistically not distinguishable from 0 because of estimation uncertainty. We approximate the state-level standard error by taking the standard deviation of the state-level estimates across the 2000 posterior draws. There are two types of uncertainty that are of interest: the uncertainty implied by the hierarchical regression model, and the uncertainty after calibration is applied.

The standard error implied by the hierarchical model is the standard deviation of the MRP estimates before calibration. It reflects the uncertainty in making inferences from the survey data. These standard errors will likely be large in districts and racial groups with fewer respondents. It is also smaller than the standard error of simple direct estimates without hierarchical model with shrinkage. Table C.3(a) uses the standard deviation of these estimates. A value of 0.05 , for example, indicates a frequentist margin of error of about 10 percentage points.

The standard error of the estimates after calibration is important because they are the final estimates we produce. By design, calibration does reduce the variance of estimates of homogeneous racial groups. Consider a state (district) such as VT-01 that is 99 percent White and 1 percent minority. The voteshare in that district is known. The racial homogeneity allows us to attribute the bulk of the calibration shift in the homogeneous racial group, and every posterior iteration of this estimate will be drawn to that voteshare target, dramatically reducing the standard error. In other words, once we know that Trump's voteshare in VT01 was exactly 34 percent, there is little uncertainty that the White vote in Vermont is also quite close to 34 percent. This idea is consistent with thinking of calibration as a principled posterior update (Rosenman, McCartan, and Olivella 2023). Table C.3(b) uses the standard deviation of these estimates. 
Table C.3 - Standard Errors of State-level Estimates. See Appendix C.4 for the difference between the two specifications.

(a) Implied by Hierarchical Model

\begin{tabular}{|c|c|c|c|c|c|}
\hline & \multirow[b]{2}{*}{ White } & \multicolumn{3}{|c|}{ Non-Whites } & \multirow[b]{2}{*}{ All } \\
\hline & & All & Black & Hisp. & \\
\hline \multicolumn{6}{|l|}{ New England } \\
\hline Connecticut & .021 & .031 & .024 & .064 & .019 \\
\hline Maine & .023 & .047 & .024 & .076 & .023 \\
\hline Massachusetts & .015 & .023 & .016 & .041 & .014 \\
\hline New Hampshire & .023 & .043 & .026 & .075 & .023 \\
\hline Rhode Island & .027 & .041 & .024 & .076 & .025 \\
\hline Vermont & .03 & .044 & .019 & .068 & .03 \\
\hline \multicolumn{6}{|l|}{ Middle Atlantic } \\
\hline New Jersey & .016 & .021 & .016 & .042 & .013 \\
\hline New York & .012 & .014 & .013 & .028 & .0099 \\
\hline Pennsylvania & .011 & .014 & .013 & .046 & .01 \\
\hline \multicolumn{6}{|l|}{ South Atlantic } \\
\hline Delaware & .026 & .024 & .022 & .08 & .022 \\
\hline Florida & .01 & .016 & .014 & .03 & .0092 \\
\hline Georgia & .015 & .015 & .015 & .059 & .012 \\
\hline Maryland & .017 & .015 & .016 & .054 & .013 \\
\hline North Carolina & .015 & .015 & .015 & .053 & .012 \\
\hline South Carolina & .019 & .019 & .021 & .071 & .016 \\
\hline Virginia & .014 & .017 & .015 & .05 & .012 \\
\hline West Virginia & .021 & .026 & .029 & .082 & .02 \\
\hline \multicolumn{6}{|l|}{ East South Central } \\
\hline Alabama & .02 & .017 & .018 & .078 & .016 \\
\hline Kentucky & .02 & .021 & .012 & .076 & .018 \\
\hline Mississippi & .023 & .022 & .024 & .085 & .017 \\
\hline Tennessee & .017 & .015 & .014 & .068 & .015 \\
\hline \multicolumn{6}{|l|}{ West South Central } \\
\hline & .021 & .024 & .023 & .08 & .019 \\
\hline Louisiana & .019 & .024 & .028 & .069 & .016 \\
\hline Oklahoma & .02 & .03 & .023 & .077 & .018 \\
\hline Texas & .012 & .019 & .014 & .029 & .011 \\
\hline \multicolumn{6}{|l|}{ East North Central } \\
\hline Illinois & .013 & .015 & .014 & .034 & .011 \\
\hline Indiana & .016 & .021 & .018 & .059 & .015 \\
\hline Michigan & .014 & .016 & .014 & .05 & .013 \\
\hline Ohio & .012 & .014 & .015 & .051 & .011 \\
\hline Wisconsin & .016 & .023 & .015 & .057 & .015 \\
\hline \multicolumn{6}{|l|}{ West North Central } \\
\hline Iowa & .019 & .04 & .031 & .08 & .018 \\
\hline Kansas & .021 & .038 & .03 & .079 & .02 \\
\hline Minnesota & .017 & .028 & .021 & .058 & .016 \\
\hline Missouri & .016 & .02 & .022 & .064 & .014 \\
\hline Nebraska & .022 & .041 & .032 & .083 & .021 \\
\hline North Dakota & .03 & .05 & .048 & .12 & .03 \\
\hline South Dakota & .03 & .058 & .052 & .11 & .029 \\
\hline \multicolumn{6}{|l|}{ Mountain } \\
\hline Arizona & .017 & .029 & .043 & .04 & .015 \\
\hline Colorado & .017 & .031 & .041 & .044 & .016 \\
\hline Idaho & .025 & .054 & .081 & .086 & .025 \\
\hline Montana & .029 & .056 & .074 & .11 & .028 \\
\hline Nevada & .021 & .033 & .046 & .055 & .02 \\
\hline New Mexico & .024 & .042 & .062 & .055 & .025 \\
\hline Utah & .023 & .044 & .063 & .065 & .022 \\
\hline Wyoming & .031 & .064 & .087 & .1 & .031 \\
\hline \multicolumn{6}{|l|}{ Pacific } \\
\hline Alaska & .03 & .057 & .07 & .11 & .03 \\
\hline California & .011 & .015 & .026 & .023 & .0095 \\
\hline Hawaii & .03 & .052 & .051 & .077 & .033 \\
\hline Oregon & .018 & .033 & .027 & .057 & .017 \\
\hline Washington & .015 & .025 & .026 & .05 & .014 \\
\hline
\end{tabular}

(b) After Calibration

\begin{tabular}{|c|c|c|c|c|}
\hline & \multirow[b]{2}{*}{ White } & \multicolumn{3}{|c|}{ Non-Whites } \\
\hline & & All & Black & Hisp. \\
\hline \multicolumn{5}{|l|}{ New England } \\
\hline Connecticut & .0069 & .024 & .024 & .053 \\
\hline Maine & .0015 & .043 & .025 & .07 \\
\hline Massachusetts & .0043 & .019 & .016 & .033 \\
\hline New Hampshire & .0021 & .04 & .029 & .071 \\
\hline Rhode Island & .0065 & .033 & .023 & .063 \\
\hline Vermont & .0043 & .039 & .019 & .057 \\
\hline \multicolumn{5}{|l|}{ Middle Atlantic } \\
\hline New Jersey & .0077 & .015 & .016 & .033 \\
\hline New York & .0053 & .01 & .012 & .021 \\
\hline Pennsylvania & .0026 & .012 & .012 & .039 \\
\hline \multicolumn{5}{|l|}{ South Atlantic } \\
\hline Delaware & .0067 & .018 & .019 & .068 \\
\hline Florida & .0056 & .011 & .013 & .023 \\
\hline Georgia & .0072 & .012 & .015 & .054 \\
\hline Maryland & .0072 & .011 & .013 & .044 \\
\hline North Carolina & .0053 & .013 & .016 & .049 \\
\hline South Carolina & .0066 & .017 & .02 & .07 \\
\hline Virginia & .0056 & .013 & .014 & .043 \\
\hline West Virginia & .0027 & .027 & .034 & .081 \\
\hline \multicolumn{5}{|l|}{ East South Central } \\
\hline Alabama & .008 & .019 & .023 & .072 \\
\hline Kentucky & .0025 & .02 & .014 & .074 \\
\hline Mississippi & .012 & .026 & .03 & .082 \\
\hline Tennessee & .0029 & .015 & .015 & .065 \\
\hline \multicolumn{5}{|l|}{ West South Central } \\
\hline Arkansas & .005 & .022 & .025 & .076 \\
\hline Louisiana & .012 & .021 & .028 & .066 \\
\hline Oklahoma & .0044 & .025 & .026 & .074 \\
\hline Texas & .007 & .011 & .015 & .019 \\
\hline \multicolumn{5}{|l|}{ East North Central } \\
\hline Illinois & .0045 & .012 & .013 & .028 \\
\hline Indiana & .0027 & .02 & .021 & .058 \\
\hline Michigan & .0029 & .015 & .015 & .047 \\
\hline Ohio & .0023 & .015 & .016 & .05 \\
\hline Wisconsin & .0026 & .021 & .016 & .053 \\
\hline \multicolumn{5}{|l|}{ West North Central } \\
\hline Iowa & .0031 & .037 & .035 & .078 \\
\hline Kansas & .0047 & .034 & .036 & .076 \\
\hline Minnesota & .0035 & .025 & .022 & .053 \\
\hline Missouri & .0033 & .022 & .027 & .064 \\
\hline Nebraska & .0044 & .038 & .041 & .08 \\
\hline North Dakota & .0045 & .042 & .063 & .12 \\
\hline South Dakota & .0043 & .05 & .061 & .11 \\
\hline \multicolumn{5}{|l|}{ Mountain } \\
\hline Arizona & .0073 & .021 & .043 & .031 \\
\hline Colorado & .0069 & .023 & .042 & .036 \\
\hline Idaho & .0048 & .049 & .094 & .083 \\
\hline Montana & .0042 & .05 & .081 & .1 \\
\hline Nevada & .011 & .023 & .046 & .044 \\
\hline New Mexico & .019 & .023 & .058 & .037 \\
\hline Utah & .005 & .038 & .073 & .061 \\
\hline Wyoming & .012 & .058 & .11 & .1 \\
\hline \multicolumn{5}{|l|}{ Pacific } \\
\hline Alaska & .013 & .041 & .072 & .1 \\
\hline California & .0064 & .0072 & .021 & .013 \\
\hline Hawaii & .031 & .022 & .037 & .057 \\
\hline Oregon & .004 & .027 & .025 & .049 \\
\hline Washington & .004 & .02 & .024 & .043 \\
\hline
\end{tabular}




\section{REFERENCES FOR APPENDIX}

Ansolabehere, Stephen, and Douglas Rivers. 1995. "Bias in Ecological Regression." MIT Department of Political Science Manuscript. 2013. “Cooperative Survey Research.” Annual Review of Political Science 16:307329.

Barreto, Matt A. 2016. “2016 Latino Election Analysis (November 30, 2016).”

Barreto, Matt A., Tyler Reny, and Bryan Wilcox-Archuleta. 2017. "Survey methodology and the Latina/o vote: Why a bilingual, bicultural, Latino-centered approach matters." Aztlan: A Journal of Chicano Studies 42 (2): 211-227.

Daily Kos. 2019. “The Daily Kos Elections naming guide to the nation's congressional districts."

_. 2021. "Calculating Statewide Election Results by Congressional and Legislative District: Statement of Methodology."

Gelman, Andrew, et al. 2020. "Bayesian Workflow." arXiv preprint arXiv:2011.01808.

Kastellec, Jonathan P., Jeffrey R. Lax, Michael Malecki, and Justin H. Phillips. 2015. "Polarizing the electoral connection: Partisan representation in Supreme Court confirmation politics." The Journal of Politics 77 (3): 787-804.

Kuriwaki, Shiro, Stephen Ansolabehere, Angelo Dagonel, and Soichiro Yamauchi. 2023. "Modeled vote share for geographic and racial subgroups with survey and ecological data." Harvard Dataverse.

Leemann, Lucas, and Fabio Wasserfallen. 2017. "Extending the Use and Prediction Precision of Subnational Public Opinion Estimation.” American Journal of Political Science 61 (4): 1003-1022.

McCartan, Cory, et al. 2022. ALARM Project: 50-State Redistricting Simulations.

Przeworski, Adam. 1974. "Contextual models of political behavior." Political Methodology, 27-61.

Rivers, Douglas. 2007. "Sampling for web surveys.” In Joint Statistical Meetings. 
Rosenman, Evan T.R., Cory McCartan, and Santiago Olivella. 2023. "Recalibration of Predicted Probabilities Using the 'Logit Shift': Why does it work, and when can it be expected to work well?" Political Analysis.

Stoker, Laura, and Jake Bowers. 2002. "Designing multi-level studies: Sampling voters and electoral contexts." Electoral Studies 21 (2): 235-267.

Yamauchi, Soichiro. 2021. emlogit: An ECM algorithm for the Multinomial Logit Model. 


\section{Estimates from Kuriwaki et al., "Geography of Racially Polarized Voting: Calibrating Surveys at the District Level"}

This section presents the estimates of two-way Republican voteshare by district by race in table form. To download the estimates in machine-readable form, refer to the Dataverse repository in https://doi.org/10.7910/DVN/MAZNJ6.

Congressional districts represent district lines in the 2016 and 2020 general elections. In the subsequent tables, numbers are rounded to the nearest full percentage point. Numbers enclosed by a parenthesis indicate that we estimate that the racial group comprise only 2 percent or less of the geography's electorate. The names of the CD come from the Daily Kos name in August 2019. Pennsylvania redrew its Congressional districts in 2018, so we designated districts with the help of Daily Kos and Lara Putnam. The names of each district is given in the subsequent tables.

\section{National, Region, Division, and State Estimates}

Tables S.1 (2016) and S.2 (2020) shows the results of these estimates at the state-level and up.

\section{Standard Errors}

Tables S.3 and S.4 show the estimated standard error of each of the state level estimates in the previous tables. They do not represent the standard errors after calibration. Tables S.5 and S.6 represent the standard error after calibration. See Appendix C.4 in Kuriwaki et al. (2023) for a discussion of the difference. 
Table S.1 - 2016 Republican Vote by Racial Group in Regions, Divisions, and States

(a) By Region

\begin{tabular}{rccccc}
\hline & & \multicolumn{3}{c}{ Non-Whites } & \\
\cline { 3 - 5 } & White & All & Black & Hisp. & All \\
\hline Northeast & 51 & 17 & 4 & 20 & 43 \\
South & 69 & 23 & 8 & 37 & 55 \\
North Central & 59 & 19 & 5 & 29 & 53 \\
West & 50 & 26 & 9 & 25 & 42 \\
\hline National & 59 & 22 & 7 & 29 & 49 \\
\hline
\end{tabular}

(b) By Division, nested within Region

\begin{tabular}{|c|c|c|c|c|c|}
\hline & \multirow[b]{2}{*}{ White } & \multicolumn{3}{|c|}{ Non-Whites } & \multirow[b]{2}{*}{ All } \\
\hline & & All & Black & Hisp. & \\
\hline \multicolumn{6}{|l|}{ Northeast } \\
\hline New England & 45 & 19 & 3 & 19 & 41 \\
\hline Middle Atlantic & 54 & 16 & 4 & 21 & 44 \\
\hline \multicolumn{6}{|l|}{ South } \\
\hline South Atlantic & 64 & 21 & 7 & 37 & 51 \\
\hline East South Central & 77 & 16 & 7 & 50 & 64 \\
\hline West South Central & 72 & 30 & 9 & 37 & 58 \\
\hline \multicolumn{6}{|l|}{ North Central } \\
\hline East North Central & 57 & 17 & 5 & 25 & 51 \\
\hline West North Central & 61 & 28 & 6 & 39 & 57 \\
\hline \multicolumn{6}{|l|}{ West } \\
\hline Mountain & 59 & 33 & 13 & 29 & 53 \\
\hline Pacific & 44 & 24 & 9 & 23 & 36 \\
\hline National & 59 & 22 & 7 & 29 & 49 \\
\hline
\end{tabular}

Note: Numbers show two-party voteshare for the Republican Presidential candidate for each geography and racial group rounded to the nearest full percentage point. Columns represent, from left to right, the Republican vote among White voters, all non-White voters, Black voters, (any-part) Hispanic voters, and all racial groups in the geography. Numbers in parentheses are those where we estimate the racial group comprises only 2 percent or less of the geography's electorate. See Table S.5 for standard errors of the state-level point estimates, and Table S.11 for the estimated composition of the electorate in each state. (c) By State, nested within Division

\begin{tabular}{|c|c|c|c|c|c|}
\hline & \multirow[b]{2}{*}{ White } & \multicolumn{3}{|c|}{ Non-Whites } & \multirow[b]{2}{*}{ All } \\
\hline & & All & Black & Hisp. & \\
\hline \multicolumn{6}{|l|}{ New England } \\
\hline Connecticut & 50 & 20 & 4 & 24 & 43 \\
\hline Maine & 49 & 33 & (4) & (26) & 49 \\
\hline Massachusetts & 40 & 16 & 2 & 15 & 36 \\
\hline New Hampshire & 51 & 32 & (4) & (25) & 50 \\
\hline Rhode Island & 45 & 21 & 3 & 21 & 42 \\
\hline Vermont & 36 & 21 & (2) & $(15)$ & 35 \\
\hline \multicolumn{6}{|l|}{ Middle Atlantic } \\
\hline New Jersey & 55 & 20 & 4 & 22 & 43 \\
\hline New York & 50 & 15 & 4 & 18 & 39 \\
\hline Pennsylvania & 58 & 15 & 3 & 28 & 51 \\
\hline \multicolumn{6}{|l|}{ South Atlantic } \\
\hline Delaware & 54 & 14 & 5 & 26 & 44 \\
\hline Florida & 63 & 27 & 6 & 37 & 51 \\
\hline Georgia & 73 & 19 & 8 & 44 & 53 \\
\hline Maryland & 51 & 13 & 6 & 25 & 36 \\
\hline North Carolina & 66 & 19 & 8 & 39 & 52 \\
\hline South Carolina & 73 & 17 & 10 & 50 & 58 \\
\hline Virginia & 60 & 19 & 7 & 32 & 47 \\
\hline West Virginia & 74 & 29 & 9 & $(54)$ & 72 \\
\hline \multicolumn{6}{|l|}{ East South Central } \\
\hline Alabama & 83 & 17 & 7 & 60 & 65 \\
\hline Kentucky & 71 & 21 & 3 & 40 & 66 \\
\hline Mississippi & 84 & 15 & 10 & $(60)$ & 60 \\
\hline Tennessee & 74 & 15 & 3 & 44 & 64 \\
\hline \multicolumn{6}{|c|}{ West South Central } \\
\hline Arkansas & 74 & 23 & 8 & 45 & 65 \\
\hline Louisiana & 81 & 22 & 13 & 54 & 61 \\
\hline Oklahoma & 73 & 48 & 6 & 48 & 70 \\
\hline Texas & 70 & 31 & 6 & 36 & 55 \\
\hline \multicolumn{6}{|l|}{ East North Central } \\
\hline Illinois & 51 & 15 & 5 & 19 & 41 \\
\hline Indiana & 65 & 23 & 7 & 38 & 60 \\
\hline Michigan & 57 & 17 & 5 & 31 & 51 \\
\hline Ohio & 61 & 16 & 6 & (34) & 55 \\
\hline Wisconsin & 54 & 23 & 3 & 31 & 51 \\
\hline \multicolumn{6}{|l|}{ West North Central } \\
\hline Iowa & 57 & 35 & 7 & 43 & 55 \\
\hline Kansas & 65 & 37 & 8 & 43 & 61 \\
\hline Minnesota & 53 & 24 & 4 & 27 & 50 \\
\hline Missouri & 66 & 20 & 6 & (43) & 60 \\
\hline Nebraska & 66 & 39 & 8 & 46 & 64 \\
\hline North Dakota & 71 & 55 & (12) & $(52)$ & 70 \\
\hline South Dakota & 67 & 53 & (10) & (47) & 66 \\
\hline \multicolumn{6}{|l|}{ Mountain } \\
\hline Arizona & 60 & 28 & 13 & 23 & 52 \\
\hline Colorado & 52 & 31 & 12 & 30 & 48 \\
\hline Idaho & 69 & 59 & (24) & 53 & 69 \\
\hline Montana & 62 & 54 & (16) & (38) & 62 \\
\hline Nevada & 57 & 32 & 12 & 28 & 49 \\
\hline New Mexico & 55 & 34 & (14) & 32 & 46 \\
\hline Utah & 65 & 48 & (18) & 39 & 63 \\
\hline Wyoming & 77 & 63 & (27) & 59 & 76 \\
\hline \multicolumn{6}{|l|}{ Pacific } \\
\hline Alaska & 62 & 47 & 16 & 45 & 59 \\
\hline California & 43 & 23 & 9 & 22 & 34 \\
\hline Hawaii & 42 & 26 & 9 & 23 & 33 \\
\hline Oregon & 46 & 29 & (6) & 27 & 44 \\
\hline Washington & 45 & 28 & 7 & 30 & 42 \\
\hline National & 59 & 22 & 7 & 29 & 49 \\
\hline
\end{tabular}


Table S.2 - 2020 Republican Vote by Race and Geography

(a) Region Level

\begin{tabular}{rccccc}
\hline & & \multicolumn{3}{c}{ Non-Whites } & \\
\cline { 3 - 5 } & White & All & Black & Hisp. & All \\
\hline Northeast & 48 & 22 & 10 & 29 & 42 \\
South & 66 & 27 & 10 & 44 & 53 \\
North Central & 56 & 24 & 9 & 37 & 51 \\
West & 48 & 31 & 12 & 34 & 42 \\
\hline National & 56 & 28 & 10 & 38 & 48 \\
\hline
\end{tabular}

(b) Division Level

\begin{tabular}{rrrrrr}
\hline & & \multicolumn{3}{c}{ Non-Whites } & \\
\cline { 3 - 4 } & White & All & Black & Hisp. & All \\
\hline Northeast & & & & & \\
New England & 40 & 25 & 12 & 28 & 38 \\
Middle Atlantic & 52 & 22 & 9 & 29 & 44 \\
South & & & & & \\
South Atlantic & 62 & 25 & 10 & 43 & 49 \\
East South Central & 73 & 22 & 11 & 60 & 62 \\
West South Central & 69 & 34 & 11 & 44 & 56 \\
North Central & & & & & \\
East North Central & 56 & 21 & 8 & 35 & 50 \\
West North Central & 58 & 32 & 14 & 42 & 55 \\
West & & & & & \\
Mountain & 56 & 39 & 16 & 40 & 51 \\
Pacific & 43 & 29 & 10 & 32 & 37 \\
\hline National & 56 & 28 & 10 & 38 & 48 \\
\hline
\end{tabular}

Note: See Table S.1 (c) State Level

\begin{tabular}{|c|c|c|c|c|c|}
\hline & \multirow[b]{2}{*}{ White } & \multicolumn{3}{|c|}{ Non-Whites } & \multirow[b]{2}{*}{ All } \\
\hline & & All & Black & Hisp. & \\
\hline \multicolumn{6}{|l|}{ New England } \\
\hline Connecticut & 44 & 28 & 15 & 34 & 40 \\
\hline Maine & 46 & 33 & (12) & (38) & 46 \\
\hline Massachusetts & 36 & 22 & 10 & 22 & 33 \\
\hline New Hampshire & 47 & 36 & (16) & (33) & 46 \\
\hline Rhode Island & 42 & 28 & 11 & 33 & 40 \\
\hline Vermont & 32 & 22 & (8) & (24) & 32 \\
\hline \multicolumn{6}{|l|}{ Middle Atlantic } \\
\hline New Jersey & 50 & 27 & 11 & 34 & 42 \\
\hline New York & 49 & 20 & 9 & 26 & 40 \\
\hline Pennsylvania & 56 & 19 & 8 & 32 & 50 \\
\hline \multicolumn{6}{|l|}{ South Atlantic } \\
\hline Delaware & 48 & 22 & 12 & 33 & 41 \\
\hline Florida & 62 & 34 & 10 & 46 & 52 \\
\hline Geor & 70 & 20 & 9 & 45 & 50 \\
\hline Maryland & 46 & 15 & 6 & 25 & 33 \\
\hline North Carolina & 62 & 24 & 13 & 40 & 51 \\
\hline South Carolina & 70 & 20 & 10 & 59 & 56 \\
\hline Virginia & 56 & 22 & 9 & 33 & 45 \\
\hline West Virginia & 72 & 38 & 16 & (51) & 70 \\
\hline \multicolumn{6}{|l|}{ East South Central } \\
\hline Alabama & 79 & 22 & 12 & 71 & 63 \\
\hline Kentucky & 68 & 26 & 11 & $(48)$ & 63 \\
\hline Mississippi & 82 & 19 & 13 & (73) & 59 \\
\hline Tennessee & 70 & 22 & 7 & 54 & 62 \\
\hline \multicolumn{6}{|l|}{ West South Central } \\
\hline$A$ & 72 & 30 & 12 & 55 & 64 \\
\hline Lou & 79 & 23 & 13 & 61 & 60 \\
\hline Oklaho & 71 & 47 & 14 & 62 & 67 \\
\hline Texas & 65 & 35 & 9 & 42 & 53 \\
\hline \multicolumn{6}{|l|}{ East North Central } \\
\hline Jlingis & 50 & 19 & 6 & 32 & 42 \\
\hline In & 62 & 28 & 14 & 42 & 58 \\
\hline Michigan & 55 & 21 & 7 & 40 & 49 \\
\hline Ohio & 59 & 19 & 9 & $(38)$ & 54 \\
\hline Wisconsin & 53 & 27 & 8 & 35 & 50 \\
\hline \multicolumn{6}{|l|}{ West North Central } \\
\hline Iowa & 56 & 37 & 16 & 46 & 54 \\
\hline Kansas & 61 & 41 & 20 & 51 & 58 \\
\hline Minnesota & 50 & 25 & 11 & 30 & 46 \\
\hline Missouri & 63 & 26 & 12 & (44) & 58 \\
\hline Nebraska & 63 & 41 & 20 & 49 & 60 \\
\hline North Dakota & 69 & 51 & $(27)$ & (53) & 67 \\
\hline South Dakota & 64 & 55 & (22) & (57) & 64 \\
\hline \multicolumn{6}{|l|}{ Mountain } \\
\hline Arizona & 57 & 36 & 15 & 35 & 50 \\
\hline Colorado & 47 & 33 & 15 & 35 & 43 \\
\hline Idaho & 67 & 62 & (29) & 59 & 66 \\
\hline Montana & 59 & 54 & (30) & $(53)$ & 59 \\
\hline Nevada & 55 & 41 & 16 & 50 & 49 \\
\hline New Mexico & 51 & 39 & (19) & 40 & 45 \\
\hline Utah & 63 & 51 & (27) & 48 & 61 \\
\hline Wyoming & 73 & 66 & (34) & 67 & 73 \\
\hline \multicolumn{6}{|l|}{ Pacific } \\
\hline Alasl & 58 & 48 & 17 & 46 & 55 \\
\hline California & 42 & 28 & 10 & 31 & 35 \\
\hline Hawaii & 42 & 31 & 14 & 26 & 35 \\
\hline Oregon & 44 & 32 & (9) & 33 & 42 \\
\hline Washington & 43 & 31 & 10 & 34 & 40 \\
\hline Tationa & 56 & 28 & 10 & 38 & 48 \\
\hline
\end{tabular}


Table S.3 - Standard Errors of 2016 Estimates, Hierarchical Model.

\begin{tabular}{|c|c|c|c|c|c|}
\hline & \multirow[b]{2}{*}{ White } & \multicolumn{3}{|c|}{ Non-Whites } & \multirow[b]{2}{*}{ All } \\
\hline & & All & Black & Hisp. & \\
\hline \multicolumn{6}{|l|}{ New England } \\
\hline Connecticut & .021 & .031 & .024 & .064 & .019 \\
\hline Maine & .023 & .047 & .024 & .076 & .023 \\
\hline Massachusetts & .015 & .023 & .016 & .041 & .014 \\
\hline New Hampshire & .023 & .043 & .026 & .075 & .023 \\
\hline Rhode Island & .027 & .041 & .024 & .076 & .025 \\
\hline Vermont & .03 & .044 & .019 & .068 & .03 \\
\hline \multicolumn{6}{|l|}{ Middle Atlantic } \\
\hline New Jersey & .016 & .021 & .016 & .042 & .013 \\
\hline New York & .012 & .014 & .013 & .028 & .0099 \\
\hline Pennsylvania & .011 & .014 & .013 & .046 & .01 \\
\hline \multicolumn{6}{|l|}{ South Atlantic } \\
\hline Delaware & .026 & .024 & .022 & .08 & .022 \\
\hline Florida & .01 & .016 & .014 & .03 & .0092 \\
\hline Georgia & .015 & .015 & .015 & .059 & .012 \\
\hline Maryland & .017 & .015 & .016 & .054 & .013 \\
\hline North Carolina & .015 & .015 & .015 & .053 & .012 \\
\hline South Carolina & .019 & .019 & .021 & .071 & .016 \\
\hline Virginia & .014 & .017 & .015 & .05 & .012 \\
\hline West Virginia & .021 & .026 & .029 & .082 & .02 \\
\hline \multicolumn{6}{|l|}{ East South Central } \\
\hline Alabama & .02 & .017 & .018 & .078 & .016 \\
\hline Kentucky & .02 & .021 & .012 & .076 & .018 \\
\hline Mississippi & .023 & .022 & .024 & .085 & .017 \\
\hline Tennessee & .017 & .015 & .014 & .068 & .015 \\
\hline \multicolumn{6}{|l|}{ West South Central } \\
\hline Arkansas & .021 & .024 & .023 & .08 & .019 \\
\hline Louisiana & .019 & .024 & .028 & .069 & .016 \\
\hline Oklahoma & .02 & .03 & .023 & .077 & .018 \\
\hline Texas & .012 & .019 & .014 & .029 & .011 \\
\hline \multicolumn{6}{|l|}{ East North Central } \\
\hline Illinois & .013 & .015 & .014 & .034 & .011 \\
\hline Indiana & .016 & .021 & .018 & .059 & .015 \\
\hline Michigan & .014 & .016 & .014 & .05 & .013 \\
\hline Ohio & .012 & .014 & .015 & .051 & .011 \\
\hline Wisconsin & .016 & .023 & .015 & .057 & .015 \\
\hline \multicolumn{6}{|l|}{ West North Central } \\
\hline Iowa & .019 & .04 & .031 & .08 & .018 \\
\hline Kansas & .021 & .038 & .03 & .079 & .02 \\
\hline Minnesota & .017 & .028 & .021 & .058 & .016 \\
\hline Missouri & .016 & .02 & .022 & .064 & .014 \\
\hline Nebraska & .022 & .041 & .032 & .083 & .021 \\
\hline North Dakota & .03 & .05 & .048 & .12 & .03 \\
\hline South Dakota & .03 & .058 & .052 & .11 & .029 \\
\hline \multicolumn{6}{|l|}{ Mountain } \\
\hline Arizona & .017 & .029 & .043 & .04 & .015 \\
\hline Colorado & .017 & .031 & .041 & .044 & .016 \\
\hline Idaho & .025 & .054 & .081 & .086 & .025 \\
\hline Montana & .029 & .056 & .074 & .11 & .028 \\
\hline Nevada & .021 & .033 & .046 & .055 & .02 \\
\hline New Mexico & .024 & .042 & .062 & .055 & .025 \\
\hline Utah & .023 & .044 & .063 & .065 & .022 \\
\hline Wyoming & .031 & .064 & .087 & .1 & .031 \\
\hline \multicolumn{6}{|l|}{ Pacific } \\
\hline Alaska & .03 & .057 & .07 & .11 & .03 \\
\hline California & .011 & .015 & .026 & .023 & .0095 \\
\hline Hawaii & .03 & .052 & .051 & .077 & .033 \\
\hline Oregon & .018 & .033 & .027 & .057 & .017 \\
\hline Washington & .015 & .025 & .026 & .05 & .014 \\
\hline
\end{tabular}


Table S.4 - Standard Errors of 2020 Estimates, Hierarchical Model.

\begin{tabular}{|c|c|c|c|c|c|}
\hline & \multicolumn{4}{|c|}{ Non-Whites } & \multirow[b]{2}{*}{ All } \\
\hline & White & All & Black & Hisp. & \\
\hline \multicolumn{6}{|l|}{ New England } \\
\hline Connecticut & .02 & .034 & .049 & .064 & .019 \\
\hline Maine & .024 & .044 & .054 & .084 & .024 \\
\hline Massachusetts & .015 & .027 & .036 & .045 & .015 \\
\hline New Hampshire & .023 & .04 & .063 & .064 & .023 \\
\hline Rhode Island & .026 & .041 & .045 & .075 & .025 \\
\hline Vermont & .026 & .043 & .044 & .069 & .026 \\
\hline \multicolumn{6}{|l|}{ Middle Atlantic } \\
\hline New Jersey & .015 & .02 & .02 & .04 & .013 \\
\hline New York & .011 & .014 & .013 & .028 & .0095 \\
\hline Pennsylvania & .01 & .014 & .015 & .041 & .0093 \\
\hline \multicolumn{6}{|l|}{ South Atlantic } \\
\hline Delaware & .03 & .035 & .044 & .082 & .026 \\
\hline Florida & .011 & .014 & .013 & .026 & .0089 \\
\hline Georgia & .016 & .012 & .01 & .051 & .011 \\
\hline Maryland & .018 & .013 & .012 & .045 & .013 \\
\hline North Carolina & .014 & .014 & .015 & .046 & .012 \\
\hline South Carolina & .019 & .015 & .016 & .066 & .015 \\
\hline Virginia & .014 & .015 & .013 & .043 & .012 \\
\hline West Virginia & .023 & .031 & .042 & .083 & .022 \\
\hline \multicolumn{6}{|l|}{ East South Central } \\
\hline Alabama & .02 & .016 & .018 & .074 & .016 \\
\hline Kentucky & .019 & .025 & .029 & .075 & .017 \\
\hline Mississippi & .028 & .021 & .023 & .08 & .021 \\
\hline Tennessee & .016 & .016 & .015 & .071 & .014 \\
\hline \multicolumn{6}{|l|}{ West South Central } \\
\hline Arkansas & .023 & .024 & .024 & .081 & .021 \\
\hline Louisiana & .024 & .018 & .019 & .067 & .018 \\
\hline Oklahoma & .023 & .03 & .034 & .076 & .021 \\
\hline Texas & .011 & .015 & .012 & .023 & .0095 \\
\hline \multicolumn{6}{|l|}{ East North Central } \\
\hline Illinois & .013 & .016 & .011 & .039 & .011 \\
\hline Indiana & .015 & .021 & .024 & .053 & .014 \\
\hline Michigan & .013 & .016 & .014 & .049 & .012 \\
\hline Ohio & .012 & .013 & .014 & .046 & .011 \\
\hline Wisconsin & .016 & .022 & .021 & .053 & .015 \\
\hline \multicolumn{6}{|l|}{ West North Central } \\
\hline Iowa & .02 & .037 & .041 & .075 & .019 \\
\hline Kansas & .023 & .035 & .045 & .07 & .022 \\
\hline Minnesota & .016 & .025 & .035 & .051 & .015 \\
\hline Missouri & .015 & .022 & .026 & .057 & .014 \\
\hline Nebraska & .025 & .038 & .051 & .074 & .024 \\
\hline North Dakota & .031 & .051 & .084 & .097 & .031 \\
\hline South Dakota & .031 & .052 & .078 & .092 & .031 \\
\hline \multicolumn{6}{|l|}{ Mountain } \\
\hline Arizona & .017 & .027 & .037 & .041 & .016 \\
\hline Colorado & .016 & .025 & .035 & .04 & .015 \\
\hline Idaho & .026 & .048 & .076 & .073 & .025 \\
\hline Montana & .027 & .057 & .088 & .09 & .027 \\
\hline Nevada & .021 & .032 & .044 & .061 & .02 \\
\hline New Mexico & .026 & .037 & .067 & .05 & .026 \\
\hline Utah & .025 & .043 & .072 & .065 & .024 \\
\hline Wyoming & .034 & .058 & .093 & .093 & .033 \\
\hline \multicolumn{6}{|l|}{ Pacific } \\
\hline Alaska & .035 & .055 & .057 & .086 & .034 \\
\hline California & .01 & .013 & .017 & .021 & .009 \\
\hline Hawaii & .032 & .043 & .057 & .061 & .032 \\
\hline Oregon & .016 & .028 & .03 & .048 & .016 \\
\hline Washington & .015 & .023 & .025 & .046 & .014 \\
\hline
\end{tabular}


Table S.5 - Standard Errors of 2016 Estimates, after Calibration. Standard errors after calibration.

\begin{tabular}{|c|c|c|c|c|}
\hline & \multirow[b]{2}{*}{ White } & \multicolumn{3}{|c|}{ Non-Whites } \\
\hline & & All & Black & Hisp. \\
\hline \multicolumn{5}{|l|}{ New England } \\
\hline Connecticut & .0069 & .024 & .024 & .053 \\
\hline Maine & .0015 & .043 & .025 & .07 \\
\hline Massachusetts & .0043 & .019 & .016 & .033 \\
\hline New Hampshire & .0021 & .04 & .029 & .071 \\
\hline Rhode Island & .0065 & .033 & .023 & .063 \\
\hline Vermont & .0043 & .039 & .019 & .057 \\
\hline \multicolumn{5}{|l|}{ Middle Atlantic } \\
\hline New Jersey & .0077 & .015 & .016 & .033 \\
\hline New York & .0053 & .01 & .012 & .021 \\
\hline Pennsylvania & .0026 & .012 & .012 & .039 \\
\hline \multicolumn{5}{|l|}{ South Atlantic } \\
\hline Delaware & .0067 & .018 & .019 & .068 \\
\hline Florida & .0056 & .011 & .013 & .023 \\
\hline Georgia & .0072 & .012 & 015 & .054 \\
\hline Maryland & .0072 & .011 & .013 & .044 \\
\hline North Carolina & .0053 & .013 & .016 & .049 \\
\hline South Carolina & .0066 & .017 & .02 & .07 \\
\hline Virginia & .0056 & .013 & .014 & .043 \\
\hline West Virginia & .0027 & .027 & .034 & .081 \\
\hline \multicolumn{5}{|l|}{ East South Central } \\
\hline Alabama & .008 & .019 & .023 & .072 \\
\hline Kentucky & .0025 & .02 & .014 & .074 \\
\hline Mississippi & .012 & .026 & .03 & .082 \\
\hline Tennessee & .0029 & .015 & .015 & .065 \\
\hline \multicolumn{5}{|l|}{ West South Central } \\
\hline Arkansas & .005 & .022 & .025 & .076 \\
\hline Louisiana & .012 & .021 & .028 & .066 \\
\hline Oklahoma & .0044 & .025 & .026 & .074 \\
\hline Texas & .007 & .011 & .015 & .019 \\
\hline \multicolumn{5}{|l|}{ East North Central } \\
\hline Illinois & .0045 & .012 & .013 & .028 \\
\hline Indiana & .0027 & .02 & .021 & .058 \\
\hline Michigan & .0029 & .015 & .015 & .047 \\
\hline Ohio & .0023 & .015 & .016 & .05 \\
\hline Wisconsin & .0026 & .021 & 016 & .053 \\
\hline \multicolumn{5}{|l|}{ West North Central } \\
\hline Iowa & .0031 & .037 & .035 & .078 \\
\hline Kansas & .0047 & .034 & .036 & .076 \\
\hline Minnesota & .0035 & .025 & .022 & .053 \\
\hline Missouri & .0033 & .022 & .027 & .064 \\
\hline Nebraska & .0044 & .038 & .041 & .08 \\
\hline North Dakota & .0045 & .042 & .063 & .12 \\
\hline South Dakota & .0043 & .05 & .061 & .11 \\
\hline \multicolumn{5}{|l|}{ Mountain } \\
\hline Arizona & .0073 & .021 & .043 & .031 \\
\hline Colorado & .0069 & .023 & .042 & .036 \\
\hline Idaho & .0048 & .049 & .094 & .083 \\
\hline Montana & .0042 & .05 & .081 & .1 \\
\hline Nevada & .011 & .023 & .046 & .044 \\
\hline New Mexico & .019 & .023 & .058 & .037 \\
\hline Utah & .005 & .038 & .073 & .061 \\
\hline Wyoming & .012 & .058 & .11 & .1 \\
\hline \multicolumn{5}{|l|}{ Pacific } \\
\hline Alaska & .013 & .041 & .072 & .1 \\
\hline California & .0064 & .0072 & .021 & .013 \\
\hline Hawaii & .031 & .022 & .037 & .057 \\
\hline Oregon & .004 & .027 & .025 & .049 \\
\hline Washington & .004 & .02 & .024 & .043 \\
\hline
\end{tabular}


Table S.6 - Standard Errors of 2020 Estimates, after Calibration.

\begin{tabular}{|c|c|c|c|c|}
\hline & \multirow[b]{2}{*}{ White } & \multicolumn{3}{|c|}{ Non-Whites } \\
\hline & & All & Black & Hisp. \\
\hline \multicolumn{5}{|l|}{ New England } \\
\hline Connecticut & .0094 & .03 & .062 & .059 \\
\hline Maine & .0027 & .041 & .07 & .082 \\
\hline Massachusetts & .0053 & .022 & .045 & .042 \\
\hline New Hampshire & .0033 & .038 & .085 & .066 \\
\hline Rhode Island & .0073 & .035 & .061 & .07 \\
\hline Vermont & .0083 & .039 & .061 & .069 \\
\hline \multicolumn{5}{|l|}{ Middle Atlantic } \\
\hline New Jersey & .0074 & .015 & .026 & .036 \\
\hline New York & .0057 & .011 & .019 & .027 \\
\hline Pennsylvania & .0032 & .015 & .021 & .041 \\
\hline \multicolumn{5}{|l|}{ South Atlantic } \\
\hline Delaware & .014 & .033 & .053 & .076 \\
\hline Florida & .006 & .011 & .019 & .021 \\
\hline Georgia & .0077 & .011 & .015 & .05 \\
\hline Maryland & .0076 & .011 & .014 & .042 \\
\hline North Carolina & .0063 & .014 & .021 & .047 \\
\hline South Carolina & .0068 & .018 & .023 & .062 \\
\hline Virginia & .006 & .013 & .018 & .042 \\
\hline West Virginia & .0033 & .037 & .062 & .083 \\
\hline \multicolumn{5}{|l|}{ East South Central } \\
\hline Alabama & .01 & .023 & .03 & .063 \\
\hline Kentucky & .0038 & .032 & .047 & .077 \\
\hline Mississippi & .015 & .029 & .034 & .068 \\
\hline Tennessee & .0041 & .02 & .025 & .07 \\
\hline \multicolumn{5}{|l|}{ West South Central } \\
\hline Arkansas & .0067 & .027 & .042 & .076 \\
\hline Louisiana & .013 & .021 & .03 & .062 \\
\hline Oklahoma & .0049 & .026 & .049 & .07 \\
\hline Texas & .0071 & .01 & .019 & .018 \\
\hline \multicolumn{5}{|l|}{ East North Central } \\
\hline Illinois & .005 & .014 & .015 & .036 \\
\hline Indiana & .0034 & .024 & .038 & .054 \\
\hline Michigan & .0035 & .016 & .02 & .049 \\
\hline Ohio & .0026 & .017 & .023 & .05 \\
\hline Wisconsin & .0031 & .022 & .032 & .054 \\
\hline \multicolumn{5}{|c|}{ West North Central } \\
\hline Iowa & .0031 & .035 & .064 & .075 \\
\hline Kansas & .006 & .032 & .067 & .067 \\
\hline Minnesota & .0043 & .025 & .049 & .052 \\
\hline Missouri & .0041 & .027 & .04 & .059 \\
\hline Nebraska & .0065 & .036 & .079 & .073 \\
\hline North Dakota & .0073 & .049 & .12 & .098 \\
\hline South Dakota & .005 & .045 & .11 & .087 \\
\hline \multicolumn{5}{|l|}{ Mountain } \\
\hline Arizona & .0089 & .018 & .047 & .033 \\
\hline Colorado & .0074 & .02 & .05 & .036 \\
\hline Idaho & .0062 & .037 & .11 & .066 \\
\hline Montana & .0056 & .049 & .12 & .088 \\
\hline Nevada & .014 & .02 & .056 & .051 \\
\hline New Mexico & .019 & .018 & .079 & .035 \\
\hline Utah & .0076 & .033 & .099 & .061 \\
\hline Wyoming & .014 & .048 & .13 & .082 \\
\hline \multicolumn{5}{|l|}{ Pacific } \\
\hline Alaska & .014 & .038 & .078 & .083 \\
\hline California & .0067 & .0065 & .022 & .013 \\
\hline Hawaii & .029 & .017 & .071 & .057 \\
\hline Oregon & .0048 & .025 & .043 & .046 \\
\hline Washington & .0051 & .019 & .036 & .044 \\
\hline
\end{tabular}




\section{Congressional District Estimates}

Tables S.7 and S.8 shows the estimated Trump vote within each in each congressional district. For example, the first number in the table means that 62 percent of all (election participating, two-party) Whites in Alaska's at-large congressional district are estimated to have voted for Trump over Clinton in 2016.

The CD-level estimates are calibrated to the actual election result so can be interpreted as the actual two-party Trump vote in that CD. Among non-Whites, we provide an "All" (non-Whites) aggregate as well.

Table S.7 - Point Estimates of 2016 Two-Party Vote for the Republican Presidential Candidate, by Race by CD

\begin{tabular}{|c|c|c|c|c|c|}
\hline & \multicolumn{4}{|c|}{ Non-Whites } & \multirow[b]{2}{*}{ All } \\
\hline & White & All & Black & Hisp. & \\
\hline All of Alaska: AK-01 & 62 & 47 & 16 & 45 & 59 \\
\hline Greater Mobile: AL-01 & 83 & 18 & 7 & (64) & 65 \\
\hline Southeastern Alabama: AL-02 & 87 & 16 & 9 & (67) & 67 \\
\hline Eastern Alabama: AL-03 & 85 & 16 & 8 & $(65)$ & 67 \\
\hline North-central Alabama: AL-04 & 87 & 41 & 8 & 69 & 83 \\
\hline Northern Alabama: AL-05 & 78 & 22 & 5 & 53 & 68 \\
\hline Birmingham suburbs: AL-06 & 84 & 28 & 7 & 60 & 73 \\
\hline Birmingham and the Black Belt: AL-07 & 66 & 8 & 5 & $(40)$ & 29 \\
\hline Northeastern Arkansas: AR-01 & 77 & 19 & 9 & $(55)$ & 69 \\
\hline Greater Little Rock: AR-02 & 68 & 15 & 6 & 42 & 56 \\
\hline Northwest Arkansas: AR-03 & 71 & 44 & 6 & 43 & 67 \\
\hline Southern and western Arkansas: AR-04 & 79 & 21 & 9 & 52 & 68 \\
\hline Northeastern Arizona: AZ-01 & 59 & 33 & $(15)$ & 24 & 51 \\
\hline Southeastern Arizona and eastern Tucson area: AZ-02 & 55 & 26 & 13 & 21 & 48 \\
\hline Southwestern Arizona and western Tucson area: AZ-03 & 50 & 20 & 12 & 15 & 35 \\
\hline North-central Arizona and Phoenix exurbs: AZ-04 & 75 & 47 & $(24)$ & 44 & 71 \\
\hline Phoenix suburbs of Mesa and Gilbert: AZ-05 & 66 & 38 & $(19)$ & 33 & 62 \\
\hline Scottsdale and North Phoenix: AZ-06 & 59 & 36 & $(15)$ & 34 & 56 \\
\hline Downtown and West Phoenix: AZ-07 & 36 & 14 & 7 & 10 & 24 \\
\hline Western suburbs of Phoenix: AZ-08 & 67 & 36 & 18 & 33 & 61 \\
\hline Central Phoenix and eastern suburbs: AZ-09 & 48 & 22 & 10 & 17 & 42 \\
\hline Northeastern California: CA-01 & 63 & 44 & $(18)$ & 41 & 61 \\
\hline Northern California coast: CA-02 & 27 & 19 & $(5)$ & 17 & 26 \\
\hline Southern Sacramento Valley: CA-03 & 51 & 31 & 13 & 31 & 44 \\
\hline Northern Sacramento suburbs and Sierra Nevada foothi...: CA-04 & 60 & 45 & $(17)$ & 41 & 58 \\
\hline Wine country: CA-05 & 31 & 18 & 6 & 17 & 26 \\
\hline Sacramento: CA-06 & 34 & 17 & 7 & 17 & 26 \\
\hline Suburban Sacramento County: CA-07 & 49 & 34 & 12 & 40 & 44 \\
\hline Northern San Bernardino County and the High Desert: CA-08 & 68 & 41 & 23 & 40 & 58 \\
\hline Stockton area and eastern Contra Costa County: CA-09 & 51 & 29 & 12 & 25 & 41 \\
\hline
\end{tabular}


Table S.7 - Point Estimates of 2016 Two-Party Vote for the Republican Presidential Candidate, by Race by CD (continued)

\begin{tabular}{|c|c|c|c|c|c|}
\hline & \multicolumn{4}{|c|}{ Non-Whites } & \multirow[b]{2}{*}{ All } \\
\hline & White & All & Black & Hisp. & \\
\hline Modesto area: CA-10 & 57 & 35 & 14 & 32 & 49 \\
\hline Contra Costa County: CA-11 & 30 & 17 & 6 & 17 & 24 \\
\hline San Francisco: CA-12 & 12 & 6 & 2 & 7 & 9 \\
\hline Oakland area: CA-13 & 11 & 5 & 3 & 5 & 8 \\
\hline San Mateo County: CA-14 & 26 & 14 & 4 & 15 & 19 \\
\hline Eastern Alameda County: CA-15 & 34 & 19 & 7 & 20 & 26 \\
\hline Fresno area: CA-16 & 55 & 28 & 14 & 23 & 39 \\
\hline Northeast San Jose area: CA-17 & 31 & 16 & 6 & 18 & 22 \\
\hline Silicon Valley: CA-18 & 25 & 16 & $(5)$ & 16 & 22 \\
\hline San Jose: CA-19 & 32 & 18 & 6 & 16 & 23 \\
\hline Monterey Bay: CA-20 & 32 & 18 & $(6)$ & 14 & 25 \\
\hline Southern Central Valley and part of Bakersfield: CA-21 & 59 & 32 & 17 & 28 & 42 \\
\hline Central Valley near Fresno and Tulare: CA-22 & 65 & 42 & 20 & 37 & 55 \\
\hline Bakersfield area: CA-23 & 70 & 47 & 26 & 45 & 62 \\
\hline San Luis Obispo and Santa Barbara: CA-24 & 45 & 27 & $(10)$ & 25 & 40 \\
\hline Northern Los Angeles County suburbs: CA-25 & 57 & 35 & 16 & 32 & 47 \\
\hline Ventura County: CA-26 & 46 & 27 & (11) & 24 & 39 \\
\hline San Gabriel Valley: CA-27 & 42 & 23 & 10 & 24 & 30 \\
\hline Burbank and Glendale: CA-28 & 27 & 17 & 5 & 16 & 24 \\
\hline East San Fernando Valley: CA-29 & 28 & 13 & 7 & 11 & 18 \\
\hline West San Fernando Valley: CA-30 & 32 & 19 & 6 & 17 & 27 \\
\hline San Bernardino area: CA-31 & 54 & 29 & 15 & 27 & 39 \\
\hline East San Gabriel Valley: CA-32 & 46 & 24 & 10 & 19 & 30 \\
\hline Coastal West Side of Los Angeles: CA-33 & 31 & 22 & 5 & 26 & 28 \\
\hline Downtown Los Angeles: CA-34 & 22 & 10 & 4 & 8 & 12 \\
\hline Southwest San Bernardino County and Pomona: CA-35 & 47 & 23 & 12 & 19 & 29 \\
\hline Eastern Riverside County: CA-36 & 55 & 30 & 14 & 25 & 46 \\
\hline Culver City area of Los Angeles: CA-37 & 16 & 8 & 4 & 9 & 11 \\
\hline Southeastern Los Angeles County: CA-38 & 46 & 24 & 10 & 21 & 29 \\
\hline San Gabriel Valley and northern Orange County: CA-39 & 58 & 36 & 16 & 32 & 46 \\
\hline East Los Angeles: CA-40 & 31 & 12 & 5 & 10 & 14 \\
\hline Riverside and Moreno Valley: CA-41 & 52 & 27 & 13 & 23 & 36 \\
\hline Southwestern Riverside County: CA- 42 & 66 & 44 & 22 & 40 & 57 \\
\hline Inland cities south of Los Angeles: CA-43 & 31 & 14 & 8 & 13 & 18 \\
\hline South Los Angeles, including Compton: CA- 44 & 31 & 11 & 6 & 9 & 13 \\
\hline Irvine area of Orange County: CA- 45 & 53 & 36 & (14) & 32 & 47 \\
\hline Santa Ana and the Anaheim area of Orange County: CA-46 & 43 & 23 & 9 & 20 & 30 \\
\hline Long Beach area: CA-47 & 43 & 24 & 10 & 24 & 33 \\
\hline Coastal Orange County: CA-48 & 53 & 41 & $(14)$ & 42 & 49 \\
\hline Southern Orange and northern San Diego Counties: CA-49 & 50 & 35 & (12) & 34 & 46 \\
\hline Inland San Diego County: CA-50 & 63 & 46 & 19 & 45 & 58 \\
\hline South San Diego and Imperial County: CA-51 & 39 & 20 & 8 & 19 & 24 \\
\hline Suburban San Diego: CA-52 & 42 & 28 & 10 & 24 & 38 \\
\hline Eastern San Diego: CA-53 & 39 & 23 & 9 & 23 & 32 \\
\hline
\end{tabular}


Table S.7 - Point Estimates of 2016 Two-Party Vote for the Republican Presidential Candidate, by Race by CD (continued)

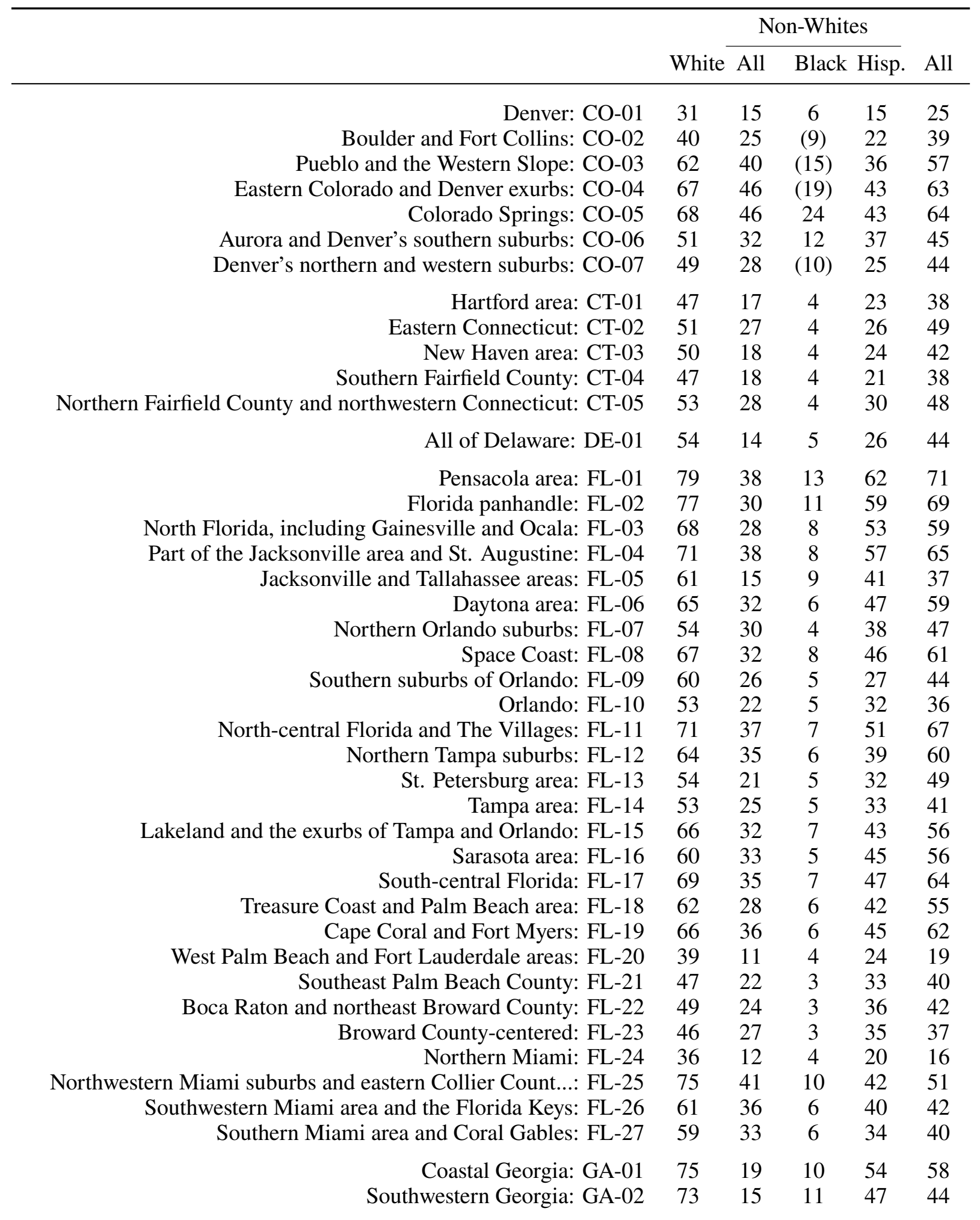


Table S.7 - Point Estimates of 2016 Two-Party Vote for the Republican Presidential Candidate, by Race by CD (continued)

\begin{tabular}{|c|c|c|c|c|c|}
\hline & \multicolumn{4}{|c|}{ Non-Whites } & \multirow[b]{2}{*}{ All } \\
\hline & White & \multicolumn{3}{|c|}{ Black Hisp. } & \\
\hline Southwestern Atlanta exurbs: GA-03 & 80 & 26 & 14 & 59 & 67 \\
\hline Eastern Atlanta suburbs: GA-04 & 51 & 10 & 5 & 27 & 23 \\
\hline Downtown Atlanta: GA-05 & 28 & 4 & 2 & 14 & 13 \\
\hline Northern Atlanta suburbs: GA-06 & 62 & 29 & 6 & 37 & 51 \\
\hline Northeastern Atlanta suburbs: GA-07 & 71 & 32 & 8 & 41 & 54 \\
\hline South-central Georgia: GA-08 & 83 & 24 & 15 & 65 & 65 \\
\hline Northeastern Georgia: GA-09 & 85 & 45 & 14 & 64 & 81 \\
\hline East-Central Georgia: GA-10 & 78 & 23 & 12 & 58 & 63 \\
\hline Northwestern Atlanta suburbs and exurbs: GA-11 & 75 & 31 & 8 & 47 & 63 \\
\hline Augusta and southeastern Georgia: GA-12 & 78 & 21 & 14 & 56 & 59 \\
\hline Southwestern Atlanta suburbs: GA-13 & 59 & 12 & 6 & 34 & 28 \\
\hline Northwestern Georgia: GA-14 & 84 & 38 & 12 & 63 & 78 \\
\hline Honolulu: HI-01 & 46 & 26 & 10 & 28 & 33 \\
\hline Northern Oahu and all other islands: HI-02 & 40 & 25 & (6) & 19 & 33 \\
\hline Northeastern Iowa: IA-01 & 54 & 30 & 6 & $(38)$ & 52 \\
\hline Southeastern Iowa: IA-02 & 55 & 31 & 6 & 39 & 53 \\
\hline Des Moines and southwestern Iowa: IA-03 & 54 & 33 & 6 & 43 & 52 \\
\hline Northwestern Iowa: IA-04 & 66 & 47 & (9) & 50 & 65 \\
\hline Idaho Panhandle and western Boise area: ID-01 & 72 & 63 & $(27)$ & 56 & 72 \\
\hline Boise and Eastern Idaho: ID-02 & 66 & 56 & $(22)$ & 52 & 65 \\
\hline South Side Chicago and southern suburbs: IL-01 & 42 & 9 & 6 & 22 & 22 \\
\hline South Side Chicago and southwestern suburbs: IL-02 & 40 & 8 & 5 & 19 & 20 \\
\hline Southwestern Chicago area: IL-03 & 50 & 23 & 4 & 21 & 42 \\
\hline Heavily Latino areas of Chicago's West and South sid...: IL-04 & 24 & 9 & 1 & 7 & 14 \\
\hline North Side Chicago: IL-05 & 29 & 14 & 2 & 12 & 26 \\
\hline Western Chicago suburbs: IL-06 & 50 & 30 & (4) & 28 & 47 \\
\hline West Side and Downtown Chicago: IL-07 & 19 & 4 & 2 & 9 & 10 \\
\hline Northwestern Chicago suburbs: IL-08 & 45 & 23 & 3 & 21 & 39 \\
\hline Northern Chicago Suburbs: IL-09 & 30 & 14 & 2 & 15 & 27 \\
\hline Chicago's North Shore suburbs: IL-10 & 40 & 19 & 3 & 19 & 35 \\
\hline Southwestern Chicago suburbs: IL-11 & 47 & 20 & 4 & 22 & 38 \\
\hline Southwestern Illinois: IL-12 & 65 & 17 & 9 & $(40)$ & 58 \\
\hline Central Illinois: IL-13 & 58 & 19 & 6 & $(32)$ & 53 \\
\hline Western Chicago exurbs: IL-14 & 56 & 31 & 5 & 28 & 52 \\
\hline East-central and southeastern Illinois: IL-15 & 77 & 32 & 12 & $(54)$ & 75 \\
\hline North-central Illinois: IL-16 & 62 & 31 & 6 & 37 & 60 \\
\hline Northwestern Illinois: IL-17 & 55 & 18 & 5 & 32 & 51 \\
\hline West-central Illinois: IL-18 & 67 & 33 & 8 & $(41)$ & 65 \\
\hline Northwestern Indiana: IN-01 & 52 & 18 & 6 & 27 & 44 \\
\hline North-central Indiana: IN-02 & 66 & 27 & 7 & 42 & 63 \\
\hline Northeastern Indiana: IN-03 & 72 & 33 & 10 & 53 & 69 \\
\hline West-central Indiana: IN-04 & 71 & 39 & 9 & 53 & 68 \\
\hline
\end{tabular}


Table S.7 - Point Estimates of 2016 Two-Party Vote for the Republican Presidential Candidate, by Race by CD (continued)

\begin{tabular}{|c|c|c|c|c|c|}
\hline & \multicolumn{4}{|c|}{ Non-Whites } & \multirow[b]{2}{*}{ All } \\
\hline & White & All & \multicolumn{2}{|c|}{ Black Hisp. } & \\
\hline Northern Indianapolis suburbs: IN-05 & 61 & 22 & 6 & 41 & 57 \\
\hline Southeastern Indiana: IN-06 & 73 & 35 & $(10)$ & $(53)$ & 72 \\
\hline Indianapolis: IN-07 & 47 & 13 & 5 & 29 & 38 \\
\hline Southwestern Indiana: IN-08 & 70 & 29 & 9 & $(52)$ & 68 \\
\hline South-central Indiana and southern Indianapolis suburbs: IN-09 & 66 & 34 & 8 & $(44)$ & 64 \\
\hline Western Kansas: KS-01 & 76 & 53 & $(14)$ & 55 & 74 \\
\hline Topeka, Lawrence, and eastern rural Kansas: KS-02 & 62 & 36 & 8 & 37 & 60 \\
\hline Suburban Kansas City area: KS-03 & 54 & 28 & 5 & 37 & 50 \\
\hline Wichita area: KS-04 & 68 & 42 & 10 & 47 & 65 \\
\hline Western Kentucky: KY-01 & 80 & 26 & 5 & $(57)$ & 76 \\
\hline West-central Kentucky: KY-02 & 75 & 31 & 4 & $(51)$ & 71 \\
\hline Louisville: KY-03 & 53 & 11 & 2 & 27 & 42 \\
\hline Cincinnati suburbs and northern Kentucky border area: KY-04 & 72 & 32 & 4 & $(43)$ & 69 \\
\hline Appalachian Kentucky: KY-05 & 83 & 41 & $(7)$ & $(67)$ & 82 \\
\hline Greater Lexington area: KY-06 & 63 & 23 & 2 & 38 & 58 \\
\hline Suburban New Orleans: LA-01 & 81 & 39 & 11 & 58 & 72 \\
\hline New Orleans and Baton Rouge: LA-02 & 50 & 10 & 6 & 24 & 23 \\
\hline Southwestern Louisiana: LA-03 & 85 & 28 & 16 & 65 & 70 \\
\hline Northwestern Louisiana: LA-04 & 83 & 24 & 16 & 63 & 63 \\
\hline Northeastern Louisiana: LA-05 & 87 & 25 & 19 & $(69)$ & 66 \\
\hline Baton Rouge suburbs: LA-06 & 82 & 28 & 14 & 58 & 68 \\
\hline Springfield area and the Berkshires: MA-01 & 44 & 17 & 4 & 16 & 39 \\
\hline Worcester area and upper Pioneer Valley: MA- 02 & 42 & 21 & 3 & 18 & 40 \\
\hline Lowell area and the Merrimack Valley: MA-03 & 43 & 22 & (3) & 17 & 38 \\
\hline Western Boston suburbs and Bristol County: MA-04 & 39 & 22 & (3) & 19 & 38 \\
\hline Boston's northern and outer western suburbs: MA-05 & 31 & 13 & 2 & 11 & 27 \\
\hline North Shore: MA-06 & 44 & 21 & (3) & 17 & 41 \\
\hline Central Boston area: MA-07 & 18 & 6 & 1 & 6 & 13 \\
\hline Southern Boston suburbs: MA-08 & 41 & 17 & 3 & 20 & 37 \\
\hline Cape Cod and South Shore: MA-09 & 46 & 25 & (3) & $(19)$ & 45 \\
\hline Eastern Shore and Baltimore exurbs: MD-01 & 71 & 22 & 9 & $(45)$ & 65 \\
\hline Suburban Baltimore area: MD-02 & 51 & 12 & 5 & 29 & 38 \\
\hline Baltimore suburbs to Annapolis to D.C. suburbs: MD-03 & 43 & 13 & 4 & 22 & 34 \\
\hline Prince George's County D.C. suburbs: MD-04 & 43 & 11 & 6 & 20 & 21 \\
\hline Southern Maryland and outer Prince George's County: MD-05 & 53 & 14 & 7 & 29 & 34 \\
\hline Western Maryland and Montgomery County D.C. suburbs: MD-06 & 50 & 23 & 4 & 29 & 42 \\
\hline Baltimore and western suburbs: MD-07 & 40 & 8 & 6 & 20 & 21 \\
\hline Montgomery County: MD-08 & 41 & 16 & 3 & 21 & 32 \\
\hline Portland and Augusta: ME-01 & 43 & 27 & (3) & $(22)$ & 42 \\
\hline Northern Maine: ME-02 & 56 & 40 & $(5)$ & $(31)$ & 56 \\
\hline Upper Peninsula and northern Lower Peninsula: MI-01 & 62 & 40 & (7) & $(37)$ & 62 \\
\hline
\end{tabular}


Table S.7 - Point Estimates of 2016 Two-Party Vote for the Republican Presidential Candidate, by Race by CD (continued)

\begin{tabular}{|c|c|c|c|c|c|}
\hline & \multicolumn{4}{|c|}{ Non-Whites } & \multirow[b]{2}{*}{ All } \\
\hline & White & All & Black & Hisp. & \\
\hline Western Michigan coast: MI-02 & 64 & 32 & 7 & 38 & 60 \\
\hline Grand Rapids area: MI-03 & 59 & 25 & 6 & 36 & 55 \\
\hline Central Michigan: MI-04 & 65 & 35 & $(7)$ & $(36)$ & 63 \\
\hline Flint, Saginaw, and Bay City: MI-05 & 55 & 13 & 5 & 32 & 48 \\
\hline Southwestern Michigan: MI-06 & 58 & 23 & 6 & 34 & 55 \\
\hline South-central Michigan: MI-07 & 61 & 28 & 6 & $(38)$ & 59 \\
\hline Lansing and northwestern Detroit exurbs: MI-08 & 57 & 27 & 5 & 30 & 54 \\
\hline Northern Detroit suburbs: MI-09 & 51 & 16 & 4 & $(28)$ & 46 \\
\hline Northern Macomb County and the "Thumb" region: MI-10 & 69 & 37 & $(8)$ & $(43)$ & 67 \\
\hline Northwestern Detroit suburbs: MI-11 & 56 & 31 & 5 & (34) & 53 \\
\hline Ann Arbor and Dearborn: MI-12 & 40 & 16 & 3 & 20 & 37 \\
\hline Western Detroit: MI-13 & 33 & 6 & 4 & 15 & 19 \\
\hline Eastern Detroit to Pontiac: MI-14 & 38 & 7 & 5 & 18 & 19 \\
\hline Southern Minnesota: MN-01 & 60 & 38 & $(9)$ & 37 & 58 \\
\hline Southern Twin Cities suburbs: MN-02 & 53 & 33 & 6 & 38 & 51 \\
\hline Western Twin Cities suburbs: MN-03 & 48 & 25 & 4 & 25 & 45 \\
\hline St. Paul: MN-04 & 38 & 19 & 4 & 20 & 34 \\
\hline Minneapolis: MN-05 & 24 & 9 & 2 & 11 & 20 \\
\hline Northern Twin Cities exurbs: MN-06 & 65 & 41 & $(12)$ & $(43)$ & 64 \\
\hline Western Minnesota: MN-07 & 68 & 49 & $(10)$ & $(45)$ & 67 \\
\hline Iron Range: $\mathrm{MN}-08$ & 59 & 43 & $(8)$ & $(35)$ & 59 \\
\hline St. Louis and northwestern suburbs: MO-01 & 32 & 6 & 4 & 19 & 20 \\
\hline $\begin{array}{l}\text { Suburban St. Louis: MO-02 } \\
\text { S }\end{array}$ & 58 & 34 & 7 & $(41)$ & 56 \\
\hline East-central Missouri: MO-03 & 72 & 37 & 11 & $(55)$ & 71 \\
\hline West-central Missouri: MO-04 & 72 & 36 & 10 & $(54)$ & 69 \\
\hline Kansas City area: MO-05 & 51 & 16 & 6 & 31 & 43 \\
\hline Northern Missouri: MO-06 & 69 & 35 & 10 & $(52)$ & 67 \\
\hline Southwestern Missouri: MO-07 & 76 & 51 & $(13)$ & (57) & 74 \\
\hline Southeastern Missouri: MO-08 & 81 & 37 & 16 & $(61)$ & 79 \\
\hline Northeastern Mississippi: MS-01 & 85 & 16 & 10 & $(61)$ & 67 \\
\hline Mississippi Delta and Jackson: MS-02 & 77 & 12 & 10 & $(53)$ & 36 \\
\hline Southwestern and eastern Mississippi: MS-03 & 85 & 17 & 11 & $(63)$ & 63 \\
\hline Gulf Coast: MS-04 & 86 & 20 & 9 & $(62)$ & 72 \\
\hline All of Montana: MT-01 & 62 & 54 & $(16)$ & $(38)$ & 62 \\
\hline Durham and northeastern North Carolina: NC-01 & 53 & 11 & 7 & 31 & 31 \\
\hline Raleigh exurbs: NC-02 & 68 & 24 & 10 & 45 & 55 \\
\hline Eastern North Carolina coast: NC-03 & 75 & 21 & 12 & 51 & 62 \\
\hline Raleigh, Cary, Chapel Hill: NC-04 & 41 & 11 & 3 & 21 & 30 \\
\hline Winston-Salem and northwestern North Carolina: NC-05 & 68 & 22 & 9 & 42 & 59 \\
\hline Part of Greensboro and rural Piedmont: NC-06 & 71 & 22 & 9 & 47 & 58 \\
\hline Southeastern North Carolina: NC-07 & 71 & 21 & 10 & 51 & 59 \\
\hline Charlotte suburbs to Fayetteville: NC-08 & 72 & 24 & 12 & 48 & 58 \\
\hline
\end{tabular}


Table S.7 - Point Estimates of 2016 Two-Party Vote for the Republican Presidential Candidate, by Race by CD (continued)

\begin{tabular}{|c|c|c|c|c|c|}
\hline & \multicolumn{4}{|c|}{ Non-Whites } & \multirow[b]{2}{*}{ All } \\
\hline & White & All & Black & Hisp. & \\
\hline South Charlotte to suburban Fayetteville: NC-09 & 69 & 28 & 9 & 48 & 56 \\
\hline Asheville and southwestern Piedmont: NC-10 & 70 & 25 & 11 & 47 & 63 \\
\hline Appalachian North Carolina: NC-11 & 68 & 35 & 7 & 47 & 65 \\
\hline Charlotte: NC-12 & 48 & 12 & 5 & 26 & 30 \\
\hline Greensboro and rural western Piedmont: NC-13 & 69 & 20 & 9 & 43 & 55 \\
\hline All of North Dakota: ND-01 & 71 & 55 & $(12)$ & $(52)$ & 70 \\
\hline Lincoln and rural eastern Nebraska: NE-01 & 63 & 43 & $(8)$ & 44 & 62 \\
\hline Greater Omaha area: NE-02 & 56 & 27 & 7 & 36 & 52 \\
\hline Western Nebraska: NE-03 & 80 & 63 & $(16)$ & 61 & 79 \\
\hline Eastern New Hampshire: NH-01 & 52 & 32 & $(5)$ & $(25)$ & 51 \\
\hline Western and northern New Hampshire: NH-02 & 50 & 32 & (4) & $(25)$ & 49 \\
\hline Inner Philadelphia suburbs: NJ-01 & 47 & 16 & 4 & 22 & 38 \\
\hline Southern New Jersey coast: NJ-02 & 62 & 25 & 7 & 31 & 53 \\
\hline Philadelphia suburbs and central Jersey Shore: NJ-03 & 60 & 23 & 6 & 31 & 54 \\
\hline Monmouth County area: NJ-04 & 63 & 29 & 7 & 35 & 58 \\
\hline Northern Bergen County and northwestern exurbs: NJ-05 & 58 & 30 & 5 & 29 & 51 \\
\hline Northern Middlesex County and northern Jersey Shore: NJ-06 & 53 & 24 & 5 & 26 & 42 \\
\hline Hunterdon County and New York City's western exurbs: NJ-07 & 56 & 28 & 5 & 28 & 50 \\
\hline Jersey City and inner New York City suburbs: NJ-08 & 36 & 15 & 2 & 15 & 22 \\
\hline Paterson and inner New York City suburbs: NJ-09 & 49 & 21 & 4 & 19 & 34 \\
\hline Newark area: NJ-10 & 30 & 7 & 3 & 14 & 13 \\
\hline Morris County area: NJ-11 & 56 & 29 & 4 & 28 & 51 \\
\hline Trenton and southern Middlesex County: NJ-12 & 45 & 16 & 4 & 19 & 33 \\
\hline Albuquerque area: NM-01 & 50 & 30 & $(11)$ & 28 & 41 \\
\hline Southern New Mexico: NM-02 & 65 & 44 & $(18)$ & 42 & 56 \\
\hline Northern New Mexico: NM-03 & 52 & 32 & $(14)$ & 28 & 42 \\
\hline Las Vegas: NV-01 & 46 & 21 & 8 & 17 & 35 \\
\hline Northern Nevada: NV-02 & 62 & 40 & $(14)$ & 33 & 57 \\
\hline Southern Las Vegas suburbs: NV-03 & 56 & 37 & 12 & 36 & 51 \\
\hline Northern Las Vegas suburbs and rural central Nevada: NV-04 & 58 & 30 & 14 & 30 & 48 \\
\hline Eastern Suffolk County: NY-01 & 62 & 30 & 6 & 32 & 57 \\
\hline Southern Long Island: NY-02 & 65 & 31 & 8 & 33 & 55 \\
\hline Northern Long Island: NY-03 & 52 & 32 & 4 & 30 & 47 \\
\hline Long Island: NY-04 & 57 & 28 & 6 & 33 & 45 \\
\hline Southeastern Queens: NY-05 & 34 & 10 & 5 & 15 & 13 \\
\hline Northeastern Queens: NY-06 & 42 & 23 & 3 & 24 & 33 \\
\hline Heavily Latino parts of northern Brooklyn and southw...: NY-07 & 18 & 7 & 1 & 7 & 11 \\
\hline Eastern Brooklyn: NY-08 & 29 & 7 & 3 & 11 & 14 \\
\hline Central Brooklyn: NY-09 & 28 & 7 & 3 & 14 & 15 \\
\hline West Side of Manhattan and part of southern Brooklyn: NY-10 & 23 & 10 & 1 & 9 & 20 \\
\hline Staten Island and part of southern Brooklyn: NY-11 & 62 & 35 & 6 & 41 & 55 \\
\hline
\end{tabular}


Table S.7 - Point Estimates of 2016 Two-Party Vote for the Republican Presidential Candidate, by Race by CD (continued)

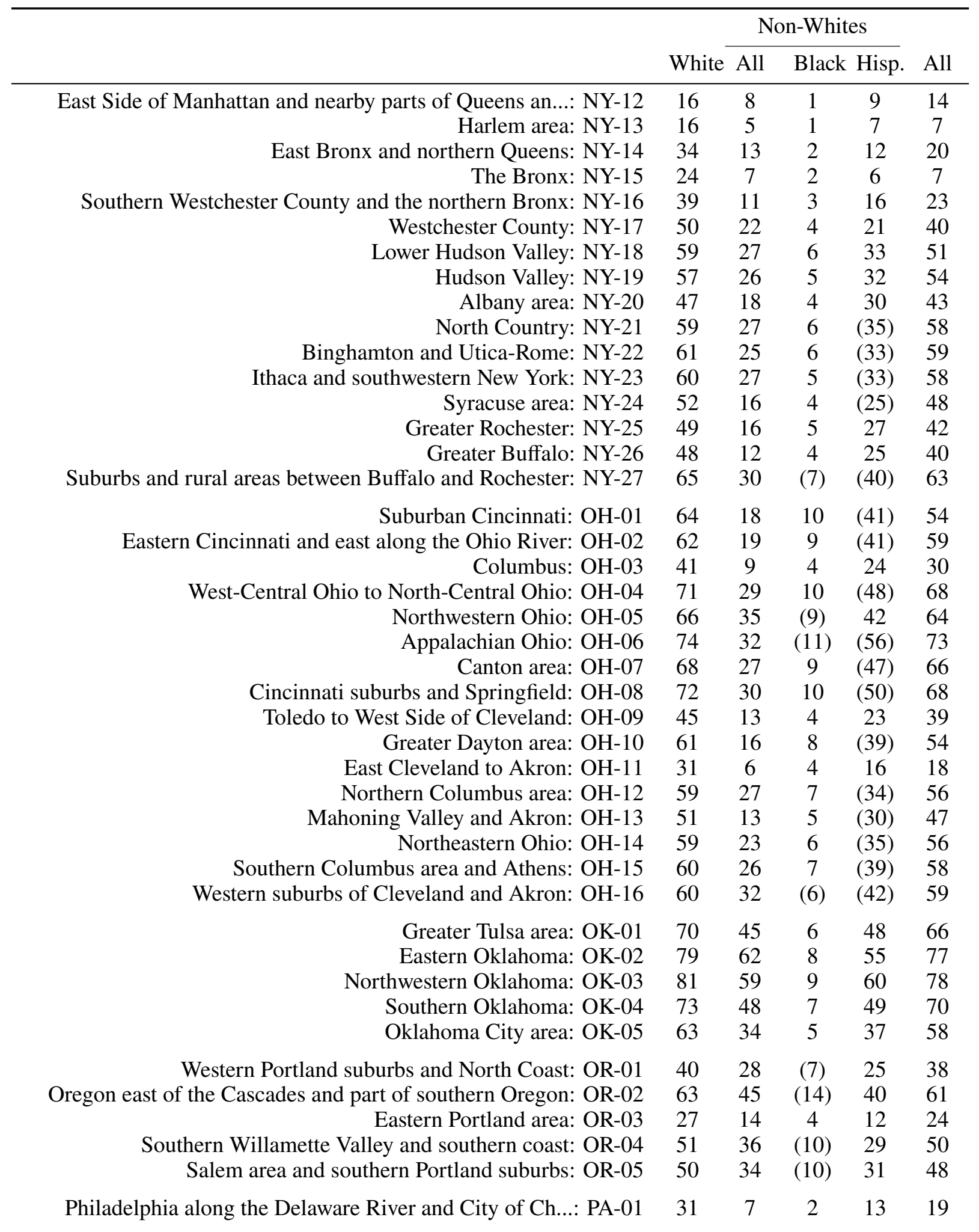


Table S.7 - Point Estimates of 2016 Two-Party Vote for the Republican Presidential Candidate, by Race by CD (continued)

\begin{tabular}{|c|c|c|c|c|c|}
\hline & \multicolumn{4}{|c|}{ Non-Whites } & \multirow[b]{2}{*}{ All } \\
\hline & White & All & Black & Hisp. & \\
\hline Philadelphia City center and Chestnut Hill sububrs: PA-02 & 20 & 3 & 2 & 9 & 9 \\
\hline Erie and northwestern Pennsylvania: PA-03 & 66 & 23 & 6 & $(45)$ & 64 \\
\hline Harrisburg and York: PA-04 & 66 & 26 & 7 & 40 & 62 \\
\hline North-central Pennsylvania through Centre County: PA-05 & 67 & 29 & 7 & $(42)$ & 65 \\
\hline Philadelphia's Chester County suburbs and Reading su...: PA-06 & 53 & 24 & 4 & 29 & 50 \\
\hline Philadelphia's Delaware and Montgomery County suburbs: PA-07 & 53 & 21 & 4 & $(32)$ & 49 \\
\hline Philadelphia's Bucks County suburbs: PA-08 & 53 & 26 & 4 & 32 & 50 \\
\hline South-central Pennsylvania: PA-09 & 74 & 30 & 10 & $(47)$ & 72 \\
\hline Williamsport area and northeastern Pennsylvania: PA-10 & 71 & 30 & 8 & $(46)$ & 69 \\
\hline Coal Region between Wilkes-Barre and Harrisburg: PA-11 & 66 & 27 & 7 & 39 & 63 \\
\hline Beaver County through Pittsburgh's North Hills to Jo...: PA-12 & 63 & 23 & 6 & $(36)$ & 61 \\
\hline Northeast Philadelphia and Norristown: PA-13 & 42 & 14 & 3 & 21 & 33 \\
\hline Pittsburgh: PA-14 & 39 & 7 & 3 & $(21)$ & 32 \\
\hline Lehigh Valley stretched to Susquehanna River: PA-15 & 59 & 29 & 5 & 31 & 54 \\
\hline Reading, Lancaster, and Coatesville: PA-16 & 59 & 29 & 5 & 36 & 54 \\
\hline Scranton/Wilkes-Barre and the Slate Belt: PA-17 & 59 & 23 & 6 & 32 & 56 \\
\hline Pittsburgh's South and West Hills, Washington, Westm...: PA-18 & 62 & 26 & $(6)$ & $(37)$ & 61 \\
\hline Part of Providence and eastern Rhode Island: RI-01 & 41 & 18 & 3 & 19 & 37 \\
\hline Part of Providence and western Rhode Island: RI-02 & 49 & 25 & 4 & 23 & 47 \\
\hline Charleston and coastal South Carolina: SC-01 & 68 & 17 & 8 & 47 & 57 \\
\hline Augusta and Columbia suburbs: SC-02 & 73 & 19 & 10 & 53 & 60 \\
\hline Northwestern South Carolina: SC-03 & 81 & 22 & 14 & (57) & 70 \\
\hline Greenville-Spartanburg area: SC-04 & 75 & 23 & 11 & 54 & 64 \\
\hline Southern Charlotte suburbs and exurbs: SC-05 & 75 & 18 & 13 & $(54)$ & 60 \\
\hline Black Belt, Columbia, and Charleston: SC-06 & 57 & 10 & 8 & 32 & 32 \\
\hline Northeastern South Carolina and the Myrtle Beach area: SC-07 & 76 & 16 & 11 & $(52)$ & 60 \\
\hline All of South Dakota: SD-01 & 67 & 53 & $(10)$ & $(47)$ & 66 \\
\hline Northeastern Tennessee: TN-01 & 82 & 38 & (6) & $(57)$ & 80 \\
\hline Knoxville area: $\mathrm{TN}-02$ & 73 & 26 & 3 & $(51)$ & 69 \\
\hline Chattanooga area: $\mathrm{TN}-03$ & 74 & 18 & 4 & $(45)$ & 69 \\
\hline Southern part of Middle Tennessee: TN-04 & 77 & 27 & 4 & 57 & 72 \\
\hline Nashville: TN-05 & 51 & 10 & 2 & 26 & 41 \\
\hline Nashville's eastern suburbs and northern Middle Tenn...: TN-06 & 78 & 34 & 5 & $(57)$ & 76 \\
\hline Nashville's southern suburbs and western Middle Tenn...: TN-07 & 77 & 24 & 5 & 55 & 71 \\
\hline West Tennessee: TN-08 & 80 & 17 & 7 & $(60)$ & 69 \\
\hline Memphis: TN-09 & 47 & 5 & 2 & 24 & 21 \\
\hline Tyler and East Texas: TX-01 & 85 & 38 & 16 & 67 & 75 \\
\hline Northern Houston and part of west Houston: TX-02 & 65 & 39 & 5 & 46 & 55 \\
\hline Collin County: TX-03 & 66 & 36 & 5 & 46 & 58 \\
\hline Northeastern Texas: TX-04 & 84 & 45 & 15 & 68 & 78 \\
\hline Eastern edge of Dallas and rural areas to its east: TX-05 & 75 & 36 & 8 & 52 & 65 \\
\hline Arlington and rural areas south of Dallas: TX-06 & 70 & 31 & 7 & 48 & 57 \\
\hline
\end{tabular}


Table S.7 - Point Estimates of 2016 Two-Party Vote for the Republican Presidential Candidate, by Race by CD (continued)

\begin{tabular}{|c|c|c|c|c|c|}
\hline & \multicolumn{4}{|c|}{ Non-Whites } & \multirow[b]{2}{*}{ All } \\
\hline & White & All & Black & Hisp. & \\
\hline West Houston: TX-07 & 62 & 30 & 4 & 37 & 50 \\
\hline Suburbs and exurbs north of Houston: TX-08 & 82 & 50 & 12 & 64 & 76 \\
\hline Southwest Houston: TX-09 & 41 & 13 & 3 & 19 & 19 \\
\hline Austin to western Houston: TX-10 & 65 & 35 & 6 & 42 & 55 \\
\hline Midland and San Angelo parts of rural west Texas: TX-11 & 87 & 63 & 14 & 67 & 81 \\
\hline Parker and western Tarrant Counties: TX-12 & 73 & 42 & 8 & 51 & 66 \\
\hline Texas Panhandle: TX-13 & 88 & 62 & 17 & 71 & 83 \\
\hline Galveston area: TX-14 & 74 & 32 & 9 & 50 & 61 \\
\hline McAllen in the Rio Grande Valley and rural counties ...: TX-15 & 65 & 32 & 5 & 30 & 42 \\
\hline El Paso: TX-16 & 54 & 21 & 3 & 19 & 29 \\
\hline College Station, Waco, and a slice of Austin suburbs: TX-17 & 69 & 35 & 7 & 49 & 60 \\
\hline Heavily black parts of central Houston: TX-18 & 40 & 13 & 3 & 21 & 21 \\
\hline Lubbock and rural West Texas: TX-19 & 84 & 56 & 13 & 62 & 76 \\
\hline Downtown San Antonio: TX-20 & 55 & 26 & 3 & 26 & 36 \\
\hline Parts of Austin and San Antonio connected by Texas H...: TX-21 & 63 & 37 & 4 & 37 & 56 \\
\hline Southern Houston suburbs: TX-22 & 68 & 39 & 6 & 47 & 54 \\
\hline El Paso to San Antonio: TX-23 & 68 & 37 & 6 & 36 & 49 \\
\hline Suburbs north of Dallas and Fort Worth: TX-24 & 65 & 33 & 6 & 35 & 54 \\
\hline Part of Austin and rural areas north toward Dallas-F...: TX-25 & 64 & 32 & 5 & 38 & 58 \\
\hline Denton County: TX-26 & 71 & 40 & 7 & 49 & 64 \\
\hline Corpus Christi and Victoria: TX-27 & 74 & 46 & 7 & 49 & 63 \\
\hline Laredo area: TX-28 & 62 & 30 & 4 & 30 & 40 \\
\hline Heavily Latino areas north and east of Downtown Houston: TX-29 & 52 & 19 & 3 & 20 & 27 \\
\hline Downtown and South Dallas: TX-30 & 41 & 11 & 3 & 19 & 19 \\
\hline Williamson and Bell Counties: TX-31 & 66 & 34 & 5 & 43 & 57 \\
\hline Suburban North Dallas: TX-32 & 60 & 28 & 5 & 34 & 49 \\
\hline Connects Downtown Fort Worth and western Dallas: TX-33 & 47 & 15 & 3 & 17 & 25 \\
\hline Brownsville in the Rio Grande Valley and rural count...: TX-34 & 63 & 29 & (4) & 28 & 39 \\
\hline San Antonio and heavily Latino areas of Austin: TX-35 & 47 & 22 & 3 & 23 & 33 \\
\hline Southern part of East Texas: TX-36 & 82 & 47 & 12 & 60 & 74 \\
\hline Ogden and northern Utah: UT-01 & 71 & 53 & $(23)$ & 46 & 69 \\
\hline Salt Lake City and southwestern Utah: UT-02 & 61 & 46 & $(16)$ & 39 & 59 \\
\hline Provo area and southeastern Utah: UT-03 & 69 & 50 & $(21)$ & 43 & 67 \\
\hline Southern Salt Lake County and rural areas to the south: UT-04 & 57 & 43 & $(15)$ & 32 & 55 \\
\hline Western Chesapeake Bay and exurbs of D.C. and Richmond: VA-01 & 68 & 27 & 8 & 48 & 57 \\
\hline Virginia Beach: VA-02 & 62 & 22 & 8 & 38 & 52 \\
\hline Hampton Roads: VA-03 & 56 & 12 & 8 & 33 & 34 \\
\hline Richmond and Southside Virginia: VA-04 & 59 & 13 & 9 & 39 & 39 \\
\hline Charlottesville and South-central Virginia: VA-05 & 66 & 15 & 7 & $(46)$ & 56 \\
\hline Shenandoah Valley: VA-06 & 69 & 24 & 8 & 51 & 63 \\
\hline Suburban Richmond: VA-07 & 65 & 23 & 7 & 49 & 54 \\
\hline Inner D.C. suburbs: VA-08 & 29 & 13 & 2 & 18 & 22 \\
\hline Virginia: VA-09 & 75 & 26 & 9 & $(52)$ & 72 \\
\hline Loudoun County and D.C. suburbs and exurbs: VA-10 & 52 & 31 & 4 & 35 & 45 \\
\hline
\end{tabular}


Table S.7 - Point Estimates of 2016 Two-Party Vote for the Republican Presidential Candidate, by Race by CD (continued)

\begin{tabular}{|c|c|c|c|c|c|}
\hline & \multicolumn{4}{|c|}{ Non-Whites } & \multirow[b]{2}{*}{ All } \\
\hline & White & All & Black & Hisp. & \\
\hline D.C. suburbs in Fairfax and Prince William Counties: VA-11 & 39 & 18 & 3 & 23 & 29 \\
\hline All of Vermont: VT-01 & 36 & 21 & (2) & $(15)$ & 35 \\
\hline Northern Seattle suburbs: WA-01 & 43 & 32 & $(8)$ & 32 & 41 \\
\hline Northern Puget Sound: WA-02 & 40 & 27 & (7) & 21 & 38 \\
\hline Vancouver and southwestern Washington: WA-03 & 56 & 41 & (12) & 34 & 54 \\
\hline Yakima and the Tri-Cities: WA-04 & 67 & 49 & $(16)$ & 45 & 63 \\
\hline Spokane area and rural eastern Washington: WA-05 & 59 & 44 & $(13)$ & 39 & 58 \\
\hline Olympic Peninsula and Tacoma: WA-06 & 45 & 30 & 9 & 29 & 44 \\
\hline Seattle: WA-07 & 15 & 8 & 1 & 7 & 13 \\
\hline Eastern Seattle suburbs and two rural counties east ...: WA-08 & 51 & 37 & $(10)$ & 36 & 49 \\
\hline Southeastern Seattle and the suburbs to its south an...: WA-09 & 30 & 17 & 5 & 17 & 25 \\
\hline Olympia area and Tacoma suburbs: WA-10 & 46 & 31 & 9 & 31 & 44 \\
\hline Southeastern Wisconsin: WI-01 & 59 & 33 & 6 & 41 & 56 \\
\hline Madison area: WI-02 & 33 & 15 & 2 & 17 & 31 \\
\hline Southwestern Wisconsin: WI-03 & 53 & 34 & $(5)$ & $(34)$ & 53 \\
\hline Milwaukee: WI-04 & 33 & 10 & 3 & 21 & 23 \\
\hline Milwaukee suburbs: WI-05 & 63 & 41 & (7) & 41 & 61 \\
\hline Fox River Valley and Sheboygan: WI-06 & 60 & 37 & (6) & $(42)$ & 59 \\
\hline Northwestern Wisconsin: WI-07 & 62 & 45 & (6) & $(43)$ & 61 \\
\hline Northeastern Wisconsin: WI-08 & 61 & 42 & (6) & (39) & 60 \\
\hline Northern West Virginia: WV-01 & 74 & 35 & (9) & $(57)$ & 72 \\
\hline Charleston to the Eastern Panhandle: WV-02 & 72 & 27 & 8 & $(51)$ & 69 \\
\hline Southern West Virginia: WV-03 & 78 & 28 & 11 & $(58)$ & 76 \\
\hline All of Wyoming: WY-01 & 77 & 63 & (27) & 59 & 76 \\
\hline National & 59 & 22 & 7 & 29 & 49 \\
\hline
\end{tabular}


Table S.8 - Point Estimates of 2020 Two-Party Vote for the Republican Presidential Candidate, by Race by CD

\begin{tabular}{|c|c|c|c|c|c|}
\hline & \multicolumn{4}{|c|}{ Non-Whites } & \multirow[b]{2}{*}{ All } \\
\hline & White & All & Black & Hisp. & \\
\hline All of Alaska: AK-01 & 58 & 48 & 17 & 46 & 55 \\
\hline Greater Mobile: AL-01 & 81 & 24 & 14 & (76) & 65 \\
\hline Southeastern Alabama: AL-02 & 84 & 24 & 15 & (76) & 65 \\
\hline Eastern Alabama: AL-03 & 81 & 23 & 15 & (74) & 66 \\
\hline North-central Alabama: AL-04 & 86 & 52 & 21 & 80 & 82 \\
\hline Northern Alabama: AL-05 & 73 & 31 & 15 & 62 & 64 \\
\hline Birmingham suburbs: AL-06 & 79 & 30 & 12 & 73 & 68 \\
\hline Birmingham and the Black Belt: AL-07 & 63 & 9 & 6 & $(54)$ & 29 \\
\hline Northeastern Arkansas: AR-01 & 79 & 27 & 15 & $(66)$ & 71 \\
\hline Greater Little Rock: AR-02 & 65 & 19 & 9 & 51 & 55 \\
\hline Northwest Arkansas: AR-03 & 67 & 49 & 10 & 53 & 64 \\
\hline Southern and western Arkansas: AR-04 & 79 & 27 & 15 & (66) & 70 \\
\hline Northeastern Arizona: AZ-01 & 55 & 41 & 19 & 40 & 49 \\
\hline Southeastern Arizona and eastern Tucson area: AZ-02 & 51 & 32 & 17 & 31 & 45 \\
\hline Southwestern Arizona and western Tucson area: AZ-03 & 44 & 32 & 13 & 31 & 36 \\
\hline North-central Arizona and Phoenix exurbs: AZ-04 & 71 & 58 & $(26)$ & 58 & 69 \\
\hline Phoenix suburbs of Mesa and Gilbert: AZ-05 & 62 & 45 & 20 & 45 & 58 \\
\hline Scottsdale and North Phoenix: AZ-06 & 56 & 39 & 14 & 40 & 52 \\
\hline Downtown and West Phoenix: AZ-07 & 33 & 21 & 7 & 22 & 25 \\
\hline Western suburbs of Phoenix: AZ-08 & 63 & 46 & 19 & 47 & 58 \\
\hline Central Phoenix and eastern suburbs: AZ-09 & 44 & 27 & 12 & 27 & 38 \\
\hline Northeastern California: CA-01 & 60 & 46 & $(20)$ & 47 & 58 \\
\hline Northern California coast: CA- 02 & 26 & 19 & $(6)$ & 19 & 25 \\
\hline Southern Sacramento Valley: CA-03 & 51 & 33 & 14 & 34 & 44 \\
\hline Northern Sacramento suburbs and Sierra Nevada foothi...: CA-04 & 57 & 46 & (19) & 46 & 55 \\
\hline Wine country: CA-05 & 31 & 19 & 6 & 19 & 26 \\
\hline Sacramento: CA-06 & 35 & 21 & 8 & 23 & 28 \\
\hline Suburban Sacramento County: CA-07 & 48 & 35 & 13 & 41 & 43 \\
\hline Northern San Bernardino County and the High Desert: CA-08 & 64 & 43 & 21 & 46 & 56 \\
\hline Stockton area and eastern Contra Costa County: CA-09 & 49 & 34 & 12 & 37 & 41 \\
\hline Modesto area: CA-10 & 54 & 41 & 15 & 42 & 49 \\
\hline Contra Costa County: CA-11 & 29 & 19 & 6 & 22 & 24 \\
\hline San Francisco: CA-12 & 14 & 10 & 4 & 11 & 12 \\
\hline Oakland area: CA-13 & 13 & 7 & 2 & 9 & 10 \\
\hline San Mateo County: CA-14 & 25 & 17 & 7 & 20 & 21 \\
\hline Eastern Alameda County: CA-15 & 32 & 23 & 7 & 27 & 27 \\
\hline Fresno area: CA-16 & 50 & 34 & 11 & 37 & 40 \\
\hline Northeast San Jose area: CA-17 & 33 & 22 & 9 & 28 & 26 \\
\hline Silicon Valley: CA-18 & 25 & 17 & $(5)$ & 21 & 22 \\
\hline San Jose: CA-19 & 36 & 25 & 9 & 26 & 29 \\
\hline Monterey Bay: CA-20 & 31 & 21 & (7) & 21 & 26 \\
\hline Southern Central Valley and part of Bakersfield: CA-21 & 52 & 41 & 15 & 43 & 45 \\
\hline Central Valley near Fresno and Tulare: CA-22 & 59 & 47 & 20 & 48 & 53 \\
\hline
\end{tabular}


Table S.8 - Point Estimates of 2020 Two-Party Vote for the Republican Presidential Candidate, by Race by CD (continued)

\begin{tabular}{|c|c|c|c|c|c|}
\hline & \multicolumn{4}{|c|}{ Non-Whites } & \multirow[b]{2}{*}{ All } \\
\hline & White & All & Black & Hisp. & \\
\hline Bakersfield area: CA-23 & 66 & 48 & 24 & 50 & 59 \\
\hline San Luis Obispo and Santa Barbara: CA-24 & 42 & 30 & $(11)$ & 31 & 38 \\
\hline Northern Los Angeles County suburbs: CA-25 & 54 & 37 & 16 & 39 & 45 \\
\hline Ventura County: CA-26 & 42 & 32 & $(11)$ & 32 & 37 \\
\hline San Gabriel Valley: CA-27 & 38 & 28 & 12 & 32 & 32 \\
\hline Burbank and Glendale: CA-28 & 30 & 23 & 7 & 27 & 28 \\
\hline East San Fernando Valley: CA-29 & 33 & 21 & 8 & 20 & 24 \\
\hline West San Fernando Valley: CA-30 & 34 & 24 & 8 & 24 & 30 \\
\hline San Bernardino area: CA-31 & 49 & 35 & 16 & 39 & 40 \\
\hline East San Gabriel Valley: CA-32 & 44 & 31 & 12 & 30 & 34 \\
\hline Coastal West Side of Los Angeles: CA-33 & 33 & 23 & 8 & 26 & 30 \\
\hline Downtown Los Angeles: CA-34 & 21 & 17 & 4 & 17 & 17 \\
\hline Southwest San Bernardino County and Pomona: CA-35 & 44 & 31 & 11 & 33 & 34 \\
\hline Eastern Riverside County: CA-36 & 50 & 34 & 15 & 35 & 43 \\
\hline Culver City area of Los Angeles: CA-37 & 20 & 12 & 6 & 15 & 14 \\
\hline Southeastern Los Angeles County: CA-38 & 46 & 30 & 10 & 30 & 33 \\
\hline San Gabriel Valley and northern Orange County: CA-39 & 52 & 40 & 16 & 44 & 45 \\
\hline East Los Angeles: CA-40 & 31 & 20 & 6 & 21 & 21 \\
\hline Riverside and Moreno Valley: CA- 41 & 47 & 33 & 13 & 35 & 37 \\
\hline Southwestern Riverside County: CA-42 & 61 & 47 & 22 & 49 & 54 \\
\hline Inland cities south of Los Angeles: CA-43 & 31 & 19 & 6 & 24 & 21 \\
\hline South Los Angeles, including Compton: CA-44 & 32 & 18 & 6 & 21 & 20 \\
\hline Irvine area of Orange County: CA- 45 & 50 & 35 & $(16)$ & 41 & 44 \\
\hline Santa Ana and the Anaheim area of Orange County: CA-46 & 42 & 31 & 10 & 31 & 34 \\
\hline Long Beach area: CA-47 & 43 & 31 & 10 & 34 & 36 \\
\hline Coastal Orange County: CA-48 & 53 & 44 & $(16)$ & 44 & 49 \\
\hline Southern Orange and northern San Diego Counties: CA-49 & 47 & 35 & $(13)$ & 37 & 44 \\
\hline Inland San Diego County: CA-50 & 59 & 44 & 18 & 43 & 54 \\
\hline South San Diego and Imperial County: CA-51 & 43 & 28 & 10 & 29 & 32 \\
\hline Suburban San Diego: CA-52 & 39 & 27 & 10 & 30 & 35 \\
\hline Eastern San Diego: CA-53 & 37 & 26 & 10 & 28 & 32 \\
\hline Denver: CO-01 & 26 & 17 & 7 & 19 & 23 \\
\hline Boulder and Fort Collins: CO-02 & 36 & 25 & $(13)$ & 24 & 35 \\
\hline Pueblo and the Western Slope: CO-03 & 56 & 43 & $(20)$ & 41 & 53 \\
\hline Eastern Colorado and Denver exurbs: CO-04 & 61 & 51 & $(23)$ & 51 & 58 \\
\hline Colorado Springs: CO-05 & 60 & 44 & 21 & 49 & 57 \\
\hline Aurora and Denver's southern suburbs: CO-06 & 46 & 30 & 17 & 32 & 40 \\
\hline Denver's northern and western suburbs: CO-07 & 41 & 32 & $(13)$ & 32 & 38 \\
\hline Hartford area: CT-01 & 41 & 25 & 13 & 31 & 36 \\
\hline Eastern Connecticut: CT-02 & 46 & 34 & 22 & 37 & 45 \\
\hline New Haven area: CT-03 & 44 & 26 & 14 & 35 & 39 \\
\hline Southern Fairfield County: CT-04 & 39 & 27 & 15 & 32 & 35 \\
\hline Northern Fairfield County and northwestern Connecticut: CT-05 & 48 & 33 & 16 & 37 & 45 \\
\hline
\end{tabular}


Table S.8 - Point Estimates of 2020 Two-Party Vote for the Republican Presidential Candidate, by Race by CD (continued)

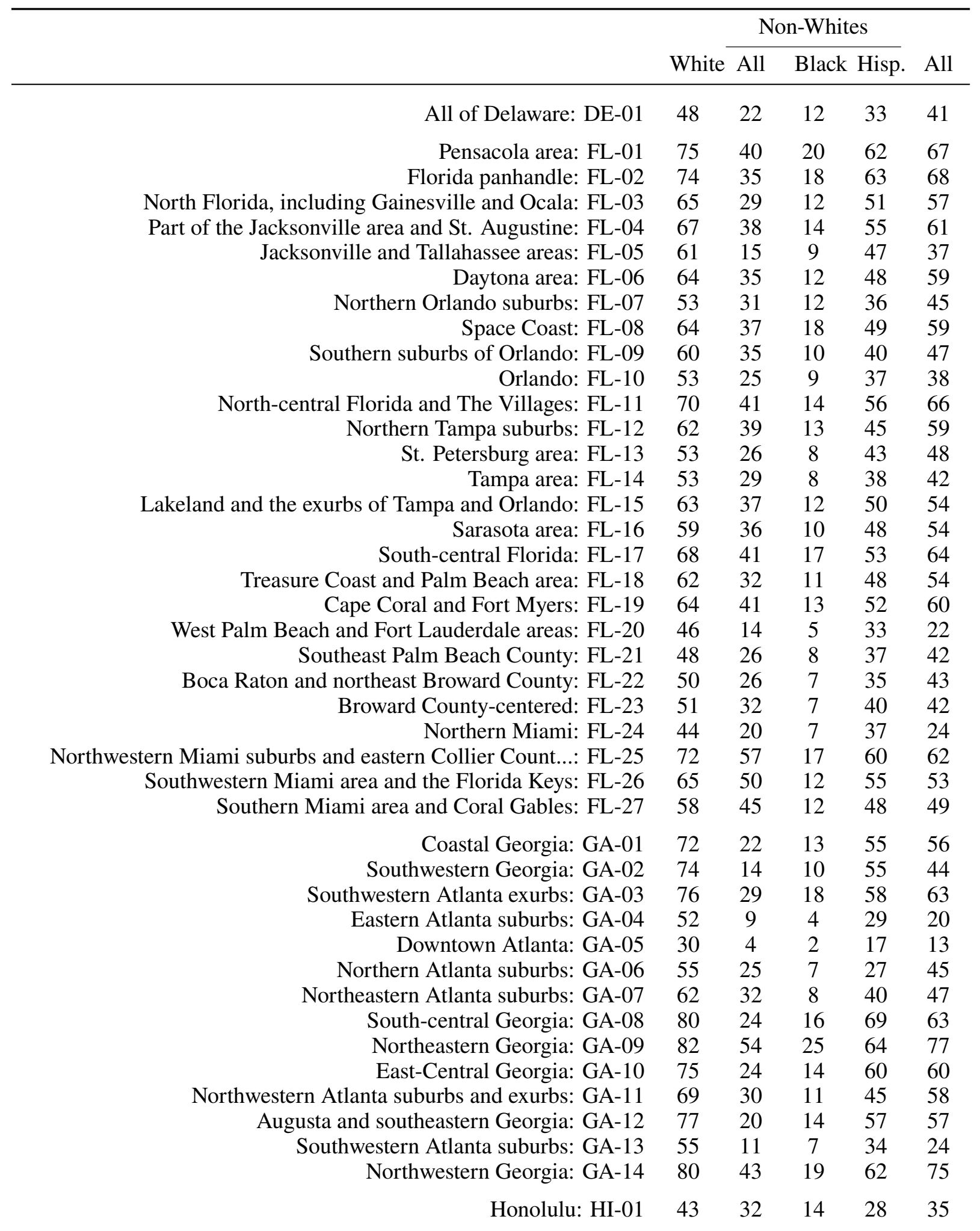


Table S.8 - Point Estimates of 2020 Two-Party Vote for the Republican Presidential Candidate, by Race by CD (continued)

\begin{tabular}{|c|c|c|c|c|c|}
\hline & \multicolumn{4}{|c|}{ Non-Whites } & \multirow[b]{2}{*}{ All } \\
\hline & White & All & Black & Hisp. & \\
\hline Northern Oahu and all other islands: HI-02 & 41 & 29 & $(14)$ & 25 & 35 \\
\hline Northeastern Iowa: IA-01 & 53 & 34 & $(16)$ & $(43)$ & 52 \\
\hline Southeastern Iowa: IA-02 & 54 & 35 & 15 & 46 & 52 \\
\hline Des Moines and southwestern Iowa: IA-03 & 52 & 35 & 15 & 43 & 50 \\
\hline Northwestern Iowa: IA-04 & 65 & 48 & $(22)$ & 51 & 64 \\
\hline Idaho Panhandle and western Boise area: ID-01 & 70 & 66 & $(31)$ & 64 & 69 \\
\hline Boise and Eastern Idaho: ID-02 & 63 & 57 & (27) & 54 & 62 \\
\hline South Side Chicago and southern suburbs: IL-01 & 44 & 11 & 6 & 42 & 25 \\
\hline South Side Chicago and southwestern suburbs: IL-02 & 41 & 9 & 4 & 34 & 22 \\
\hline Southwestern Chicago area: IL-03 & 49 & 31 & 7 & 37 & 44 \\
\hline Heavily Latino areas of Chicago's West and South sid...: IL-04 & 23 & 15 & 4 & 17 & 18 \\
\hline North Side Chicago: IL-05 & 29 & 17 & 4 & 22 & 27 \\
\hline Western Chicago suburbs: IL-06 & 47 & 28 & 7 & 36 & 44 \\
\hline West Side and Downtown Chicago: IL-07 & 22 & 6 & 2 & 19 & 13 \\
\hline Northwestern Chicago suburbs: IL-08 & 43 & 31 & 6 & 40 & 40 \\
\hline Northern Chicago Suburbs: IL-09 & 32 & 15 & 4 & 23 & 28 \\
\hline Chicago's North Shore suburbs: IL-10 & 39 & 24 & 6 & 33 & 35 \\
\hline Southwestern Chicago suburbs: IL-11 & 43 & 26 & 6 & 37 & 37 \\
\hline Southwestern Illinois: IL-12 & 63 & 21 & 13 & $(52)$ & 57 \\
\hline Central Illinois: IL-13 & 56 & 22 & 11 & (44) & 52 \\
\hline Western Chicago exurbs: IL-14 & 51 & 35 & 10 & 42 & 49 \\
\hline East-central and southeastern Illinois: IL-15 & 75 & 41 & 22 & $(69)$ & 74 \\
\hline North-central Illinois: IL-16 & 60 & 40 & 14 & 53 & 58 \\
\hline Northwestern Illinois: IL-17 & 55 & 24 & 9 & 47 & 51 \\
\hline West-central Illinois: IL-18 & 64 & 35 & 14 & $(58)$ & 63 \\
\hline Northwestern Indiana: IN-01 & 53 & 26 & 14 & 37 & 46 \\
\hline North-central Indiana: IN-02 & 64 & 34 & 16 & 49 & 61 \\
\hline Northeastern Indiana: IN-03 & 68 & 38 & 19 & 53 & 65 \\
\hline West-central Indiana: IN-04 & 67 & 43 & 24 & 55 & 65 \\
\hline Northern Indianapolis suburbs: IN-05 & 56 & 24 & 11 & 34 & 51 \\
\hline Southeastern Indiana: IN-06 & 72 & 45 & $(24)$ & $(55)$ & 70 \\
\hline Indianapolis: IN-07 & 43 & 16 & 8 & 30 & 36 \\
\hline Southwestern Indiana: IN-08 & 68 & 36 & 20 & $(52)$ & 66 \\
\hline South-central Indiana and southern Indianapolis suburbs: IN-09 & 64 & 37 & 16 & $(46)$ & 62 \\
\hline Western Kansas: KS-01 & 73 & 61 & 39 & 65 & 71 \\
\hline Topeka, Lawrence, and eastern rural Kansas: KS-02 & 59 & 45 & 27 & 54 & 58 \\
\hline Suburban Kansas City area: KS-03 & 49 & 29 & 12 & 39 & 45 \\
\hline Wichita area: KS-04 & 64 & 47 & 24 & 57 & 61 \\
\hline Western Kentucky: KY-01 & 77 & 36 & 19 & $(64)$ & 74 \\
\hline West-central Kentucky: KY-02 & 72 & 36 & 14 & $(61)$ & 69 \\
\hline Louisville: KY-03 & 48 & 13 & 6 & 34 & 39 \\
\hline Cincinnati suburbs and northern Kentucky border area: KY-04 & 68 & 39 & 11 & (54) & 66 \\
\hline
\end{tabular}


Table S.8 - Point Estimates of 2020 Two-Party Vote for the Republican Presidential Candidate, by Race by CD (continued)

\begin{tabular}{|c|c|c|c|c|c|}
\hline & \multicolumn{4}{|c|}{ Non-Whites } & \multirow[b]{2}{*}{ All } \\
\hline & White & \multicolumn{3}{|c|}{$\overline{\text { Black Hisn }}$} & \\
\hline Appalachian Kentucky: KY-05 & 82 & 57 & (23) & (74) & 81 \\
\hline Greater Lexington area: KY-06 & 58 & 29 & 17 & 45 & 55 \\
\hline Suburban New Orleans: LA-01 & 78 & 42 & 13 & 65 & 69 \\
\hline New Orleans and Baton Rouge: LA-02 & 52 & 9 & 4 & 36 & 24 \\
\hline Southwestern Louisiana: LA-03 & 84 & 28 & 17 & 72 & 69 \\
\hline Northwestern Louisiana: LA-04 & 83 & 25 & 17 & 70 & 63 \\
\hline Northeastern Louisiana: LA-05 & 87 & 24 & 18 & $(78)$ & 65 \\
\hline Baton Rouge suburbs: LA-06 & 79 & 29 & 16 & 67 & 65 \\
\hline Springfield area and the Berkshires: MA-01 & 40 & 26 & 15 & 27 & 38 \\
\hline Worcester area and upper Pioneer Valley: MA-02 & 39 & 26 & 13 & 25 & 37 \\
\hline Lowell area and the Merrimack Valley: MA-03 & 39 & 26 & 12 & 25 & 35 \\
\hline Western Boston suburbs and Bristol County: MA-04 & 35 & 28 & 11 & 25 & 35 \\
\hline Boston's northern and outer western suburbs: MA-05 & 26 & 18 & 7 & 16 & 24 \\
\hline North Shore: MA-06 & 38 & 27 & 16 & 25 & 36 \\
\hline Central Boston area: MA-07 & 16 & 10 & 5 & 11 & 14 \\
\hline Southern Boston suburbs: MA-08 & 36 & 22 & 12 & 25 & 33 \\
\hline Cape Cod and South Shore: MA-09 & 42 & 30 & 14 & 30 & 41 \\
\hline Eastern Shore and Baltimore exurbs: MD-01 & 67 & 25 & 12 & $(47)$ & 60 \\
\hline Suburban Baltimore area: MD-02 & 44 & 13 & 6 & 27 & 33 \\
\hline Baltimore suburbs to Annapolis to D.C. suburbs: MD-03 & 37 & 15 & 8 & 20 & 30 \\
\hline Prince George's County D.C. suburbs: MD-04 & 41 & 11 & 4 & 24 & 20 \\
\hline Southern Maryland and outer Prince George's County: MD-05 & 48 & 14 & 6 & 32 & 30 \\
\hline Western Maryland and Montgomery County D.C. suburbs: MD-06 & 45 & 23 & 6 & 27 & 38 \\
\hline Baltimore and western suburbs: MD-07 & 34 & 9 & 6 & 19 & 20 \\
\hline Montgomery County: MD-08 & 36 & 17 & 6 & 19 & 30 \\
\hline Portland and Augusta: ME-01 & 39 & 28 & $(11)$ & $(33)$ & 38 \\
\hline Northern Maine: ME-02 & 54 & 42 & (16) & (46) & 54 \\
\hline Upper Peninsula and northern Lower Peninsula: MI-01 & 60 & 44 & $(14)$ & $(49)$ & 59 \\
\hline Western Michigan coast: MI-02 & 60 & 35 & 12 & 45 & 56 \\
\hline Grand Rapids area: MI-03 & 55 & 31 & 11 & 44 & 52 \\
\hline Central Michigan: MI-04 & 63 & 43 & $(14)$ & $(53)$ & 62 \\
\hline Flint, Saginaw, and Bay City: MI-05 & 55 & 19 & 9 & 43 & 48 \\
\hline Southwestern Michigan: MI-06 & 56 & 30 & 14 & 44 & 52 \\
\hline South-central Michigan: MI-07 & 60 & 37 & 13 & 49 & 58 \\
\hline Lansing and northwestern Detroit exurbs: MI-08 & 54 & 30 & 11 & 41 & 51 \\
\hline Northern Detroit suburbs: MI-09 & 48 & 20 & 10 & $(40)$ & 43 \\
\hline Northern Macomb County and the "Thumb" region: MI-10 & 67 & 43 & 15 & 54 & 65 \\
\hline Northwestern Detroit suburbs: MI-11 & 52 & 28 & 9 & 37 & 48 \\
\hline Ann Arbor and Dearborn: MI-12 & 39 & 18 & 6 & 27 & 35 \\
\hline Western Detroit: MI-13 & 35 & 8 & 4 & 25 & 20 \\
\hline Eastern Detroit to Pontiac: MI-14 & 39 & 7 & 4 & 30 & 20 \\
\hline Southern Minnesota: MN-01 & 57 & 40 & (19) & 40 & 55 \\
\hline
\end{tabular}


Table S.8 - Point Estimates of 2020 Two-Party Vote for the Republican Presidential Candidate, by Race by CD (continued)

\begin{tabular}{|c|c|c|c|c|c|}
\hline & \multicolumn{4}{|c|}{ Non-Whites } & \multirow[b]{2}{*}{ All } \\
\hline & White & \multicolumn{3}{|c|}{ Black Hisp. } & \\
\hline Southern Twin Cities suburbs: MN-02 & 49 & 32 & 14 & 36 & 47 \\
\hline Western Twin Cities suburbs: MN-03 & 44 & 25 & 15 & 28 & 40 \\
\hline St. Paul: MN-04 & 35 & 19 & 10 & 22 & 31 \\
\hline Minneapolis: MN-05 & 22 & 10 & 4 & 12 & 18 \\
\hline Northern Twin Cities exurbs: MN-06 & 62 & 45 & 23 & $(47)$ & 60 \\
\hline Western Minnesota: MN-07 & 66 & 51 & $(26)$ & 49 & 65 \\
\hline Iron Range: $\mathrm{MN}-08$ & 58 & 46 & $(22)$ & $(40)$ & 58 \\
\hline St. Louis and northwestern suburbs: MO-01 & 27 & 8 & 6 & $(18)$ & 18 \\
\hline Suburban St. Louis: MO-02 & 52 & 32 & 15 & $(38)$ & 50 \\
\hline East-central Missouri: MO-03 & 70 & 49 & 29 & $(56)$ & 68 \\
\hline West-central Missouri: MO-04 & 69 & 48 & 27 & $(58)$ & 68 \\
\hline Kansas City area: MO-05 & 47 & 20 & 11 & 34 & 41 \\
\hline Northern Missouri: MO-06 & 66 & 47 & 31 & 53 & 65 \\
\hline Southwestern Missouri: MO-07 & 72 & 58 & $(31)$ & $(59)$ & 72 \\
\hline Southeastern Missouri: MO-08 & 80 & 58 & 45 & $(70)$ & 79 \\
\hline Northeastern Mississippi: MS-01 & 83 & 22 & 15 & $(75)$ & 66 \\
\hline Mississippi Delta and Jackson: MS-02 & 76 & 11 & 9 & $(66)$ & 35 \\
\hline Southwestern and eastern Mississippi: MS-03 & 83 & 21 & 16 & $(75)$ & 61 \\
\hline Gulf Coast: MS-04 & 81 & 28 & 15 & 73 & 69 \\
\hline All of Montana: MT-01 & 59 & 54 & $(30)$ & $(53)$ & 59 \\
\hline Durham and northeastern North Carolina: NC-01 & 67 & 23 & 17 & 50 & 46 \\
\hline Raleigh exurbs: NC-02 & 43 & 17 & 8 & 25 & 35 \\
\hline Eastern North Carolina coast: NC-03 & 73 & 29 & 15 & 57 & 62 \\
\hline Raleigh, Cary, Chapel Hill: NC-04 & 44 & 17 & 7 & 25 & 33 \\
\hline Winston-Salem and northwestern North Carolina: NC-05 & 76 & 36 & 20 & 58 & 68 \\
\hline Part of Greensboro and rural Piedmont: NC-06 & 47 & 16 & 7 & 30 & 38 \\
\hline Southeastern North Carolina: NC-07 & 70 & 28 & 14 & 49 & 59 \\
\hline Charlotte suburbs to Fayetteville: NC-08 & 66 & 28 & 14 & 49 & 53 \\
\hline South Charlotte to suburban Fayetteville: NC-09 & 65 & 31 & 13 & 47 & 54 \\
\hline Asheville and southwestern Piedmont: NC-10 & 75 & 37 & 20 & 59 & 69 \\
\hline Appalachian North Carolina: NC-11 & 58 & 37 & 14 & 38 & 56 \\
\hline Charlotte: NC-12 & 46 & 16 & 6 & 27 & 29 \\
\hline Greensboro and rural western Piedmont: NC-13 & 80 & 38 & 25 & 65 & 68 \\
\hline All of North Dakota: ND-01 & 69 & 51 & $(27)$ & $(53)$ & 67 \\
\hline Lincoln and rural eastern Nebraska: NE-01 & 60 & 45 & 22 & 47 & 58 \\
\hline Greater Omaha area: NE-02 & 52 & 29 & 18 & 36 & 47 \\
\hline Western Nebraska: NE-03 & 78 & 68 & $(41)$ & 67 & 77 \\
\hline Eastern New Hampshire: NH-01 & 48 & 37 & $(17)$ & $(34)$ & 47 \\
\hline Western and northern New Hampshire: NH-02 & 46 & 34 & $(15)$ & $(32)$ & 46 \\
\hline Inner Philadelphia suburbs: NJ-01 & 43 & 24 & 10 & 32 & 37 \\
\hline Southern New Jersey coast: NJ-02 & 57 & 35 & 13 & 46 & 52 \\
\hline
\end{tabular}


Table S.8 - Point Estimates of 2020 Two-Party Vote for the Republican Presidential Candidate, by Race by CD (continued)

\begin{tabular}{|c|c|c|c|c|c|}
\hline & \multicolumn{4}{|c|}{ Non-Whites } & \multirow[b]{2}{*}{ All } \\
\hline & White & All & Black & Hisp. & \\
\hline Philadelphia suburbs and central Jersey Shore: NJ-03 & 55 & 31 & 16 & 41 & 50 \\
\hline Monmouth County area: NJ-04 & 58 & 40 & 18 & 48 & 55 \\
\hline Northern Bergen County and northwestern exurbs: NJ-05 & 52 & 35 & 20 & 36 & 48 \\
\hline Northern Middlesex County and northern Jersey Shore: NJ-06 & 49 & 30 & 12 & 36 & 42 \\
\hline Hunterdon County and New York City's western exurbs: NJ-07 & 49 & 34 & 14 & 37 & 45 \\
\hline Jersey City and inner New York City suburbs: NJ-08 & 32 & 23 & 7 & 25 & 26 \\
\hline Paterson and inner New York City suburbs: NJ-09 & 45 & 30 & 11 & 35 & 37 \\
\hline Newark area: NJ-10 & 29 & 12 & 6 & 19 & 17 \\
\hline Morris County area: NJ-11 & 50 & 34 & 14 & 39 & 47 \\
\hline Trenton and southern Middlesex County: NJ-12 & 40 & 20 & 8 & 27 & 32 \\
\hline Albuquerque area: NM-01 & 44 & 34 & 14 & 35 & 38 \\
\hline Southern New Mexico: NM-02 & 62 & 50 & $(26)$ & 51 & 56 \\
\hline Northern New Mexico: NM-03 & 47 & 36 & (19) & 38 & 41 \\
\hline Las Vegas: NV-01 & 44 & 32 & 12 & 37 & 37 \\
\hline Northern Nevada: NV-02 & 58 & 49 & $(22)$ & 53 & 55 \\
\hline Southern Las Vegas suburbs: NV-03 & 55 & 42 & 18 & 58 & 50 \\
\hline Northern Las Vegas suburbs and rural central Nevada: NV-04 & 56 & 39 & 17 & 52 & 48 \\
\hline Eastern Suffolk County: NY-01 & 56 & 34 & 19 & 37 & 52 \\
\hline Southern Long Island: NY-02 & 60 & 35 & 17 & 38 & 52 \\
\hline Northern Long Island: NY-03 & 50 & 30 & 15 & 32 & 45 \\
\hline Long Island: NY-04 & 54 & 30 & 13 & 37 & 44 \\
\hline Southeastern Queens: NY-05 & 35 & 13 & 7 & 21 & 16 \\
\hline Northeastern Queens: NY-06 & 46 & 27 & 11 & 29 & 38 \\
\hline Heavily Latino parts of northern Brooklyn and southw...: NY-07 & 23 & 13 & 5 & 15 & 18 \\
\hline Eastern Brooklyn: NY-08 & 30 & 9 & 5 & 17 & 17 \\
\hline Central Brooklyn: NY-09 & 29 & 10 & 6 & 20 & 18 \\
\hline West Side of Manhattan and part of southern Brooklyn: NY-10 & 26 & 14 & 11 & 15 & 23 \\
\hline Staten Island and part of southern Brooklyn: NY-11 & 61 & 38 & 20 & 45 & 55 \\
\hline East Side of Manhattan and nearby parts of Queens an...: NY-12 & 17 & 9 & 5 & 10 & 15 \\
\hline Harlem area: NY-13 & 19 & 10 & 4 & 13 & 12 \\
\hline East Bronx and northern Queens: NY-14 & 37 & 20 & 8 & 23 & 26 \\
\hline The Bronx: NY-15 & 29 & 13 & 4 & 16 & 14 \\
\hline Southern Westchester County and the northern Bronx: NY-16 & 37 & 13 & 7 & 21 & 24 \\
\hline Westchester County: NY-17 & 48 & 25 & 12 & 29 & 40 \\
\hline Lower Hudson Valley: NY-18 & 53 & 30 & 15 & 33 & 48 \\
\hline Hudson Valley: NY-19 & 52 & 27 & 14 & 33 & 49 \\
\hline Albany area: NY-20 & 43 & 21 & 11 & 28 & 40 \\
\hline North Country: NY-21 & 57 & 32 & $(20)$ & $(37)$ & 55 \\
\hline Binghamton and Utica-Rome: NY-22 & 58 & 30 & 18 & $(36)$ & 56 \\
\hline Ithaca and southwestern New York: NY-23 & 57 & 31 & $(17)$ & $(37)$ & 56 \\
\hline Syracuse area: NY-24 & 48 & 20 & 11 & $(30)$ & 46 \\
\hline Greater Rochester: NY-25 & 44 & 18 & 10 & 27 & 39 \\
\hline Greater Buffalo: NY-26 & 41 & 17 & 11 & 26 & 36 \\
\hline
\end{tabular}


Table S.8 - Point Estimates of 2020 Two-Party Vote for the Republican Presidential Candidate, by Race by CD (continued)

\begin{tabular}{|c|c|c|c|c|c|}
\hline & \multicolumn{4}{|c|}{ Non-Whites } & \multirow[b]{2}{*}{ All } \\
\hline & White & All & Black & Hisp. & \\
\hline Suburbs and rural areas between Buffalo and Rochester: NY-27 & 59 & 37 & $(22)$ & $(42)$ & 58 \\
\hline Suburban Cincinnati: OH-01 & 62 & 18 & 11 & $(43)$ & 52 \\
\hline Eastern Cincinnati and east along the Ohio River: $\mathrm{OH}-02$ & 60 & 24 & 16 & $(42)$ & 57 \\
\hline Columbus: $\mathrm{OH}-03$ & 37 & 11 & 8 & 22 & 29 \\
\hline West-Central Ohio to North-Central Ohio: OH-04 & 71 & 35 & 19 & $(55)$ & 68 \\
\hline Northwestern Ohio: OH-05 & 65 & 38 & 15 & 46 & 63 \\
\hline Appalachian Ohio: OH-06 & 74 & 38 & $(21)$ & $(55)$ & 73 \\
\hline Canton area: $\mathrm{OH}-07$ & 68 & 31 & 17 & $(50)$ & 66 \\
\hline Cincinnati suburbs and Springfield: $\mathrm{OH}-08$ & 70 & 34 & 18 & $(51)$ & 67 \\
\hline Toledo to West Side of Cleveland: OH-09 & 46 & 16 & 7 & 29 & 40 \\
\hline Greater Dayton area: OH-10 & 59 & 19 & 11 & $(41)$ & 52 \\
\hline East Cleveland to Akron: OH-11 & 34 & 5 & 3 & 22 & 19 \\
\hline Northern Columbus area: $\mathrm{OH}-12$ & 56 & 27 & 13 & $(38)$ & 53 \\
\hline Mahoning Valley and Akron: OH-13 & 52 & 16 & 9 & $(35)$ & 48 \\
\hline Northeastern Ohio: OH-14 & 56 & 29 & 16 & $(38)$ & 55 \\
\hline Southern Columbus area and Athens: OH-15 & 59 & 28 & 13 & $(38)$ & 57 \\
\hline Western suburbs of Cleveland and Akron: OH-16 & 59 & 34 & (13) & $(42)$ & 57 \\
\hline Greater Tulsa area: OK-01 & 66 & 45 & 13 & 62 & 62 \\
\hline Eastern Oklahoma: OK-02 & 80 & 62 & 21 & 70 & 78 \\
\hline Northwestern Oklahoma: OK-03 & 79 & 59 & 21 & 73 & 76 \\
\hline Southern Oklahoma: OK-04 & 70 & 49 & 14 & 66 & 67 \\
\hline Oklahoma City area: OK-05 & 58 & 33 & 10 & 51 & 53 \\
\hline Western Portland suburbs and North Coast: OR-01 & 37 & 28 & (9) & 29 & 35 \\
\hline Oregon east of the Cascades and part of southern Oregon: OR-02 & 58 & 49 & (18) & 48 & 57 \\
\hline Eastern Portland area: OR-03 & 26 & 17 & 6 & 19 & 24 \\
\hline Southern Willamette Valley and southern coast: OR-04 & 49 & 43 & (14) & 40 & 48 \\
\hline Salem area and southern Portland suburbs: OR-05 & 48 & 34 & (14) & 32 & 45 \\
\hline Philadelphia's Bucks County suburbs: PA-01 & 51 & 25 & 12 & 33 & 47 \\
\hline Northeast Philadelphia: PA-02 & 40 & 17 & 9 & 23 & 30 \\
\hline West, Northwest, and Center City Philadelphia: PA-03 & 19 & 4 & 2 & 11 & 9 \\
\hline Philadelphia's Montgomery County suburbs: PA-04 & 43 & 18 & 10 & 26 & 38 \\
\hline Philadelphia's Delaware County suburbs and South Phi...: PA-05 & 44 & 14 & 8 & (26) & 34 \\
\hline Philadelphia's Chester County suburbs and Reading: PA-06 & 48 & 24 & 9 & 27 & 43 \\
\hline Lehigh Valley and southern Monroe County: PA-07 & 52 & 29 & 11 & 34 & 48 \\
\hline Scranton/Wilkes-Barre and northeastern Pennsylvania: PA-08 & 56 & 27 & 12 & 33 & 52 \\
\hline Coal Region between Wilkes-Barre and Harrisburg: PA-09 & 67 & 39 & 19 & 47 & 66 \\
\hline Harrisburg and York: PA-10 & 57 & 26 & 13 & 39 & 52 \\
\hline Lancaster and southern York Counties: PA-11 & 64 & 38 & 18 & 46 & 61 \\
\hline Williamsport area and Northern Tier: PA-12 & 70 & 39 & $(21)$ & $(50)$ & 69 \\
\hline South-central Pennsylvania: PA-13 & 74 & 43 & 27 & $(57)$ & 73 \\
\hline Southern Pittsburgh exurbs and southwestern Pennsylv...: PA-14 & 65 & 30 & 19 & $(46)$ & 64 \\
\hline North-central Pennsylvania: PA-15 & 73 & 39 & $(24)$ & $(54)$ & 72 \\
\hline Erie and northwestern Pennsylvania: PA-16 & 61 & 28 & 17 & (41) & 60 \\
\hline
\end{tabular}


Table S.8 - Point Estimates of 2020 Two-Party Vote for the Republican Presidential Candidate, by Race by CD (continued)

\begin{tabular}{|c|c|c|c|c|c|}
\hline & \multicolumn{4}{|c|}{ Non-Whites } & \multirow[b]{2}{*}{ All } \\
\hline & White & All & Black & Hisp. & \\
\hline Pittsburgh suburbs and Beaver County: PA-17 & 51 & 22 & 12 & (35) & 49 \\
\hline Pittsburgh: PA-18 & 40 & 13 & 9 & $(25)$ & 35 \\
\hline Part of Providence and eastern Rhode Island: RI-01 & 38 & 25 & 10 & 31 & 35 \\
\hline Part of Providence and western Rhode Island: RI-02 & 45 & 32 & 13 & 35 & 43 \\
\hline Charleston and coastal South Carolina: SC-01 & 63 & 23 & 8 & 53 & 53 \\
\hline Augusta and Columbia suburbs: SC-02 & 70 & 20 & 9 & 59 & 56 \\
\hline Northwestern South Carolina: SC-03 & 78 & 28 & 17 & $(70)$ & 69 \\
\hline Greenville-Spartanburg area: SC-04 & 71 & 30 & 12 & 60 & 61 \\
\hline Southern Charlotte suburbs and exurbs: SC-05 & 73 & 22 & 12 & 64 & 59 \\
\hline Black Belt, Columbia, and Charleston: SC-06 & 59 & 9 & 6 & $(51)$ & 32 \\
\hline Northeastern South Carolina and the Myrtle Beach area: SC-07 & 73 & 18 & 10 & $(63)$ & 60 \\
\hline All of South Dakota: SD-01 & 64 & 55 & $(22)$ & $(57)$ & 64 \\
\hline Northeastern Tennessee: TN-01 & 79 & 49 & $(15)$ & $(69)$ & 78 \\
\hline Knoxville area: TN-02 & 68 & 34 & 10 & $(59)$ & 65 \\
\hline Chattanooga area: $\mathrm{TN}-03$ & 71 & 30 & 10 & $(61)$ & 67 \\
\hline Southern part of Middle Tennessee: TN-04 & 74 & 35 & 11 & 64 & 69 \\
\hline Nashville: TN-05 & 48 & 13 & 3 & 36 & 38 \\
\hline Nashville's eastern suburbs and northern Middle Tenn...: TN-06 & 76 & 46 & 16 & $(66)$ & 74 \\
\hline Nashville's southern suburbs and western Middle Tenn...: TN-07 & 74 & 35 & 11 & 62 & 68 \\
\hline West Tennessee: TN-08 & 77 & 26 & 13 & $(66)$ & 67 \\
\hline Memphis: TN-09 & 45 & 7 & 3 & 34 & 20 \\
\hline Tyler and East Texas: TX-01 & 82 & 40 & 20 & 68 & 73 \\
\hline Northern Houston and part of west Houston: TX-02 & 59 & 38 & 8 & 49 & 51 \\
\hline Collin County: TX-03 & 59 & 34 & 11 & 41 & 51 \\
\hline Northeastern Texas: TX-04 & 82 & 46 & 20 & 67 & 75 \\
\hline Eastern edge of Dallas and rural areas to its east: TX-05 & 71 & 37 & 13 & 54 & 62 \\
\hline Arlington and rural areas south of Dallas: TX-06 & 64 & 32 & 8 & 52 & 52 \\
\hline West Houston: TX-07 & 56 & 32 & 6 & 40 & 46 \\
\hline Suburbs and exurbs north of Houston: TX-08 & 77 & 52 & 20 & 65 & 72 \\
\hline Southwest Houston: TX-09 & 45 & 18 & 5 & 28 & 24 \\
\hline Austin to western Houston: TX-10 & 61 & 34 & 8 & 41 & 51 \\
\hline Midland and San Angelo parts of rural west Texas: TX-11 & 85 & 67 & 25 & 72 & 80 \\
\hline Parker and western Tarrant Counties: TX-12 & 68 & 43 & 12 & 54 & 62 \\
\hline Texas Panhandle: TX-13 & 85 & 63 & 25 & 71 & 81 \\
\hline Galveston area: TX-14 & 72 & 36 & 14 & 55 & 60 \\
\hline McAllen in the Rio Grande Valley and rural counties ...: TX-15 & 65 & 43 & 11 & 43 & 49 \\
\hline El Paso: TX-16 & 47 & 28 & 6 & 28 & 33 \\
\hline College Station, Waco, and a slice of Austin suburbs: TX-17 & 64 & 34 & 10 & 47 & 56 \\
\hline Heavily black parts of central Houston: TX-18 & 40 & 17 & 4 & 30 & 23 \\
\hline Lubbock and rural West Texas: TX-19 & 80 & 57 & 21 & 64 & 73 \\
\hline Downtown San Antonio: TX-20 & 49 & 28 & 8 & 29 & 35 \\
\hline Parts of Austin and San Antonio connected by Texas H...: TX-21 & 57 & 38 & 8 & 40 & 52 \\
\hline
\end{tabular}


Table S.8 - Point Estimates of 2020 Two-Party Vote for the Republican Presidential Candidate, by Race by CD (continued)

\begin{tabular}{|c|c|c|c|c|c|}
\hline & \multicolumn{4}{|c|}{ Non-Whites } & \multirow[b]{2}{*}{ All } \\
\hline & White & All & Black & Hisp. & \\
\hline Southern Houston suburbs: TX-22 & 64 & 38 & 9 & 48 & 51 \\
\hline El Paso to San Antonio: TX-23 & 66 & 43 & 10 & 44 & 51 \\
\hline Suburbs north of Dallas and Fort Worth: TX-24 & 56 & 33 & 9 & 41 & 47 \\
\hline Part of Austin and rural areas north toward Dallas-F...: TX-25 & 60 & 38 & 9 & 48 & 55 \\
\hline Denton County: TX-26 & 64 & 41 & 9 & 53 & 57 \\
\hline Corpus Christi and Victoria: TX-27 & 72 & 47 & 14 & 50 & 62 \\
\hline Laredo area: TX-28 & 61 & 43 & 9 & 45 & 48 \\
\hline Heavily Latino areas north and east of Downtown Houston: TX-29 & 50 & 28 & 6 & 33 & 33 \\
\hline Downtown and South Dallas: TX-30 & 38 & 12 & 4 & 24 & 19 \\
\hline Williamson and Bell Counties: TX-31 & 59 & 36 & 9 & 46 & 52 \\
\hline Suburban North Dallas: TX-32 & 53 & 30 & 8 & 38 & 45 \\
\hline Connects Downtown Fort Worth and western Dallas: TX-33 & 40 & 20 & 6 & 24 & 26 \\
\hline Brownsville in the Rio Grande Valley and rural count...: TX-34 & 60 & 44 & (8) & 44 & 48 \\
\hline San Antonio and heavily Latino areas of Austin: TX-35 & 41 & 24 & 6 & 26 & 31 \\
\hline Southern part of East Texas: TX-36 & 79 & 50 & 18 & 63 & 73 \\
\hline Ogden and northern Utah: UT-01 & 69 & 58 & $(33)$ & 56 & 67 \\
\hline Salt Lake City and southwestern Utah: UT-02 & 60 & 50 & $(25)$ & 46 & 58 \\
\hline Provo area and southeastern Utah: UT-03 & 65 & 52 & $(28)$ & 50 & 63 \\
\hline Southern Salt Lake County and rural areas to the south: UT-04 & 57 & 48 & $(25)$ & 44 & 55 \\
\hline Western Chesapeake Bay and exurbs of D.C. and Richmond: VA-01 & 62 & 30 & 10 & 46 & 52 \\
\hline Virginia Beach: VA-02 & 55 & 26 & 10 & 42 & 48 \\
\hline Hampton Roads: VA-03 & 51 & 12 & 6 & 36 & 32 \\
\hline Richmond and Southside Virginia: VA-04 & 53 & 16 & 10 & 39 & 38 \\
\hline Charlottesville and South-central Virginia: VA-05 & 63 & 22 & 13 & $(45)$ & 54 \\
\hline Shenandoah Valley: VA-06 & 66 & 30 & 13 & 52 & 61 \\
\hline Suburban Richmond: VA-07 & 60 & 25 & 10 & 42 & 50 \\
\hline Inner D.C. suburbs: VA-08 & 27 & 14 & 3 & 19 & 22 \\
\hline Southwest Virginia: VA-09 & 74 & 33 & 16 & $(56)$ & 71 \\
\hline Loudoun County and D.C. suburbs and exurbs: VA-10 & 46 & 30 & 7 & 31 & 40 \\
\hline D.C. suburbs in Fairfax and Prince William Counties: VA-11 & 37 & 20 & 4 & 24 & 29 \\
\hline All of Vermont: VT-01 & 32 & 22 & (8) & $(24)$ & 32 \\
\hline Northern Seattle suburbs: WA-01 & 41 & 32 & $(12)$ & 35 & 39 \\
\hline Northern Puget Sound: WA-02 & 38 & 30 & 13 & 28 & 36 \\
\hline Vancouver and southwestern Washington: WA-03 & 53 & 43 & $(20)$ & 41 & 52 \\
\hline Yakima and the Tri-Cities: WA-04 & 63 & 51 & $(21)$ & 50 & 59 \\
\hline Spokane area and rural eastern Washington: WA-05 & 56 & 43 & $(18)$ & 42 & 55 \\
\hline Olympic Peninsula and Tacoma: WA-06 & 43 & 31 & 11 & 31 & 41 \\
\hline Seattle: WA-07 & 14 & 9 & 2 & 11 & 13 \\
\hline Eastern Seattle suburbs and two rural counties east ...: WA-08 & 49 & 38 & $(15)$ & 38 & 47 \\
\hline Southeastern Seattle and the suburbs to its south an...: WA-09 & 29 & 20 & 6 & 21 & 25 \\
\hline Olympia area and Tacoma suburbs: WA- 10 & 45 & 31 & 12 & 33 & 42 \\
\hline Southeastern Wisconsin: WI-01 & 58 & 37 & 13 & 43 & 55 \\
\hline
\end{tabular}


Table S.8 - Point Estimates of 2020 Two-Party Vote for the Republican Presidential Candidate, by Race by CD (continued)

\begin{tabular}{|c|c|c|c|c|c|}
\hline & \multicolumn{5}{|c|}{ Non-Whites } \\
\hline & White & All & Black & Hisp. & All \\
\hline Madison area: WI-02 & 32 & 16 & 6 & 20 & 30 \\
\hline Southwestern Wisconsin: WI-03 & 53 & 38 & (13) & $(42)$ & 53 \\
\hline Milwaukee: WI-04 & 32 & 12 & 5 & 21 & 23 \\
\hline Milwaukee suburbs: WI-05 & 60 & 42 & (16) & 49 & 58 \\
\hline Fox River Valley and Sheboygan: WI-06 & 59 & 39 & (15) & 43 & 58 \\
\hline Northwestern Wisconsin: WI-07 & 61 & 46 & (20) & $(46)$ & 60 \\
\hline Northeastern Wisconsin: WI-08 & 59 & 44 & (16) & 46 & 58 \\
\hline Northern West Virginia: WV-01 & 70 & 41 & (15) & $(54)$ & 69 \\
\hline Charleston to the Eastern Panhandle: WV-02 & 69 & 35 & 14 & $(46)$ & 67 \\
\hline Southern West Virginia: WV-03 & 76 & 40 & 20 & $(58)$ & 74 \\
\hline All of Wyoming: WY-01 & 73 & 66 & $(34)$ & 67 & 73 \\
\hline National & 56 & 28 & 10 & 38 & 48 \\
\hline
\end{tabular}

\section{Turnout Composition Estimates}

Here we provide the estimates of the size of the group in the electorate. In our estimation, we ensure that the racial composition of the Voting Age Population (VAP) in the CD matches the ACS. We also ensure that the total VAP turnout rate at the district level is consistent with the true turnout. Tables S.9 and S.9 returns the population size at the district level, transformed as a percent of the entire electorate in the geography. Table S.11 and S.12 aggregates the counts to the state level.

Table S.9 - Composition of 2016 Electorate, by Race by CD

\begin{tabular}{rccccc}
\hline & & \multicolumn{3}{c}{ Non-Whites } & \\
\cline { 5 - 6 } & White & All & Black Hisp. & All \\
\hline All of Alaska: AK-01 & 76 & 24 & 2 & 3 & 100 \\
Greater Mobile: AL-01 & 73 & 27 & 22 & 2 & 100 \\
Southeastern Alabama: AL-02 & 71 & 29 & 26 & 1 & 100 \\
Eastern Alabama: AL-03 & 74 & 26 & 22 & 1 & 100 \\
North-central Alabama: AL-04 & 89 & 11 & 5 & 3 & 100 \\
Northern Alabama: AL-05 & 81 & 19 & 14 & 2 & 100 \\
Birmingham suburbs: AL-06 & 81 & 19 & 13 & 3 & 100 \\
Birmingham and the Black Belt: AL-07 & 37 & 63 & 59 & 2 & 100 \\
Northeastern Arkansas: AR-01 & 85 & 15 & 12 & 1 & 100
\end{tabular}


Table S.9 - Composition of 2016 Electorate, by Race by CD (continued)

\begin{tabular}{|c|c|c|c|c|c|}
\hline & \multicolumn{4}{|c|}{ Non-Whites } & \multirow[b]{2}{*}{ All } \\
\hline & White & All & Black & Hisp. & \\
\hline Greater Little Rock: AR-02 & 78 & 22 & 17 & 2 & 100 \\
\hline Northwest Arkansas: AR-03 & 86 & 14 & 2 & 7 & 100 \\
\hline Southern and western Arkansas: AR-04 & 81 & 19 & 15 & 2 & 100 \\
\hline Northeastern Arizona: AZ-01 & 69 & 31 & 2 & 15 & 100 \\
\hline Southeastern Arizona and eastern Tucson area: AZ-02 & 76 & 24 & 2 & 16 & 100 \\
\hline Southwestern Arizona and western Tucson area: AZ-03 & 48 & 52 & 4 & 36 & 100 \\
\hline North-central Arizona and Phoenix exurbs: AZ-04 & 87 & 13 & 1 & 9 & 100 \\
\hline Phoenix suburbs of Mesa and Gilbert: AZ-05 & 83 & 17 & 2 & 10 & 100 \\
\hline Scottsdale and North Phoenix: AZ-06 & 85 & 15 & 2 & 9 & 100 \\
\hline Downtown and West Phoenix: AZ-07 & 46 & 54 & 9 & 31 & 100 \\
\hline Western suburbs of Phoenix: AZ-08 & 83 & 17 & 3 & 11 & 100 \\
\hline Central Phoenix and eastern suburbs: AZ-09 & 74 & 26 & 3 & 15 & 100 \\
\hline Northeastern California: CA-01 & 88 & 12 & 1 & 6 & 100 \\
\hline Northern California coast: CA- 02 & 83 & 17 & 1 & 8 & 100 \\
\hline Southern Sacramento Valley: CA-03 & 65 & 35 & 6 & 16 & 100 \\
\hline Northern Sacramento suburbs and Sierra Nevada foothi...: CA-04 & 86 & 14 & 1 & 7 & 100 \\
\hline Wine country: CA-05 & 65 & 35 & 5 & 15 & 100 \\
\hline Sacramento: CA-06 & 55 & 45 & 11 & 17 & 100 \\
\hline Suburban Sacramento County: CA-07 & 70 & 30 & 6 & 10 & 100 \\
\hline Northern San Bernardino County and the High Desert: CA-08 & 65 & 35 & 6 & 21 & 100 \\
\hline Stockton area and eastern Contra Costa County: CA-09 & 52 & 48 & 8 & 23 & 100 \\
\hline Modesto area: CA-10 & 62 & 38 & 3 & 24 & 100 \\
\hline Contra Costa County: CA-11 & 59 & 41 & 7 & 15 & 100 \\
\hline San Francisco: CA-12 & 52 & 48 & 5 & 9 & 100 \\
\hline Oakland area: CA-13 & 42 & 58 & 17 & 13 & 100 \\
\hline San Mateo County: CA-14 & 48 & 52 & 3 & 15 & 100 \\
\hline Eastern Alameda County: CA-15 & 49 & 51 & 6 & 15 & 100 \\
\hline Fresno area: CA-16 & 41 & 59 & 6 & 34 & 100 \\
\hline Northeast San Jose area: CA-17 & 42 & 58 & 3 & 13 & 100 \\
\hline Silicon Valley: CA-18 & 67 & 33 & 2 & 9 & 100 \\
\hline San Jose: CA-19 & 38 & 62 & 3 & 26 & 100 \\
\hline Monterey Bay: CA-20 & 53 & 47 & 2 & 30 & 100 \\
\hline Southern Central Valley and part of Bakersfield: CA-21 & 37 & 63 & 5 & 41 & 100 \\
\hline Central Valley near Fresno and Tulare: CA-22 & 58 & 42 & 3 & 27 & 100 \\
\hline Bakersfield area: CA-23 & 65 & 35 & 5 & 21 & 100 \\
\hline San Luis Obispo and Santa Barbara: CA-24 & 70 & 30 & 2 & 20 & 100 \\
\hline Northern Los Angeles County suburbs: CA-25 & 54 & 46 & 6 & 24 & 100 \\
\hline Ventura County: CA-26 & 60 & 40 & 2 & 28 & 100 \\
\hline San Gabriel Valley: CA-27 & 39 & 61 & 5 & 20 & 100 \\
\hline Burbank and Glendale: CA-28 & 68 & 32 & 2 & 15 & 100 \\
\hline East San Fernando Valley: CA-29 & 32 & 68 & 4 & 42 & 100 \\
\hline West San Fernando Valley: CA-30 & 65 & 35 & 4 & 16 & 100 \\
\hline San Bernardino area: CA-31 & 41 & 59 & 10 & 34 & 100 \\
\hline East San Gabriel Valley: CA-32 & 24 & 76 & 3 & 42 & 100 \\
\hline Coastal West Side of Los Angeles: CA-33 & 73 & 27 & 3 & 9 & 100 \\
\hline
\end{tabular}


Table S.9 - Composition of 2016 Electorate, by Race by CD (continued)

\begin{tabular}{|c|c|c|c|c|c|}
\hline & \multicolumn{4}{|c|}{ Non-Whites } & \multirow[b]{2}{*}{ All } \\
\hline & White & All & Black & Hisp. & \\
\hline Downtown Los Angeles: CA-34 & 17 & 83 & 5 & 49 & 100 \\
\hline Southwest San Bernardino County and Pomona: CA-35 & 24 & 76 & 7 & 43 & 100 \\
\hline Eastern Riverside County: CA-36 & 63 & 37 & 4 & 23 & 100 \\
\hline Culver City area of Los Angeles: CA-37 & 33 & 67 & 23 & 24 & 100 \\
\hline Southeastern Los Angeles County: CA-38 & 24 & 76 & 3 & 42 & 100 \\
\hline San Gabriel Valley and northern Orange County: CA-39 & 44 & 56 & 2 & 24 & 100 \\
\hline East Los Angeles: CA-40 & 9 & 91 & 6 & 61 & 100 \\
\hline Riverside and Moreno Valley: CA-41 & 36 & 64 & 9 & 35 & 100 \\
\hline Southwestern Riverside County: CA-42 & 57 & 43 & 5 & 23 & 100 \\
\hline Inland cities south of Los Angeles: CA-43 & 22 & 78 & 22 & 31 & 100 \\
\hline South Los Angeles, including Compton: CA-44 & 12 & 88 & 16 & 49 & 100 \\
\hline Irvine area of Orange County: CA-45 & 66 & 34 & 2 & 12 & 100 \\
\hline Santa Ana and the Anaheim area of Orange County: CA-46 & 34 & 66 & 2 & 40 & 100 \\
\hline Long Beach area: CA-47 & 48 & 52 & 7 & 22 & 100 \\
\hline Coastal Orange County: CA-48 & 69 & 31 & 1 & 12 & 100 \\
\hline Southern Orange and northern San Diego Counties: CA-49 & 75 & 25 & 2 & 14 & 100 \\
\hline Inland San Diego County: CA-50 & 71 & 29 & 2 & 18 & 100 \\
\hline South San Diego and Imperial County: CA-51 & 23 & 77 & 7 & 50 & 100 \\
\hline Suburban San Diego: CA-52 & 73 & 27 & 3 & 9 & 100 \\
\hline Eastern San Diego: CA-53 & 55 & 45 & 7 & 22 & 100 \\
\hline Denver: CO-01 & 67 & 33 & 6 & 20 & 100 \\
\hline Boulder and Fort Collins: CO-02 & 89 & 11 & 0 & 6 & 100 \\
\hline Pueblo and the Western Slope: CO-03 & 79 & 21 & 0 & 16 & 100 \\
\hline Eastern Colorado and Denver exurbs: CO-04 & 80 & 20 & 1 & 15 & 100 \\
\hline Colorado Springs: CO-05 & 80 & 20 & 4 & 10 & 100 \\
\hline Aurora and Denver's southern suburbs: CO-06 & 71 & 29 & 7 & 13 & 100 \\
\hline Denver's northern and western suburbs: CO-07 & 73 & 27 & 1 & 21 & 100 \\
\hline Hartford area: CT-01 & 71 & 29 & 13 & 9 & 100 \\
\hline Eastern Connecticut: CT-02 & 91 & 9 & 2 & 3 & 100 \\
\hline New Haven area: CT-03 & 76 & 24 & 11 & 7 & 100 \\
\hline Southern Fairfield County: CT-04 & 70 & 30 & 11 & 13 & 100 \\
\hline Northern Fairfield County and northwestern Connecticut: CT-05 & 80 & 20 & 4 & 9 & 100 \\
\hline All of Delaware: DE-01 & 75 & 25 & 16 & 5 & 100 \\
\hline Pensacola area: FL-01 & 79 & 21 & 11 & 3 & 100 \\
\hline Florida panhandle: FL-02 & 83 & 17 & 11 & 3 & 100 \\
\hline North Florida, including Gainesville and Ocala: FL-03 & 77 & 23 & 13 & 5 & 100 \\
\hline Part of the Jacksonville area and St. Augustine: FL-04 & 82 & 18 & 7 & 4 & 100 \\
\hline Jacksonville and Tallahassee areas: FL-05 & 48 & 52 & 44 & 4 & 100 \\
\hline Daytona area: FL-06 & 84 & 16 & 7 & 6 & 100 \\
\hline Northern Orlando suburbs: FL-07 & 67 & 33 & 8 & 16 & 100 \\
\hline Space Coast: FL-08 & 84 & 16 & 7 & 5 & 100 \\
\hline Southern suburbs of Orlando: FL-09 & 52 & 48 & 11 & 28 & 100 \\
\hline Orlando: FL-10 & 47 & 53 & 23 & 18 & 100 \\
\hline North-central Florida and The Villages: FL-11 & 89 & 11 & 4 & 5 & 100 \\
\hline
\end{tabular}


Table S.9 - Composition of 2016 Electorate, by Race by CD (continued)

\begin{tabular}{|c|c|c|c|c|c|}
\hline & \multicolumn{4}{|c|}{ Non-Whites } & \multirow[b]{2}{*}{ All } \\
\hline & White & All & Black & Hisp. & \\
\hline Northern Tampa suburbs: FL-12 & 87 & 13 & 3 & 6 & 100 \\
\hline St. Petersburg area: FL-13 & 83 & 17 & 8 & 5 & 100 \\
\hline Tampa area: FL-14 & 55 & 45 & 15 & 21 & 100 \\
\hline Lakeland and the exurbs of Tampa and Orlando: FL-15 & 70 & 30 & 11 & 12 & 100 \\
\hline Sarasota area: FL-16 & 84 & 16 & 5 & 7 & 100 \\
\hline South-central Florida: FL-17 & 87 & 13 & 4 & 6 & 100 \\
\hline Treasure Coast and Palm Beach area: FL-18 & 79 & 21 & 9 & 8 & 100 \\
\hline Cape Coral and Fort Myers: FL-19 & 84 & 16 & 4 & 9 & 100 \\
\hline West Palm Beach and Fort Lauderdale areas: FL-20 & 28 & 72 & 48 & 18 & 100 \\
\hline Southeast Palm Beach County: FL-21 & 73 & 27 & 10 & 13 & 100 \\
\hline Boca Raton and northeast Broward County: FL-22 & 72 & 28 & 10 & 13 & 100 \\
\hline Broward County-centered: FL-23 & 51 & 49 & 11 & 29 & 100 \\
\hline Northern Miami: FL-24 & 17 & 83 & 44 & 33 & 100 \\
\hline Northwestern Miami suburbs and eastern Collier Count...: FL-25 & 30 & 70 & 4 & 61 & 100 \\
\hline Southwestern Miami area and the Florida Keys: FL-26 & 23 & 77 & 9 & 63 & 100 \\
\hline Southern Miami area and Coral Gables: FL-27 & 27 & 73 & 4 & 63 & 100 \\
\hline Coastal Georgia: GA-01 & 70 & 30 & 24 & 3 & 100 \\
\hline Southwestern Georgia: GA-02 & 51 & 49 & 44 & 2 & 100 \\
\hline Southwestern Atlanta exurbs: GA-03 & 75 & 25 & 20 & 2 & 100 \\
\hline Eastern Atlanta suburbs: GA-04 & 31 & 69 & 56 & 4 & 100 \\
\hline Downtown Atlanta: GA-05 & 35 & 65 & 56 & 3 & 100 \\
\hline Northern Atlanta suburbs: GA-06 & 67 & 33 & 11 & 8 & 100 \\
\hline Northeastern Atlanta suburbs: GA-07 & 56 & 44 & 17 & 11 & 100 \\
\hline South-central Georgia: GA-08 & 70 & 30 & 25 & 2 & 100 \\
\hline Northeastern Georgia: GA-09 & 88 & 12 & 5 & 5 & 100 \\
\hline East-Central Georgia: GA-10 & 74 & 26 & 21 & 2 & 100 \\
\hline Northwestern Atlanta suburbs and exurbs: GA-11 & 74 & 26 & 12 & 7 & 100 \\
\hline Augusta and southeastern Georgia: GA-12 & 66 & 34 & 28 & 2 & 100 \\
\hline Southwestern Atlanta suburbs: GA-13 & 33 & 67 & 54 & 7 & 100 \\
\hline Northwestern Georgia: GA-14 & 86 & 14 & 7 & 4 & 100 \\
\hline Honolulu: HI-01 & 33 & 67 & 2 & 7 & 100 \\
\hline Northern Oahu and all other islands: HI-02 & 54 & 46 & 2 & 7 & 100 \\
\hline Northeastern Iowa: IA-01 & 94 & 6 & 2 & 2 & 100 \\
\hline Southeastern Iowa: IA-02 & 91 & 9 & 3 & 3 & 100 \\
\hline Des Moines and southwestern Iowa: IA-03 & 91 & 9 & 2 & 3 & 100 \\
\hline Northwestern Iowa: IA-04 & 93 & 7 & 1 & 3 & 100 \\
\hline Idaho Panhandle and western Boise area: ID-01 & 93 & 7 & 0 & 3 & 100 \\
\hline Boise and Eastern Idaho: ID-02 & 91 & 9 & 0 & 5 & 100 \\
\hline South Side Chicago and southern suburbs: IL-01 & 40 & 60 & 51 & 5 & 100 \\
\hline South Side Chicago and southwestern suburbs: IL-02 & 37 & 63 & 52 & 8 & 100 \\
\hline Southwestern Chicago area: IL-03 & 72 & 28 & 4 & 16 & 100 \\
\hline Heavily Latino areas of Chicago's West and South sid...: IL-04 & 34 & 66 & 4 & 43 & 100 \\
\hline North Side Chicago: IL-05 & 80 & 20 & 2 & 11 & 100 \\
\hline Western Chicago suburbs: IL-06 & 84 & 16 & 2 & 6 & 100 \\
\hline
\end{tabular}


Table S.9 - Composition of 2016 Electorate, by Race by CD (continued)

\begin{tabular}{|c|c|c|c|c|c|}
\hline & \multicolumn{4}{|c|}{ Non-Whites } & \multirow[b]{2}{*}{ All } \\
\hline & White & All & Black & Hisp. & \\
\hline West Side and Downtown Chicago: IL-07 & 38 & 62 & 44 & 9 & 100 \\
\hline Northwestern Chicago suburbs: IL-08 & 73 & 27 & 4 & 13 & 100 \\
\hline Northern Chicago Suburbs: IL-09 & 76 & 24 & 7 & 7 & 100 \\
\hline Chicago's North Shore suburbs: IL-10 & 75 & 25 & 5 & 11 & 100 \\
\hline Southwestern Chicago suburbs: IL-11 & 66 & 34 & 9 & 14 & 100 \\
\hline Southwestern Illinois: IL-12 & 85 & 15 & 12 & 1 & 100 \\
\hline Central Illinois: IL-13 & 89 & 11 & 7 & 1 & 100 \\
\hline Western Chicago exurbs: IL-14 & 87 & 13 & 2 & 7 & 100 \\
\hline East-central and southeastern Illinois: IL-15 & 95 & 5 & 3 & 1 & 100 \\
\hline North-central Illinois: IL-16 & 92 & 8 & 2 & 4 & 100 \\
\hline Northwestern Illinois: IL-17 & 87 & 13 & 7 & 4 & 100 \\
\hline West-central Illinois: IL-18 & 94 & 6 & 2 & 1 & 100 \\
\hline Northwestern Indiana: IN-01 & 75 & 25 & 13 & 8 & 100 \\
\hline North-central Indiana: IN-02 & 91 & 9 & 5 & 3 & 100 \\
\hline Northeastern Indiana: IN-03 & 92 & 8 & 4 & 2 & 100 \\
\hline West-central Indiana: IN-04 & 93 & 7 & 3 & 2 & 100 \\
\hline Northern Indianapolis suburbs: IN-05 & 88 & 12 & 7 & 2 & 100 \\
\hline Southeastern Indiana: IN-06 & 96 & 4 & 2 & 1 & 100 \\
\hline Indianapolis: IN-07 & 74 & 26 & 19 & 4 & 100 \\
\hline Southwestern Indiana: IN-08 & 95 & 5 & 3 & 1 & 100 \\
\hline South-central Indiana and southern Indianapolis suburbs: IN-09 & 95 & 5 & 2 & 1 & 100 \\
\hline Western Kansas: KS-01 & 91 & 9 & 2 & 4 & 100 \\
\hline Topeka, Lawrence, and eastern rural Kansas: KS-02 & 92 & 8 & 2 & 2 & 100 \\
\hline Suburban Kansas City area: KS-03 & 83 & 17 & 6 & 6 & 100 \\
\hline Wichita area: KS-04 & 89 & 11 & 3 & 4 & 100 \\
\hline Western Kentucky: KY-01 & 92 & 8 & 5 & 1 & 100 \\
\hline West-central Kentucky: KY-02 & 92 & 8 & 4 & 2 & 100 \\
\hline Louisville: KY-03 & 75 & 25 & 18 & 4 & 100 \\
\hline Cincinnati suburbs and northern Kentucky border area: KY-04 & 94 & 6 & 2 & 2 & 100 \\
\hline Appalachian Kentucky: KY-05 & 98 & 2 & 1 & 0 & 100 \\
\hline Greater Lexington area: KY-06 & 88 & 12 & 6 & 3 & 100 \\
\hline Suburban New Orleans: LA-01 & 79 & 21 & 10 & 7 & 100 \\
\hline New Orleans and Baton Rouge: LA-02 & 34 & 66 & 58 & 4 & 100 \\
\hline Southwestern Louisiana: LA-03 & 74 & 26 & 21 & 3 & 100 \\
\hline Northwestern Louisiana: LA-04 & 65 & 35 & 30 & 2 & 100 \\
\hline Northeastern Louisiana: LA-05 & 66 & 34 & 31 & 2 & 100 \\
\hline Baton Rouge suburbs: LA-06 & 74 & 26 & 19 & 3 & 100 \\
\hline Springfield area and the Berkshires: MA-01 & 83 & 17 & 4 & 10 & 100 \\
\hline Worcester area and upper Pioneer Valley: MA-02 & 88 & 12 & 3 & 4 & 100 \\
\hline Lowell area and the Merrimack Valley: MA-03 & 76 & 24 & 2 & 12 & 100 \\
\hline Western Boston suburbs and Bristol County: MA-04 & 90 & 10 & 2 & 2 & 100 \\
\hline Boston's northern and outer western suburbs: MA-05 & 80 & 20 & 3 & 5 & 100 \\
\hline North Shore: MA-06 & 87 & 13 & 2 & 5 & 100 \\
\hline Central Boston area: MA-07 & 56 & 44 & 19 & 12 & 100 \\
\hline
\end{tabular}


Table S.9 - Composition of 2016 Electorate, by Race by CD (continued)

\begin{tabular}{|c|c|c|c|c|c|}
\hline & \multicolumn{5}{|c|}{ Non-Whites } \\
\hline & White & All & Black & Hisp. & All \\
\hline Southern Boston suburbs: MA-08 & 81 & 19 & 8 & 3 & 100 \\
\hline Cape Cod and South Shore: MA-09 & 92 & 8 & 2 & 2 & 100 \\
\hline Eastern Shore and Baltimore exurbs: MD-01 & 88 & 12 & 8 & 2 & 100 \\
\hline Suburban Baltimore area: MD-02 & 65 & 35 & 27 & 4 & 100 \\
\hline Baltimore suburbs to Annapolis to D.C. suburbs: MD-03 & 71 & 29 & 17 & 5 & 100 \\
\hline Prince George's County D.C. suburbs: MD-04 & 30 & 70 & 51 & 9 & 100 \\
\hline Southern Maryland and outer Prince George's County: MD-05 & 51 & 49 & 37 & 6 & 100 \\
\hline Western Maryland and Montgomery County D.C. suburbs: MD-06 & 71 & 29 & 9 & 9 & 100 \\
\hline Baltimore and western suburbs: MD-07 & 41 & 59 & 51 & 2 & 100 \\
\hline Montgomery County: MD-08 & 66 & 34 & 10 & 10 & 100 \\
\hline Portland and Augusta: ME-01 & 98 & 2 & 1 & 1 & 100 \\
\hline Northern Maine: ME-02 & 97 & 3 & 0 & 0 & 100 \\
\hline Upper Peninsula and northern Lower Peninsula: MI-01 & 96 & 4 & 1 & 1 & 100 \\
\hline Western Michigan coast: MI-02 & 88 & 12 & 4 & 5 & 100 \\
\hline Grand Rapids area: MI-03 & 89 & 11 & 5 & 3 & 100 \\
\hline Central Michigan: MI-04 & 96 & 4 & 1 & 1 & 100 \\
\hline Flint, Saginaw, and Bay City: MI-05 & 83 & 17 & 13 & 2 & 100 \\
\hline Southwestern Michigan: MI-06 & 90 & 10 & 5 & 2 & 100 \\
\hline South-central Michigan: MI-07 & 94 & 6 & 3 & 2 & 100 \\
\hline Lansing and northwestern Detroit exurbs: MI-08 & 89 & 11 & 4 & 3 & 100 \\
\hline Northern Detroit suburbs: MI-09 & 88 & 12 & 8 & 1 & 100 \\
\hline Northern Macomb County and the "Thumb" region: MI-10 & 95 & 5 & 2 & 1 & 100 \\
\hline Northwestern Detroit suburbs: MI-11 & 86 & 14 & 4 & 2 & 100 \\
\hline Ann Arbor and Dearborn: MI-12 & 85 & 15 & 7 & 3 & 100 \\
\hline Western Detroit: MI-13 & 47 & 53 & 46 & 4 & 100 \\
\hline Eastern Detroit to Pontiac: MI-14 & 39 & 61 & 54 & 3 & 100 \\
\hline Southern Minnesota: MN-01 & 92 & 8 & 1 & 4 & 100 \\
\hline Southern Twin Cities suburbs: MN-02 & 88 & 12 & 3 & 3 & 100 \\
\hline Western Twin Cities suburbs: MN-03 & 86 & 14 & 5 & 2 & 100 \\
\hline St. Paul: MN-04 & 79 & 21 & 7 & 4 & 100 \\
\hline Minneapolis: MN-05 & 74 & 26 & 12 & 5 & 100 \\
\hline Northern Twin Cities exurbs: MN-06 & 95 & 5 & 1 & 1 & 100 \\
\hline Western Minnesota: MN-07 & 95 & 5 & 1 & 2 & 100 \\
\hline Iron Range: MN-08 & 96 & 4 & 1 & 1 & 100 \\
\hline St. Louis and northwestern suburbs: MO-01 & 54 & 46 & 41 & 2 & 100 \\
\hline Suburban St. Louis: MO-02 & 91 & 9 & 3 & 2 & 100 \\
\hline East-central Missouri: MO-03 & 95 & 5 & 2 & 1 & 100 \\
\hline West-central Missouri: MO-04 & 93 & 7 & 3 & 2 & 100 \\
\hline Kansas City area: MO-05 & 77 & 23 & 15 & 4 & 100 \\
\hline Northern Missouri: MO-06 & 93 & 7 & 3 & 2 & 100 \\
\hline Southwestern Missouri: MO-07 & 95 & 5 & 1 & 2 & 100 \\
\hline Southeastern Missouri: MO-08 & 95 & 5 & 3 & 1 & 100 \\
\hline Northeastern Mississippi: MS-01 & 74 & 26 & 23 & 1 & 100 \\
\hline
\end{tabular}


Table S.9 - Composition of 2016 Electorate, by Race by CD (continued)

\begin{tabular}{|c|c|c|c|c|c|}
\hline & \multicolumn{4}{|c|}{ Non-Whites } & \multirow[b]{2}{*}{ All } \\
\hline & White & All & Black & Hisp. & \\
\hline Mississippi Delta and Jackson: MS-02 & 37 & 63 & 61 & 1 & 100 \\
\hline Southwestern and eastern Mississippi: MS-03 & 67 & 33 & 30 & 1 & 100 \\
\hline Gulf Coast: MS-04 & 78 & 22 & 18 & 2 & 100 \\
\hline All of Montana: MT-01 & 95 & 5 & 0 & 1 & 100 \\
\hline Durham and northeastern North Carolina: NC-01 & 49 & 51 & 43 & 5 & 100 \\
\hline Raleigh exurbs: NC-02 & 72 & 28 & 18 & 6 & 100 \\
\hline Eastern North Carolina coast: NC-03 & 76 & 24 & 19 & 3 & 100 \\
\hline Raleigh, Cary, Chapel Hill: NC-04 & 61 & 39 & 21 & 7 & 100 \\
\hline Winston-Salem and northwestern North Carolina: NC-05 & 81 & 19 & 13 & 5 & 100 \\
\hline Part of Greensboro and rural Piedmont: NC-06 & 73 & 27 & 19 & 5 & 100 \\
\hline Southeastern North Carolina: NC-07 & 77 & 23 & 17 & 4 & 100 \\
\hline Charlotte suburbs to Fayetteville: NC-08 & 71 & 29 & 21 & 5 & 100 \\
\hline South Charlotte to suburban Fayetteville: NC-09 & 69 & 31 & 18 & 4 & 100 \\
\hline Asheville and southwestern Piedmont: NC-10 & 84 & 16 & 10 & 3 & 100 \\
\hline Appalachian North Carolina: NC-11 & 93 & 7 & 3 & 2 & 100 \\
\hline Charlotte: NC-12 & 48 & 52 & 37 & 9 & 100 \\
\hline Greensboro and rural western Piedmont: NC-13 & 72 & 28 & 20 & 5 & 100 \\
\hline All of North Dakota: ND-01 & 95 & 5 & 1 & 1 & 100 \\
\hline Lincoln and rural eastern Nebraska: NE-01 & 92 & 8 & 1 & 3 & 100 \\
\hline Greater Omaha area: NE-02 & 85 & 15 & 6 & 5 & 100 \\
\hline Western Nebraska: NE-03 & 94 & 6 & 1 & 4 & 100 \\
\hline Eastern New Hampshire: NH-01 & 96 & 4 & 1 & 1 & 100 \\
\hline Western and northern New Hampshire: NH-02 & 95 & 5 & 1 & 1 & 100 \\
\hline Inner Philadelphia suburbs: NJ-01 & 70 & 30 & 13 & 8 & 100 \\
\hline Southern New Jersey coast: NJ-02 & 75 & 25 & 9 & 10 & 100 \\
\hline Philadelphia suburbs and central Jersey Shore: NJ-03 & 83 & 17 & 8 & 4 & 100 \\
\hline Monmouth County area: NJ-04 & 84 & 16 & 6 & 6 & 100 \\
\hline Northern Bergen County and northwestern exurbs: NJ-05 & 75 & 25 & 4 & 11 & 100 \\
\hline Northern Middlesex County and northern Jersey Shore: NJ-06 & 62 & 38 & 8 & 14 & 100 \\
\hline Hunterdon County and New York City's western exurbs: NJ-07 & 78 & 22 & 4 & 8 & 100 \\
\hline Jersey City and inner New York City suburbs: NJ-08 & 36 & 64 & 9 & 39 & 100 \\
\hline Paterson and inner New York City suburbs: NJ-09 & 49 & 51 & 8 & 25 & 100 \\
\hline Newark area: NJ-10 & 26 & 74 & 48 & 15 & 100 \\
\hline Morris County area: NJ-11 & 79 & 21 & 3 & 8 & 100 \\
\hline Trenton and southern Middlesex County: NJ-12 & 59 & 41 & 14 & 12 & 100 \\
\hline Albuquerque area: NM-01 & 53 & 47 & 2 & 34 & 100 \\
\hline Southern New Mexico: NM-02 & 58 & 42 & 2 & 33 & 100 \\
\hline Northern New Mexico: NM-03 & 51 & 49 & 1 & 31 & 100 \\
\hline Las Vegas: NV-01 & 54 & 46 & 8 & 25 & 100 \\
\hline Northern Nevada: NV-02 & 77 & 23 & 1 & 12 & 100 \\
\hline Southern Las Vegas suburbs: NV-03 & 72 & 28 & 5 & 11 & 100 \\
\hline Northern Las Vegas suburbs and rural central Nevada: NV-04 & 63 & 37 & 10 & 18 & 100 \\
\hline
\end{tabular}


Table S.9 - Composition of 2016 Electorate, by Race by CD (continued)

\begin{tabular}{|c|c|c|c|c|c|}
\hline & \multicolumn{4}{|c|}{ Non-Whites } & \multirow[b]{2}{*}{ All } \\
\hline & White & All & Black & Hisp. & \\
\hline Eastern Suffolk County: NY-01 & 85 & 15 & 4 & 8 & 100 \\
\hline Southern Long Island: NY-02 & 71 & 29 & 8 & 14 & 100 \\
\hline Northern Long Island: NY-03 & 76 & 24 & 3 & 6 & 100 \\
\hline Long Island: NY-04 & 60 & 40 & 14 & 13 & 100 \\
\hline Southeastern Queens: NY-05 & 16 & 84 & 53 & 14 & 100 \\
\hline Northeastern Queens: NY-06 & 57 & 43 & 6 & 15 & 100 \\
\hline Heavily Latino parts of northern Brooklyn and southw...: NY-07 & 40 & 60 & 12 & 27 & 100 \\
\hline Eastern Brooklyn: NY-08 & 33 & 67 & 48 & 11 & 100 \\
\hline Central Brooklyn: NY-09 & 39 & 61 & 46 & 8 & 100 \\
\hline West Side of Manhattan and part of southern Brooklyn: NY-10 & 75 & 25 & 4 & 9 & 100 \\
\hline Staten Island and part of southern Brooklyn: NY-11 & 76 & 24 & 7 & 9 & 100 \\
\hline East Side of Manhattan and nearby parts of Queens an...: NY-12 & 76 & 24 & 5 & 9 & 100 \\
\hline Harlem area: NY-13 & 16 & 84 & 27 & 34 & 100 \\
\hline East Bronx and northern Queens: NY-14 & 36 & 64 & 13 & 32 & 100 \\
\hline The Bronx: NY-15 & 3 & 97 & 31 & 41 & 100 \\
\hline Southern Westchester County and the northern Bronx: NY-16 & 45 & 55 & 31 & 15 & 100 \\
\hline Westchester County: NY-17 & 63 & 37 & 10 & 14 & 100 \\
\hline Lower Hudson Valley: NY-18 & 76 & 24 & 8 & 9 & 100 \\
\hline Hudson Valley: NY-19 & 91 & 9 & 3 & 3 & 100 \\
\hline Albany area: NY-20 & 86 & 14 & 7 & 3 & 100 \\
\hline North Country: NY-21 & 95 & 5 & 2 & 1 & 100 \\
\hline Binghamton and Utica-Rome: NY-22 & 94 & 6 & 3 & 2 & 100 \\
\hline Ithaca and southwestern New York: NY-23 & 94 & 6 & 2 & 2 & 100 \\
\hline Syracuse area: NY-24 & 90 & 10 & 6 & 2 & 100 \\
\hline Greater Rochester: NY-25 & 78 & 22 & 13 & 4 & 100 \\
\hline Greater Buffalo: NY-26 & 78 & 22 & 15 & 3 & 100 \\
\hline Suburbs and rural areas between Buffalo and Rochester: NY-27 & 96 & 4 & 2 & 1 & 100 \\
\hline Suburban Cincinnati: OH-01 & 78 & 22 & 18 & 1 & 100 \\
\hline Eastern Cincinnati and east along the Ohio River: $\mathrm{OH}-02$ & 91 & 9 & 6 & 1 & 100 \\
\hline Columbus: $\mathrm{OH}-03$ & 67 & 33 & 25 & 3 & 100 \\
\hline West-Central Ohio to North-Central Ohio: OH-04 & 93 & 7 & 4 & 2 & 100 \\
\hline Northwestern Ohio: OH-05 & 94 & 6 & 2 & 2 & 100 \\
\hline Appalachian Ohio: OH-06 & 97 & 3 & 2 & 1 & 100 \\
\hline Canton area: $\mathrm{OH}-07$ & 95 & 5 & 3 & 1 & 100 \\
\hline Cincinnati suburbs and Springfield: $\mathrm{OH}-08$ & 93 & 7 & 4 & 1 & 100 \\
\hline Toledo to West Side of Cleveland: OH-09 & 81 & 19 & 11 & 5 & 100 \\
\hline Greater Dayton area: $\mathrm{OH}-10$ & 84 & 16 & 13 & 1 & 100 \\
\hline East Cleveland to Akron: $\mathrm{OH}-11$ & 47 & 53 & 47 & 3 & 100 \\
\hline Northern Columbus area: OH-12 & 92 & 8 & 3 & 1 & 100 \\
\hline Mahoning Valley and Akron: OH-13 & 89 & 11 & 8 & 2 & 100 \\
\hline Northeastern Ohio: OH-14 & 94 & 6 & 3 & 1 & 100 \\
\hline Southern Columbus area and Athens: OH-15 & 94 & 6 & 3 & 1 & 100 \\
\hline Western suburbs of Cleveland and Akron: OH-16 & 96 & 4 & 2 & 1 & 100 \\
\hline Greater Tulsa area: OK-01 & 83 & 17 & 5 & 4 & 100 \\
\hline Eastern Oklahoma: OK-02 & 86 & 14 & 2 & 2 & 100 \\
\hline
\end{tabular}


Table S.9 - Composition of 2016 Electorate, by Race by CD (continued)

\begin{tabular}{|c|c|c|c|c|c|}
\hline & \multicolumn{4}{|c|}{ Non-Whites } & \multirow[b]{2}{*}{ All } \\
\hline & White & All & Black & Hisp. & \\
\hline Northwestern Oklahoma: OK-03 & 89 & 11 & 2 & 3 & 100 \\
\hline Southern Oklahoma: OK-04 & 87 & 13 & 3 & 3 & 100 \\
\hline Oklahoma City area: OK-05 & 81 & 19 & 6 & 5 & 100 \\
\hline Western Portland suburbs and North Coast: OR-01 & 84 & 16 & 1 & 7 & 100 \\
\hline Oregon east of the Cascades and part of southern Oregon: OR-02 & 91 & 9 & 0 & 6 & 100 \\
\hline Eastern Portland area: OR-03 & 83 & 17 & 4 & 5 & 100 \\
\hline Southern Willamette Valley and southern coast: OR-04 & 93 & 7 & 0 & 3 & 100 \\
\hline Salem area and southern Portland suburbs: OR-05 & 88 & 12 & 1 & 7 & 100 \\
\hline Philadelphia along the Delaware River and City of Ch...: PA-01 & 49 & 51 & 32 & 9 & 100 \\
\hline Philadelphia City center and Chestnut Hill sububrs: PA-02 & 33 & 67 & 58 & 3 & 100 \\
\hline Erie and northwestern Pennsylvania: PA-03 & 95 & 5 & 3 & 1 & 100 \\
\hline Harrisburg and York: PA-04 & 89 & 11 & 5 & 3 & 100 \\
\hline North-central Pennsylvania through Centre County: PA-05 & 95 & 5 & 2 & 1 & 100 \\
\hline Philadelphia's Chester County suburbs and Reading su...: PA-06 & 89 & 11 & 3 & 3 & 100 \\
\hline Philadelphia's Delaware and Montgomery County suburbs: PA-07 & 89 & 11 & 5 & 2 & 100 \\
\hline Philadelphia's Bucks County suburbs: PA-08 & 90 & 10 & 3 & 3 & 100 \\
\hline South-central Pennsylvania: PA-09 & 96 & 4 & 2 & 1 & 100 \\
\hline Williamsport area and northeastern Pennsylvania: PA-10 & 95 & 5 & 3 & 1 & 100 \\
\hline Coal Region between Wilkes-Barre and Harrisburg: PA-11 & 92 & 8 & 4 & 2 & 100 \\
\hline Beaver County through Pittsburgh's North Hills to Jo...: PA-12 & 95 & 5 & 2 & 1 & 100 \\
\hline Northeast Philadelphia and Norristown: PA-13 & 68 & 32 & 15 & 6 & 100 \\
\hline Pittsburgh: PA-14 & 78 & 22 & 17 & 1 & 100 \\
\hline Lehigh Valley stretched to Susquehanna River: PA-15 & 84 & 16 & 3 & 8 & 100 \\
\hline Reading, Lancaster, and Coatesville: PA-16 & 82 & 18 & 5 & 8 & 100 \\
\hline Scranton/Wilkes-Barre and the Slate Belt: PA-17 & 90 & 10 & 4 & 3 & 100 \\
\hline Pittsburgh's South and West Hills, Washington, Westm...: PA-18 & 96 & 4 & 2 & 1 & 100 \\
\hline Part of Prov & 83 & 17 & 4 & 7 & 100 \\
\hline Part of Providence and western Rhode Island: RI-02 & 88 & 12 & 2 & 5 & 100 \\
\hline Charleston and coastal South Carolina: SC-01 & 79 & 21 & 16 & 2 & 100 \\
\hline Augusta and Columbia suburbs: SC-02 & 75 & 25 & 20 & 2 & 100 \\
\hline Northwestern South Carolina: SC-03 & 81 & 19 & 16 & 2 & 100 \\
\hline Greenville-Spartanburg area: SC-04 & 78 & 22 & 16 & 3 & 100 \\
\hline Southern Charlotte suburbs and exurbs: SC-05 & 73 & 27 & 24 & 2 & 100 \\
\hline Black Belt, Columbia, and Charleston: SC-06 & 45 & 55 & 51 & 2 & 100 \\
\hline Northeastern South Carolina and the Myrtle Beach area: SC-07 & 74 & 26 & 23 & 2 & 100 \\
\hline All of South Dakota: SD-01 & 93 & 7 & 1 & 1 & 100 \\
\hline Northeastern Tennessee: TN-01 & 96 & 4 & 2 & 1 & 100 \\
\hline Knoxville area: $\mathrm{TN}-02$ & 92 & 8 & 4 & 2 & 100 \\
\hline Chattanooga area: $\mathrm{TN}-03$ & 90 & 10 & 7 & 2 & 100 \\
\hline Southern part of Middle Tennessee: TN-04 & 90 & 10 & 6 & 2 & 100 \\
\hline Nashville: TN-05 & 74 & 26 & 19 & 4 & 100 \\
\hline Nashville's eastern suburbs and northern Middle Tenn...: TN-06 & 94 & 6 & 3 & 2 & 100 \\
\hline Nashville's southern suburbs and western Middle Tenn...: TN-07 & 89 & 11 & 7 & 2 & 100 \\
\hline
\end{tabular}


Table S.9 - Composition of 2016 Electorate, by Race by CD (continued)

\begin{tabular}{|c|c|c|c|c|c|}
\hline & \multicolumn{4}{|c|}{ Non-Whites } & \multirow[b]{2}{*}{ All } \\
\hline & White & All & Black & Hisp. & \\
\hline West Tennessee: TN-08 & 82 & 18 & 15 & 1 & 100 \\
\hline Memphis: TN-09 & 37 & 63 & 57 & 4 & 100 \\
\hline Tyler and East Texas: TX-01 & 78 & 22 & 13 & 7 & 100 \\
\hline Northern Houston and part of west Houston: TX-02 & 62 & 38 & 9 & 19 & 100 \\
\hline Collin County: TX-03 & 72 & 28 & 8 & 9 & 100 \\
\hline Northeastern Texas: TX-04 & 84 & 16 & 7 & 6 & 100 \\
\hline Eastern edge of Dallas and rural areas to its east: TX-05 & 74 & 26 & 10 & 13 & 100 \\
\hline Arlington and rural areas south of Dallas: TX-06 & 65 & 35 & 16 & 12 & 100 \\
\hline West Houston: TX-07 & 61 & 39 & 11 & 19 & 100 \\
\hline Suburbs and exurbs north of Houston: TX-08 & 80 & 20 & 6 & 11 & 100 \\
\hline Southwest Houston: TX-09 & 21 & 79 & 38 & 28 & 100 \\
\hline Austin to western Houston: TX-10 & 67 & 33 & 8 & 16 & 100 \\
\hline Midland and San Angelo parts of rural west Texas: TX-11 & 74 & 26 & 3 & 19 & 100 \\
\hline Parker and western Tarrant Counties: TX-12 & 78 & 22 & 6 & 11 & 100 \\
\hline Texas Panhandle: TX-13 & 80 & 20 & 4 & 13 & 100 \\
\hline Galveston area: TX-14 & 67 & 33 & 16 & 13 & 100 \\
\hline McAllen in the Rio Grande Valley and rural counties ...: TX-15 & 29 & 71 & 2 & 60 & 100 \\
\hline El Paso: TX-16 & 24 & 76 & 4 & 65 & 100 \\
\hline College Station, Waco, and a slice of Austin suburbs: TX-17 & 73 & 27 & 10 & 13 & 100 \\
\hline Heavily black parts of central Houston: TX-18 & 29 & 71 & 35 & 28 & 100 \\
\hline Lubbock and rural West Texas: TX-19 & 71 & 29 & 5 & 20 & 100 \\
\hline Downtown San Antonio: TX-20 & 37 & 63 & 5 & 51 & 100 \\
\hline Parts of Austin and San Antonio connected by Texas H...: TX-21 & 73 & 27 & 3 & 19 & 100 \\
\hline Southern Houston suburbs: TX-22 & 54 & 46 & 12 & 18 & 100 \\
\hline El Paso to San Antonio: TX-23 & 38 & 62 & 3 & 51 & 100 \\
\hline Suburbs north of Dallas and Fort Worth: TX-24 & 66 & 34 & 9 & 14 & 100 \\
\hline Part of Austin and rural areas north toward Dallas-F...: TX-25 & 81 & 19 & 5 & 10 & 100 \\
\hline Denton County: TX-26 & 77 & 23 & 6 & 10 & 100 \\
\hline Corpus Christi and Victoria: TX-27 & 59 & 41 & 5 & 32 & 100 \\
\hline Laredo area: TX-28 & 32 & 68 & 5 & 58 & 100 \\
\hline Heavily Latino areas north and east of Downtown Houston: TX-29 & 22 & 78 & 13 & 55 & 100 \\
\hline Downtown and South Dallas: TX-30 & 28 & 72 & 43 & 25 & 100 \\
\hline Williamson and Bell Counties: TX-31 & 72 & 28 & 9 & 14 & 100 \\
\hline Suburban North Dallas: TX-32 & 67 & 33 & 10 & 15 & 100 \\
\hline Connects Downtown Fort Worth and west & 31 & 69 & 18 & 43 & 100 \\
\hline Brownsville in the Rio Grande Valley and ru & 29 & 71 & 2 & 64 & 100 \\
\hline San Antonio and heavily Latino areas of & 44 & 56 & 9 & 40 & 100 \\
\hline Southern part of East Texas: TX-36 & 77 & 23 & 7 & 12 & 100 \\
\hline Ogden and northern Utah: UT-01 & 90 & 10 & 1 & 5 & 100 \\
\hline Salt Lake City and southwestern Utah: UT-02 & 88 & 12 & 1 & 6 & 100 \\
\hline Provo area and southeastern Utah: UT-03 & 91 & 9 & 0 & 5 & 100 \\
\hline Southern Salt Lake County and rural areas to the south: UT-04 & 86 & 14 & 1 & 7 & 100 \\
\hline Western Chesapeake Bay and exurbs of D.C. and Richmond: VA-01 & 73 & 27 & 15 & 6 & 100 \\
\hline Virginia Beach: VA-02 & 74 & 26 & 15 & 4 & 100 \\
\hline Hampton Roads: VA-03 & 50 & 50 & 43 & 3 & 100 \\
\hline
\end{tabular}


Table S.9 - Composition of 2016 Electorate, by Race by CD (continued)

\begin{tabular}{|c|c|c|c|c|c|}
\hline & \multicolumn{4}{|c|}{ Non-Whites } & \multirow[b]{2}{*}{ All } \\
\hline & White & All & Black & Hisp. & \\
\hline Richmond and Southside Virginia: VA-04 & 56 & 44 & 38 & 3 & 100 \\
\hline Charlottesville and South-central Virginia: VA-05 & 81 & 19 & 15 & 2 & 100 \\
\hline Shenandoah Valley: VA-06 & 89 & 11 & 7 & 2 & 100 \\
\hline Suburban Richmond: VA-07 & 74 & 26 & 16 & 4 & 100 \\
\hline Inner D.C. suburbs: VA-08 & 59 & 41 & 11 & 15 & 100 \\
\hline Southwest Virginia: VA-09 & 94 & 6 & 4 & 1 & 100 \\
\hline Loudoun County and D.C. suburbs and exurbs: VA-10 & 68 & 32 & 5 & 11 & 100 \\
\hline D.C. suburbs in Fairfax and Prince William Counties: VA-11 & 54 & 46 & 10 & 16 & 100 \\
\hline All of Vermont: VT-01 & 98 & 2 & 0 & 1 & 100 \\
\hline Northern Seattle suburbs: WA-01 & 86 & 14 & 1 & 4 & 100 \\
\hline Northern Puget Sound: WA-02 & 86 & 14 & 2 & 5 & 100 \\
\hline Vancouver and southwestern Washington: WA-03 & 92 & 8 & 1 & 4 & 100 \\
\hline Yakima and the Tri-Cities: WA-04 & 75 & 25 & 1 & 15 & 100 \\
\hline Spokane area and rural eastern Washington: WA-05 & 93 & 7 & 1 & 3 & 100 \\
\hline Olympic Peninsula and Tacoma: WA-06 & 90 & 10 & 2 & 3 & 100 \\
\hline Seattle: WA-07 & 78 & 22 & 4 & 5 & 100 \\
\hline Eastern Seattle suburbs and two rural counties east ...: WA-08 & 86 & 14 & 2 & 5 & 100 \\
\hline Southeastern Seattle and the suburbs to its south an...: WA-09 & 66 & 34 & 8 & 7 & 100 \\
\hline Olympia area and Tacoma suburbs: WA-10 & 85 & 15 & 3 & 5 & 100 \\
\hline Southeastern Wisconsin: WI-01 & 89 & 11 & 3 & 6 & 100 \\
\hline Madison area: WI-02 & 89 & 11 & 3 & 3 & 100 \\
\hline Southwestern Wisconsin: WI-03 & 97 & 3 & 1 & 1 & 100 \\
\hline Milwaukee: WI-04 & 55 & 45 & 28 & 10 & 100 \\
\hline Milwaukee suburbs: WI-05 & 92 & 8 & 1 & 3 & 100 \\
\hline Fox River Valley and Sheboygan: WI-06 & 96 & 4 & 1 & 2 & 100 \\
\hline Northwestern Wisconsin: WI-07 & 97 & 3 & 0 & 1 & 100 \\
\hline Northeastern Wisconsin: WI-08 & 94 & 6 & 1 & 2 & 100 \\
\hline Northern West Virginia: WV-01 & 97 & 3 & 2 & 1 & 100 \\
\hline Charleston to the Eastern Panhandle: WV-02 & 95 & 5 & 3 & 1 & 100 \\
\hline Southern West Virginia: WV-03 & 96 & 4 & 3 & 1 & 100 \\
\hline All of Wyoming: WY-01 & 93 & 7 & 0 & 4 & 100 \\
\hline National & 74 & 26 & 10 & 9 & 100 \\
\hline
\end{tabular}


Table S.10 - Composition of 2020 Electorate, by Race by CD

\begin{tabular}{|c|c|c|c|c|c|}
\hline & \multicolumn{4}{|c|}{ Non-Whites } & \multirow[b]{2}{*}{ All } \\
\hline & White & All & Black & Hisp. & \\
\hline All of Alaska: AK-01 & 73 & 27 & 3 & 4 & 100 \\
\hline Greater Mobile: AL-01 & 72 & 28 & 24 & 2 & 100 \\
\hline Southeastern Alabama: AL-02 & 68 & 32 & 27 & 2 & 100 \\
\hline Eastern Alabama: AL-03 & 74 & 26 & 22 & 1 & 100 \\
\hline North-central Alabama: AL-04 & 90 & 10 & 5 & 2 & 100 \\
\hline Northern Alabama: AL-05 & 78 & 22 & 15 & 3 & 100 \\
\hline Birmingham suburbs: AL-06 & 77 & 23 & 16 & 3 & 100 \\
\hline Birmingham and the Black Belt: AL-07 & 37 & 63 & 60 & 2 & 100 \\
\hline Northeastern Arkansas: AR-01 & 86 & 14 & 11 & 1 & 100 \\
\hline Greater Little Rock: AR-02 & 77 & 23 & 18 & 2 & 100 \\
\hline Northwest Arkansas: AR-03 & 83 & 17 & 2 & 7 & 100 \\
\hline Southern and western Arkansas: AR-04 & 82 & 18 & 13 & 2 & 100 \\
\hline Northeastern Arizona: AZ-01 & 61 & 39 & 2 & 16 & 100 \\
\hline Southeastern Arizona and eastern Tucson area: AZ-02 & 67 & 33 & 3 & 19 & 100 \\
\hline Southwestern Arizona and western Tucson area: AZ-03 & 38 & 62 & 4 & 39 & 100 \\
\hline North-central Arizona and Phoenix exurbs: AZ-04 & 83 & 17 & 1 & 9 & 100 \\
\hline Phoenix suburbs of Mesa and Gilbert: AZ-05 & 75 & 25 & 3 & 11 & 100 \\
\hline Scottsdale and North Phoenix: AZ-06 & 78 & 22 & 2 & 11 & 100 \\
\hline Downtown and West Phoenix: AZ-07 & 36 & 64 & 9 & 36 & 100 \\
\hline Western suburbs of Phoenix: AZ-08 & 73 & 27 & 3 & 13 & 100 \\
\hline Central Phoenix and eastern suburbs: AZ-09 & 67 & 33 & 5 & 16 & 100 \\
\hline Northeastern California: CA-01 & 87 & 13 & 1 & 7 & 100 \\
\hline Northern California coast: CA-02 & 80 & 20 & 1 & 9 & 100 \\
\hline Southern Sacramento Valley: CA-03 & 61 & 39 & 6 & 19 & 100 \\
\hline Northern Sacramento suburbs and Sierra Nevada foothi...: CA-04 & 82 & 18 & 1 & 8 & 100 \\
\hline Wine country: CA-05 & 62 & 38 & 5 & 16 & 100 \\
\hline Sacramento: CA-06 & 50 & 50 & 11 & 18 & 100 \\
\hline Suburban Sacramento County: CA-07 & 63 & 37 & 6 & 11 & 100 \\
\hline Northern San Bernardino County and the High Desert: CA-08 & 60 & 40 & 7 & 26 & 100 \\
\hline Stockton area and eastern Contra Costa County: CA-09 & 47 & 53 & 8 & 24 & 100 \\
\hline Modesto area: CA-10 & 57 & 43 & 3 & 28 & 100 \\
\hline Contra Costa County: CA-11 & 56 & 44 & 7 & 16 & 100 \\
\hline San Francisco: CA-12 & 54 & 46 & 5 & 11 & 100 \\
\hline Oakland area: CA-13 & 43 & 57 & 16 & 14 & 100 \\
\hline San Mateo County: CA-14 & 45 & 55 & 3 & 16 & 100 \\
\hline Eastern Alameda County: CA-15 & 45 & 55 & 5 & 15 & 100 \\
\hline Fresno area: CA-16 & 37 & 63 & 6 & 38 & 100 \\
\hline Northeast San Jose area: CA-17 & 37 & 63 & 3 & 14 & 100 \\
\hline Silicon Valley: CA-18 & 66 & 34 & 2 & 10 & 100 \\
\hline San Jose: CA-19 & 35 & 65 & 3 & 26 & 100 \\
\hline Monterey Bay: CA-20 & 49 & 51 & 2 & 30 & 100 \\
\hline Southern Central Valley and part of Bakersfield: CA-21 & 35 & 65 & 5 & 40 & 100 \\
\hline Central Valley near Fresno and Tulare: CA-22 & 51 & 49 & 3 & 32 & 100 \\
\hline Bakersfield area: CA-23 & 59 & 41 & 5 & 25 & 100 \\
\hline
\end{tabular}


Table S.10 - Composition of 2020 Electorate, by Race by CD (continued)

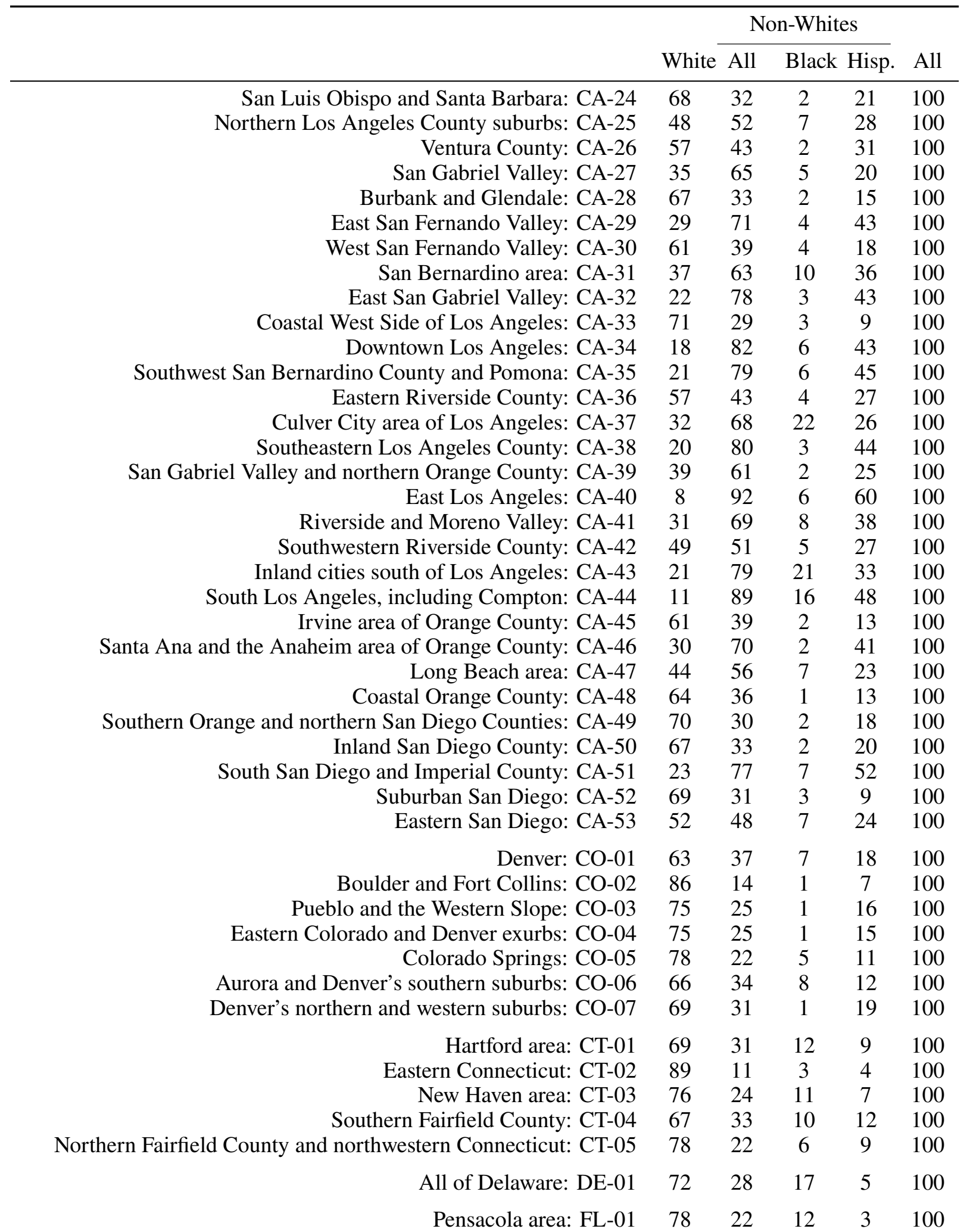


Table S.10 - Composition of 2020 Electorate, by Race by CD (continued)

\begin{tabular}{|c|c|c|c|c|c|}
\hline & \multicolumn{4}{|c|}{ Non-Whites } & \multirow[b]{2}{*}{ All } \\
\hline & White & All & Black & Hisp. & \\
\hline Florida panhandle: FL-02 & 84 & 16 & 10 & 3 & 100 \\
\hline North Florida, including Gainesville and Ocala: FL-03 & 77 & 23 & 14 & 5 & 100 \\
\hline Part of the Jacksonville area and St. Augustine: FL-04 & 80 & 20 & 8 & 5 & 100 \\
\hline Jacksonville and Tallahassee areas: FL-05 & 47 & 53 & 45 & 4 & 100 \\
\hline Daytona area: FL-06 & 82 & 18 & 8 & 7 & 100 \\
\hline Northern Orlando suburbs: FL-07 & 64 & 36 & 9 & 19 & 100 \\
\hline Space Coast: FL-08 & 82 & 18 & 8 & 6 & 100 \\
\hline Southern suburbs of Orlando: FL-09 & 48 & 52 & 11 & 32 & 100 \\
\hline Orlando: FL-10 & 45 & 55 & 25 & 20 & 100 \\
\hline North-central Florida and The Villages: FL-11 & 87 & 13 & 5 & 6 & 100 \\
\hline Northern Tampa suburbs: FL-12 & 84 & 16 & 4 & 8 & 100 \\
\hline St. Petersburg area: FL-13 & 82 & 18 & 9 & 5 & 100 \\
\hline Tampa area: FL-14 & 56 & 44 & 15 & 23 & 100 \\
\hline Lakeland and the exurbs of Tampa and Orlando: FL-15 & 68 & 32 & 12 & 14 & 100 \\
\hline Sarasota area: FL-16 & 81 & 19 & 6 & 9 & 100 \\
\hline South-central Florida: FL-17 & 86 & 14 & 5 & 7 & 100 \\
\hline Treasure Coast and Palm Beach area: FL-18 & 75 & 25 & 11 & 10 & 100 \\
\hline Cape Coral and Fort Myers: FL-19 & 83 & 17 & 5 & 10 & 100 \\
\hline West Palm Beach and Fort Lauderdale areas: FL-20 & 27 & 73 & 50 & 19 & 100 \\
\hline Southeast Palm Beach County: FL-21 & 70 & 30 & 11 & 15 & 100 \\
\hline Boca Raton and northeast Broward County: FL-22 & 69 & 31 & 11 & 14 & 100 \\
\hline Broward County-centered: FL-23 & 49 & 51 & 12 & 32 & 100 \\
\hline Northern Miami: FL-24 & 16 & 84 & 46 & 33 & 100 \\
\hline Northwestern Miami suburbs and eastern Collier Count...: FL-25 & 29 & 71 & 5 & 63 & 100 \\
\hline Southwestern Miami area and the Florida Keys: FL-26 & 21 & 79 & 10 & 65 & 100 \\
\hline Southern Miami area and Coral Gables: FL-27 & 26 & 74 & 5 & 64 & 100 \\
\hline Coastal Georgia: GA-01 & 69 & 31 & 26 & 3 & 100 \\
\hline Southwestern Georgia: GA-02 & 50 & 50 & 46 & 2 & 100 \\
\hline Southwestern Atlanta exurbs: GA-03 & 72 & 28 & 22 & 4 & 100 \\
\hline Eastern Atlanta suburbs: GA-04 & 28 & 72 & 62 & 5 & 100 \\
\hline Downtown Atlanta: GA-05 & 34 & 66 & 59 & 3 & 100 \\
\hline Northern Atlanta suburbs: GA-06 & 65 & 35 & 14 & 9 & 100 \\
\hline Northeastern Atlanta suburbs: GA-07 & 51 & 49 & 18 & 14 & 100 \\
\hline South-central Georgia: GA-08 & 69 & 31 & 27 & 3 & 100 \\
\hline Northeastern Georgia: GA-09 & 84 & 16 & 5 & 9 & 100 \\
\hline East-Central Georgia: GA-10 & 72 & 28 & 23 & 3 & 100 \\
\hline Northwestern Atlanta suburbs and exurbs: GA-11 & 73 & 27 & 14 & 8 & 100 \\
\hline Augusta and southeastern Georgia: GA-12 & 64 & 36 & 31 & 3 & 100 \\
\hline Southwestern Atlanta suburbs: GA-13 & 29 & 71 & 61 & 5 & 100 \\
\hline Northwestern Georgia: GA-14 & 86 & 14 & 7 & 6 & 100 \\
\hline Honolulu: HI-01 & 28 & 72 & 3 & 8 & 100 \\
\hline Northern Oahu and all other islands: HI-02 & 48 & 52 & 2 & 9 & 100 \\
\hline Northeastern Iowa: IA-01 & 95 & 5 & 2 & 2 & 100 \\
\hline Southeastern Iowa: IA- 02 & 92 & 8 & 3 & 3 & 100 \\
\hline Des Moines and southwestern Iowa: IA-03 & 89 & 11 & 2 & 4 & 100 \\
\hline
\end{tabular}


Table S.10 - Composition of 2020 Electorate, by Race by CD (continued)

\begin{tabular}{|c|c|c|c|c|c|}
\hline & & & n-White & & \\
\hline & White & All & Black & Hisp. & All \\
\hline Northwestern Iowa: IA-04 & 93 & 7 & 1 & 3 & 100 \\
\hline Idaho Panhandle and western Boise area: ID-01 & 87 & 13 & 0 & 6 & 100 \\
\hline Boise and Eastern Idaho: ID-02 & 86 & 14 & 0 & 8 & 100 \\
\hline South Side Chicago and southern suburbs: IL-01 & 44 & 56 & 47 & 6 & 100 \\
\hline South Side Chicago and southwestern suburbs: IL-02 & 39 & 61 & 50 & 8 & 100 \\
\hline Southwestern Chicago area: IL-03 & 72 & 28 & 5 & 16 & 100 \\
\hline Heavily Latino areas of Chicago's West and South sid...: IL-04 & 35 & 65 & 4 & 43 & 100 \\
\hline North Side Chicago: IL-05 & 79 & 21 & 3 & 11 & 100 \\
\hline Western Chicago suburbs: IL-06 & 83 & 17 & 2 & 6 & 100 \\
\hline West Side and Downtown Chicago: IL-07 & 41 & 59 & 43 & 9 & 100 \\
\hline Northwestern Chicago suburbs: IL-08 & 72 & 28 & 4 & 13 & 100 \\
\hline Northern Chicago Suburbs: IL-09 & 76 & 24 & 8 & 7 & 100 \\
\hline Chicago's North Shore suburbs: IL-10 & 74 & 26 & 6 & 11 & 100 \\
\hline Southwestern Chicago suburbs: IL-11 & 67 & 33 & 9 & 15 & 100 \\
\hline Southwestern Illinois: IL-12 & 86 & 14 & 11 & 2 & 100 \\
\hline Central Illinois: IL-13 & 89 & 11 & 7 & 2 & 100 \\
\hline Western Chicago exurbs: IL-14 & 86 & 14 & 2 & 7 & 100 \\
\hline East-central and southeastern Illinois: IL-15 & 95 & 5 & 2 & 1 & 100 \\
\hline North-central Illinois: IL-16 & 92 & 8 & 2 & 4 & 100 \\
\hline Northwestern Illinois: IL-17 & 87 & 13 & 7 & 4 & 100 \\
\hline West-central Illinois: IL-18 & 95 & 5 & 2 & 1 & 100 \\
\hline Northwestern Indiana: IN-01 & 73 & 27 & 13 & 8 & 100 \\
\hline North-central Indiana: IN-02 & 90 & 10 & 5 & 3 & 100 \\
\hline Northeastern Indiana: IN-03 & 91 & 9 & 4 & 2 & 100 \\
\hline West-central Indiana: IN-04 & 93 & 7 & 3 & 2 & 100 \\
\hline Northern Indianapolis suburbs: IN-05 & 86 & 14 & 7 & 2 & 100 \\
\hline Southeastern Indiana: IN-06 & 95 & 5 & 2 & 1 & 100 \\
\hline Indianapolis: IN-07 & 74 & 26 & 18 & 4 & 100 \\
\hline Southwestern Indiana: IN-08 & 95 & 5 & 3 & 1 & 100 \\
\hline South-central Indiana and southern Indianapolis suburbs: IN-09 & 94 & 6 & 2 & 1 & 100 \\
\hline Western Kansas: KS-01 & 89 & 11 & 2 & 6 & 100 \\
\hline Topeka, Lawrence, and eastern rural Kansas: KS-02 & 91 & 9 & 3 & 3 & 100 \\
\hline Suburban Kansas City area: KS-03 & 76 & 24 & 8 & 7 & 100 \\
\hline Wichita area: KS-04 & 85 & 15 & 5 & 5 & 100 \\
\hline Western Kentucky: KY-01 & 93 & 7 & 4 & 1 & 100 \\
\hline West-central Kentucky: KY-02 & 92 & 8 & 4 & 1 & 100 \\
\hline Louisville: KY-03 & 74 & 26 & 19 & 3 & 100 \\
\hline Cincinnati suburbs and northern Kentucky border area: KY-04 & 93 & 7 & 2 & 2 & 100 \\
\hline Appalachian Kentucky: KY-05 & 98 & 2 & 1 & 0 & 100 \\
\hline Greater Lexington area: KY-06 & 88 & 12 & 7 & 2 & 100 \\
\hline Suburban New Orleans: LA-01 & 76 & 24 & 11 & 6 & 100 \\
\hline New Orleans and Baton Rouge: LA-02 & 33 & 67 & 58 & 5 & 100 \\
\hline Southwestern Louisiana: LA-03 & 74 & 26 & 21 & 2 & 100 \\
\hline
\end{tabular}


Table S.10 - Composition of 2020 Electorate, by Race by CD (continued)

\begin{tabular}{|c|c|c|c|c|c|}
\hline & \multicolumn{4}{|c|}{ Non-Whites } & \multirow[b]{2}{*}{ All } \\
\hline & White & All & Black & Hisp. & \\
\hline Northwestern Louisiana: LA-04 & 65 & 35 & 30 & 2 & 100 \\
\hline Northeastern Louisiana: LA-05 & 66 & 34 & 31 & 1 & 100 \\
\hline Baton Rouge suburbs: LA-06 & 72 & 28 & 21 & 3 & 100 \\
\hline Springfield area and the Berkshires: MA- 01 & 83 & 17 & 4 & 8 & 100 \\
\hline Worcester area and upper Pioneer Valley: MA-02 & 86 & 14 & 4 & 5 & 100 \\
\hline Lowell area and the Merrimack Valley: MA-03 & 73 & 27 & 3 & 13 & 100 \\
\hline Western Boston suburbs and Bristol County: MA-04 & 87 & 13 & 2 & 2 & 100 \\
\hline Boston's northern and outer western suburbs: MA-05 & 78 & 22 & 4 & 6 & 100 \\
\hline North Shore: MA-06 & 85 & 15 & 3 & 6 & 100 \\
\hline Central Boston area: MA-07 & 59 & 41 & 16 & 12 & 100 \\
\hline Southern Boston suburbs: MA-08 & 79 & 21 & 9 & 3 & 100 \\
\hline Cape Cod and South Shore: MA-09 & 91 & 9 & 2 & 2 & 100 \\
\hline Eastern Shore and Baltimore exurbs: MD-01 & 85 & 15 & 10 & 2 & 100 \\
\hline Suburban Baltimore area: MD-02 & 64 & 36 & 26 & 3 & 100 \\
\hline Baltimore suburbs to Annapolis to D.C. suburbs: MD-03 & 69 & 31 & 18 & 5 & 100 \\
\hline Prince George's County D.C. suburbs: MD-04 & 29 & 71 & 49 & 11 & 100 \\
\hline Southern Maryland and outer Prince George's County: MD-05 & 48 & 52 & 38 & 5 & 100 \\
\hline Western Maryland and Montgomery County D.C. suburbs: MD-06 & 69 & 31 & 11 & 7 & 100 \\
\hline Baltimore and western suburbs: MD-07 & 45 & 55 & 45 & 3 & 100 \\
\hline Montgomery County: MD-08 & 65 & 35 & 11 & 10 & 100 \\
\hline Portland and Augusta: ME-01 & 96 & 4 & 1 & 1 & 100 \\
\hline Northern Maine: ME-02 & 97 & 3 & 0 & 1 & 100 \\
\hline Upper Peninsula and northern Lower Peninsula: MI-01 & 95 & 5 & 1 & 1 & 100 \\
\hline Western Michigan coast: MI-02 & 84 & 16 & 5 & 6 & 100 \\
\hline Grand Rapids area: MI-03 & 86 & 14 & 5 & 5 & 100 \\
\hline Central Michigan: MI-04 & 95 & 5 & 1 & 2 & 100 \\
\hline Flint, Saginaw, and Bay City: MI-05 & 81 & 19 & 14 & 3 & 100 \\
\hline Southwestern Michigan: MI-06 & 87 & 13 & 6 & 3 & 100 \\
\hline South-central Michigan: MI-07 & 93 & 7 & 3 & 2 & 100 \\
\hline Lansing and northwestern Detroit exurbs: MI-08 & 87 & 13 & 4 & 4 & 100 \\
\hline Northern Detroit suburbs: MI-09 & 84 & 16 & 10 & 1 & 100 \\
\hline Northern Macomb County and the "Thumb" region: MI-10 & 93 & 7 & 2 & 2 & 100 \\
\hline Northwestern Detroit suburbs: MI-11 & 82 & 18 & 4 & 2 & 100 \\
\hline Ann Arbor and Dearborn: MI-12 & 81 & 19 & 8 & 4 & 100 \\
\hline Western Detroit: MI-13 & 45 & 55 & 46 & 5 & 100 \\
\hline Eastern Detroit to Pontiac: MI-14 & 39 & 61 & 53 & 2 & 100 \\
\hline Southern Minnesota: MN-01 & 91 & 9 & 2 & 4 & 100 \\
\hline Southern Twin Cities suburbs: MN-02 & 84 & 16 & 4 & 4 & 100 \\
\hline Western Twin Cities suburbs: MN-03 & 81 & 19 & 6 & 3 & 100 \\
\hline St. Paul: MN-04 & 75 & 25 & 8 & 4 & 100 \\
\hline Minneapolis: MN-05 & 71 & 29 & 13 & 6 & 100 \\
\hline Northern Twin Cities exurbs: MN-06 & 93 & 7 & 2 & 2 & 100 \\
\hline Western Minnesota: MN-07 & 94 & 6 & 1 & 3 & 100 \\
\hline Iron Range: MN-08 & 95 & 5 & 1 & 1 & 100 \\
\hline
\end{tabular}


Table S.10 - Composition of 2020 Electorate, by Race by CD (continued)

\begin{tabular}{|c|c|c|c|c|c|}
\hline & \multicolumn{4}{|c|}{ Non-Whites } & \multirow[b]{2}{*}{ All } \\
\hline & White & All & Black & Hisp. & \\
\hline St. Louis and northwestern suburbs: MO-01 & 55 & 45 & 39 & 2 & 100 \\
\hline Suburban St. Louis: MO-02 & 90 & 10 & 3 & 1 & 100 \\
\hline East-central Missouri: MO-03 & 94 & 6 & 2 & 1 & 100 \\
\hline West-central Missouri: MO-04 & 93 & 7 & 3 & 1 & 100 \\
\hline Kansas City area: MO-05 & 77 & 23 & 15 & 4 & 100 \\
\hline Northern Missouri: MO-06 & 92 & 8 & 3 & 2 & 100 \\
\hline Southwestern Missouri: MO-07 & 94 & 6 & 1 & 2 & 100 \\
\hline Southeastern Missouri: MO-08 & 95 & 5 & 3 & 1 & 100 \\
\hline Northeastern Mississippi: MS-01 & 72 & 28 & 25 & 2 & 100 \\
\hline Mississippi Delta and Jackson: MS-02 & 37 & 63 & 61 & 1 & 100 \\
\hline Southwestern and eastern Mississippi: MS-03 & 64 & 36 & 32 & 1 & 100 \\
\hline Gulf Coast: MS-04 & 78 & 22 & 17 & 2 & 100 \\
\hline All of Montana: MT-01 & 92 & 8 & 0 & 2 & 100 \\
\hline Durham and northeastern North Carolina: NC-01 & 52 & 48 & 40 & 4 & 100 \\
\hline Raleigh exurbs: NC-02 & 69 & 31 & 18 & 7 & 100 \\
\hline Eastern North Carolina coast: NC-03 & 75 & 25 & 17 & 3 & 100 \\
\hline Raleigh, Cary, Chapel Hill: NC-04 & 58 & 42 & 21 & 7 & 100 \\
\hline Winston-Salem and northwestern North Carolina: NC-05 & 80 & 20 & 13 & 4 & 100 \\
\hline Part of Greensboro and rural Piedmont: NC-06 & 71 & 29 & 19 & 6 & 100 \\
\hline Southeastern North Carolina: NC-07 & 74 & 26 & 17 & 5 & 100 \\
\hline Charlotte suburbs to Fayetteville: NC-08 & 67 & 33 & 21 & 5 & 100 \\
\hline South Charlotte to suburban Fayetteville: NC-09 & 67 & 33 & 17 & 5 & 100 \\
\hline Asheville and southwestern Piedmont: NC-10 & 83 & 17 & 10 & 4 & 100 \\
\hline Appalachian North Carolina: NC-11 & 91 & 9 & 2 & 3 & 100 \\
\hline Charlotte: NC-12 & 44 & 56 & 35 & 10 & 100 \\
\hline Greensboro and rural western Piedmont: NC-13 & 72 & 28 & 19 & 4 & 100 \\
\hline All of North Dakota: ND-01 & 93 & 7 & 2 & 1 & 100 \\
\hline Lincoln and rural eastern Nebraska: NE-01 & 89 & 11 & 2 & 5 & 100 \\
\hline Greater Omaha area: NE-02 & 79 & 21 & 9 & 6 & 100 \\
\hline Western Nebraska: NE-03 & 90 & 10 & 1 & 6 & 100 \\
\hline Eastern New Hampshire: NH-01 & 94 & 6 & 1 & 1 & 100 \\
\hline Western and northern New Hampshire: NH-02 & 95 & 5 & 1 & 2 & 100 \\
\hline Inner Philadelphia suburbs: NJ-01 & 70 & 30 & 13 & 7 & 100 \\
\hline Southern New Jersey coast: NJ-02 & 75 & 25 & 9 & 9 & 100 \\
\hline Philadelphia suburbs and central Jersey Shore: NJ-03 & 82 & 18 & 9 & 4 & 100 \\
\hline Monmouth County area: NJ-04 & 84 & 16 & 4 & 6 & 100 \\
\hline Northern Bergen County and northwestern exurbs: NJ-05 & 74 & 26 & 4 & 10 & 100 \\
\hline Northern Middlesex County and northern Jersey Shore: NJ-06 & 63 & 37 & 9 & 13 & 100 \\
\hline Hunterdon County and New York City's western exurbs: NJ-07 & 75 & 25 & 4 & 8 & 100 \\
\hline Jersey City and inner New York City suburbs: NJ-08 & 42 & 58 & 10 & 27 & 100 \\
\hline Paterson and inner New York City suburbs: NJ-09 & 50 & 50 & 9 & 21 & 100 \\
\hline Newark area: $\mathrm{NJ}-10$ & 29 & 71 & 43 & 15 & 100 \\
\hline
\end{tabular}


Table S.10 - Composition of 2020 Electorate, by Race by CD (continued)

\begin{tabular}{|c|c|c|c|c|c|}
\hline & \multicolumn{4}{|c|}{ Non-Whites } & \multirow[b]{2}{*}{ All } \\
\hline & White & All & Black & Hisp. & \\
\hline Morris County area: NJ-11 & 79 & 21 & 3 & 7 & 100 \\
\hline Trenton and southern Middlesex County: NJ-12 & 59 & 41 & 15 & 11 & 100 \\
\hline Albuquerque area: NM-01 & 47 & 53 & 2 & 33 & 100 \\
\hline Southern New Mexico: NM-02 & 51 & 49 & 2 & 34 & 100 \\
\hline Northern New Mexico: NM-03 & 45 & 55 & 1 & 31 & 100 \\
\hline Las Vegas: NV-01 & 48 & 52 & 10 & 24 & 100 \\
\hline Northern Nevada: NV-02 & 70 & 30 & 1 & 15 & 100 \\
\hline Southern Las Vegas suburbs: NV-03 & 61 & 39 & 7 & 12 & 100 \\
\hline Northern Las Vegas suburbs and rural central Nevada: NV-04 & 52 & 48 & 14 & 18 & 100 \\
\hline Eastern Suffolk County: NY-01 & 82 & 18 & 4 & 9 & 100 \\
\hline Southern Long Island: NY-02 & 69 & 31 & 8 & 15 & 100 \\
\hline Northern Long Island: NY-03 & 76 & 24 & 3 & 6 & 100 \\
\hline Long Island: NY-04 & 59 & 41 & 14 & 13 & 100 \\
\hline Southeastern Queens: NY-05 & 17 & 83 & 51 & 14 & 100 \\
\hline Northeastern Queens: NY-06 & 56 & 44 & 6 & 13 & 100 \\
\hline Heavily Latino parts of northern Brooklyn and southw...: NY-07 & 43 & 57 & 11 & 24 & 100 \\
\hline Eastern Brooklyn: NY-08 & 37 & 63 & 45 & 11 & 100 \\
\hline Central Brooklyn: NY-09 & 42 & 58 & 44 & 7 & 100 \\
\hline West Side of Manhattan and part of southern Brooklyn: NY-10 & 78 & 22 & 5 & 8 & 100 \\
\hline Staten Island and part of southern Brooklyn: NY-11 & 77 & 23 & 6 & 9 & 100 \\
\hline East Side of Manhattan and nearby parts of Queens an...: NY-12 & 78 & 22 & 5 & 8 & 100 \\
\hline Harlem area: NY-13 & 20 & 80 & 26 & 33 & 100 \\
\hline East Bronx and northern Queens: NY-14 & 35 & 65 & 12 & 30 & 100 \\
\hline The Bronx: NY-15 & 4 & 96 & 31 & 40 & 100 \\
\hline Southern Westchester County and the northern Bronx: NY-16 & 46 & 54 & 30 & 15 & 100 \\
\hline Westchester County: NY-17 & 66 & 34 & 9 & 13 & 100 \\
\hline Lower Hudson Valley: NY-18 & 76 & 24 & 8 & 10 & 100 \\
\hline Hudson Valley: NY-19 & 91 & 9 & 3 & 3 & 100 \\
\hline Albany area: NY-20 & 87 & 13 & 7 & 3 & 100 \\
\hline North Country: NY-21 & 95 & 5 & 2 & 1 & 100 \\
\hline Binghamton and Utica-Rome: NY-22 & 94 & 6 & 2 & 1 & 100 \\
\hline Ithaca and southwestern New York: NY-23 & 95 & 5 & 2 & 1 & 100 \\
\hline Syracuse area: NY-24 & 91 & 9 & 5 & 2 & 100 \\
\hline Greater Rochester: NY-25 & 79 & 21 & 13 & 4 & 100 \\
\hline Greater Buffalo: NY-26 & 81 & 19 & 13 & 3 & 100 \\
\hline Suburbs and rural areas between Buffalo and Rochester: NY-27 & 96 & 4 & 2 & 1 & 100 \\
\hline Suburban Cincinnati: OH-01 & 77 & 23 & 18 & 1 & 100 \\
\hline Eastern Cincinnati and east along the Ohio River: $\mathrm{OH}-02$ & 91 & 9 & 6 & 1 & 100 \\
\hline Columbus: $\mathrm{OH}-03$ & 68 & 32 & 25 & 3 & 100 \\
\hline West-Central Ohio to North-Central Ohio: OH-04 & 93 & 7 & 4 & 2 & 100 \\
\hline Northwestern Ohio: OH-05 & 93 & 7 & 2 & 3 & 100 \\
\hline Appalachian Ohio: OH-06 & 97 & 3 & 2 & 1 & 100 \\
\hline Canton area: $\mathrm{OH}-07$ & 96 & 4 & 3 & 1 & 100 \\
\hline Cincinnati suburbs and Springfield: $\mathrm{OH}-08$ & 92 & 8 & 4 & 1 & 100 \\
\hline
\end{tabular}


Table S.10 - Composition of 2020 Electorate, by Race by CD (continued)

\begin{tabular}{|c|c|c|c|c|c|}
\hline & \multicolumn{4}{|c|}{ Non-Whites } & \multirow[b]{2}{*}{ All } \\
\hline & White & All & Black & Hisp. & \\
\hline Toledo to West Side of Cleveland: OH-09 & 83 & 17 & 10 & 4 & 100 \\
\hline Greater Dayton area: $\mathrm{OH}-10$ & 84 & 16 & 13 & 1 & 100 \\
\hline East Cleveland to Akron: $\mathrm{OH}-11$ & 50 & 50 & 45 & 2 & 100 \\
\hline Northern Columbus area: OH-12 & 90 & 10 & 4 & 1 & 100 \\
\hline Mahoning Valley and Akron: $\mathrm{OH}-13$ & 90 & 10 & 7 & 1 & 100 \\
\hline Northeastern Ohio: OH-14 & 94 & 6 & 3 & 1 & 100 \\
\hline Southern Columbus area and Athens: OH-15 & 94 & 6 & 3 & 1 & 100 \\
\hline Western suburbs of Cleveland and Akron: OH-16 & 95 & 5 & 2 & 1 & 100 \\
\hline Greater Tulsa area: OK-01 & 82 & 18 & 6 & 5 & 100 \\
\hline Eastern Oklahoma: OK-02 & 87 & 13 & 3 & 3 & 100 \\
\hline Northwestern Oklahoma: OK-03 & 89 & 11 & 3 & 4 & 100 \\
\hline Southern Oklahoma: OK-04 & 87 & 13 & 4 & 4 & 100 \\
\hline Oklahoma City area: OK-05 & 79 & 21 & 9 & 6 & 100 \\
\hline Western Portland suburbs and North Coast: OR-01 & 79 & 21 & 1 & 9 & 100 \\
\hline Oregon east of the Cascades and part of southern Oregon: OR-02 & 88 & 12 & 0 & 7 & 100 \\
\hline Eastern Portland area: OR-03 & 81 & 19 & 3 & 7 & 100 \\
\hline Southern Willamette Valley and southern coast: OR-04 & 91 & 9 & 0 & 4 & 100 \\
\hline Salem area and southern Portland suburbs: OR-05 & 82 & 18 & 1 & 9 & 100 \\
\hline Philadelphia's Bucks County suburbs: PA-01 & 87 & 13 & 4 & 3 & 100 \\
\hline Northeast Philadelphia: PA-02 & 54 & 46 & 23 & 11 & 100 \\
\hline West, Northwest, and Center City Philadelphia: PA-03 & 36 & 64 & 57 & 2 & 100 \\
\hline Philadelphia's Montgomery County suburbs: PA-04 & 81 & 19 & 9 & 2 & 100 \\
\hline Philadelphia's Delaware County suburbs and South Phi...: PA-05 & 69 & 31 & 23 & 2 & 100 \\
\hline Philadelphia's Chester County suburbs and Reading: PA-06 & 78 & 22 & 6 & 9 & 100 \\
\hline Lehigh Valley and southern Monroe County: PA-07 & 81 & 19 & 6 & 8 & 100 \\
\hline Scranton/Wilkes-Barre and northeastern Pennsylvania: PA-08 & 89 & 11 & 5 & 4 & 100 \\
\hline Coal Region between Wilkes-Barre and Harrisburg: PA-09 & 94 & 6 & 2 & 2 & 100 \\
\hline Harrisburg and York: PA-10 & 83 & 17 & 9 & 3 & 100 \\
\hline Lancaster and southern York Counties: PA-11 & 91 & 9 & 3 & 3 & 100 \\
\hline Williamsport area and Northern Tier: PA-12 & 96 & 4 & 2 & 1 & 100 \\
\hline South-central Pennsylvania: PA-13 & 96 & 4 & 2 & 1 & 100 \\
\hline Southern Pittsburgh exurbs and southwestern Pennsylv...: PA-14 & 96 & 4 & 3 & 1 & 100 \\
\hline North-central Pennsylvania: PA-15 & 97 & 3 & 2 & 1 & 100 \\
\hline Erie and northwestern Pennsylvania: PA-16 & 95 & 5 & 3 & 1 & 100 \\
\hline Pittsburgh suburbs and Beaver County: PA-17 & 92 & 8 & 5 & 1 & 100 \\
\hline Pittsburgh: PA-18 & 81 & 19 & 15 & 1 & 100 \\
\hline Part of Providence and eastern Rhode Island: RI-01 & 82 & 18 & 5 & 7 & 100 \\
\hline Part of Providence and western Rhode Island: RI-02 & 87 & 13 & 3 & 6 & 100 \\
\hline Charleston and coastal South Carolina: SC-01 & 76 & 24 & 16 & 4 & 100 \\
\hline Augusta and Columbia suburbs: SC-02 & 72 & 28 & 22 & 3 & 100 \\
\hline Northwestern South Carolina: SC-03 & 82 & 18 & 14 & 2 & 100 \\
\hline Greenville-Spartanburg area: SC-04 & 75 & 25 & 16 & 4 & 100 \\
\hline Southern Charlotte suburbs and exurbs: SC-05 & 72 & 28 & 23 & 2 & 100 \\
\hline Black Belt, Columbia, and Charleston: SC-06 & 46 & 54 & 49 & 2 & 100 \\
\hline
\end{tabular}


Table S.10 - Composition of 2020 Electorate, by Race by CD (continued)

\begin{tabular}{|c|c|c|c|c|c|}
\hline & \multicolumn{4}{|c|}{ Non-Whites } & \multirow[b]{2}{*}{ All } \\
\hline & White & All & Black & Hisp. & \\
\hline Northeastern South Carolina and the Myrtle Beach area: SC-07 & 75 & 25 & 21 & 2 & 100 \\
\hline All of South Dakota: SD-01 & 92 & 8 & 1 & 1 & 100 \\
\hline Northeastern Tennessee: TN-01 & 96 & 4 & 2 & 1 & 100 \\
\hline Knoxville area: TN-02 & 91 & 9 & 4 & 2 & 100 \\
\hline Chattanooga area: $\mathrm{TN}-03$ & 89 & 11 & 7 & 1 & 100 \\
\hline Southern part of Middle Tennessee: TN-04 & 87 & 13 & 7 & 3 & 100 \\
\hline Nashville: TN-05 & 71 & 29 & 21 & 4 & 100 \\
\hline Nashville's eastern suburbs and northern Middle Tenn...: TN-06 & 93 & 7 & 3 & 2 & 100 \\
\hline Nashville's southern suburbs and western Middle Tenn...: TN-07 & 86 & 14 & 8 & 3 & 100 \\
\hline West Tennessee: TN-08 & 80 & 20 & 15 & 2 & 100 \\
\hline Memphis: TN-09 & 36 & 64 & 57 & 3 & 100 \\
\hline Tyler and East Texas: TX-01 & 77 & 23 & 13 & 7 & 100 \\
\hline Northern Houston and part of west Houston: TX-02 & 60 & 40 & 9 & 19 & 100 \\
\hline Collin County: TX-03 & 67 & 33 & 8 & 9 & 100 \\
\hline Northeastern Texas: TX-04 & 83 & 17 & 8 & 6 & 100 \\
\hline Eastern edge of Dallas and rural areas to its east: TX-05 & 73 & 27 & 12 & 13 & 100 \\
\hline Arlington and rural areas south of Dallas: TX-06 & 62 & 38 & 17 & 13 & 100 \\
\hline West Houston: TX-07 & 58 & 42 & 11 & 20 & 100 \\
\hline Suburbs and exurbs north of Houston: TX-08 & 77 & 23 & 7 & 12 & 100 \\
\hline Southwest Houston: TX-09 & 20 & 80 & 37 & 28 & 100 \\
\hline Austin to western Houston: TX-10 & 63 & 37 & 9 & 18 & 100 \\
\hline Midland and San Angelo parts of rural west Texas: TX-11 & 76 & 24 & 3 & 17 & 100 \\
\hline Parker and western Tarrant Counties: TX-12 & 76 & 24 & 7 & 12 & 100 \\
\hline Texas Panhandle: TX-13 & 81 & 19 & 4 & 12 & 100 \\
\hline Galveston area: TX-14 & 67 & 33 & 16 & 14 & 100 \\
\hline McAllen in the Rio Grande Valley and rural counties ...: TX-15 & 27 & 73 & 2 & 61 & 100 \\
\hline El Paso: TX-16 & 22 & 78 & 4 & 65 & 100 \\
\hline College Station, Waco, and a slice of Austin suburbs: TX-17 & 73 & 27 & 10 & 12 & 100 \\
\hline Heavily black parts of central Houston: TX-18 & 29 & 71 & 36 & 27 & 100 \\
\hline Lubbock and rural West Texas: TX-19 & 72 & 28 & 5 & 18 & 100 \\
\hline Downtown San Antonio: TX-20 & 34 & 66 & 5 & 53 & 100 \\
\hline Parts of Austin and San Antonio connected by Texas H...: TX-21 & 70 & 30 & 3 & 21 & 100 \\
\hline Southern Houston suburbs: TX-22 & 49 & 51 & 13 & 18 & 100 \\
\hline El Paso to San Antonio: TX-23 & 34 & 66 & 4 & 54 & 100 \\
\hline Suburbs north of Dallas and Fort Worth: TX-24 & 63 & 37 & 10 & 14 & 100 \\
\hline Part of Austin and rural areas north toward Dallas-F...: TX-25 & 78 & 22 & 5 & 10 & 100 \\
\hline Denton County: TX-26 & 72 & 28 & 7 & 11 & 100 \\
\hline Corpus Christi and Victoria: TX-27 & 59 & 41 & 5 & 32 & 100 \\
\hline Laredo area: TX-28 & 29 & 71 & 5 & 61 & 100 \\
\hline Heavily Latino areas north and east of Downtow & 23 & 77 & 15 & 52 & 100 \\
\hline Downtown and South Dallas: TX-30 & 27 & 73 & 44 & 24 & 100 \\
\hline Williamson and Bell Counties: TX-31 & 67 & 33 & 10 & 16 & 100 \\
\hline Suburban North Dallas: TX-32 & 65 & 35 & 11 & 15 & 100 \\
\hline Connects Downtov & 31 & 69 & 19 & 40 & 100 \\
\hline Brownsville in the Rio Grande Valley and rural count...: TX-34 & 28 & 72 & 2 & 65 & 100 \\
\hline
\end{tabular}


Table S.10 - Composition of 2020 Electorate, by Race by CD (continued)

\begin{tabular}{|c|c|c|c|c|c|}
\hline & \multicolumn{4}{|c|}{ Non-Whites } & \multirow[b]{2}{*}{ All } \\
\hline & White & All & Black & Hisp. & \\
\hline San Antonio and heavily Latino areas of Austin: TX-35 & 42 & 58 & 10 & 40 & 100 \\
\hline Southern part of East Texas: TX-36 & 78 & 22 & 7 & 12 & 100 \\
\hline Ogden and northern Utah: UT-01 & 85 & 15 & 1 & 9 & 100 \\
\hline Salt Lake City and southwestern Utah: UT-02 & 81 & 19 & 1 & 9 & 100 \\
\hline Provo area and southeastern Utah: UT-03 & 85 & 15 & 0 & 8 & 100 \\
\hline Southern Salt Lake County and rural areas to the south: UT-04 & 76 & 24 & 1 & 12 & 100 \\
\hline Western Chesapeake Bay and exurbs of D.C. and Richmond: VA-01 & 69 & 31 & 15 & 8 & 100 \\
\hline Virginia Beach: VA-02 & 74 & 26 & 15 & 4 & 100 \\
\hline Hampton Roads: VA-03 & 51 & 49 & 40 & 4 & 100 \\
\hline Richmond and Southside Virginia: VA-04 & 57 & 43 & 35 & 3 & 100 \\
\hline Charlottesville and South-central Virginia: VA-05 & 79 & 21 & 16 & 2 & 100 \\
\hline Shenandoah Valley: VA-06 & 87 & 13 & 8 & 2 & 100 \\
\hline Suburban Richmond: VA-07 & 70 & 30 & 17 & 5 & 100 \\
\hline Inner D.C. suburbs: VA-08 & 61 & 39 & 14 & 11 & 100 \\
\hline Southwest Virginia: VA-09 & 93 & 7 & 4 & 1 & 100 \\
\hline Loudoun County and D.C. suburbs and exurbs: VA-10 & 63 & 37 & 6 & 11 & 100 \\
\hline D.C. suburbs in Fairfax and Prince William Counties: VA-11 & 54 & 46 & 12 & 13 & 100 \\
\hline All of Vermont: VT-01 & 96 & 4 & 1 & 1 & 100 \\
\hline Northern Seattle suburbs: WA-01 & 80 & 20 & 1 & 5 & 100 \\
\hline Northern Puget Sound: WA-02 & 81 & 19 & 2 & 6 & 100 \\
\hline Vancouver and southwestern Washington: WA-03 & 87 & 13 & 1 & 5 & 100 \\
\hline Yakima and the Tri-Cities: WA-04 & 68 & 32 & 1 & 20 & 100 \\
\hline Spokane area and rural eastern Washington: WA-05 & 91 & 9 & 1 & 3 & 100 \\
\hline Olympic Peninsula and Tacoma: WA-06 & 85 & 15 & 2 & 4 & 100 \\
\hline Seattle: WA-07 & 77 & 23 & 4 & 6 & 100 \\
\hline Eastern Seattle suburbs and two rural counties east ...: WA-08 & 78 & 22 & 2 & 6 & 100 \\
\hline Southeastern Seattle and the suburbs to its south an...: WA-09 & 61 & 39 & 8 & 8 & 100 \\
\hline Olympia area and Tacoma suburbs: WA-10 & 79 & 21 & 5 & 7 & 100 \\
\hline Southeastern Wisconsin: WI-01 & 86 & 14 & 3 & 6 & 100 \\
\hline Madison area: WI-02 & 88 & 12 & 3 & 4 & 100 \\
\hline Southwestern Wisconsin: WI-03 & 96 & 4 & 1 & 1 & 100 \\
\hline Milwaukee: WI-04 & 55 & 45 & 26 & 10 & 100 \\
\hline Milwaukee suburbs: WI-05 & 90 & 10 & 2 & 4 & 100 \\
\hline Fox River Valley and Sheboygan: WI-06 & 94 & 6 & 1 & 2 & 100 \\
\hline Northwestern Wisconsin: WI-07 & 96 & 4 & 0 & 1 & 100 \\
\hline Northeastern Wisconsin: WI-08 & 93 & 7 & 1 & 3 & 100 \\
\hline Northern West Virginia: WV-01 & 96 & 4 & 2 & 0 & 100 \\
\hline Charleston to the Eastern Panhandle: WV-02 & 94 & 6 & 3 & 1 & 100 \\
\hline Southern West Virginia: WV-03 & 96 & 4 & 2 & 0 & 100 \\
\hline All of Wyoming: WY-01 & 92 & 8 & 1 & 4 & 100 \\
\hline National & 72 & 28 & 10 & 10 & 100 \\
\hline
\end{tabular}


Table S.11 - 2016 Composition of Electorate, by Race by State

\begin{tabular}{|c|c|c|c|c|c|}
\hline & \multicolumn{4}{|c|}{ Non-Whites } & \multirow[b]{2}{*}{ All } \\
\hline & White & All & Black & Hisp. & \\
\hline \multicolumn{6}{|l|}{ New England } \\
\hline Connecticut & 78 & 22 & 8 & 8 & 100 \\
\hline Maine & 97 & 3 & 0 & 0 & 100 \\
\hline Massachusetts & 82 & 18 & 5 & 6 & 100 \\
\hline New Hampshire & 96 & 4 & 1 & 1 & 100 \\
\hline Rhode Island & 86 & 14 & 3 & 6 & 100 \\
\hline Vermont & 98 & 2 & 0 & 1 & 100 \\
\hline \multicolumn{6}{|l|}{ Middle Atlantic } \\
\hline New Jersey & 67 & 33 & 10 & 12 & 100 \\
\hline New York & 68 & 32 & 13 & 10 & 100 \\
\hline Pennsylvania & 84 & 16 & 10 & 3 & 100 \\
\hline \multicolumn{6}{|l|}{ South Atlantic } \\
\hline Delaware & 75 & 25 & 16 & 5 & 100 \\
\hline Florida & 67 & 33 & 12 & 16 & 100 \\
\hline Georgia & 63 & 37 & 27 & 5 & 100 \\
\hline Maryland & 61 & 39 & 26 & 6 & 100 \\
\hline North Carolina & 71 & 29 & 20 & 5 & 100 \\
\hline South Carolina & 73 & 27 & 23 & 2 & 100 \\
\hline Virginia & 70 & 30 & 16 & 6 & 100 \\
\hline West Virginia & 96 & 4 & 2 & 1 & 100 \\
\hline \multicolumn{6}{|l|}{ East South Central } \\
\hline Alabama & 73 & 27 & 23 & 2 & 100 \\
\hline Kentucky & 90 & 10 & 6 & 2 & 100 \\
\hline Mississippi & 64 & 36 & 32 & 2 & 100 \\
\hline Tennessee & 84 & 16 & 12 & 2 & 100 \\
\hline \multicolumn{6}{|l|}{ West South Central } \\
\hline Arkansas & 82 & 18 & 12 & 3 & 100 \\
\hline Louisiana & 66 & 34 & 28 & 4 & 100 \\
\hline Oklahoma & 85 & 15 & 4 & 4 & 100 \\
\hline Texas & 61 & 39 & 10 & 23 & 100 \\
\hline \multicolumn{6}{|l|}{ East North Central } \\
\hline Illinois & 74 & 26 & 12 & 8 & 100 \\
\hline Indiana & 89 & 11 & 6 & 3 & 100 \\
\hline Michigan & 84 & 16 & 10 & 2 & 100 \\
\hline Ohio & 87 & 13 & 9 & 2 & 100 \\
\hline Wisconsin & 89 & 11 & 4 & 3 & 100 \\
\hline \multicolumn{6}{|l|}{ West North Central } \\
\hline Iowa & 92 & 8 & 2 & 3 & 100 \\
\hline Kansas & 88 & 12 & 3 & 4 & 100 \\
\hline Minnesota & 88 & 12 & 4 & 3 & 100 \\
\hline Missouri & 87 & 13 & 8 & 2 & 100 \\
\hline Nebraska & 90 & 10 & 3 & 4 & 100 \\
\hline North Dakota & 95 & 5 & 1 & 1 & 100 \\
\hline South Dakota & 93 & 7 & 1 & 1 & 100 \\
\hline \multicolumn{6}{|l|}{ Mountain } \\
\hline Arizona & 75 & 25 & 3 & 15 & 100 \\
\hline Colorado & 77 & 23 & 3 & 14 & 100 \\
\hline Idaho & 92 & 8 & 0 & 4 & 100 \\
\hline Montana & 95 & 5 & 0 & 1 & 100 \\
\hline Nevada & 68 & 32 & 6 & 16 & 100 \\
\hline New Mexico & 54 & 46 & 2 & 32 & 100 \\
\hline Utah & 89 & 11 & 1 & 6 & 100 \\
\hline Wyoming & 93 & 7 & 0 & 4 & 100 \\
\hline \multicolumn{6}{|l|}{ Pacific } \\
\hline Alaska & 76 & 24 & 2 & 3 & 100 \\
\hline California & 55 & 45 & 5 & 21 & 100 \\
\hline Hawaii & 44 & 56 & 2 & 7 & 100 \\
\hline Oregon & 88 & 12 & 1 & 6 & 100 \\
\hline Washington & 84 & 16 & 2 & 5 & 100 \\
\hline National & 74 & 26 & 10 & 9 & 100 \\
\hline
\end{tabular}


Table S.12 - 2020 Composition of Electorate, by Race by State

\begin{tabular}{|c|c|c|c|c|c|}
\hline & \multirow[b]{2}{*}{ White } & \multicolumn{3}{|c|}{ Non-Whites } & \multirow[b]{2}{*}{ All } \\
\hline & & All & Black & Hisp. & \\
\hline \multicolumn{6}{|l|}{ New England } \\
\hline Connecticut & 76 & 24 & 8 & 8 & 100 \\
\hline Maine & 97 & 3 & 1 & 1 & 100 \\
\hline Massachusetts & 81 & 19 & 5 & 6 & 100 \\
\hline New Hampshire & 95 & 5 & 1 & 1 & 100 \\
\hline Rhode Island & 85 & 15 & 4 & 6 & 100 \\
\hline Vermont & 96 & 4 & 1 & 1 & 100 \\
\hline \multicolumn{6}{|l|}{ Middle Atlantic } \\
\hline New Jersey & 68 & 32 & 10 & 10 & 100 \\
\hline New York & 69 & 31 & 12 & 10 & 100 \\
\hline Pennsylvania & 83 & 17 & 10 & 3 & 100 \\
\hline \multicolumn{6}{|l|}{ South Atlantic } \\
\hline Delaware & 72 & 28 & 17 & 5 & 100 \\
\hline Florida & 65 & 35 & 13 & 17 & 100 \\
\hline Georgia & 60 & 40 & 29 & 6 & 100 \\
\hline Maryland & 60 & 40 & 26 & 6 & 100 \\
\hline North Carolina & 70 & 30 & 19 & 5 & 100 \\
\hline South Carolina & 72 & 28 & 22 & 3 & 100 \\
\hline Virginia & 69 & 31 & 16 & 6 & 100 \\
\hline West Virginia & 95 & 5 & 2 & 1 & 100 \\
\hline \multicolumn{6}{|l|}{ East South Central } \\
\hline Alabama & 71 & 29 & 23 & 2 & 100 \\
\hline Kentucky & 89 & 11 & 6 & 2 & 100 \\
\hline Mississippi & 64 & 36 & 33 & 1 & 100 \\
\hline Tennessee & 82 & 18 & 12 & 2 & 100 \\
\hline \multicolumn{6}{|l|}{ West South Central } \\
\hline Arkansas & 82 & 18 & 11 & 3 & 100 \\
\hline Louisiana & 65 & 35 & 28 & 3 & 100 \\
\hline Oklahoma & 85 & 15 & 5 & 4 & 100 \\
\hline Texas & 59 & 41 & 10 & 23 & 100 \\
\hline \multicolumn{6}{|l|}{ East North Central } \\
\hline Illinois & 74 & 26 & 11 & 8 & 100 \\
\hline Indiana & 88 & 12 & 6 & 3 & 100 \\
\hline Michigan & 82 & 18 & 10 & 3 & 100 \\
\hline Ohio & 87 & 13 & 9 & 2 & 100 \\
\hline Wisconsin & 88 & 12 & 4 & 4 & 100 \\
\hline \multicolumn{6}{|l|}{ West North Central } \\
\hline Iowa & 92 & 8 & 2 & 3 & 100 \\
\hline Kansas & 85 & 15 & 5 & 5 & 100 \\
\hline Minnesota & 85 & 15 & 5 & 3 & 100 \\
\hline Missouri & 87 & 13 & 8 & 2 & 100 \\
\hline Nebraska & 86 & 14 & 4 & 6 & 100 \\
\hline North Dakota & 93 & 7 & 2 & 1 & 100 \\
\hline South Dakota & 92 & 8 & 1 & 1 & 100 \\
\hline \multicolumn{6}{|l|}{ Mountain } \\
\hline Arizona & 67 & 33 & 3 & 17 & 100 \\
\hline Colorado & 73 & 27 & 3 & 14 & 100 \\
\hline Idaho & 87 & 13 & 0 & 7 & 100 \\
\hline Montana & 92 & 8 & 0 & 2 & 100 \\
\hline Nevada & 60 & 40 & 7 & 16 & 100 \\
\hline New Mexico & 48 & 52 & 2 & 33 & 100 \\
\hline Utah & 81 & 19 & 1 & 10 & 100 \\
\hline Wyoming & 92 & 8 & 1 & 4 & 100 \\
\hline \multicolumn{6}{|l|}{ Pacific } \\
\hline Alaska & 73 & 27 & 3 & 4 & 100 \\
\hline California & 51 & 49 & 5 & 23 & 100 \\
\hline Hawaii & 38 & 62 & 2 & 8 & 100 \\
\hline Oregon & 84 & 16 & 1 & 7 & 100 \\
\hline Washington & 79 & 21 & 3 & 7 & 100 \\
\hline National & 72 & 28 & 10 & 10 & 100 \\
\hline
\end{tabular}

